NBS MONOGRAPH 52

\author{
ARDED BY \\ U. S. D. A
}

Annotated Bibliography on

Soft X-ray Spectroscopy

LIBRARY

i)? E.IUE]

Alý, 141962

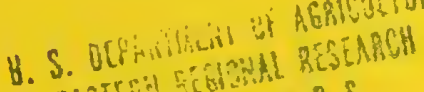

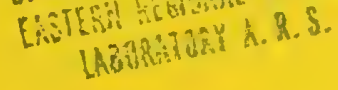

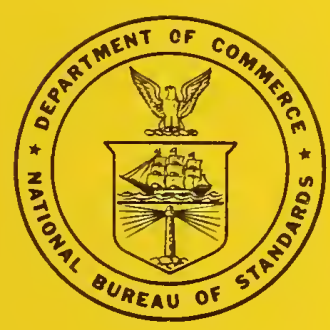

U.S. DEPARTMENT OF COMMERCE

NATIONAL BUREAU OF STANDARDS 


\section{THE NATIONAL BUREAU OF STANDARDS}

\section{Functions and Activities}

The functions of the National Bureau of Standards are set forth in the Act of Congress, March 3, 1901, as amended by Congress in Public Law 619, 1950. These include the development and maintenance of the national standards of measurement and the provision of means and methods for making measurements consistent with these standards; the deternination of physical constants and properties of materials; the development of methods and instruments for testing materials, derices, and structures; advisory services to government agencies on scientific and technical problems; invention and development of devices to serve special needs of the Govermment; and the development of standard practices codes, and specifications. The work includes basic and applied research, development, engineering, instrumentation, testing, evaluation, calibration services, and various consultation and information services. Research projects are also performed for other government agencies when the work relates to and supplements the basic program of the Bureau or when the Bureaus unique competence is required. The scope of activities is suggested by the listing of divisions and sections on the inside of the back cover.

\section{Publications}

The results of the Bureau's research are published either in the Bureau's own series of publications or in the journals of professional and scientific societies. The Bureau itself publishes three periodicals available from the Government Printing Office: The Journal of Research, published in four separate sections, presents complete scientific and technical papers; the Technical News Bulletin presents summary and preliminary reports on work in progress; and Basic Radio Propagation Predictions provides data for determining the best frequencies to use for radio communications throughout the world. There are also five series of non-periodical publications: Monographs, Applied Mathematics Series, Handbooks, Miscellaneous Publications, and Technical Notes.

A complete listing of the Bureau's publications can be found in National Bureau of Standards Circular 460, Publications of the National Bureau of Standards, 1901 to June 1947 (\$1.25), and the Supplenent to National Bureau of Standards Circular 460, July 1947 to June 1957 (\$1.50), and Miscellaneous Publication 240, July 1957 to June 1960 (Includes Titles of Papers Published in Outside Jounals 1950 to 1959) ( $\$ 2.25$ ) ; available from the Superintendent of Documents, Government Printing Office, Washington 25, D.C. 
UNITED STATES DEPARTMENT OF COMMERCE • Luther H. Hodges, Secretary NATIONAL BLREAU OF STANDARDS • A. V. Astin, Director

\section{Annotated Bibliography on}

\section{Soft X-ray Spectroscopy}

H. Yakowitz and J. R. Cuthill

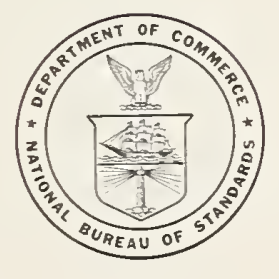

National Bureau of Standards Monograph 52

Issued June 29, 1962 



\section{Preface}

Emission and absorption spectra of solids in the 25 to 800 A range, termed "soft X-ray spectra" by X-ray spectroscopists working up in wavelength from the normal X-ray region, and "far ultra violet spectra" by the optical spectroscopists working down from the visible region, have been observed since the early nineteen thirties. However, the activity was centered in relatively few laboratories until the last decade, during which there has been a rapid expansion of interest in this spectral range. The increase in activity is the result of a number of simultaneous developments. First, the recent developments in ultra high vacuum technology and in detectors for this wavelength region have overcome many of the experimental difficulties. At the same time there has been a sudden expansion in the scope of this region of spectroscopy with the advent of space studies of solar radiation and laboratory research on plasmas as well as solid state physics. These new vistas, and new tools with which to exploit this spectral region, have brought many new people into the field who should find this compilation to be a useful reference. 


\section{Contents}

Preface

Introduction

Introduction -

Index of elements_-_-_-_-_-

Emission spectra index

K-spectra

K shell satellites only

$\mathrm{L}$-spectra

L shell satellites only__-__-_-_- 10

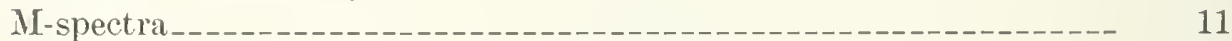

M shell satellites only_-_-_-_- 11

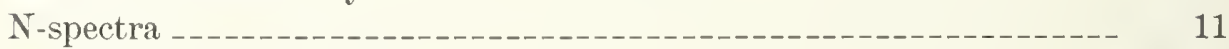

Absorption spectra index

K-spectri _._-_-_-_-_- 12

K-absorption spectra of elements in complexes_-_-_-_-_-_-_-_-_ 14

L-spectra _-_-_-_-_-_-_-_- 14

L-absorption spectra of elements in complexes_-_-_-_-_-_-_-_-_-_ 15

II-spectra _-_-_-_-_-_-_-_-_-_-_-_- 15

$\mathrm{N}$-spectra _._._._. 15

Soft X-ray absorption coefficient studies index_-_-_-_-_-_-_-_-_-_ 16

Energy band calculations index

Transition probabilities for soft X-rays index

$\mathrm{X}$-ray screening constants index

Critical potentials for soft X-rays index

Photoelectric phenomena index_-_- 17

Auger phenomena index $x_{--1}$

X-ray scattering studies index__-_-_-_-_-_-_-_-_-_-_-_-_- 18

General review papers (alphabetical by authors)

Bibliographic entries (alphabetical by authors, by years) --_-_-_----- 20

Author index

Subject index

Bibliographic entries (by periodical) _-_-_-_-_-_-_-_-_-_-_- 101

Bibliographic aids_-_-_-_- 108 


\title{
Annotated Bibliography on Soft X-ray Spectroscopy
}

\author{
H. Yakowitz and J. R. Guthill
}

\begin{abstract}
About 550 references are contained in this bibliography which includes, it is believed, a complete coverage of the soft X-ray literature since 1950 and through 1960 . Some references to earlier work are given but the general review references, listed separately, give an adequate coverage of the earlier work.

The emphasis is on the application of soft $\mathrm{X}$-ray spectroscopy to the study of valence band electronic states in metals and alloys and thelefore the spectral region of 25 to 800 angstroms involving ruled glass grating spectrometers is of principal interest. However, a wealth of data have been gathered, primarily by the Russians, on valence electronic states by means of high energy transitions where crystal spectrometers are satisfactory. These references and any X-ray work leading to the distribution of valence electronic states are included regardless of the transitions employed.

In addition to soft $\mathrm{X}$-ray data, references on all pertinent aspects of the apparatus and experimental problems are included. Also listed separately are references of value in corroborating soft X-ray data with other results, such as energy band calculations.

Subject, author, X-ray band, material, and other indices are included.
\end{abstract}

\section{Introduction}

Soft X-ray spectroscopy, concerned with electron transitions from the valence band to an ionized inner shell, constitutes one of the most direct and universal methods of obtaining the energy distribution of electrons in the valence band in solids. In the soft $\mathrm{X}$-ray literature the term "valence band" is taken to include all of the electrons outside of the outermost filled shell. Generally, the transitions studied are between the valence band and the outermost filled shell, which results in radiation in the $50 \mathrm{~A}$ to $700 \mathrm{~A}$ region. This is low energy radiation compared to that which is customarily employed in X-ray diffraction and in fluorescent analysis, and hence is called "soft". Howerer, some investigators, particularly the Russians, have been utilizing transitions from the valence band to the $K$ shell, even for the very heavy elements. The disadvantage of utilizing these transitions is the necessity of observing small differences in very large energy values. Utilization of these high energy transitions has the advantage, however, of permitting the use of crystal spectrometer's rather than ruled glass grating spectrometers. For the purposes of this bibliog- raphy, all X-ray studies seeking to obtain information on the electronic structure of the ralence band are included regardless of the wavelength range utilized.

This bibliography was compiled in connection with a research program on the electronic structure of metals and alloys in progress at the $\mathrm{Ya}$ tional Bureau of Standards. The bibliography contains about 550 references which constitute, it is believed, a complete coverage of the soft Xray literature that has appeared since 1950 . Some references to work published before 1950 are included, but no attempt has been made to include all of the early work because Volume 1, part 4 of the Landolt-Bornstein Tables contains a systematic summary of the earlier work. The reference sources include, in addition to the regularly published literature, unclassified reports on gorernment sponsored research that are generally available from the Office of Technical Services, Department of Commerce, Washington 25, D.C. In addition to the soft $\mathrm{X}$-ray work itself, material having to do with the interpretation of the soft 
$\mathrm{X}$-ray results is included and will be characterized in more detail later in the Introduction.

The first group of references is to general survey and review papers and books which have been written usually in connection with various significant occasions in the course of development of the field of soft X-ray spectroscopy by leading authorities.

The main listing of references then follows, grouped by year and listed alphabetically by author within each year. Under each year the references are further separated into two groups. The first group consists of references concerned specifically with $\mathrm{X}$-ray work, which have been classified under one of three categories: theoretical with no experimental results; contains some experimental results; or description of apparatus only. These categories are designated by a $\mathrm{T}, \mathrm{E}$, or $\mathrm{A}$, respectively, following the reference number. The second group under each year has each reference number preceded by a " $\mathrm{C}$ " to indicate that the material is not X-ray work but is corroborative to the $\mathrm{X}$-ray results. No attempt was made to make the coverage of corroborative material as complete as that of the soft X-ray papers because this would have resulted in a prohibitively long list. Therefore, only a selected list of corroborative material is given. The intention was to include the most useful data in connection with the analysis and evaluation of soft X-ray data. The corroborative material is limited primarily to energy band calculations and bond structure discussions. These references also carry suffix of T, $\mathrm{E}$, or $\mathrm{A}$, having the same connotation as in the case of the X-ray work.

The annotations under each reference are in the following form:

1. Type of data.

2. Method.

3. Results.

4. Conclusions.
One or more of these headings may not apply to a particular reference, in which case that number or numbers a re omitted from the list.

A number of indexes are given, at the front of the Bibliography, for ready reference to papers that contain the specific data to which the index applies. No attempt has been made, in the General Subject Index at the rear of the Bibliography, to duplicate any subject heading covered by the specific indexes at the front. Therefore, references that give data only may be listed only under a specific index at the front and will be found in the General Subject Index only if there is something in the paper pertaining to one of the subject headings given in the General Subject Index.

The spectra have been presented in the literature in a variety of energy units. In compiling this bibliography the units given in the original paper in each case were retained. A chart is appended to the bibliography for convenience in convelting from one unit to another. Each cycle is identical in so far as the locations of the lines are concerned, and only the multiplying factors will change, corresponding to the wavelength range designated. For example, $40 \mathrm{~A}$ is seen from the chart to correspond to approximately $310 \mathrm{ev}$, whereas 400 A corresponds to approximately 31 $\mathrm{ev}$, and continuing the chart would give $3.1 \mathrm{er}$ corresponding to $4 \mathrm{~A}$.

It is planned to continue this bibliography and to issue supplements periodically. The authors would appreciate suggestions regarding significant omissions or corrections.

The authors thank Dr. M. L. Williams of this laboratory for his suggestion of the wavelength conversion chart and for the compilation of it. The authors also express their sincere appreciation to Prof. E. L. Jossem, Prof. D. H. Tomboulian and Dr. J. E. Holliday for their helpful comments and suggestions. 
Atomic

No.

$3 \quad$ Li $1934(1) ; 1937(1) ; 1940(5) ; 1950(9)$, (10); $1951(6) ; 1952(13) ; 1954(12)$; 1955(17); 1956(20); 1958(10), (33), $(\mathrm{C}-2) ; 1959(8),(9),(28) ; 1960(11)$, (12), (15), (18), (c-4).

$4 \quad$ Be $1934(1) ; 1938(1) ; 1940(5) ; 1951(6)$; $1953(1),(c-4) ; 1954(12) ; 1955(33)$, (34); $1956(\mathrm{C}-11) ; 1957(7),(26)$; $1958(10),(28) ; 1959(9) ; 1960(17)$, (29), (31), (43).

5 B $1940(5) ; 1951(6) ; 1958(C-7),(C-18)$; $1957(24) ; 1960(29),(c-14)$.

$6 \quad$ C $1940(5) ; 1951(6) ; 1952(\mathrm{C}-4) ; 1953$ (1), (c-4); 1955(9); 1956(18), (c-1); $1957(24) ; 1958(C-4),(C-6),(c-18)$; $1959(16),(c-6),(c-15) ; 1960(17)$, (29).

7 N $1953(\mathrm{C}-4) ; 1957(24) ; 1960(22)$.

$801953(C-4) ; 1956(8) ; 1960(29)$.

9 F $1960(29),(30),(44)$.

10 Ne 1955(20); 1959(C-8); 1960(16).

$11 \mathrm{Na} 1940(5) ; 1941(2),(3) ; 1954(13)$, $(\mathrm{C}-7) ; 1955(14),(17),(38) ; 1956(8)$; $1958(10),(c-2),(c-3) ; 1960(18),(30)$ (44).

12 Mg 1934(1); 1937(1); 1940(5); 1941(2), (3); $1942(1) ; 1950(1),(4) ; 1952$ $(\mathrm{C}-1) ; 1953(18) ; 1954(6),(\mathrm{C}-7)$; $1955(10),(17),(34) ; 1956(11),(20)$; $1957(6),(c-13) ; 1958(7),(10),(24)$; $1959(9),(10) ; 1960(12),(18)$.

13

Al $1934(1) ; 1936(8) ; 1938(1) ; 1939(3)$; $1940(5) ; 1941(2),(3) ; 1950(1),(4)$; $1951(18) ; 1952(4),(5),(24) ; 1953$ (4), (c-4); $1954(6),(13),(19),(c-7)$; $1955(2),(9),(10),(17),(23),(29)$, (34); $1956(8),(10),(11),(19),(20)$, (22), (c-1), (c-8), (c-11); $1957(22)$; $1958(4),(10),(15),(24) ; 1959(C-27)$; $1960(12),(18),(38),(44),(c-6)$, $(c-7),(c-16),(c-19),(s-1),(s-2)$, $(\mathrm{s}-3)$.

$14 \quad$ Si $1940(5) ; 1950(4) ; 1954(2) ; 1955$ (10), (33), (37); 1956(1), (8); 1958 $(24),(c-4),(c-18) ; 1960(21),(36)$, (53).

15 P $1940(5) ; 1955(33) ; 1957(19)$; $1958(24)$.

16 S 1935(2); 1936(3),(4); 1940(5); $1948(2) ; 1951(20) ; 1952(12) ; 1954$ (9); $1955(33) ; 1958(24) ; 1960$ (33), (42).

Atomic

No.

17

18

19

20

21

\section{Cl}

$1935(2) ; 1936(3),(4) ; 1951(14),(20)$; $1954(15) ; 1955(14),(23),(37),(38)$, $(c-8) ; 1957(3),(4) ; 1958(24) ; 1959$ (30); $1960(3),(44)$.

A $1955(C-6) ; 1959(33)$.

K

$1935(2) ; 1936(3),(4) ; 1941(1) ; 1951$ (11),(12), (14); 1952(18); 1954(15); $1955(14),(17),(24),(35),(c-5) ; 1956$ (16); $1957(3),(30),(34) ; 1958(10)$, $(24),(c-2) ; 1959(30) ; 1960(10)$.

Ca $1935(2) ; 1936(3),(4) ; 1951(11),(12)$; $1954(21) ; 1955(17) ; 1958(24) ; 1960$ (42).

Sc $1935(2) ; 1936(3),(4) ; 1958(24)$, $(c-14)$.

Ti 1935(2); 1936(2),(3),(4); 1954(3), (4), (5), (21); $1955(35) ; 1956(21)$, (25); 1957(40), (41); 1958(22), (36), $(C-14) ; 1959(39),(40),(41) ; 1960$ $(7),(9),(30),(44),(45),(46),(c-17)$.

V 1935(2); 1936(3),(4); 1957(2),(22) $1958(24),(\mathrm{C}-14) ; 1959(42),(\mathrm{C}-8)$; $1960(7),(35),(41),(53)$.

Cr 1935(2); 1936(4); 1952(15),(19); $1953(7),(9) ; 1954(21) ; 1955(15)$, $(17),(28),(33) ; 1956(13),(15) ; 1957$ (1), (10), (13), (22), (23), (37), (42); $1958(3),(24),(20),(c-12),(c-24)$; $1959(5),(7),(27),(c-3) ; 1960(2)$, (3), (6), (7), (19), (33), (34), (36), (46).

Mn 1935(2); 1936(4); 1948(1); 1950(6); 1952(19); $1953(7) ; 1954(11),(21)$; $1955(16),(28),(29),(37) ; 1956(13)$. (17), (25); $1957(22),(33),(42) ; 1958$ (1), (15), (16), (24); $1959(23),(\mathrm{c}-8)$; $1960(32),(c-11)$.

Fe $1935(2) ; 1936(4) ; 1948(17) ; 1949$ (3); $1950(3),(4),(6) ; 1952(19)$; $1953(7) ; 1954(5),(11),(21) ; 1955$ (15), (17), (28), (29); $1956(3),(13)$, (15), (23), (24), (c-8); 1957 (13), $(22),(23),(37),(42),(c-8) ; 1958(3)$, (4), (24), (c-11), (c-12), (c-24); 1959 (1), (2), (5), (6), (8), (20), (27), (26), (37), (38), $(c-2),(c-3),(c-29),(c-30)$ $1960(3),(6),(7),(8),(16),(20),(34)$, $(41),(46),(48),(c-11),(c-16)$.

Co

$1935(2) ; 1936(4) ; 1939(1) ; 1950(7)$ $1954(6),(21) ; 1955(15),(28) ; 1956$ (13); $1957(37),(42) ; 1958(25)$, $(c-24) ; 1959(14),(27) ; 1960(7),(34)$. 
Atomic
No.

No.

$28 \quad \mathrm{Ni} \quad 1935(2) ; 1936(4) ; 1937(1) ; 1939(1)$; $1940(1),(3) ; 1949(1),(2),(5) ; 1950$ $(2),(6),(8),(13),(14) ; 1951(13)$, $(c-1) ; 1952(19),(c-5) ; 1953(3),(7)$, $(c-4) ; 1954(11),(21) ; 1955(2),(16)$, (17), (28), (29), (33), (c-3); 1956(13), $(24),(c-1),(c-8) ; 1957(16),(22),(37)$. $(c-11) ; 1958(13),(24),(35),(c-22)$, $(c-24) ; 1959(1),(2),(4),(14),(19)$, $(22),(23),(24),(27),(c-3),(c-30)$; $1960(7),(13),(31),(34),(37),(42)$, (43).

$29 \mathrm{Cu}$ 1935(2), (c-1); 1936(4), (8); 1937(1); $1938(1) ; 1939(1),(5) ; 1940(2),(3)$; $1941(1) ; 1949(1),(2),(3) ; 1950(2)$, $(6),(8),(14) ; 1952(15),(21) ; 1953(3)$, (7), (10), (c-4), (c-7); 1954(5), (16), (20), (21); 1955(6), (8), (17), (27), (28), (29); $1956(6),(7),(17),(18)$, (26), (c-8); $1957(16),(25),(35),(37)$, (39), (c-8), (c-11), (c-12); 1958(10), $(12),(13),(15),(16),(17),(24),(28)$, (30), (31), (c-24); $1959(3),(4),(19)$, (31), (33), (c-2), (c-20), (c-29); 1960 (7), (13), (24), (27), (34), (42), (44), $(45),(c-3),(c-6)$.

$30 \quad$ Zn $1936(1),(4),(7) ; 1939(1),(3) ; 1940$ (1), (2); 1941(1); 1949(1); 1950(6); $1951(10) ; 1953(10) ; 1955(6),(17)$, (21), (28); $1957(3),(10),(35),(37)$, $(c-11) ; 1958(6),(14),(24),(33) ; 1959$ $(c-20) ; 1960(3),(25),(27),(34),(38)$, (48).

31 Ga $1936(1),(4),(7) ; 1939(1) ; 1949(1)$; $1951(10) ; 1957(19),(37) ; 1958(22)$; $1959(C-20) ; 1960(27)$.

$32 \mathrm{Ge}$ 1936(1),(4),(7); 1939(1); 1950(6); $1951(7),(10) ; 1954(c-4) ; 1955(33)$; $1956(1) ; 1957(14),(18),(37) ; 1958$ (9), (24), (c-4); $1959(25),(34),(c-20)$; $1960(3),(27),(47),(c-19)$.

33 As 1936(1); 1949(1); 1951(10); 1958(24).

34 Se 1936(1); 1951(10); 1958(23),(24); $1959(15),(c-20) ; 1960(33)$.

35 Br 1936(1); 1951(10); 1958(24), (32); $1960(3),(30)$.

$36 \mathrm{Kr} \quad 1951(10) ; 1955(\mathrm{C}-6) ; 1957(29) ; 1958$ (24); $1959(34)$.

37 Rb $1929(1) ; 1936(1) ; 1949(1) ; 1951(9)$; $1952(14) ; 1958(24),(c-2) ; 1959(29)$.

38 Sr $1929(1) ; 1936(1) ; 1951(9) ; 1952(14)$; $1953(C-5) ; 1958(24) ; 1960(30)$.

39 Y $1929(1) ; 1936(1) ; 1951(9) ; 1952(14)$; $1958(24)$.
Atomic

No. Element Papers

$40 \quad$ Zr $\quad 1929(1) ; 1933(1) ; 1936(1) ; 1951(9)$; $1952(14) ; 1953(\mathrm{C}-5) ; 1954(\mathrm{C}-8) ; 1955$ (17); 1956(21); 1958(24); 1960(26).

$41 \quad \mathrm{Nb} \quad 1929(1) ; 1936(1) ; 1951(9) ; 1952(14)$; $1954(C-8) ; 1957(24) ; 1958(24) ; 1960$ (17), (22), (23).

42 Mo $1929(1) ; 1933(1) ; 1936(1) ; 1940(4)$; $1951(9) ; 1952(2),(14) ; 1953(12)$, $(\mathrm{C}-5) ; 1954(5),(17),(\mathrm{c}-5),(\mathrm{c}-8)$; 1956(23); 1957(5); $1958(24),(28)$; $1959(7),(12),(36) ; 1960(17),(23)$.

44 Ru 1929(1); 1933(1); 1936(1),(7); 1940 (24). (4); $1951(9) ; 1952(14) ; 1958$

45 Rh $1929(1) ; 1933(1) ; 1936(1),(7) ; 1940$ (4); $1951(19) ; 1952(14) ; 1953(\mathrm{C}-5)$; $1954(c-8) ; 1958(13),(24) ; 1960(13)$, (23).

46 Pd 1929(1); 1933(1); 1936(1),(7); 1940 (4); $1951(9) ; 1952(14) ; 1953(\mathrm{C}-5)$; $1954(\mathrm{C}-8) ; 1955(18) ; 1957(27) ; 1958$ $(24) ; 1959(c-20) ; 1960(13),(23),(32)$.

47 Ag 1929(1); 1933(1); 1935(1); 1936(1), (5); $1939(2),(6) ; 1940(4) ; 1951(9)$, (13); $1952(6),(14) ; 1953(C-3),(C-5)$; $1954(c-8) ; 1955(17),(19),(c-6) ; 1956$ $(c-1) ; 1957(11) ; 1958(24),(32)$, $(C-13) ; 1959(C-16),(C-20),(C-27)$; $1960(13),(23),(c-19)$.

$48 \quad$ cd

$1929(1) ; 1935(1) ; 1936(1) ; 1940(4)$; $1951(9) ; 1952(14) ; 1953(c-5) ; 1954$ $(\mathrm{C}-8) ; 1958(24) ; 1959(28),(\mathrm{C}-20)$, $(c-27) ; 1960(c-19)$.

49 In 1929(1); 1935(1); 1940(4); 1951(9); $1952(14) ; 1955(17) ; 1958(24) ; 1959$ $(c-20),(c-27) ; 1960(c-19)$.

50 Sn 1929(1); 1931(1); 1935(1); 1940(4); $1951(9) ; 1952(14) ; 1953(c-5) ; 1954$ $(\mathrm{c}-8) ; 1955(2),(17) ; 1957(15),(\mathrm{c}-6)$; $1958(24),(28) ; 1959(7),(22),(c-20)$, $(c-27) ; 1960(c-19)$.

$1931(1) ; 1935(1) ; 1940(4) ; 1952(20)$; $1957(19) ; 1958(24) ; 1959(C-20) ; 1960$ (33), $(c-19)$.

$1931(1) ; 1935(1) ; 1940(4) ; 1953(6)$; $1955(39) ; 1958(24) ; 1959(C-5),(c-20)$; $1960(33),(c-19)$.

$1940(4) ; 1957(36) ; 1958(22) ; 1960(30)$.

55 Cs

$1940(4) ; 1957(36),(c-5) ; 1958(24)$, $(c-2) ; 1959(29) ; 1960(30)$.

$1931(1) ; 1940(4) ; 1953(c-4) ; 1958(24)$. 
INDEX OF ELEMENTS (Cont'd)

Atomic

\begin{tabular}{|c|c|c|}
\hline No. & Element & Papers \\
\hline 58 & $\mathrm{Ce}$ & $\begin{array}{l}1931(1) ; 1953(2) ; 1958(19),(24), \\
(34) ; 1959(c-4) ; 1960(4) .\end{array}$ \\
\hline 59 & $\mathrm{Pr}$ & $\begin{array}{l}1952(26) ; 1953(2) ; 1959(23),(c-4) ; \\
1960(4) .\end{array}$ \\
\hline 60 & Nd & $\begin{array}{l}1931(1) ; 1952(26) ; 1953(2) ; 1958 \\
(22),(24) ; 1959(c-4) ; 1960(4) .\end{array}$ \\
\hline 62 & $\mathrm{Sm}$ & $\begin{array}{l}1952(26) ; 1953(2) ; 1956(9) ; 1958 \\
(22),(24) ; 1959(C-4) ; 1960(4) .\end{array}$ \\
\hline 63 & Eu & $\begin{array}{l}1952(26) ; 1953(2),(13),(14) ; 1955 \\
(25),(26) ; 1958(24),(27) ; 1959(C-4) ; \\
1960(4) .\end{array}$ \\
\hline
\end{tabular}

64 Gd $1953(2),(13),(15) ; 1955(25),(26)$; $1958(22),(24),(25) ; 1959(C-4) ; 1960$ (4).

65 Tb $1953(2),(13),(14) ; 1955(25),(26)$; $1958(22),(24),(27) ; 1959(c-4) ; 1960$ (4).

66 Dy $1953(2) ; 1958(22),(24) ; 1959(C-4)$; $1960(4)$.

67 Ho $1953(2),(13),(16) ; 1955(25),(26)$; $1958(22),(24),(27) ; 1959(c-4) ; 1960$ (4).

68 Er $1951(17) ; 1953(2) ; 1954(18) ; 1958$ $(22),(24),(26),(27) ; 1959(\mathrm{c}-4)$; $1960(4)$.

69 Tm $1953(2),(13),(15) ; 1955(25),(26)$; $1958(22),(24),(27) ; 1959(\mathrm{C}-4)$; $1960(4)$.

70 Yb $1953(2) ; 1958(22),(24) ; 1959(C-4)$; $1960(4)$.

71 Lu $1953(2) ; 1958(22),(24) ; 1959(c-4)$; $1960(4)$.

72 Hf 1956(21); 1958(24).

73 Ta $1932(1) ; 1933(2) ; 1952(7),(11) ; 1953$ (17); 1954(10); 1955(4),(11); 1958 (24); $1960(\mathrm{C}-6)$.

74 W 1932(1); 1933(2); 1939(4); 1951(2); $1952(7) ; 1953(6),(17) ; 1954(8),(10)$, (17); $1955(4),(11),(17),(36),(c-14)$; $1957(\mathrm{C}-8) ; 1958(24) ; 1959(\mathrm{C}-16)$; $1960(28),(30),(31),(43)$.
Atomic
No. Element $\quad$ Papers

$75 \quad \operatorname{Re} 1933(2) ; 1952(7) ; 1954(6),(10) ; 1955$ (4), (11); 1958(24); $1959(14)$.

76 os $1933(2) ; 1952(7) ; 1954(10) ; 1955(4)$, (11); $1958(24)$.

77 Ir 1932(1); 1933(2); 1942(2); 1952(7); $1954(10) ; 1955(4),(11) ; 1958(24)$.

$78 \quad$ Pt $1932(1) ; 1933(2) ; 1939(4) ; 1942(2)$; $1950(5) ; 1951(3),(13) ; 1952(7),(10)$, (17); $1953(17),(\mathrm{C}-4) ; 1954(10) ; 1955$ (4), (11), (c-4); $1958(8),(13),(24)$, (26); 1959(13), (14), (c-11); 1960(30), $(40)$.

79 Au $1933(2) ; 1936(5) ; 1939(5) ; 1942(2)$; $1951(16) ; 1952(7),(17) ; 1954(10)$; $1955(4),(11),(17),(18),(19) ; 1956$ $(c-1) ; 1957(27) ; 1958(8),(13),(24)$; $1959(14),(c-27) ; 1960(32),(c-3)$, $(\mathrm{c}-19)$.

$80 \quad \mathrm{Hg} \quad 1933(2) ; 1942(2) ; 1949(4) ; 1951(2) ;$ $1952(7),(9),(10) ; 1954(10) ; 1955(4)$, (11); 1958(2); $1959(\mathrm{C}-1)$.

$81 \quad$ TI $1933(2) ; 1942(2) ; 1952(7),(17) ; 1954$ (8), (10); $1955(4),(11)$.

$82 \quad \mathrm{~Pb} \quad 1933(2) ; 1942(2) ; 1952(7),(17) ; 1954$ $(10),(c-5) ; 1955(4),(11),(17),(c-4)$; $1957(15),(26),(c-11)$.

$83 \quad$ 8i $1933(2) ; 1942(2) ; 1952(7),(17) ; 1954$ (10); 1955(4), (11), (c-4); $1959(c-27)$; $1960(C-19)$.

90 Th $1933(2) ; 1942(2) ; 1952(7),(17) ; 1954$ (10); 1955(3), (4),(11); 1956(21); $1957(\mathrm{c}-9)$.

$92 \mathrm{U} \quad 1933(2) ; 1942(2) ; 1951(3) ; 1952(7)$, (17); 1953(12); 1954(6), (10), (c-5); $1955(4),(11) ; 1956(\mathrm{C}-5) ; 1957(\mathrm{C}-9)$; $1958(18) ; 1959(c-21)$.

93 Np $1957(17)$.

$94 \quad$ Pu $1954(7) ; 1956(5) ; 1957(c-9) ; 1958$ (18). 
K-SPECTRA:

\section{Element}

Ag

Al

A

$\mathrm{Al}$ in $\mathrm{Al}-\mathrm{Cu} \quad 1936(8) ; 1938(1)$.

Al in Al-0 1950(4); 1956(19).

As

Au

B

$B$ in $B N$

$\mathrm{Be}$

$B e$ in $B e-A l$

$\mathrm{Be} \operatorname{ln~Be}-\mathrm{Cu}$

Bi

$8 \mathrm{r}$

$\mathrm{Br}$ in $\mathrm{LiBr} \quad 1940(4)$.

$8 r$ in $\mathrm{KBr} \quad 1940(4)$.

$\mathrm{Br}$ in $\mathrm{RbBr} \quad 1940(4)$.

$\mathrm{Br}$ in $\mathrm{AgBr} \quad 1940(4)$.

c $\quad 1960(17)$.

$\mathrm{Cb} \quad$ (See Nb).

Cd $1951(9) ; 1952(14),(c-2)$.

Cl in K-Cl 1940(4); 1951(14); 1954(15); 1955 (24); $1957(34)$; $1959(30)$.

$\mathrm{Cl}$ in $\mathrm{Li}-\mathrm{Cl} 1940(4)$.

Cl in $\mathrm{Rb}-\mathrm{Cl} 1940(4)$.

$\mathrm{Cl}$ in $\mathrm{Cs}-\mathrm{Cl} 1940(4)$.

Cl in Ba-Cl $1940(4)$.

Co $1950(6)$.

Cr $\quad 1958(3) ; 1959(5) ; 1960(19)$.

$\mathrm{Cr}$ in $\mathrm{Cr}-\mathrm{Fe} \quad$ 1956(14); 1957(13); 1958(3); $1959(5)$.

$\mathrm{Cr}$ in Fe-Ni $1959(5) ; 1960(6)$.

$\mathrm{Cu}$
$1950(6) ; 1951(9) ; 1952(14),(c-7)$; $1957(c-8)$.
Element

Papers

Cu in Cu-Mn 1956(17); 1958(15).

Cu In Cu-Mn-Al 1958(15).

Cu in Cu-Zn 1940(2).

Dy $1958(22)$.

Er $1958(22)$.

F $1960(30)$.

F in K-F 1940(4).

F in Li-F 1940(4).

$\mathrm{F}$ in $\mathrm{Na}-\mathrm{F} \quad 1940(4)$.

$F$ in $M g-F \quad 1940(4)$.

Fe $\quad 1950(6) ; 1954(5) ; 1957(c-8)$;

$1958(3) ; 1959(5)$.

$\mathrm{Fe}$ in $\mathrm{Fe}-\mathrm{Cr} \quad$ 1956(15); 1957(13); 1958(3); $1959(5)$.

$\mathrm{Fe}$ in $\mathrm{Cr}-\mathrm{Ni} \quad 1959(5) ; 1960(6)$.

Ga $1951(10)$.

Ge

Gd

$\mathrm{Hg}$

1 in Csl

$1950(7) ; 1951(10) ; 1956(1)$.

$1958(22)$.

1951 (2); $1955(4) ; 1958(2)$; $1959(c-4)$.

$1940(4)$.

In

I r

$K$ in $K-B r$

$K$ in $\mathrm{C}-0-\mathrm{K}$

$\mathrm{K}$ in $\mathrm{Cl}-\mathrm{K}$

$K \ln 1-K$

$K$ in $K-s$

$\mathrm{Kr}$

Li

$1951(9) ; 1952(14),(c-2)$.

$1955(4)$.

$1956(16)$.

$1956(16)$.

1951 (14); $1954(15) ; 1955(24)$;

1956(16); $1957(34)$; $1959(30)$.

$1956(16)$.

$1956(16)$.

$1951(10)$.

$1934(1) ; 1940(6) ; 1956(20) ; 1957$

(7); 1958(33); 1959(9); 1960(11), (12).

Li in Li-Mg 1959(9); 1960(12).

Lu ig58(22).

Mg $1950(4) ; 1956(20) ; 1959(9),(10)$. 
K-SPECTRA (Cont'd)

\section{Element}

Papers

Mg in Mg-Li 1959 (9); $1960(12)$.

$\mathrm{Mg}$ in 0-Mg 1950(4); $1959(10)$.

Mg in S-Mg $1950(4)$.

Mn $1950(6)$.

Mn in Mn-Cu 1958(15).

Mn in Mn-Cu-Al 1958(15).

Mn in Mn-Ni 1955(16); $1959(22)$.

Mo $1951(9) ; 1952(14),(c-2)$; $1953(12) ; 1954(5)$.

$N$ in BN 1940(4)

Nb $1951(9) ; 1952(14),(C-2)$.

Nd $1958(22)$.

Ne $1955(20)$.

Ni $1950(6) ; 1959(5),(24)$.

$\mathrm{Ni}$ in Ni-Mn 1955(16).

$\mathrm{Ni}$ in $\mathrm{Zn}-\mathrm{Ni}$ 1940(1), (3).

1960(29).

0 in 0-Be $1940(4)$.

0 in 0-Li $1940(4)$.

0 in 0-B $1940(4)$.

0 in 0-Mg $1940(4)$.

0 in 0-Al $1940(4)$.

0 in 0-5i 1940(4).

0 in 0-Ca $1940(4)$.

0 in 0-Fe 1940(4).

0 in $0-2 n \quad 1940(4)$.

0 in 0-5r 1940(4).

0 in 0-Ba $1940(4)$.

Os $1955(4)$.

Po 1955(4), (c-4).

Pd $1951(9) ; 1952(14),(C-2)$.

Pt $1939(3) ; 1955(4),(C-4)$.

Rb $1951(9) ; 1952(14),(c-2)$.

EMISSION SPECTRA INDEX (CON't'd)

\section{Element}

Re

Rh

Ru

S

$S$ in $S-C a$

$S$ in Ca-0-s

$s$ in $\mathrm{K}-0-\mathrm{s}$

$S$ in Cu-S

$S$ in Mn-S

$S$ in $\mathrm{Zn}-\mathrm{S}$

$s$ in $s r-s$

Se

si

si in $\mathrm{Si}-\mathrm{C}$

si in 0-si

$\mathrm{Sm}$

Sn

Sr

$\mathrm{Ta}$

Tb

Th

$\mathrm{Ti}$

$\mathrm{Ti}$ in $\mathrm{Ti}-\mathrm{C}$

$\mathrm{Ti}$ in $\mathrm{Ti}-\mathrm{H}$

$\mathrm{Ti}$ in $\mathrm{Ti}=\mathrm{N}$

TI

Tm

U

W

Y

Yb

$\mathrm{Zn}$

$\mathrm{Zn}$ in $\mathrm{Zn}-\mathrm{Cu}$
Papers

$1955(4)$.

$1951(9) ; 1952(14),(C-2)$.

1951 (9); $1952(14),(c-2)$.

1954 (9).

1954 (9).

1954 (9).

$1954(9) ; 1956(13)=$

$1940(4)$.

$1954(9)$.

$1940(4)$.

1954 (9).

$1949(4) ; 1951(10)$.

$1950(4) ; 1960(21)$.

$1950(4) ; 1960(21)$.

$1950(4) ; 1960(21)$.

$1958(22)$.

1951 (9); 1952(14), (C-2).

1951 (9); $1952(14),(c-2)$.

$1955(4)$.

$1958(22)$.

$1955(4)$.

1954(5); 1959(39).

1959(32).

$1959(32)$.

1959 (32).

$1955(4)$.

$1958(22)$.

1955(4).

$1939(3) ; 1955(4) ; 1957(C-8)$.

1951 (9); 1952(14), (C-2).

1958(22).

$1950(6) ; 1951(10)$.

$1940(2)$. 
K-SPECTRA (Cont'd)

Element

$\mathrm{Zn}$ in $\mathrm{Ni}-\mathrm{Zn}$

$\mathrm{Zr}$

K SHELL SATELLITES ONLY:

\section{Element}

As

$\mathrm{Be}$

$\mathrm{Br}$

$\mathrm{Ca}$

$\mathrm{cb}$

Cl

Co

$\mathrm{Cr}$

$\mathrm{Cu}$

$\mathrm{Fe}$

Ga

Ge

K

LI

$\mathrm{Mg}$

Mn

Mo

$\mathrm{Nb}$

$\mathrm{Ne}$

$\mathrm{NI}$

Pd

$\mathrm{Rb}$

Rh

Ru

$1959(9)$.

$1942(1)$.

$1936(7)$.

$1936(7)$.

$1936(7)$.
EMISSION SPECTRA INDEX (Cont'd)

$1935(2) ; 1936(2),(3),(4)$;

$1955(c-1)$.

(See $\mathrm{Nb}$ ).

$1935(2) ; 1936(3),(4)$.

$1935(2) ; 1936(4) ; 1955(28),(c-1)$.

$1935(2) ; 1936(4) ; 1953(9) ; 1955$

$(28),(c-1) ; 1957(38)$.

$1935(2) ; 1936(4) ; 1955(28),(c-1)$.

$1935(2) ; 1936(4) ; 1955(28),(c-1)$;

$1957(38) ; 1960(15)$.

$1936(4),(7) ; 1955(c-1)$.

$1936(4),(7) ; 1955(c-1)$.

$1935(2) ; 1936(3),(4),(6)$;

$1955(c-1)$.

$1935(2) ; 1936(4) ; 1955(28),(c-1)$.

$1936(7) ; 1955(\mathrm{C}-1)$.

$1936(7) ; 1955(\mathrm{C}-1)$.

$1960(15)$.

$1935(2) ; 1936(4) ; 1955(28),(c-1)$.

$1936(7) ; 1955(\mathrm{C}-1)$.

$1935(2) ; 1936(3),(4)$.

$1936(7) ; 1949(4) ; 1955(\mathrm{c}-1)$.

$1936(7) ; 1955(\mathrm{C}-1)$.

Al in $\mathrm{Al}-\mathrm{Cu}$

\section{Element}

$\mathrm{Ti}$

V

Y

$\mathrm{Zr}$

L-SPECTRA:

Element

$\mathrm{Ag}$

Al

\section{Papers}

$1935(2) ; 1936(2),(3),(4) ; 1955(c-1)$. $1935(2) ; 1936(3),(4) ; 1955(c-1)$. $1936(7) ; 1955(\mathrm{C}-1)$.

$1936(7) ; 1955(C-1)$.

\section{Papers}

$1952(6)$

$1934(1) ; 1940(6) ; 1941(2) ; 1952$

(24); $1955(9)$; $1956(20),(22)$; $1960(12),(s-2),(s-3)$.

$1955(29)$.

Al in $\mathrm{Mg}-\mathrm{Al}$

$1955(10) ; 1956(11)$.

Al in Si-Al

$1955(10)$.

Au

$1951(16) ; 1960(32)$.

B

$B$ in $B N$

$1940(6)$.

$1940(4)$.

Bi

$1955(c-4)$.

$\mathrm{Br}$ in $\mathrm{Li}-\mathrm{Br}$

$1940(4)$.

$\mathrm{Br}$ in $\mathrm{K}-\mathrm{Br} \quad 1940(4)$.

$\mathrm{Br}$ in Rb-Br $1940(4)$.

$\mathrm{Br}$ in $\mathrm{Ag}-\mathrm{Br} \quad 1940(4)$.

c

$\mathrm{Ca}$

$1940(6)$.

$1951(11),(12) ; 1954(21)$.

Ca in Ca-0 1954(21).

$\mathrm{Cb} \quad$ (See Nb).

Cl in Li-Cl $1940(4)$.

Cl in K-Cl $1940(4)$.

Cl in $\mathrm{Rb}-\mathrm{Cl} 1940(4)$.

$\mathrm{Cl}$ in $\mathrm{Cs}-\mathrm{Cl} \quad 1940(4)$.

Cl in Ba-Cl $1940(4)$.

Co $1954(21)$.

Cr $1954(21)$.

$\mathrm{Cr}$ in $\mathrm{Cr}-0 \quad 1954(21)$.

Cu

$1953(3),(10) ; 1954(21) ; 1955(29)$;

$1957(16),(35) ; 1958(14) ; 1959(30)$. 
L-SPECTRA (Cont'd)

Element

Papers

Cu in Cu-Al 1955(29); 1957(25).

Cu in $\mathrm{Ni} \quad 1957(25)$.

Cu in $0-\mathrm{Cu} \quad 1959(3)$.

Cu in Zn-Cu 1953(10); 1957(25); $1959(30)$.

Er

Eu

Eu in Eu-0 $1955(25),(26)$.

F in Li-F $1940(4)$.

$\mathrm{F}$ in $\mathrm{Na}-\mathrm{F} \quad 1940(4)$.

F in K-F $1940(4)$.

F in F-Mg $1940(4)$.

$\mathrm{Fe}$

$1954(21) ; 1955(29)$.

$\mathrm{Fe}$ in $\mathrm{Fe}-\mathrm{Al} \quad 1950(4)$.

Ga $1960(27)$.

Gd

Gd in Gd-0

$1953(13),(15)$.

Ge

$1955(25),(26)$.

$1956(1) ; 1957(14) ; 1959(25)$;

$1960(26)$.

Ge in Ge-0 1957(14).

Ho $1953(13),(16)$.

Ho in Ho-O $1955(25),(26)$.

$\mathrm{Hg} \quad 1949(4)$.

1 in 1 -cs $1940(4)$.

Ir $\quad 1932(1)$.

K 1951(11),(12); 1960(10).

Kr 1957(29).

Li $\quad 1956(20)$.

Li in Li-Mg $1960(12)$.

$\mathrm{Mg}$

$1934(1) ; 1940(6) ; 1941(2)$;

$1956(20) ; 1958(7) ; 1960(12)$.

$\mathrm{Mg}$ in Mg-Al 1955(10); 1956(11).

Mg in Li-Mg 1960(12).

Mg in Si-Mg 1955(10).

$\mathrm{Mn}$

EMISSION SPECTRA INDEX (Cont'd)

\section{Element}

Mn in Mn-0 1954(21).

Mo $1959(12)$.

$N$ in $B-N \quad 1940(4)$.

$\mathrm{Na}$

$\mathrm{Nb}$

$\mathrm{Nb}$ in Nb-B 1957(24); 1960(22).

$\mathrm{Nb}$ in Nb-C 1957(24); $1960(22)$.

$\mathrm{Nb}$ in $\mathrm{Nb}-\mathrm{N} \quad$ 1957(24): 1960(22).

$\mathrm{Ni}$

0 in $0-B e \quad 1940(4)$.

0 in 0-Li $1940(4)$.

0 in $0-B \quad 1940(4)$.

0 in 0-Mg $1940(4)$.

0 in 0-Al $1940(4)$.

0 in 0-si $1940(4)$.

0 in $0-\mathrm{Ca} \quad 1940(4)$.

0 in $0-\mathrm{Fe} \quad 1940(4)$.

0 in $0-2 n \quad 1940(4)$.

0 in $0-5 r \quad 1940(4)$

0 in 0-Ba $1940(4)$.

P

$\mathrm{Pb}$

Pd

Pt

Pu

S

$S$ in cu-s $1940(4)$.

$S$ in $Z n-S \quad 1940(4)$.

Si $1940(6)$.

si in Si-Al 1955(10).

Si in Mg-Si $1955(10)$.

Sm

\section{Papers}


L-SPECTRA (Cont'd)

\section{Element}

$\mathrm{Ta}$

Tb

Tb in Tb-o

TI

TI in TI-0

$\operatorname{Tm}$

$\mathrm{Tm}$ in $\mathrm{Tm}-0$

U

W

$\mathrm{Zn}$

$\mathrm{Zn}$ in $\mathrm{Zn}-\mathrm{Cu}$

$2 r$

L SHELL SATELLITES ONLY:

\section{Element}

Ag

As

Au

$8 a$

Bi

$8 r$

cb

cd

ce

Co

$\mathrm{Cr}$

Cu

$\mathrm{Fe}$

Ga

Ge

$\mathrm{Hg}$

1932(1).

$1954(21)$.

$1954(21)$.

$1960(26)$.

$1936(1)$.

1955 (11).

$1936(1)$.

(See Nb).

1933 (1).

$1955(28)$.

$1955(28)$.

$1955(28)$.

$1955(28)$.

$1936(1)$.

1936(1).

\section{Papers}

$1953(13),(14)$.

$1955(25),(26)$.

$1953(13),(15)$.

$1955(25),(26)$.

$1953(12) ; 1954(21) ; 1958(18)$.

$1932(1) ; 1951(2) ; 1955(c-4)$.

$1953(10) ; 1954(21) ; 1957(35)$;

$1958(14)$; $1959(31)$.

$1953(10) ; 1959(31)$.

Papers

$1929(1) ; 1933$ (1); 1935(1); 1936(1), Ru (5); $1939(2) ; 1940(5)$.

$1933(2) ; 1951(16) ; 1954(10)$;

$1933(1) ; 1940(5)$.

$1933(2) ; 1954(10) ; 1955(11)$.

$1929(1) ; 1935(1) ; 1936(1) ; 1940(5)$.

$1933(2) ; 1952(9),(10) ; 1954(10)$;

$1955(11)$.

\section{Element}

I

In

I r

Mn

Mo

$\mathrm{Nb}$

$\mathrm{Nd}$

NI

Os

$\mathrm{Pb}$

Pd

Pt

$\mathrm{Rb}$

Re

Rh

Ru

Sb

Se

Sn

Sr

Ta

Te

Th

TI

U

W

Y

$\mathrm{Zn}$

$\mathrm{Zr}$

\section{Papers}

$1933(1) ; 1940(5)$.

$1935(1) ; 1940(5)$.

$1933(2) ; 1954(10) ; 1955(11)$.

$1955(28)$.

$1929(1) ; 1933(1) ; 1936(1) ; 1940(5)$.

$1929(1) ; 1936(1)$.

1933 (1).

$1955(28)$.

$1933(2) ; 1954(10) ; 1955(11)$.

$1933(2) ; 1954(10) ; 1955(11)$.

$1929(1) ; 1933(1) ; 1936(1) ; 1940(5)$.

$1933(2) ; 1951(4) ; 1952(10)$;

$1954(10)$; 1955(11); $1960(40)$.

$1929(1) ; 1936(1)$.

$1933(2) ; 1954(10) ; 1955(11)$.

1929(1); 1933(1); 1936(1); 1940(5).

$1929(1) ; 1933(1) ; 1936(1) ; 1940(5)$.

$1933(1) ; 1935(1) ; 1940(5)$.

$1936(1)$.

$1933(1) ; 1935(1) ; 1940(5)$.

$1929(1) ; 1936(1)$.

$1933(2) ; 1954(10) ; 1955(11)$.

$1933(1) ; 1935(1) ; 1940(5)$.

$1933(2) ; 1954(10) ; 1955(11)$.

$1933(2) ; 1954(10) ; 1955(11)$.

$1933(2) ; 1954(10) ; 1955(11)$.

$1933(2) ; 1954(10) ; 1955(11)$.

$1929(1) ; 1936(1)$.

$1936(1) ; 1955(28)$.

$1929(1) ; 1933(1) ; 1936(1)$. 
M-SPECTRA:

\section{Element}

Ca

$1954(21)$.

Ca in $\mathrm{Ca}-0$ 1954(21).

Cb (See Nb).

Co

Cr

$1954(21)$.

$1952(15) ; 1953(7) ; 1954(21)$;

$1957(1)$.

$\mathrm{Cr}$ in $\mathrm{Cr}-0 \quad 1954(21)$.

Cu

$1952(15) ; 1953(7) ; 1954(20,(21)$; $1955(29)$.

Cu in Cu-Al 1955(29).

Fe

$1953(7) ; 1954(11),(21) ; 1955(29)$.

1956(1).

$1960(10)$.

$1953(7) ; 1954(11),(21) ; 1955(29)$.

Mn

$M n$ in $M n-0$

$1954(21)$.

$1954(17) ; 1960(17)$.

$1953(7) ; 1954(11),(21) ; 1955(29)$;

U
$1960(17)$.

$1960(13)$.

Ti $1954(21)$.

$\mathrm{Ti}$ in Ti-0 1954(21).

$\mathrm{Nb}$

$\mathrm{Ni}$

$1954(21)$.

M SHELL SATELLITES ONLY:

\section{Element}

Au

Bi

$\mathrm{Hg}$

Ir

$\mathrm{Pb}$

Pt

Th

TI

U

N-SPECTRA:

\section{Element}

Ag

Pd

Rh

W
Papers

$1936(5) ; 1952(17)$.

$1942(2) ; 1952(17)$.

$1942(2)$.

$1942(2)$.

$1942(2) ; 1952(17)$.

$1942(2) ; 1952(17)$.

$1942(2) ; 1952(17)$.

$1942(2) ; 1952(17)$.

$1942(2) ; 1952(17)$.

\section{Papers}

$1960(13)$.

$1960(13)$.

$1960(13)$.

$1954(17)$. 
K-SPECTRA:

\section{Element}

A

Al

Al In $\mathrm{Al}-\mathrm{Cu}$

Al in Al-Mg 1950(1).

Al in Al-Mg-Si 1950(1).

Al in Al-Zn $1960(38)$.

As $1949(1)$.

As in As-Ga $1957(19)$.

As in As-In 1957(19).

As in As-Ni $1949(1)$.

8 $1951(6)$.

Be $\quad 1951(6) ; 1954(12) ; 1955(33)$;

$1956(c-11)$.

Be in Be-0 1955(33).

C

$\mathrm{Cl}$ in $\mathrm{Cl}-\mathrm{Cs}$

$\mathrm{Cl}$ in $\mathrm{Cl}-\mathrm{H}$

$\mathrm{Cl}$ in $\mathrm{Cl}-\mathrm{K}$

$\mathrm{Cl}$ in $\mathrm{Cl}-\mathrm{Li}$

$\mathrm{Cl}$ in $\mathrm{Cl}-\mathrm{Na}$

$\mathrm{Cl}$ in $\mathrm{Cl}-\mathrm{Rb}$

Co

Co in $\mathrm{Co} C \mathrm{Cr} \quad 1956(13)$.

Co in Co-fe $1959(27)$.

Co in Co-0 $1960(34)$.

Co in Co-s $1960(34)$.

$\mathrm{Cr}$

$\mathrm{Cr}$ in $\mathrm{Cr}-\mathrm{B} \quad 1958(20)$.

Cr in $\mathrm{Cr}-\mathrm{C} \quad 1958(20)$.

$\mathrm{Cr}$ in $\mathrm{Cr}$-Co $1956(13)$.

Cr in Cr-Fe 1956(13); 1957(23); 1959(27).

Cr in Cr-Mo $1959(7)$.

Cr In $\mathrm{Cr}-\mathrm{N} \quad 1958(20)$.

\section{Papers}

$1958(20) ; 1960(34)$.

$1960(33),(34)$.

$1960(33)$.

$1960(33)$.

$1960(36)$.

$1960(33)$.

1958(21); 1959 (29).

$1939(1) ; 1949(2),(3)$;

$1950(8) ; 1958(17)$;

$1960(7),(34),(42)$.

$\mathrm{Cu}$ in $\mathrm{Cu}-\mathrm{Al}-\mathrm{Mn}$

$\mathrm{Cu}$ in $\mathrm{Cu}-\mathrm{Ni}$

$\mathrm{Cu}$ in $\mathrm{Cu}-\mathrm{O}$

$\mathrm{Cu}$ in $\mathrm{Cu}-\mathrm{S}$

$\mathrm{Cu}$ in $\mathrm{Cu}-\mathrm{Zn}$

$\mathrm{Fe}$

$\mathrm{Fe}$ in $\mathrm{Fe}-\mathrm{Al}$

$\mathrm{Fe}$ in $\mathrm{Fe}-\mathrm{Co}$

$\mathrm{Fe}$ In $\mathrm{Fe}-\mathrm{Cr}$

$\mathrm{Fe}$ in $\mathrm{Fe}-\mathrm{Mo}$

$\mathrm{Fe}$ in $\mathrm{Fe}-\mathrm{Ni}$

$\mathrm{Fe}$ in $\mathrm{Fe}-\mathrm{O}$

$\mathrm{Fe}$ in $\mathrm{Fe}-\mathrm{Pt}$

$\mathrm{Fe}$ in $\mathrm{Fe}-\mathrm{S}$

Ga

Ga in Ga-As

Ga in Ga-P

Ga in Ga-Sb

Ge

$\mathrm{Ge}$ in $\mathrm{Ge}-\mathrm{Br}$

$\mathrm{Ge}$ in $\mathrm{Ge}-\mathrm{Cl}$

$\mathrm{Ge}$ in $\mathrm{Ge}-\mathrm{H}$

$K$ in $K-B r$
$1958(16)$.

$1950(14) ; 1958(17)$.

$1949(1) ; 1958(17) ; 1960(34)$.

$1960(34),(42)$.

$1940(2) ; 1955(6) ; 1958(17)$.

1939 (1); 1948(1); 1949 (3);

$1956(24) ; 1959(8),(26)$;

$1960(7),(8),(34)$.

$1960(34)$.

$1959(27)$.

$1956(13) ; 1957(23) ; 1959(27)$.

$1956(23)$.

$1959(1),(2),(27)$.

$1950(3) ; 1959(38) ; 1960(34)$.

$1960(20)$.

$1960(34),(41)$.

1939(1); $1949(1)$.

1957 (19).

$1957(19)$.

1957 (19).

$1939(1) ; 1955(33) ; 1957(18)$;

$1958(9)$; $1960(47)$.

$1951(7)$.

$1951(7)$.

$1957(7)$.

$1952(18) ; 1955(35) ; 1957$

(3), (30). 
K-SPECTRA (CONt'd)

\section{Element}

\section{Papers}

$\mathrm{K}$ in $\mathrm{K}-\mathrm{Cl} \quad 1952(18) ; 1955(14),(24),(35)$;

$1957(3),(4),(30),(34)$.

K in K-F 1952(18); 1955(35); $1957(3),(30)$.

$K$ in K-1 1952(18); $1955(35) ; 1957(3),(30)$.

$\mathrm{Kr} \quad 1959(34)$.

Li 1937(1); 1950(9); 1952(13).

Li in Li-Cl 1959(29).

Mg 1957(6).

$M g$ in Mg-Al-Si 1950(1).

Mn 1948(1); 1955(33); $1960(34)$.

$\mathrm{Mn}$ in Mn-Al-Cu 1958(16).

Mn in Mn-Ni 1956(13); $1959(23)$.

Mn in Mn-0 1960(34).

Mn in Mn-s 1960(34).

Mo in Mo-Cr 1959(7).

$\mathrm{Na}$ in $\mathrm{Na}-\mathrm{Cl} 1955(14)$.

$\mathrm{Ni}$

$1939(1) ; 1940(3) ; 1949(1),(2)$;

$1950(2),(8),(13) ; 1955(33) ; 1956$

(24); $1959(24) ; 1960(7),(34),(42)$.

$\mathrm{Ni}$ in Ni-Al 1960(37).

$\mathrm{Ni}$ in $\mathrm{Ni}$-As $1949(1)$.

$\mathrm{Ni}$ in $\mathrm{Ni}-\mathrm{Cl} 1949(5)$.

$\mathrm{Ni}$ in $\mathrm{Ni}-\mathrm{Cu}$ 1950(2), (14).

$\mathrm{Ni}$ in $\mathrm{Ni}-\mathrm{Fe} \quad 1959(1),(2),(27)$.

Ni In Ni-Mn 1956(13).

$\mathrm{Ni}$ in Ni-O $1949(1) ; 1950(2),(13) ; 1958(35)$; $1960(34)$.

$\mathrm{Ni}$ in Ni-0-S 1949(5); 1950(13).

$\mathrm{Ni}$ in Ni-s $1949(1) ; 1950(13) ; 1960(34),(42)$.

$\mathrm{Ni}$ in $\mathrm{Ni}-\mathrm{Zn} \quad 1940(1),(3)$.

P $1955(33)$.

P in P-Ga 1957(19).

$\mathrm{Pb}$ in $\mathrm{Pb}-\mathrm{Sn} \quad 1959(7)$.

Pd $1957(27)$.

Pd in Pd-Au 1957(27).
Element

S

$s$ in $s-c$

$S$ in $\mathrm{S}-\mathrm{H}$

$s$ in $s-0$

$\mathrm{Sb}$

Sb in Sb-Ga

$\mathrm{Se}$

si

si in Si-0

$\mathrm{Sn}$ in $\mathrm{Sn}-\mathrm{Pb}$

$\mathrm{Ti}$

$T i$ in $T i-B$

$T i$ in $T i-B a-0$

$\mathrm{Ti}$ in $\mathrm{Ti}-\mathrm{C}$

$T i$ in $T i-C-W$

$\mathrm{Ti}$ in $\mathrm{Ti}-\mathrm{Ca}-\mathrm{O}$

$\mathrm{Ti}$ in $\mathrm{Ti}-\mathrm{Fe}-\mathrm{O}$

$\mathrm{Ti}$ in $\mathrm{Ti}-\mathrm{H}$

$\mathrm{Ti}$ in $\mathrm{Ti}-\mathrm{Mg}-\mathrm{O}$

$T i$ in $T i-N$

$\mathrm{Ti}$ in $\mathrm{Ti}-0-\mathrm{Pb}$

$\mathrm{Ti}$ in $\mathrm{Ti}-0-\mathrm{S}$

$T i$ in $T i-0$

$T i$ in $T i=0-Z n$

$\mathrm{Ti}$ in $\mathrm{Ti}-\mathrm{Si}$

v

$V$ in $V-B$

$v$ in $v-c$

$V$ in $V-F e$

$V$ in $V-H$

$\mathrm{V}$ in $\mathrm{V}-\mathrm{N}$

$v$ in $V-S n$

Zn

\section{Papers}

$1955(33) ; 1960(42)$.

$1951(20)$.

1951 (20).

1951 (20).

$1952(20)$.

$1957(19)$.

$1959(15)$.

$1955(33)$.

$1955(33)$.

1959(7).

1956(25); 1960(7).

$1959(40),(41)$.

$1954(3),(4) ; 1958(36) ; 1960(9)$.

1957(40), (41); 1958(37); $1959(41)$.

$1957(40)$.

1958(34).

1958(36).

$1957(40) ; 1959(40),(41)$.

1958(36).

1957(40); 1959(41).

1954(3), (4).

1958(36).

$1954(3) ; 1955(36) ; 1956(25)$;

$1957(40)$; $1958(37)$.

1958(36).

$1959(40)$.

$1960(7),(35)$.

$1959(42)$.

$1959(42)$.

$1960(41)$.

$1959(42) ; 1960(35)$.

$1959(42)$.

$1960(53)$.

$1939(1) ; 1940(3) ; 1960(34)$. 
K-SPECTRA (Cont'd)

Element

Papers

$\mathrm{Zn}$ in $\mathrm{Zn-Al} 1960(38)$.

Zn in $2 n-C u \quad 1940(2) ; 1941(1) ; 1956(7)$.

$\mathrm{Zn}$ in $\mathrm{Zn}-\mathrm{Ni} \quad 1940(1),(3)$.

Zn in $2 n-0 \quad 1949(1) ; 1960(34)$.

Zn in Zn-S 1957(19); 1960(34).

K-ABSORPTION SPECTRA OF ELEMENTS IN COMPLEXES:

\section{Element and Complex}

Papers

Co in $\mathrm{COSO}_{4} \cdot 7 \mathrm{H}_{2} \mathrm{O} ; \mathrm{CoCl}_{2} \cdot 6 \mathrm{H}_{2} \mathrm{O}$;

$\mathrm{Co}\left(\mathrm{HO}_{3}\right)_{2} \cdot 6 \mathrm{H}_{2} \mathrm{O}$

$1958(25)$

Co in various salts

$1957(42) ; 1959(14)$.

$\mathrm{Cr}$ in cyano and carbonyl salts $1957(10)$.

$\mathrm{Cr}$ in $\mathrm{Cr}_{2}\left(\mathrm{SO}_{4}\right)_{3}$

$1958(20)$.

Cr in various salts

$1952(19) ; 1957(42)$.

$\mathrm{Cu}$ in $\mathrm{Cu}\left(\mathrm{H}_{2} \mathrm{O}\right)_{6}{ }^{++}$ $1956(7)$.

$\mathrm{Cu}$ in cyano and carbonyl salts $1957(10)$.

Cu in various salts

Fe in various salts

Mn in various salts

$\mathrm{Ni}$ in various salts

$\mathrm{Zn}^{++}$in various salts

$1956(7)$.

$1952(19) ; 1957(42)$.

1952(19); $1957(42)$.

1952(19); $1959(14)$.

$1958(6)$.

L-SPECTRA:

Element

Papers

Al

Au

$\mathrm{Au}$ in $\mathrm{Au}-\mathrm{Ag}$

$\mathrm{Au}$ in $\mathrm{Au}-\mathrm{Pd}$

$1939(3) ; 1951(18) ; 1960(39),(s-1)$, $(s-3)$.

$1939(5) ; 1955(18),(19) ; 1960(32)$.

$1955(19)$

$1955(18) ; 1960(32)$.

Be

$1955(33)$

Ce in Ce-Al 1958(19).

Ce in Ce-B 1958(34).

Ce in Ce-0 $1958(34)$.

Cr $1955(33)$.

Cs in Cs-Br 1957(36).

Cs in Cs-Cl 1957(36).
Element

\section{Cs in Cs-F 1957(36). \\ Cs In Cs-1 $1957(36)$.}

$\mathrm{Cu}$

$\mathrm{Cu}$ in $\mathrm{Cu}-\mathrm{Al}$

$\mathrm{Cu}$ in $\mathrm{Cu}-\mathrm{NI}$

$\mathrm{Cu}$ in $\mathrm{Cu}-\mathrm{O}$

$\mathrm{Cu}$ in $\mathrm{Cu}-\mathrm{Zn}$

Er

Er in $\mathrm{Er}-\mathrm{O}$

Eu

Eu in Eu-O

Ga

Gd

Gd in Gd-0

Ge

Ho

Ho in Ho-O

1 in $1-C s$

1 in $1-K$

1 in $1-L i$

I in $\mathrm{Na}-1$

1 in $R b-1$

Mg

$\mathrm{Mn}$

Mo

Mo in Mo-C

Mo in Mo-0

Mo in Mo-s

Ni

Np

P

$\mathrm{Pb}$ in $\mathrm{Pb}-0$

$\mathrm{Pb}$ in $\mathrm{Pb}-\mathrm{Sn}$

Re in $R e-0$

$1954(18)$.

1958(27).

1953(14).

1958(27).

1960(27).

1953(15).

1958(27).

$1953(16)$.

$1958(27)$.

1957(36).

1957(36).

$1957(36)$.

1957(36).

$1957(36)$.

1937(1).

1955(33).

1957(5).

1957(5).

$1957(5)$.

1957(17).

1955(33).

1957(15).

1957(15).

$1954(6)$.
Papers

$1953(3) ; 1957(16) ; 1958(17)$. 1958(17); 1960(27).

1958(17); 1960(27).

1958(17); 1959(3).

1958(17); 1960(27).

1955(33); $1959(25) ; 1960(27)$.

1959(12), (36).

$1953(3) ; 1955(33) ; 1957(16)$. 


\section{L-SPECTRA (Cont'd)}

Element

Papers

$s$

Se $1955(33)$. 1958(23).

Se in Se-0 1958(23).

S1 1954(2); 1955(33); 1956(1).

Si in si-0 1954(2).

Tb $1953(14)$.

Tm $1953(15)$.

Tm in Tm-0 1958(27).

$U$ in U-0 1951(3); $1954(6)$.

$2 n \quad 1939(3) ; 1960(27)$.

Zr $1960(26)$.

L-ABSORPTION SPECTRA OF ELEMENTS IN COMPLEXES:

Element and Complex

Au $\left(\mathrm{NaAuCl}_{4} ; \mathrm{KAuCl}_{4}\right) \quad 1958(8)$.

Aus $1959(14)$.

Mo in $\left(\mathrm{NH}_{4}\right)_{2} \mathrm{MOO}_{4} ; \mathrm{K}_{4} \mathrm{MO}(\mathrm{CN})_{8} \quad 1952(2)$.

$\mathrm{Pt}$ in $\mathrm{K}_{2} \mathrm{Pt}(\mathrm{CN})_{6} ; \mathrm{K}_{2} \mathrm{PtCl}_{3} \quad 1958(8)$.

$\operatorname{Pr}$ (20 salts)

Re (various salts)
ABSORPTION SPECTRA INDEX (Cont'd)

M-SPECTRA:

\begin{tabular}{|c|c|}
\hline Element & Papers \\
\hline Au & $1960(32)$ \\
\hline $\mathrm{Au}$ in $\mathrm{Au}-\mathrm{Cu}$ & $1939(5)$ \\
\hline Co & $1957(37)$ \\
\hline $\mathrm{Cr}$ & $1955(33) ; 1957(1),(37) ; 1960(2)$. \\
\hline $\mathrm{Cu}$ & $1937(1) ; 1957(37) ; 1960(39)$. \\
\hline $\mathrm{Er}$ & $1951(17)$ \\
\hline Eu & $1952(26)$ \\
\hline $\mathrm{Fe}$ & $1956(3) ; 1957(37)$ \\
\hline $\mathrm{Fe}$ in $\mathrm{Fe}=0$ & $1956(3)$ \\
\hline $\mathrm{Ga}$ & $1957(37)$ \\
\hline $\mathrm{Ge}$ & $1955(33) ; 1956(1) ; 1957(37)$. \\
\hline Mn & $1955(33) ; 1957(37) ; 1958(1)$. \\
\hline Mn in Mn-0 & $1958(1)$ \\
\hline Nd & $1952(26)$ \\
\hline $\mathrm{Ni}$ & $1937(1) ; 1955(33) ; 1957(37)$. \\
\hline Pr & $1952(26)$ \\
\hline $\mathrm{Ta}$ & $1952(14)$ \\
\hline Th in Th-0 & $1955(3)$ \\
\hline Th in Th-O-N & $1955(3)$ \\
\hline$v$ & $1957(2)$. \\
\hline$U$ in $U-0$ & $1951(3)$ \\
\hline $\mathrm{Zn}$ & $1957(37)$ \\
\hline \multicolumn{2}{|l|}{ N-SPECTRA: } \\
\hline Element & Papers \\
\hline Te & $1955(39)$. \\
\hline
\end{tabular}


SOFT $X$-RAY ABSORPTION COEFFICIENT STUDIES INDEX

Substances Spectral Reqion Papers

$Z=1-36$

5-50 A

$1957(20)$

LI

$5 \cdot 5-20 \mathrm{keV}$

$1960(15)$

Mg

80-350 A

$1953(18)$

Mg

MgO

7-24A

$1957(6)$

$80-350 \mathrm{~A}$

$1953(18)$

Te

$100-400 \mathrm{~A}$

1955(39)

ENERGY BAND CALCULATIONS INDEX

Element

Papers

Ag

$1960(23)$

Al

$1954(13) ; 1958(\mathrm{C}-8)$.

$B$ in $B-N \quad 1958(C-7) ; 1960(C-14)$.

C $1952(\mathrm{C}-4) ; 1958(\mathrm{C}-4),(\mathrm{C}-6)$;

$1959(17),(c-15)$.

Co

$1958(C-24)$.

Cr

$1958(C-24) ; 1959(C-3)$.

$\mathrm{Cr}$ in $\mathrm{Cr}-\mathrm{Fe} 1958(\mathrm{C}-12)$.

Cs $1957(\mathrm{C}-5) ; 1958(\mathrm{C}-2)$.

Cu $1935(\mathrm{C}-1) ; 1958(\mathrm{c}-8),(\mathrm{C}-24)$.

Fe $1958(C-11),(c-23) ; 1959(c-3)$;

$1960(C-11)$.

$\mathrm{Fe}$ in $\mathrm{Fe}-\mathrm{Cr}$ 1958(C-12).

Ge

$\mathrm{K}$

Li

Mg

Mn

Mo

$\mathrm{Na}$

Nb

$\mathrm{Ne}$

$\mathrm{Ni}$

Pd

Pu

$\mathrm{Rb}$ $1958(c-4)$.

$1958(\mathrm{C}-2)$.

$1954(13) ; 1958(C-2)$.

$1952(\mathrm{C}-1)$.

$1960(C-11)$.

$1960(23)$.

$1954(13) ; 1958(C-2),(c-3)$.

$1960(23)$.

$1958(\mathrm{C}-10)$.

$1950(\mathrm{C}-1) ; 1952(\mathrm{C}-5) ; 1955(\mathrm{C}-3)$;

$1958(c-24) ; 1959(c-3)$.

$1960(23)$.

$1957(C-9)$.

$1958(C-2)$.
Element

Papers

$\begin{array}{ll}\text { Rh } & 1960(23) . \\ \text { Sc in Sc-0 } & 1958(C-14) . \\ \text { Te } & 1959(C-5) . \\ \text { Th } & 1959(C-9) . \\ T i \text { In Ti-0 } & 1958(C-14) . \\ V \text { in V-0 } & 1958(C-14) . \\ U & 1957(C-9) .\end{array}$

TRANSITION PROBABILITIES FOR SOFT X-RAYS INDEX

Element

Papers

Al

$1941(3)$.

Bi

$1955(c-4)$.

K

$1955(c-5)$.

Mg

1941 (3).

$\mathrm{Na}$

$1941(3)$.

$\mathrm{Pb}$

$1955(c-4)$.

Pt

$1955(c-4)$.

W

$1955(c-4)$.

X-RAY SCREENING CONSTANTS INDEX

Element

Papers

Ca

$1960(48)$

$\mathrm{Cr}$

$1957(22)$

$\mathrm{Fe}$

$1957(22) ; 1960(48)$.

$\mathrm{Mn}$

$1957(22)$

$\mathrm{Na}$

$1957(22)$.

$\mathrm{Ni}$

$1957(22)$.

V

$1957(22)$.

$\mathrm{Zn}$

$1960(48)$

$Z=23-92 \quad 1956(C-7)$.

CRITICAL POTENTIALS FOR SOFT $X$-RAYS INDEX

Element

Papers

$\mathrm{Cu}$

$\mathrm{Fe}$

Li

Ni

$1953(C-7) ; 1955(27)$.

$1959(20)$.

$1950(10)$.

$1959(22)$. 
PHOTOELECTRIC PHENOMENA INDEX

\section{Element}

Papers

Ag

$\mathrm{Ag}$ in $\mathrm{Ag}-\mathrm{Br} \quad 1958(32)$.

Al $1960(C-19)$.

Aul 1958(13); $1960(c-19)$.

Au in Au-Sn 1959(28).

Be 1960(29).

Bi 1960(C-19).

Br-Na 1960(30).

c $1959(32)$.

Ca-F 1960(31).

cd $1959(28) ; 1960(c-17)$.

Cd in Cd-O $1959(28)$.

Cl-Na $1960(31)$.

Cr $1959(32)$.

Cs in Cs-1 1960(30).

Cs In Cs-Br $1960(\mathrm{C}-18)$.

Cs in Cs-Li $1960(C-18)$.

Cu $1958(13),(30),(31) ; 1959(C-20)$.

$\mathrm{Cu}$ in $\mathrm{Cu}-\mathrm{O}$ 1958(30), (31).

Dy

Er

Eu

F in F-Li 1960(31).

F in F-Na $1960(31)$.

F in F-Sr $1960(30),(31)$.

Ga

Gd

Ge

Hf

Ho

1 in $1-K$

1 in $1-\mathrm{Na}$

1 in $1-R b$

In
Element

Papers

$K$ in $K-1 \quad 1960(C-18)$.

Li in Li-Cs $1960(C-18)$.

Lu $1960(4)$.

Mo $1959(32)$.

Na in $\mathrm{Na}-1$ 1960(C-18).

Nd $1960(4)$.

Ni $1958(13) ; 1960(31),(43)$.

Pt 1958(13); 1960(30).

$\mathrm{Rb}$ in $\mathrm{Rb}-1$ 1960(C-18).

Rh 1958(13).

$5 \quad 1959(32)$.

Sb $1960(c-19)$.

Se $1959(C-20)$.

Si $1959(32)$.

Sm 1960(4).

Sn $1959(28) ; 1960(c-19)$.

Sn in Sn-Au 1959(28).

Sn in Sn-0 1959(28).

Tb 1960(4).

Te

$1960(C-19)$.

$1959(32) ; 1960(30),(c-19)$.

$1960(4)$.

$1959(C-21)$.

1959(32); 1960(30), (31), (43).

$1960(4)$.

$1959(C-20)$.

$\mathrm{Zn}$

$1959(32)$. 
AUGER PHENOMENA INDEX

Element

Papers

Ag

Al

Ba

$\mathrm{Be}$

c

cd

Cl

$\mathrm{Cu}$

$\mathrm{Hg}$

$\mathrm{Kr}$

Mg

Mn

Mo

$N$

$\mathrm{Nb}$

$\mathrm{Ne}$

$\mathrm{Ni}$

0

$\mathrm{Pb}$

Pd

Pt

Rh

Sn

Sr

vo

Zn

$\mathrm{Zr}$

$1955(c-6)$. $1958(c-13)$.

$1953(c-4)$.

$1953(c-4)$.

$1953(c-4)$.

$1955(c-8)$.

$1959(c-1)$.

$1955(C-6)$.

$1957(c-13)$.

$1959(c-8)$.

$1953(c-4)$.

$1954(c-8)$.

$1959(\mathrm{c}-8)$.

$1953(c-4)$.

$1957(c-11)$.

$1953(c-4)$.

$1953(c-5)$.

$1959(c-8)$.

$1957(c-11)$. $1953(c-3),(c-5) ; 1954(c-8) ; 1955(c-6)$;

$1953(c-4) ; 1956(c-10)$.

$1953(\mathrm{C}-5) ; 1954(\mathrm{C}-8)$.

$1953(c-4) ; 1957(c-11),(c-12) ; 1959(33)$.

$1953(\mathrm{C}-5) ; 1954(\mathrm{C}-8)$.

$1953(c-4) ; 1957(c-11) ; 1958(c-19)$.

$1953(C-5) ; 1954(C-8)$.

$1953(c-5) ; 1954(c-8)$.

$1953(c-5) ; 1954(c-8) ; 1957(c-6)$.

$1953(c-5) ; 1954(c-8)$.
X-RAY SCATTERING STUDIES INDEX

Element

Papers

Al

co

Cr

$\mathrm{Cu}$

$\mathrm{Fe}$

$\mathrm{Na}$

$\mathrm{Ni}$

0

si

$1956(8)$.

1958(C-24).

$1958(c-24)$.

$1958(C-24) ; 1959(19),(c-2),(c-29)$.

$1958(C-24) ; 1959(C-2),(C-20),(C-29)$. $1956(8)$.

$1958(c-24) ; 1959(19),(c-30)$.

$1956(8)$.

$1956(8)$. 
$(R-1)$

BOYCE, J. C. SPECTROSCOPY IN THE VACUUM

ULTRAVIOLET.

Rev. Mod. Phys. 13, 1-57 (1941).

1. This is a review of vacuum ultraviolet and

soft $X-r a y$ techniques. Numerous references

for the period 1893-1940 are given.

Subject headings include:

Transmission of gases and vacuum requlrement,

Transmission of solid materials,

Reflecting power of gratings and mlrrors,

Photographic techniques and other methods of

detection,

Spectrographic design,

Light sources,

Wavelength standards,

Atomic spectra,

Molecular spectra,

Spectra of the solid state,

Astrophysical and other applications,

Principal absorption band heads in oxygen and

In nitrogen,

Tables of wavelength standards in the vacuum ultraviolet,

Bibliography of atomic spectra in the vacuum ultraviolet.

$(R-2)$

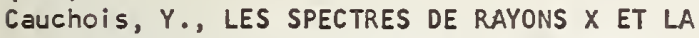

STRUCTURE ELECTRONIQUE DE LA MATIERE.

(In French.)

Paris, Gauthier-Villars (1948), 102 pp.

$(R-3)$

Cauchois, Y., X-RAY SPECTROSCOPY WITH CURVED

CRYSTALS.

Instruments \& Measurements Conference

Stockholm, Transactions 1949, 46=59.

1. A general discussion of method and technique using crystal spectrometers is given as is a

literature review on $\mathrm{Ga}, \mathrm{Zn}, \mathrm{Br}, \mathrm{Cu}, \mathrm{Ni}$, Mo, In, $\mathrm{Cd}, \mathrm{Sm}, \mathrm{Sb}, \mathrm{Te}$.

$(R-4)$

Cauchols, Y., ATOMES, SPECTRES MATIERE.(In French.) Paris, Albin Michel (1952), 640 pp.

$(R-5)$

LANDOLT-BORNSTEIN TABLES (Verlag Springer, Berlin 1955). Vol. 1, Part 4 (6th edition) 769-867.

1. Experimental data are reproduced, but no explanation or discusslon of them is presented.

$(R-6)$

M.I.T. SOLID STATE PHYSICS GROUP, QUARTERLY REPORTS. M.1.T. Research Laboratory of Electronics; published January, April, July, and October. issues of interest and topics are as follows:

Issue Page Topic

10-15-50 20 Calibration of vacuum spectrograph.

1-15-51 24 L emission spectrum of Al.

1-15-52 13 Preliminary results on $\mathrm{Cr}$.

4-15-52 $13 \quad M_{2,3}$ bands of evaporated Cu.

7-15-52 $12 \mathrm{M}_{2,3}$ bandwidths of $\mathrm{Cu}$ and $\mathrm{Cr}$.
Issue Page $\quad \underline{\text { Topic }}$

10-15-52 10 Preliminary results on the $M_{2,3}$ band of $\mathrm{Ni}$.

4-15-53 12 3p emission of $\mathrm{Mn}$.

7-15-53 16 Final results on $\mathrm{Cu}, \mathrm{Cr}, \mathrm{Ni}, \mathrm{Mn}$, and $\mathrm{Fe}$.

1-15-54 9 General description of the apparatus.

7-15-58 3 Magnitude of soft $X$-ray production and photoelectric emission in Ta, W, and Mo.

4-15-59 13 Focusing properties of a $3 \pi / 2$ electron spectrometer for studies of photoelectric emission excited by soft $X$-rays.

7-15-59 44 M-emission bands of $\mathrm{Cu}$ and $\mathrm{Ni}$ in the solid state.

1-15-60 60 Discussion of $H_{2,3}$ emission band results.

1-15-60 62 Soft $X$-ray detection by means of

Be-Cu photomul tipliers.

7-15-60 63 Construction of a new photoelectric spectrograph capable of being evacuated to $10^{-10} \mathrm{~mm} \mathrm{Hg}$.

$(R-7)$

Niehrs, H., RONTGENSPEKTROSCOPIE DER VALENZELEKTRONEN-BANDER IN KRISTALLEN. (In German.) Ergeb. exakt. Naturw. 23, 359-409 (1950).

$(R-8)$

Parratt, L. G., ELECTRONIC BAND STRUCTURE OF SOLIDS BY THE METHOD OF EXPERIMENTAL X-RAY SPECTROSCOPY. Office of Technical Services, PB151453, 117 pp. (1958).

1. A discussion of the fundamental aspects of solid state $X$-ray spectroscopy is presented and correlated insofar as possible with selected experimental work; much emphasis is placed upon data interpretation.

Note: 76 references are appended.

$(R-9)$

Parratt, L. G., ELECTRONIC BAND STRUCTURE OF SOLIDS BY X-RAY SPECTROSCOPY.

Rev. Modern Phys. 31, 616-645 (1959).

1. Pertinent solid state $X$-ray spectra, terms applicable to $X$-ray spectroscopy, experimental difficulties, etc., are discussed. Bandwidths are presented. Excitedstate energy level diagrams are contrasted with the conventional energy level diagrams and the effects on the observed spectra due to changes in the electron energy level values are discussed.

$(R-10)$

Parratt, L. G., ELECTRONIC BAND STRUCTURE OF SOLIDS BY $X$-RAY SPECTROSCOPY.

Methods of Experimental Physics - Solid State Physics B-6, 281-292 (1959).

1. A brief review of the general principles of $X$-ray spectroscopy is given. For a more complete treatment by the same author see Refs. $R-8$ and $R-9$. 
$(R-11)$

Pike, E. R., INTRODUCTION TO SOFT X-RAY SPECTROSCOPY.

American Journal of Physics 28, 235-242 (1960).

1. A general review in which the experimental methods are outlined and recent trends are detailed.

$(R-12)$

Sandstrom, A. E., EXPERIMENTAL METHODS OF X-RAY SPECTROSCOPY: OROINARY WAVELENGTHS.

Encyclopedia of Physics (Handbuch der Physik) 30, 78-245 (1959).

1. The following tables are presented: wavelength of emission lines from $100-20,000 \mathrm{XU}, \mathrm{K} \alpha$ satellites for $Z=16-46, K \beta$ satellites for $Z=14-47$, wavelengths of $K, L_{1}, L_{2}$, and $L_{3}$ absorption edges, fine structure of absorption spectra, relative values of energy levels, Ilne widths at half-maximum for $Z=16-42$ and relative line intensities.

Note: 128 references are appended.

$(R-13)$

ShaW, C. H. X-RAY SPECTROSCOPY OF SOLIDS. Theory of Alloy Phases - Amer. Soc. for Metals 1956, 13-62. Text 13-47, 8ibliography 48-62.

1. In this review article, containing 353 references, such things as the history of the art, earlier work, satellite production, etc., are discussed; a great many $K, L$, and $M$ spectra are reproduced from the literature and evaluated.

$(R-14)$

Shaw, C. H., THE X-RAY SPECTROSCOPY OF SOLIDS. U.S. At. Energy Comm. AECU-3190, 75 pp. (1956).

1. See annotation for Ref, $R-13$.

$(\mathrm{R}-15)$

Skinner, H. W. B., THE SOFT X-RAY SPECTROSCOPY OF THE SOLID STATE.

Reports on Progress in Physics 5, 257-283

(1939). (The Physical Society, London.)

1. This is a review with 46 references. (See Ref. 6 (1940) for the aspects discussed.)

$(R-16)$

Tomboulian, D. H., THE EXPERIMENTAL METHODS OF SOFT $X$-RAY SPECTROSCOPY.

Encyclopedia of Physics (Handbuch der Physik) 30, 246-304 (1959).

1. Electronic states, emission and absorption processes in solids and such special features as satellite bands, high and low energy tails, emission edges, and insulators are discussed.

2. Experimental methods, and results for many $K$, $L$, and $M$ spectra are presented.

3. Tables give bandwidths, absorption edges, emission edges, and term values.

Note: Thirteen summarized references are appended.

$(R-17)$

Tsutsumi, K, et al, THE X-RAY SPECTROSCOPY OF THE SOLID STATE.

Ann. Rept. Sci. Work, Fac. Sci. Osaka U. I, $1-88$ (1959).

1. A general review of the subject is presented.

$(R-18)$

CONFERENCE ON THE APPLICATIONS OF X-RAY SPECTROSCOPY TO SOLID STATE PROBLEMS.

Office of Naval Research, NP-4287; NAVEXOS P-1033, 81 pp. (1950).

Papers presented:

1) $x$-ray spectra and the theory of solids.

2) X-ray spectroscopy at the Unlversity of Paris.

3) Fine structure near X-ray absorption edges.

4) Energy band calculations for soft $X$-ray emission.

5) Bent crystal vacuum spectrograph and the spectra of $\mathrm{KCl}$.

6) Radiative and electronic excitation of $X$-ray states.

7) Absorption of $\mathrm{Se}$ and $\mathrm{Al}$ in the soft $\mathrm{X}$-ray region.

8) X-ray absorption edges of covalently bonded $\mathrm{Cr}, \mathrm{Mn}, \mathrm{Fe}$, and $\mathrm{Ni}$.

9) Crystais for a double crystal spectrometer $(3-15 A)$.

10) Beaded wi re G-M counter for X-ray intensity measurements.

$(\mathrm{R}-19)$

Vainshtein, E. E., (Book) X-RAY SPECTRA OF ATOMS AND MOLECULES IN CHEMICAL COMPOUNDS AND ALLOYS. (In Russian.)

Acad. Sci. U.S.S.R. Press (1950).

1929

(1) $E$

Richtmyer, F. K. and R. D. Richtmyer, THE SATELLITES OF THE X-RAY LINES $L \alpha_{1}, L \beta_{1}$, and $\mathrm{LB}_{2}$.

Phys. Rev. 34, 574-581 (1929).

1. The $L \alpha_{1}, L \beta_{1}$, and $L_{2}$ satellite structure for elements $\mathrm{Rb}$ to $\mathrm{Sn}$ were studied.

2. A crystal (calcite or quartz) spectrometer was used; intensities were recorded photographically.

3. Tables of $\lambda, \nu / R$, and $\Delta \nu / R$ for $5 L \alpha_{1}$ satellites, $4 L \beta_{1}$ satellites, and $5 L^{L} \beta_{2}$ satellites are presented.

4. The square root of the difference in frequency between a parent and its satellite is a linear function of atomic number.

1931

(I) $E$

Richtmyer, R. D., UPPER ATOMIC-NUMBER LIMITS FOR SATELLITES OF THE X-RAY LINE LB 2 . Phys, Rev. 38, 1802-1807 (1931). 
1. LE 2 satellites in elements of $Z=50,51,52$, $53,56,58$, and 60 were studied.

2. A siegbahn crystal (calcite) spectrometer was used; intensities were recorded photographically.

3a. Results are tabulated.

$3 b$. The results disagree with the WentzelOruyvesteyn formula for the ratio of the number of $\mathrm{KL}$ ionizations to the number of $K$ ionizations which should take place.

\section{2}

(1)E

Andrew, $V$. J., RELATIVE INTENSITIES OF $L \beta \beta_{1,2} L \alpha_{1}$, and LYI LINES IN Ta, $W, 1 \mathrm{r}$, and $\mathrm{Pr}$.

Phys. Rev. 42, $591-608$ (1932).

2. A bent crystal (mica) spectrometer and a $\mathrm{CH}_{3} \mathrm{Br}$ ionization chamber were used to obtain data.

3. Complete tables of results corrected for absorption in the ionization chamber, partial reflection by the crystal, target absorption, and interference from adjacent $l$ ines are presented.

(2) $\mathrm{T}$

HOY $t$, A., THE SHAPE OF AN X-RAY LINE. Phys. Rev. 40, 477-483 (1932).

1,2. An emission line measured in a double crystal spectrometer in the antiparallel position is represented by an empirical formula of the type:

$$
y=\frac{a}{1+(x / b)^{2}}
$$

3a. This type of formula is al so shown to be a good representation of the rocking curves obtained in the parallel position of the spectrometer.

3b. The maximum ordinate predicted is independent of the spontaneous transition probability.

(3)E

Mack, J. E., J.R. Stehn, and B. Edlen. ON THE CONCAVE GRATING SPECTROGRAPH ESPECIALLY AT LARGE ANGLES OF INCIDENCE.

J. Opt. SOC. Am. 22, 245-264 (1932).

1. A review covering the physical optics of the perfect concave grating, optimum grating width, elimination of grazing incidence aberrations, and the inexactness of the grating equation is presented.

3a. Equations for the optimum grating width, and slit width are given. These can be plotted easily as a function of wavelength.

3b. A resolution criterion is given such that two lines are resolved when the wavelength difference between them $(\Delta \lambda)$ is such that the minimum total intensity between the lines is $8 / \pi^{2}$ as great as the total intensity of both at the central maximum of either of the lines.
1933

(1)E

Hirsh, Jr., F. R. and F. K. Richtmyer. THE RELATIVE INTENSITIES OF CERTAIN L-SERIES X-RAY SATELLITES IN CATHODE RAY AND IN FLUORESCENCE EXCITATION.

Phys. Rev. 44, 955-960 (1933).

1. The $L \alpha$ satellites in $\mathrm{Zr}$, Mo, Ru, Rh, Pd, and Ag were studied.

2. A Siegbahn (bent crystal) spectrograph was used; intensities were recorded photographically.

3a. The magnitude of the integrated satellite intensity varies from $10-70 \%$ of the parent $L \alpha$ depending upon the element in question.

3b. Spectra and tabular data are presented.

4. The peripheral electron structure of the atom has an effect, but the LM ionization is the most probable cause of the observed satellites.

(2)E

Richtmyer, F. K., and S. Kaufman . X-RAY SATELLITES OF HIG'H ATOMIC NUMBER ELEMENTS. Phys. Rev. 44, 605-609 (1933).

1. The satellites of the $L \alpha_{1}, L \beta_{2}$, and $L \alpha_{2}$ lines for elements from $T a$ to $U$ were studied.

2. A Siegbahn-Thoraeus (crystal) spectrometer was used; intensities were recorded photographically.

3a. L $\alpha$ was found to have two satellites.

3b. The values of $\lambda, \Delta \lambda$, and $\Delta \nu / R$ for all satelli tes observed are tabulated.

1934

(1) T

Jones, H., N. F. Mott, and H. W. B. Skinner, THEORY OF THE FORM OF $X$-RAY EMISSION BANDS OF METALS.

Phys. Rev. 45, 379-384 (1934).

1. Results for $\mathrm{Li}, \mathrm{Be}, \mathrm{Mg}$, and $\mathrm{Al}$ are explained.

3. Transition probabilities from the conduction band to $K$ and $L$ levels may vary strongly within the lowest allowed zone, and they will also depend on the azlmuthal quantum number of final states.

1935

(1) E

Hirsh, Jr., F. R. RELATIVE ENERGY OF L $\alpha$ SATELLITES PRODUCEO BY CATHODE RAYS IN ELEMENTS FROM Ag(47) TO Te(52). Phys. Rev. $48,722-724$ (1935).

2. A Siegbahn spectrometer was used; intensities were recorded photographically.

3a. From $Z=47$ to $Z=52$, the satellites decrease rapidly in relative energy.

3b. The results agree with the Coster-Kronig theory. 
(1) E Cont'd.

3c. Tables and spectra are presented.

(2) $E$

Pearsall, A. W. INTENSITIES OF SATELLITES OF $K \alpha$. Phys. Rev. 48, 133-135 (1935).

1. The intensities relative to that of the parent line for $K \alpha_{1}$ satellites of elements with atomic number 16-29 were measured.

2. A Siegbahn spectrograph was used; intensities were recorded photographically.

3a. The intensities are lower $(0.7 \%$ to $5 \%$ ) than the $L \beta_{2}$ satellites $(32 \%)$.

3b. Data are tabulated and the Fe spectrum is presented.

4. An intensity maximum found cannot be explained by the Auger effect.

$(\mathrm{C}-1) \mathrm{T}$

Krutter, H. M. ENERGY BANDS IN COPPER.

Phys. Rev. 48, 664-670 (1935).

1,2. A corrected Hartree field is used to calculate the bands in FCC metals using copper as an example.

3a. The 3d and $4 \mathrm{~s}$ band overlap is shown and a correlation of the $\langle 100\rangle,\langle 110\rangle$, and $\langle 111\rangle$

direction bands is given.

3b. Electrons are assigned to lowest energy bands.

1936

(1) E

Hirsh, Jr., F. R., THE ENHANCEMENT OF CERTAIN L AND M SERIES $X$-RAY LINES BY THE AUGER EFFECT. Phys. Rev. 50, 191-197 (1936).

1. The $L B_{1}$ lines of elements of $Z=30-48(5-12 A)$ were studied.

2. A crystal (gypsum) spectrometer was used; intensities were recorded photographically.

3a. A large change in relative intensity was observed at $Z=40$ due to Auger enhancement.

3b. Spectra are presented and all results are tabulated.

(2)E

Parratt, L. G. EXCITATION POTENTIAL OF K $\alpha_{3,4}$ SATELLITE LINES.

Phys. Rev. 49, 132-139 (1936).

1. The $K$ satellite intensity vs. X-ray tube voltage for the $K \alpha_{3}, 4$ lines of titanium was determined.

2. A double crystal (calcite) spectrometer was used; intensities were recorded, using ion chamber detection.

3a. The excitation potential of the $\mathrm{Ti}-\mathrm{K} \alpha_{3,4}$ is $5450 \pm 100$ vol ts.

3b. A state of KL ill ionization is 5455 volts in Tl using 0.85 as the screenlng constant of a $\mathrm{K}$ electron.

(3) $E$

Parratt, L. G. EXCITATION POTENTIAL, RELATIVE INTENSITIES AND WAVELENGTHS OF THE $K \alpha^{\prime \prime} \mathrm{X}$-RAY SATELLITE LINE.

Phys. Rev. 49, 502-507 (1936).
1. The ionization curves of the $K \alpha^{\prime \prime}$ for the elements $S(16)$ to $V(23)$ were studied.

2. A double crystal (calcite) spectrometer was used and intensities were recorded, using ion chamber detection.

3. Tables and spectra and a plot of satellite intensity as a percentage of the parent line intensity are presented.

4. The $K \alpha^{\prime \prime}$ Is the result of a KM Ionization.

(4)E

Parratt, L. G. K $\alpha$ SATELLITE LINES.

Phys. Rev. 50, 1-15 (1936).

1. The $K \alpha_{3}, 4$ group of satellite lines for elements $\mathrm{S}(16)$ to $\mathrm{Ge}(32)$ were studied.

2. A double crystal (calcite) spectrometer with either $\mathrm{CH}_{3} \mathrm{Br}$ or argon in the ionlzation chamber was used to obtain intensity data.

3a. Five component satellites for elements with $16 \leq z \leq 28$ and four component satellites for elements with $29 \leq Z \leq 32$ were found.

3b. All spectra and tables of the wavelength, relative intensity, and the half-maximum line width for each satellite component are presented.

(5)E

Parratt, L. G. ON X-RAY SATELLITES, RELATIVE INTENSITIES, AND LINE WIDTHS. Phys. Rev. 50, 598-602 (1936).

1. The $L \alpha_{1,2,3,4,5,6,7}$ lines of $\mathrm{Ag}$ and the $\mathrm{M} \alpha \beta$ 1 ines of Au were studied.

2. A double crystal (calcite) spectrometer was used; intensities were recorded, using ion chamber detection.

3a. Spectra are presented.

3b. Discrepancies in interpretation of widths are due to differences in (a) the effective resolving power of the instrument used and in (b) the assumed shapes of the component lines comprising an unresolved complex structure.

(6) $T$

Richtmyer, R. D. THE PROBABILITY OF KL IONIZATION AND $X$-RAY SATELLITES.

Phys. Rev. 49, 1-8 (1936).

1. A theory of the multiple ionizations produced by a fast cathode electron in the target of an $X$-ray tube is suggested, using potassium as an example.

2. The Born approximation of collision theory was used.

3. The results lead to the following transitions:

$$
\begin{aligned}
& \text { Parent line }(1 \mathrm{~S})^{2} \mathrm{~S}_{1 / 2} \rightarrow 2 \mathrm{P}{ }^{2} \mathrm{P}_{3 / 2,1 / 2} \\
& \text { Satellites }(1 \mathrm{~S} 2 \mathrm{~S}) 1^{1} \mathrm{SO}_{3}^{l} \rightarrow(2 \mathrm{P} 2 \mathrm{~S})^{1} \mathrm{P}_{1}{ }^{3} \mathrm{P}_{012}
\end{aligned}
$$

(7) $E$

Shaw, C. H., and L. G. Parratt, THE K $\alpha$ SATELLITES FOR Zn(30) TO Pd(46).

Phys. Rev. 50, 1006-1011 (1936).

1. $K$ spectra for $Z=30-46$ are presented.

2. A double crystal spectrometer was used. 
(7)E Cont'd.

3a. Four component lines for $30 \leq z \leq 33$, three component lines for $34 \leq Z \leq 40$, and two component $\alpha_{3}$ and $\alpha_{4}$ lines for $41 \leq Z \leq 46$ were found.

3b. A sharp and anomalous decrease in total satellite intensity relative to $\alpha_{\boldsymbol{q}}$ intensity was found in the region of $Y(39)$.

3c. Data are tabulated and spectra are presented.

(8)E

Yoshida, S. ALUMINUM KB BANDS FROM Al-CU ALLOYS. Sci. Papers Inst. Phys. Chem. Research (Tokyo) 28, 243-250 (1936).

1. Some 7 alloys ranging from $10-100 \%$ Al were studied.

2. A crystal spectrometer was used and intensities were recorded photographically.

3a. The Al bandwidth for KB was $62.8 \mathrm{xU}$.

3b. As the Al percentage was decreased, the band was resolved into two overlapping peaks; the long wavelength peak (at $7970.9 \mathrm{XU}$ ) becomes stronger.

4. Brillouin zone overlap is responsible for the results.

1937

(1)E

Skinner, H. W. B., and J. E. Johnston, FINE STRUCTURE OF SOFT X-RAY ABSORPTION EDGE 1: Li, Mg, $\mathrm{Ni}$, CU METALS.

Proc. Roy. Soc. (London) A-161, 420-440(1937).

1. The $\mathrm{LI}_{1}-\mathrm{K}$; the $\mathrm{Mg}-\mathrm{L}_{3}, \mathrm{~L}_{2}, \mathrm{~L}_{1} ; \mathrm{Cu}-\mathrm{M}_{2}, 3$ and $\mathrm{Ni}-\mathrm{M}_{2,3}$ absorption edges were studied; specimens were $1-5$ micron foils evaporated in vacuo on to celluloid-backed napthalene.

2. A grating spectrograph at grazing incidence was used with intensities being recorded photographically; the continuous radiation source was a vacuum spark generated between metal electrodes $1.5 \mathrm{~cm}$. from the slit.

3a. The fine structure and the edge spectra are presented in detail for all materials studied.

3b. No attempt to interpret the spectra is made but the results are tabulated.

\section{8}

(1) $E$

Skinner, H. W. B., and J. E. Johnston, SOFT X-RAY BANDS FROM DILUTE ALLOYS.

Proc. Cambridge Phil. Soc. 34, 109-114 (1938).

1. Alloys of $\mathrm{Al}-\mathrm{Cu}, \mathrm{Be}-\mathrm{Cu}$, and $\mathrm{Be}-\mathrm{Al}$ were studied.

2. A one-meter grating spectrograph at grazing incidence was used; intensities were recorded photographically.

3. An attempt to correlate the results wi th the Mott-Jones theory of alloys was made; spectra are presented.

4a. All the valence electrons of the impurity atom are shared with the lattice. 4b. The impurity "selects" from the electrons in the lattice those which it chooses to have within it.

1939

(1) $E$

Beeman, $W . W_{.}$, and H. Friedman, THE X-RAY K ABSORPTION EDGES OF THE ELEMENTS Fe(26) to Ge(32). Phys. Rev. 56, 392-405 (1939).

1. Absorbers were prepared as follows: A 5-10 thick film of $\mathrm{Fe}, \mathrm{Co}, \mathrm{Ni}$, and $\mathrm{Cu}$ was plated onto stainless steel and stripped off; $G$ a was used as a liquid and $G e$ as a powder.

2. A double crystal (calcite) spectrometer with a resolving power of 30,000 was used; intensities were measured wi th a Geiger counter.

3a. Spectra and tables of results are presented.

$3 b$. Widths of $K$ states $( \pm 1 / 2$ vol $t)$ were assigned by matching theoretical arctangent curves to the experimental edges.

3c. The first empty levels above the Fermi surface were assigned wave length positions.

4. The $K \beta_{5}$ line is a dipole transition arising from the mixture of $\rho$ function in the $3 d$ bands.

(2) $E$

Burbank, C. J., NEW X-RAY LINES IN THE L SERIES RESULTING FROM K AUGER TRANSITIONS. Phys. Rev. 56, 142-146 (1939).

1. The $L$ series of silver was studied.

2. A crystal spectrometer was used and intensities were recorded photographically.

3. Three new lines at 4.03A, 4.016A, and 3.805A were found.

4. These lines are due to processes in which an atom, initially ionized in the $\mathrm{K}$ shell undergoes transitions of the type:

$\mathrm{K} \rightarrow \mathrm{LL}+$ expelled electron (Auger transition) $L L \rightarrow L M+$ photon (radiative transition).

(3) $E$

Johnston, J.E., THE FINE STRUCTURE OF THE X-RAY ABSORPTION EDGES OF AI AND $\mathrm{Zn}$. Proc. Cambridge Phil. Soc. 35, 108-113 (1939).

1. The $L_{2,3}$ edges of $A l$ and $Z n$ were studled.

2. A concave 1 meter grating at grazing incidence in a vacuum spectrograph was used; a condenser spark between cu electrodes was the light source, and intensities were recorded photographically.

3a. The spectra obtained and tabular results are presented.

3b. The spectra are described; no attempt to interpret them is made.

(4)E

Kliever, W. H., INTENSITIES OF K SERIES X-RAY LINES OF $W$ AND Pt.

Phys. Rev. 56, 387-391 (1939).

1. Intensities were found by determining, with a planimeter, the area under the curves of the $X-r a y ~ l i n e s$ vs. Bragg angle. 
(4) E Cont'd.

2. A double crystal spectrometer (calcite in the $1,+1$ position) equipped with an ionization chamber and amplifier was used.

3. Spectra and tabular results are presented.

(5) $\mathrm{E}$

McGrath, J. W., THE DIFFERENCES BETUEEN THE M5 AND M4 ABSORPTION EDGES OF GOLD IN THE PURE METAL AND IN A GOLD-COPPER ALLOY.

Phys. Rev. 56, 137-142 (1939).

1. The $M_{4}$ and $M_{5}$ absorption edges of pure Au and of $\mathrm{Au}$ in a $50 \mathrm{a} / \mathrm{O}^{\circ} \mathrm{Au}-\mathrm{Cu}$ alloy were studied; absorbers were evaporated on to a soft glass backing with a predetermined optimum absorber thickness being used.

2. A crystal spectrometer was used; intensities were recorded photographically.

3. The edge shifis were 6.8 and $2.5 \mathrm{eV}$ for the gold $M_{4}$ and $M_{5}$, respectively, in the alloy showing that the final levels of these transitions are lattice levels.

4. The results show that there are preferred atomic to low lattice level transitions which are often given by $\Delta l= \pm 1$.

(6) T

Richtmyer, R. D., THEORY OF X-RAY LINES LL-LM. Phys. Rev. 56, 146-152 (1939).

1. Quantum theory is applied to determine the transition probabilities from doubly ionized states of LL-LM type for Ag.

3a. It was assumed that the excitations of the initial (LL) levels arise from the internal conversion of $K$ excitation energy.

3b. Complete tables of results are presented.

1940

(1) E

Bearden, J. A. and W. W. Beeman, K ABSORPTION EDGES AND $K \beta_{2,5}$ EMISSION LINES OF TWO $\mathrm{Zn}-\mathrm{Ni}$ ALLOYS.

Phys. Rev. 58, 396-399 (1940).

1. The shapes of the $K \beta_{2,5}$ emission lines and the $\mathrm{K}$ absorption edge of $\mathrm{Zn}$ and $\mathrm{Ni}$ in two $\mathrm{Zn}-\mathrm{Ni}$ alloys containing 17 and $30 \mathrm{w} / \mathrm{O} \mathrm{Zn}$ respectively were obtained.

2. A double crystal (calcite) spectrometer was used; intensities were recorded with the aid of a Geiger counter.

3a. The transitions responsible for the features were valence $\left(\mathrm{K}_{5}\right)$ or $3 \mathrm{~d}$ electrons dropping into a $K$ shell vacancy.

3b. Spectra and tabular results are presented.

3c. The $Z n$ emission line was shifted one electronvolt toward lower energies and was narrowed, while the $\mathrm{Ni}$ line was changed only slightly.

4. Higher energy valence electrons of $\mathrm{Zn}$ are shared with nickel and probably go into the $3 d$ states of the nickel atoms.

(2) $E$

Bearden, J. A. and $H$. Friedman, X-RAY K $\beta_{2}, 5$ EMISSION LINES AND K ABSORPTION LIMItS OF
Cu-Zn ALLOYS.

Phys. Rev. 58, 387-395 (1940).

2. A double crystal (calcite) spectrometer was used; intensities were recorded wi th the aid of a Geiger counter.

3a. Mixing $\mathrm{Cu}$ with $\mathrm{Zn}$ caused an increase in the

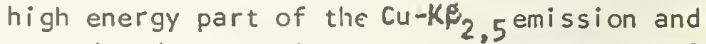
caused a decrease in the corresponding $\mathrm{Zn}-\mathrm{K}_{5}$ emission.

36. In every alloy the $\mathrm{Zn}-\mathrm{K} \beta_{5}$ appeared with very little change in width or intensity per $\mathrm{Zn}$ atom; hence, the $Z n-K \beta_{5}$ was assigned as a $3 d$ quadrupole emission line.

3c. No shifts of the high energy sides of the lines or of the absorption edges were observed.

3d. There was no evidence of any effect of crystal structure on the emission lines.

3e. Spectra are presented for an entire series of $\mathrm{Cu}-\mathrm{Zn}$ alloys.

(3) E

Friedman, H. and $W$. W. Beeman, COPPER AND NICKEL $X-R A Y K B_{2}$ and $K \beta_{5}$ EMISSION LINES AND $K$ ABSORPTION LIMITS IN CU-NI ALLOYS. Phys. Rev. 58, 400-406 (1940).

1. Pure $\mathrm{Ni}$ and $\mathrm{Cu}$ and $\mathrm{Ni}-30 \mathrm{w} / \mathrm{O} \mathrm{Cu}, \mathrm{Ni}-54 \mathrm{w} / \mathrm{O}$ $\mathrm{Cu}$, and $\mathrm{Ni}-79 \mathrm{w} / \mathrm{o} \mathrm{Cu}$ alloys were studied.

2. A double crystal (calcite) spectrometer was used; intensities were measured with a Geiger counter.

3a. Spectra are given in detail and tabular results are presented.

3b. The shapes of the $\mathrm{CuK} \mathrm{K}_{2}, 5 \mathrm{lines}$ and the $\mathrm{Ni} \mathrm{KB}_{5}$ lines vary smoothly with composition.

3c. The absorption edge data showed no influence of alloying.

4. The major effect of alloying in $\mathrm{Cu}-\mathrm{Ni}$ is a loss of $3 \mathrm{~d}$ band dipole radiation with dilution of the emitting atom.

(4)E

O'Bryan, H. M. and H. W. B. Skinner, THE SOFT $X$-RAY SPECTROSCOPY OF SOLIDS. II. EMISSION SPECTRA FROM SIMPLE CHEMICAL COMPOUNDS. Proc. Roy. Soc. (London) Al76, 229-262(1940).

1. The $K$ and $L$ emission bands of fluorides, chlorides, bromides, iodides, oxides, sulfides, carbides, $B N$, and other boron compounds were lnvestigated.

2. Two separate grazing incidence glass grating (30,000 lines per inch) spectrographs were used. The first was used for wavelengths below $50 \mathrm{~A}$ and had a grazing angle of $1.5^{\circ}$. The second was used for all other wavelengths and had a grazing angle of $6^{\circ}$. Spectra were recorded photographically.

3. The observed spectra are presented and the $p$ and $s$ bandwidths are tabulated in eV. Comparison with the Sommerfeld bandwidth is fair.

4. The ratio of bandwidth to linewidth seems to be a measure of the degree of polarity in the compound. 
(5)E

Randall, C. A., L $\alpha$ SATELLITE LINES FOR Mo(42) to $\mathrm{Ba}(56)$.

Phys. Rev. 57, 786-791 (1940).

1. Satellite components for $Z=42-56$ are resolved.

2. Crystal spectrometry was used; the vacuum was $10^{-4} \mathrm{~mm} \mathrm{Hg}$ in the spectrometer.

3a. The Coster-Kronig crossover was found to occur at $Z=50$.

3b. Some 30 , instead of 15 , gold satellites were found.

3c. Spectra and tabular data are presented.

(6)E

SKinner, H. W. B., THE SOFT X-RAY SPECTROSCOPY OF SOLIDS. I: K AND L EMISSION SPECTRA FROM

ELEMENTS OF THE FIRST TWO GROUPS.

Phil. Trans, Roy. Soc. (London) A239, 95-134 (1940).

1. $\mathrm{Li}, \mathrm{Be}, \mathrm{Na}, \mathrm{Mg}, \mathrm{Al}, \mathrm{Si}, \mathrm{P}, \mathrm{S}, \mathrm{C}$, and $\mathrm{B}$ were studied.

2. A 1 -meter grating spectrograph with a $15 \mathrm{~mm}$ grating surface, a slit width of $0.02 \mathrm{~mm}$ and a $6^{\circ}$ grazing angle was used; spectra were recorded by photographic photometry.

3. Complete tables, spectra, and explanation of the results are given.

4. In determining the precise features of a band, the crystal structure of the material is the most important factor.

1941

(1) $T$

Sa to, M., ENERgy States of THE VALENCE ELECTRONS IN SOME METALS.

Sci. Repts. Tohoku Univ. First Ser. 30 , 267-286 (1941).

1. Level values for $\mathrm{Zn}$ are tabulated.

3. Tabular data on lower limit lines of the $K$ absorption edge are given. These lines in $\mathrm{Cu}-\mathrm{Zn}$ alloys are discussed.

4. Possible transitions to explain the results are suggested and attempts to justify them are made.

(2)E

Tomboulian, D. H. and W. M. Cady, THE L EMISSION BANDS OF $\mathrm{Na}, \mathrm{Mg}$, and $\mathrm{Al}$.

Phys. Rev. 59, 481-485 (1941).

1. Thin-evaporated films of $\mathrm{Na}, \mathrm{Mg}$, and $\mathrm{Al}$ were studied.

2. A 30,000 1 ines per inch glass grating at a grazing angle of $5.1^{\circ}$ and a vacuum of $4 \times 10^{-6}$ $\mathrm{mm} \mathrm{Hg}$ was used. Spectra were recorded photographically.

3a. Spectra and tables of intensity distribution are presented.

3b. Bandwidths were:

\begin{tabular}{|c|c|}
\hline Element & Bandwidth (ev) \\
\hline $\mathrm{Na}$ & $3.05 \pm 0.10$ \\
\hline $\mathrm{Mg}$ & 6.4 \\
\hline
\end{tabular}

(3) $T$

Tomboulian, D. H. and W. M. Cady, RADIATIVE X-RAY TRANSITIONS WITHIN THE L-SHELL.

Phys. Rev. 59, 422-423 (1941).

1. The $L-L$ radiation in the spectra of the lightest elements that have complete $L$ shells was predicted.

2. The screening doublet law was used to make this prediction.

3. Tables of $L_{1}-L_{1}$ probabilities for $\mathrm{Na}, \mathrm{Mg}$, and $A l$, and $L$ terms and $L-L$ lines of elements with $Z=11-26$ are presented.

1942

(1) $T$

Hayashi, T., NEW SYSTEMATIZATION OF X-RAY LINE SPECTRA SATELLITES OF $M g K \alpha$ and K $\beta$ LINES. Sci. Repts. Tohoku Univ. First Ser. 31, 1-7 (1942).

1,2. Additional energy levels (quasi-stationary states) to account for satellite lines are postulated.

4. All Mg-K lines can be derived with this scheme.

(2)E

Hirsh, Jr., F. R., THE ABSENCE OF THE MB X-RAY SATELL ITE INTENSITY ANOMALY.

Phys. Rev. 62, 137-140 (1942).

1. MB satellites for the elements Ir to $U$ (3.76A) were studied.

2. A crystal (quartz or calcite) spectrometer was used; intensities were recorded photographically.

3a. No MB satellite intensity maximum was found; this absence was explained in terms of the relative probability of Auger transitions, these relative probabilities being determined by means of diagram line widths.

3b. Tables and spectra are presented.

\section{5}

(c-1) T

Beutler, H. G., THE THEORY OF THE CONCAVE GRATING J. Opt. Soc. Am. 35, 311-350 (1945).

1,2. A general theory of the image formation of the concave grating, based on Fermat's principle, is developed.

3a. Conditions for a focus, and various image defects such as astigmatism and coma are developed mathematically for several common types of mounting of the concave grating.

3b. Results of the computations are presented in the form of tables and charts. 
$(\mathrm{C}-1) \mathrm{T}$

Pauling, L., THE NATURE OF THE BONDS IN METALS AND INTERMETALLIC COMPOUNDS.

Proc. Intern. Congr. Pure and Appl. Chem. 11. 249-257 (1947).

1. A general discussion of possible hybrids in metals and intermetallic compounds (AuSn, $\mathrm{AuAl}_{2}, \mathrm{Cu}_{3} \mathrm{Sn}_{8}$ ) is presented.

3a. An equation for bond atomic radi $i$ was derived:

$$
R(1)-R(\underline{n})=0.300 \log \underline{n}
$$

where $R(I)$ is the effective atomic radius for a single covalent bond and $R(\underline{n})$ is the effective atomic radius for bond number $(n)$.

3b. The metallic radi $i$ for metal elements are given.

\section{8}

(1) $E$

Coster, D. and S. Kiestra, ON THE EMPTY ELECTRON BANDS OF LOWEST ENERGY OF THE TRANSITION METALS Mn AND Fe AND THEIR OXIDES. Physica 14, 175-188 (1948).

1,2. A bent crystal spectrograph was used to study the $\mathrm{K}$ absorption spectra of $\mathrm{Fe}, \mathrm{Mn}$, and their oxides; intensities were recorded photographically.

3a. The initial absorption jump on the long wavelength side of the edge was attributed to a $K$ electron transition to an empty state of the $4 \mathrm{~s}$ band having $p$ character.

3b. The oxides studied exhibited this initial jump effect to a much lesser extent than the pure metals.

3c. All spectra and density of states curves for $\mathrm{Mn}, \mathrm{Fe}, \mathrm{Ni}$, and $\mathrm{Zn}$ are presented.

(2) $E$

Tomboulian, D. H., RADIATIVE X-RAY TRANSITIONS WITHIN THE L-SHELL OF SULFUR.

Phys. Rev. 74, 1887 (1948).

1. The $L_{1} \rightarrow L_{2,3}$ sulfur transition was found.

3. The 1 ine was $1.5 \mathrm{eV}$ wide with a peak at $203 \mathrm{~A}$.

4. The absence of the $L_{1}$ emission band is in part due to a radiative process within the $L$ shell of the light elements.

(C-1) T

Rundle, R. E., A NEW INTERPRETATION OF INTERSTITIAL COMPOUNDS - METALLIC CARBIDES, NITRIDES, AND OXIDES OF COMPOSITION MX. Acta Cryst. I, 180-187 (1948).

1. Interstitial phases were regarded as electrondeficient structures, i.e., the non-metal forms more bonds than it has bond orbitals.

3a. The use of $s p$ and $p$ orbitals for $M-X$ bonding was suggested.

3b. Resonance of $\mathrm{sp}$ and $\mathrm{p}$ bonds led to octahedral bonding.
$3 c, 4$. A single p orbital forms two bonds at $180^{\circ}$ using a single electron pair (half-bond); the conditions for forming such a half-bond are out lined.

3d. Some physical properties are correlated wi th the proposed bonding scheme.

1949

(1) $E$

Cauchois, Y. and N. F. Mott, X-RAY ABSORPTION SPECTRA OF SOLIDS.

Phil. Mag. (7) 40, 1260-1269 (1949).

1. $\mathrm{Ni}$ in $\mathrm{NiS}, \mathrm{Ni}_{2} \mathrm{O}_{3}$ and $\mathrm{NiAs}, \mathrm{Rb}$ in $\mathrm{RbCl}$, and metallic As, $\mathrm{Ni}$ and $\mathrm{Ga}$, As in NiAs, $\mathrm{Cu}$ in $\mathrm{CuO}$, and $\mathrm{Cu}_{2} \mathrm{O}$ and $\mathrm{Zn}$ in $\mathrm{ZnO}$ were studied.

2. A bent crystal (mica) spectrograph was used, and a record of the intensities was made photographically.

3. Actual experimental spectra and a tabulation of all data are presented.

4. The white ray at a $\mathrm{K}$ absorption edge may be due to a high density of normally unoccupied states with $p$ symmetry in the neighborhood of the absorbing atom and/or the formation of excitation levels.

(2) $T$

Hayashi, T., THEORY OF THE FINE STRUCTURE OF ROENTGEN K ABSORPTION SPECTRA: II. INFLUENCE OF THERMAL VIBRATION OF THE CRYSTAL LATTICE ON THE FINE STRUCTURE.

Sci. Repts. Tohoku Univ. First Ser. 33 , 183-194 (1949).

1. Broadening of $K$ absorption bands, particularly those for $\mathrm{Ni}$ and $\mathrm{Cu}$, were investigated.

2. Einstein's theory of specific heat was used and the width of the $K$ absorption bands for $\mathrm{Ni}$ and $\mathrm{Cu}$ was calculated.

3. Fair agreement with experimental results was obtained.

4. The effect will be more prominent at very low temperatures.

(3) $T$

Kostarev, A. I., INTERPRETATION OF HYPERFINE STRUCTURE OF X-RAY ABSORPTION IN SOLIDS. (In Russian.)

Zhur. Eksptl. Teoret. Fiz. 19, 413-420 (1949).

1. BCC-Fe and FCC-Cu were studied.

3. For $\mathrm{Cu}$, the $1 \mathrm{st}, 3 \mathrm{rd}, 5 \mathrm{th}$, and 7 th shells with intensity ratios of $10: 4: 2: 3$ are the major contributors to the hyperfine structure, while for $\mathrm{Fe}$ the first four layers are the major contributors with intensity ratios of $10: 5: 4: 6$.

4. The hyperfine structure is due to the scattering of the liberated electron by the shells of atoms surrounding the absorbing atom.

(4) E

Morlet, J., THE K SPECTRUM OF Se AND THE L SPECTRUM OF Hg VAPOR. (In French.) Bull. Classe Sci. Acad. Roy. Belg. 35, 1059-1072 (1949). 
(4)E Cont'd.

2. Radiation was analyzed with a curved crystal (mica) spectrometer having a first order dispersive power of $20 \times \mathrm{Xu} / \mathrm{mm}$ and intensities were photographically recorded.

3a. Some $85 \mathrm{lines}$ of $\mathrm{Hg}$ were measured; many faint satellite lines and some intensity anomalies among the principal lines were discovered.

3b. The $\alpha$ and $\beta$ lines and satellites for solid and gaseous $\mathrm{Se}$ are listed.

(5)E

Vainshtein, E. E., K ABSORPTION LIMIT STRUCTURE OF NICKEL IN SOLUTION. (In RUSsian.) Doklady Akad. Nauk S.S.S.R. 69, 771-772(1949).

1. $\mathrm{Ni}$ in $\mathrm{NiCl}_{2}$ and $\mathrm{NiSO}_{4}$ in aqueous and alcohollc solution corresponding to a $5-7 \mu$ thickness of $\mathrm{Ni}$ metal was studied.

2. The structure of the $K$ edge of $\mathrm{Ni}$ was $\mathrm{identi-}$ cal in these dissolved compounds.

(6)E

Victoreen, J. A., X-RAY MASS ABSORPTION COEFFICIENTS.

J. Appl. Phys. 20, 1141-1147 (1949).

1. Complete tables of constants for calculating $\mu / p$ for $Z=1-100$ and for wavelengths less than the K critical absorption wavelengths are presented.

2. An empirical method to obtain the data was used.

3a. Partial tables give constants for $\mu / \rho$ calculations for wavelengths between the $L_{1}$ and $M_{1}$ critical wavelengths.

3b. Calculated $\mu / \rho$ is given for the common elements.

\section{0}

(1) $E$

Cauchois, Y., K EMISSION DISCONTINUITIES OF AI AND $\mathrm{Mg}$ IN DILUTE ALLOYS. (In French.) Compt. Rend. (French Academy) 231, 574-576 (1950).

1. Alloys of $\mathrm{Mg} \ln \mathrm{Al}$ and $\mathrm{Al}$ in $\mathrm{Cu}$ and in $\mathrm{Al}-\mathrm{Mg}$ Si were studied.

2. A bent crystal spectrograph was used and Intensities were recorded photographically.

3a. All alloys studied showed sharp KB emission edges except Al $-95 \% \mathrm{Mg}-1.85 \% \mathrm{Si}$.

3b. For $\mathrm{Al}-\mathrm{Mg}-\mathrm{Si}$ alloy, a broad band was found at a longer wavelength than the usual $K B$ emission edge.

(2)E

Cauchois, $Y$. and I. Manescu, $K$ ABSORPTION SPECTRA OF Ni, ITS Ni-OXIDES, AND Ni ALLOYED WITH Cu. J. Chim. Phys. 47, 392-897 (1950). (In French.)

1. $\mathrm{Ni}, \mathrm{Ni}(\mathrm{OH})_{2}, \mathrm{NiO}, \mathrm{Ni}_{3} \mathrm{O}_{4}, \mathrm{Ni}_{2} \mathrm{O}_{3}$, and laminated sheets of $\mathrm{Ni}$ and $\mathrm{Cu}$ with $\mathrm{Ni}$ varying from $0.5-10 \%$ were studied.

2. A bent crystal spectrometer was used and
Intensities were recorded photographically.

3a. Kronig structures somewhal like that of pure $\mathrm{Ni}$ varied slightly with concentration in the 2 , 5, and $10 \%$ alloys of $\mathrm{Ni}$ in $\mathrm{Cu}$.

3b. Spectra are presented.

(3)E

Coster, D. and S. Kiestra, FINE STRUCTURE NEAR THE IRON K ABSORPTION EDGES IN THE VARIOUS OXIDES OF IRON.

Phil. Mag. (7) 41, 144-151 (1950).

1. Spectra for $\mathrm{Fe}$ in $\mathrm{Fe}$ oxides are presented.

2. A bent crystal (calcite) spectrograph was used; spectra were recorded photographically.

3,4. The data led to these conclusions:

a) In a region about $70 \mathrm{eV}$ from the edge, the absorption coefficlent is a property of the atom in question.

b) In a region 70-175 eV from the edge, the fine structure is determined by the immediate surroundings of the atom.

c) Above $175 \mathrm{eV}$, the fine structure depends on the crystal lattice.

(4)E

Das Gupta, K., THE SOFT X-RAY VALENCE BAND SPECTRA AND THE HEAT OF FORMATION OF CHEMICAL COMPOUNDS AND ALLOYS.

Phys. Rev. 80, 281-282 (1950).

1. $\mathrm{Mg}, \mathrm{Al}, \mathrm{Si}$, and their oxides, $\mathrm{Si}$ in $\mathrm{SiC}$ and the $\mathrm{Fe}_{-} \mathrm{L}_{3}$ in $\mathrm{AlFe}_{3}$ were investigated.

2. A bent crystal (gypsum or mica vacuum spectrograph was used.

3. An equation and a tabulation of data correlating the heat of formation of chemical compounds and alloys with soft $X$-ray valence band shitts are given.

(5) E

Deodhar, G. B., and C. Mande, FORBIDDEN LINES IN THE L SPECTRUM OF PLATINUM.

J. Sci. E Indust. Res. (India) 98, 263-265 (1950).

2. A plane crystal spectrometer was used and spectra were recorded photographically.

3a. Data are tabulated.

3b. Two new lines at 1386.6 and $1110.6 \mathrm{XU}$ respectlvely, corresponding to transitions $\mathrm{L}_{3} \mathrm{M}_{3}$ and $\mathrm{L}_{2} \mathrm{M}_{5}$, were found.

4. No one (up to 1950) has found $\Delta 1$ or $\Delta \mathbf{j}=3$ for $\mathrm{Pt}$.

(6)E

Edamo to, I, FINE STRUCTURE OF $K$ SERIES $X-$ RAY EMISSION SPECTRA FOR $Z=25-30$ and 32 . Sci. Repts. Tohoku Univ. Ser. A-2, 561-612 (1950).

1. Fine structure data are obtained for $Z=25-$ 30 and 32 .

2. A bent crystal (quartz-bent by author) spectrograph was used, capable of being read to $3^{\prime}$ of arc; the spectrograph uses reference lines; the glancing angle $\theta \alpha$ for $k \alpha_{1}$ of quartz is tabulated; targets were $1 \mathrm{~mm}$ plates soldered to $\mathrm{Cu}$ anticathode.

3a. Individual data are presented for each element. 


\section{(6) E Cont'd.}

3b. Line widths, asymmetry values, peak intensities, and the overlapping factor are tabulated and compared with Parratt's results (1936).

$3 c$. The lines are resolved into components and the results are tabulated.

4. Resolved lines were of the "classical dispersion" type.

(7) A

Gokhale, B. G., EFFECT OF SLIT WIDTH ON LINE WIDTHS IN X-RAY SPECTRA. (In French.) Compt. Rend. (French Academy) 230, 636-638 (1950).

1,2. The intensity of a line obtained by photographic photometry is assumed to be:

$|\lambda=|_{\lambda_{0}} \exp \cdot\left[-\left(\lambda-\lambda_{0}\right)^{2} \log 2 / \omega^{2}\right]$

$\lambda_{0}=$ wavelength for a maximum intensity.

$w=$ half-width at half-maximum of the line.

3. Since the dispersion is $D=\frac{d x}{d \lambda}$ and

$x=\left(\lambda-\lambda_{0}\right) 0 ; 1_{0}=\omega D$

and $2 S$ is the slit width; then the recorded intensity $I_{x}$ is:

$I_{x}=\int_{x-s}^{x+s} 1_{0} \exp \left[-x^{2} \log 2 /\left(1_{0}\right)^{2}\right] d x$

(8)E

Hayashi, T., FINE STRUCTURE OF K ABSORPTION SPECTRUM - WAVELENGTH OF ABSORPTION MAXIMA IN K ABSORPTION SPECTRA OF NI AND CU.

Sci. Repts. Tohoku Univ., First Ser. 33, 123-132 (1950).

1. Experimental data show that the $\mathrm{Cu}$ and $\mathrm{Ni}$ fine structure does not give sharp peaks.

2. The free-single electron method is used to calculate quasi-stationary states.

4. More quasi-stationary states of free-electrons exist than are possible when interference with electron waves due to the presence of neighboring planes of atoms is considered.

(9) $T$

Hayashi, T., THE FINE STRUCTURE OF THE K ABSORPTION SPECTRUM OF METALLIC Li.

Sci. Repts. Tohoku Univ., First Ser. 34 , $185-188$ (1950).

1. Theoretical considerations (Ref. 8-1950) were extended to BCC-Li .

3. The theoretical values were compared with experimental results.

4. The theory is applicable to BCC-Li as well as to $\mathrm{FCC}-\mathrm{Ni}$ and $\mathrm{Cu}$.

(10)T

Hayashi, T., CRITICAL POTENTIALS FOR SOFT X-RAYS IN Li .

Sci. Repts. Tohoku Univ., First Ser. 34 , 189-191 (1950).
3. The critical potentials agree, in electronvolts, with quasi-stationary state energies.

4. The Auger effect may be used to explain the agreement of critical X-ray potentials with those of secondary electron emission.

(11)E

Hirsh, Jr., F. R., THE SATELLITES OF THE X-RAY LINE MB.

Physica 16, 377-378 (1950).

1,3. Data and discussion are presented leading to the result that the $M \beta$ satellites are exact counterparts of $H_{1} \alpha_{1}$ satellites; the data are in the form of plots of the square root of energy separation of satellite and parent vs. a tomic number.

4. An ionization study with a double crystal vacuum spectrometer is suggested.

Niehrs, H., - See Review (R-7).

Valnshtein, E. E., - See Review (R-19).

(12)E

Vainshtein, E. E., STRUCTURE OF THE K ABSORPTION LIMIT OF TRANSITION ELEMENTS. (In Russian.) Doklady Akad. Nauk S.S.S.R. 70, 21-23 (1950).

1. It was assumed that the structure of the main absorption limit of atoms in metals represents a superposition of 2 or more limits.

3a. These limits correspond to a K-electron transition into a continuous energy band or to a free optical level.

3b. There is one transition for each state of ionization.

(13) E

Vainshtein, E. E., FORM OF X-RAY $K \alpha_{1} \alpha_{2}$ LINES OF $\mathrm{NI}$ ATOMS IN THE SIMPLEST CHEMICAL COMPOUNDS. (In Russian.)

Zhur. Eksptl. Teoret. Fiz. 20, 442-445(1950).

1. Line widths and the index of asymmetry for $\mathrm{Ni}, \mathrm{NiSO}_{4}, \mathrm{NiO}_{2} \mathrm{Ni}_{2} \mathrm{O}_{3}, \mathrm{NiS}$, and $\mathrm{Ni}_{3} \mathrm{~S}_{4}$ were studied.

2. A bent crystal spectrograph was used.

3. When these compounds are prepared stoichimetrically, the $\mathrm{Ni}-\mathrm{K} \alpha$ lines are symmetrical.

4. Any asymmetry is due to $\mathrm{Ni}$ in 2 valence states in the compound.

(14) E

Vainshtein, E. E., FORM OF X-RAY $K \alpha_{1}, \alpha_{2}$ LINES OF $\mathrm{Cu}$ AND Ni IN Cu-Ni ALLOYS. (In Russian.) Zhur. Eksptl. Teoret. Fiz. 20, 446-450(1950).

1. The asymmetry index and line widths for eleven alloys are listed.

2. A bent crystal spectrograph was used.

3. Asymmetry decreases sharply at $\mathrm{Cu}: \mathrm{Ni}$ ratios of: $1: 1,3: 1$, and $1: 3$. 
(1) T

Averbukh, E. O., CALCULATION OF THE OPTIMUM ABSORBER THICKNESS FOR X-RAY ABSORPTION SPECTRA. Nauch. Byull. Leningrad Gosudarst. Univ. in. (In Russian.) A. A. Zhdanova 1951 (28) 8-11 Annotation from Chem. Abs. 49 -52f

3. Optimum thickness was given by

$$
d_{\text {opt. }}=\frac{\left(\ln \mu_{2}-\ln \mu_{1}\right)}{\mu_{2}-\mu_{1}}
$$

where $\mu_{1}$ and $\mu_{2}$ are the generalized mass absorption coefficients on either side of the absorption edge:

$$
\mu=\frac{\mu^{\prime} A^{\prime}}{M}+\frac{\mu^{\prime \prime} A^{\prime \prime}}{M}+\ldots . . .
$$

where $\mu^{\prime}, \mu^{\prime \prime}$ etc. are the mass absorption coefficients of individual elements in the absorbing compound. $A, A^{\prime \prime}$, etc. are weight fractions of these elements. $M$ is the compound's molecular weight.

(2)E

Barrere, G., NEW LINES IN THE X-RAY SPECTRA OF $W$ AND Hg. (In French.)

Compt. Rend. (French Academy) 233, 376-377 (1951).

1. A new line, $L Y^{\prime}$, for $W$ at $1090.5 X U$ was found.

2. This line was emitted by a $W$ target excited at $400 \mathrm{kV}$.

3. The $K \alpha_{1}, K \alpha_{2}$ lines of $\mathrm{Hg}$ emitted by $\mathrm{Au}$ at $140 \mathrm{kV}$ were 174.7 and $179.8 \mathrm{XU}$ respectively.

4. The frequency of the $\mathrm{K}$ level of $\mathrm{Hg}$ ls $6122 \mathrm{~V} / \mathrm{R}$.

(3)E

Borovskii, I. B., FINE STRUCTURE OF X-RAY ABSORPTION STRUCTURES. (In RUSSian.)

Izvest. Akad. Nauk S.S.S.R. Ser. Fiz. 15, 225-230 (1951).

1. The $L_{3}, M_{3}$, and $M_{5}$ absorption in $\mathrm{UO}_{3}$ and $L_{3}$ and $\mathrm{M}_{5}$ absorption in $\mathrm{UO}_{2}$ were studied.

3. Homopolar bonds were found in $\mathrm{UO}_{3}$ while ionic bonds were found in $\mathrm{UO}_{2}$.

(4)E

Deodhar, G. B., and C. Mande, A NEW NON-QUADRUPOLAR RADIATION IN THE PLATINUM L SPECTRUM. J. Sci. \& Indust. Research (India) 10B, 260 (1951).

1. Forbidden lines in Pt spectra were studied. 3. Observed satellites are tabulated.

(5)E

Frilley, M., B. G. Gokhale and M. Valadares, THE INFLUENCE OF NUCLEAR MAGNETIC MOMENT ON LINE WIDTHS IN X-RAY SPECTRA. (In French.)

Compt. Rend. (French Academy) 233, 1183-1186
1. Data were taken from Gokhale's line width data for $Z=37-50$ (Ref. 9, 1951).

2. Breit's formula was used to calculate the influence of the magnetic moment.

3. The influence of the moment is less than that required by theory; almost no hyperfine separation of $K$ levels was found.

(6) $\mathrm{T}$

Fujimoto, H. and S. Chiba, X-RAY K ABSORPTION EDGE ENERGIES OF ELEMENTS $L i, B e, B$ and $C$. Sci. Repts. Tohoku Univ. 35, First Ser. 154-164 (1951).

la. The $K$ absorption energies of free atoms of $\mathrm{Li}, \mathrm{Be}, \mathrm{B}$, and $\mathrm{C}$ were calculated by Skinner's method and each transition was listed.

1b. The ionization energies of atoms with $(1 \mathrm{~s} 2 \mathrm{~s})^{3} \mathrm{~s}$ and $\left(1 s 2 s^{2}\right)$ configurations were calculated. The results are tabulated.

3a. The results of "la"t were compared to observed $K$ edges and good agreement was found.

3b. The K-ray K-term value was calculated and tabulated.

(7) $E$

Glaser, H., THE ABSOLUTE ABSORPTION COEFFICIENT OF GERMANIUM AND THE FINE STRUCTURE IN THE K EOGE OF SOME OF ITS COMPOUNDS. Phys. Rev. 82,616-621 (1951).

1. Absolute values for the $K$ absorption limit of $\mathrm{Ge}$ in $\mathrm{GeH}_{4}, \mathrm{Ge}_{2} \mathrm{H}_{6}, \mathrm{GeCl}_{4}$ and $\mathrm{GeBr}_{4}$ were obtained.

2. A double crystal (calcite) spectrometer was used; intensities were measured with a chlorine quenched argon proportional counter.

3. All spectra and a tabulation of energy shifts, fine structure details and the mass absorption coefficients are presented.

(8) A

Gokhale, B. G., ON A CURVED CRYSTAL SPECTROGRAPH HAVING A HIGH RESOLVING POWER. (In French.) Compt. Rend. (French Academy) 232, 1086-1088 (1951).

1. The characteristics of a mica curved crystal as compared to calcite in a double crystal spectrometer were discussed.

2. The theoretical resolving power was computed from Ewald's equations.

3. A higher resolution than that of the doublecrystal spectrometer was claimed.

(9) E

Gokhale, B. G., WIDTH OF K $\alpha$ LINES FOR Rb-Sn. (In French.)

Compt. Rend. (French Academy) 233, 937-939 (1951).

1. $K \alpha$ widths in $X U$ for $R b-S n$ are presented.

2. A bent crystal spectrograph was used, and intensities were photographically recorded.

3a. A plot of $\log$ of width for $K \alpha_{1}$ vs. $\log Z$ was linear.

3b. The $K \alpha$ width expressed in eV increased as $z^{3}$. 3c. A correction of the widths for spectrometer broadening ranged from $0-8 \%$. 
(9)E Cont'd.

3d. Ele- $\mathrm{K} \alpha_{1}$ Width Ele-

\begin{tabular}{|c|c|c|c|c|c|}
\hline ment & (Xu) & ment & Width & ment & Width \\
\hline $\mathrm{Rb}$ & 0.303 & Mo & 0.260 & $\mathrm{Cd}$ & 0.230 \\
\hline $\mathrm{Sr}$ & 0.298 & Ru & 0.238 & In & 0.220 \\
\hline$Y$ & 0.282 & Rh & 0.233 & Sn & 0.216 \\
\hline $\mathrm{Zr}$ & 0.273 & Pd & 0.229 & & \\
\hline $\mathrm{Nb}$ & 0.268 & $\mathrm{Ag}$ & 0.230 & & \\
\hline
\end{tabular}

(10)E

Groven, L. and J. Morlet, WEAK RAYS IN THE K SERIES X-RAY EMISSION SPECTRA OF ELEMENTS BETWEEN Zn AND $\mathrm{Kr}$. (In French.) Bull. Classe Scí. Acad. Roy. Belg. 37, 630-639 (1951).

2. The specimen was in the form of a rarified vapor which was excited by a damped electron wave; this excitation produced the desired $\mathrm{X}$-rays.

3. The spectra obtained are systematically analyzed and an attempt was made at interpretation.

(11) E

Kingston, R. H., SPECTROSCOPY OF THE SOLID STATE: POTASSIUM AND CALCIUM.

Phys. Rev. 84, 944-949 (1951).

1. The $k$ and $\mathrm{Ca}$ radiation produced by transitions of the conduction electrons into the ionized $3 p$ state of the atom was studied.

2. A grating spectrometer was used to study the thin evaporated films of $K$ and $\mathrm{Ca}$ at a vacuum of less than $10^{-5} \mathrm{~mm} \mathrm{Hg}$.

3a. Bandwidth data for $\mathrm{Li}, \mathrm{Be}, \mathrm{Na}, \mathrm{Mg}, \mathrm{Al}, \mathrm{K}, \mathrm{Ca}$, $\mathrm{Ti}, \mathrm{V}, \mathrm{Cr}, \mathrm{Mn}, \mathrm{Fe}, \mathrm{Co}, \mathrm{Ni}, \mathrm{Cu}$, and $\mathrm{Zn}$ were tabulated.

3b. Data for $K$ and $\mathrm{Ca}$ are not in good agreement with theory.

3c. Spectra are presented.

(12) E

Kingston, R. H., A SPECTROSCOPIC STUDY OF THE ELECTRONIC STRUCTURE OF METALLIC POTASSIUM AND CALCIUH.

Research Lab. of Electronics M.I.T., Tech. Rept. 193, 30 pp. (1951).

1,2. A grazing incidence grating spectrograph was used to study the emission bands of $\mathrm{K}$ and $\mathrm{Ca}$ at a pressure of $10^{-6} \mathrm{~mm} \mathrm{Hg}$; radiation was produced by bombarding the target wi th $300-$ 500 volt electrons at 2-6 ma and photons were counted by a Be-Cu photomultiplier.

3a. The radiation studied was produced in the evaporated targets by transitions of the valence electrons into the ionized $3 p$ state of the atom. 3b. Detailed descriptions and diagrams of the apparatus are presented; actual and idealized spectra are shown.

3u. Emission

Element edge (A) Energy (eV) Bandwidth (eV)

$\begin{array}{llll}K & 675 \pm 2 & 18.4 \pm 0.1 & 1.9 \pm 0.2\end{array}$

$\mathrm{Ca} \quad 500 \pm 2 \quad 24.8 \pm 0.1 \quad 3.0 \pm 0.2$

(13) E

NEFF, H., ENERGY DISTRIBUTION IN A CONTINUOUS $X$-RAY SPECTRUM OF 1-2 kV ENERGY. (In German.) Z. Physik, 131, 1-9 (1951).

1. $\mathrm{Pt}, \mathrm{Ag}$, and $\mathrm{Ni}$ between 6 and $20 \mathrm{~A}$ were studied.

2. A plane grating vacuum spectrometer was used and radiation was collected with a photon counter.

3. The energy distribution was given by:

$$
E_{\nu} d \nu=c z\left(\nu_{0}-\nu\right) d \nu
$$

$v_{0}=$ frequency limit, $\nu=$ frequency,

$Z$ = atomic number.

4. Deviations in the $Z$ proportionality were thought to be due to screening effects.

(14)E

Parratt, L. G. and E. L. Jossem, X-RAY SPECTROSCOPY OF THE SOLID STATE.

Phys. Rev. 84,362 (1951).

1a. Preliminary work on the $K \beta$ region of $K$ and $\mathrm{Cl}$ in solid KCl was sutlined.

lb. Some basic principles of solid state spectroscopy are briefly discussed.

3a. The lowest atomic level is $2.75 \mathrm{eV}$ below the bottom of the $3 p$ mother band for $K$ and about $3.8 \mathrm{eV}$ for the $\mathrm{Cl}$ case.

$3 b$. The $K-3 p$ band has an intensity maximum near the low energy side.

(15)A

Piore, E. R., R. H. Kingston, and G. G. Harvey, SOFT $X$-RAY SPECTROSCOPY OF SOLIDS.

Rev. Sci. Instr. 22, 543 (1951).

1. A description of the M.1.T. spectrograph see Ref. \#12 (1951) for details.

(16)E

Salgueiro, L. and G. Ferreira, THE SHAPE AND INTENSITY OF THE LB 2 LINE OF GOLD AND ITS SATELLITE. (In French.)

Portugalie Physica 2, 117-126 (1951).

2. A curved crystal spectrometer was used and intensities were recorded photographically. 3a. The ratio $L \beta_{2} / L \beta_{15}$ (intensity) is $45.5 / 3.0$. 3b. The ratio $L \beta_{2}$ /satellite (intensity) is 0.11 . 
(17)E

Stewardson, E. A. and P. A. Lee, THE MIV AND MV ABSORPTION EDGE OF ERBIUM $(Z=68)$.

Proc. Phys. Soc. (London) 64A, 318-319 (1951).

1.3. The positions of the MIV,V for Er were:

$\begin{array}{ll}\text { MIV } & 8583 \mathrm{XU} \\ M_{V} & 8829 \mathrm{XU}\end{array}$

2. Oxide specimens were used.

(18)E

Tomboulian, D. H. and E. M. Pell, ALUMINUM ABSORPTION IN THE SOFT X-RAY REGION.

Phys. Rev. 83, 1196-1201 (1951).

1. Al absorption was studied in the spectral region 80-600 A.

2a. A grating spectrometer was used, and spectra were recorded photographically on 11 ford plates.

2b. The radiation source was a condensed spark discharge in a glass capillary which produced an intense line spectrum on a weak background.

3a. If evaporation was carried out at an interrupted rate, the deposits are sandwiches of pure metal and oxide.

3b. Fine structure was found on the short wavelength side of the $L_{2}, 3$ edge.

3c. The mass absorption coefficient $\mu / p$ varied from $1 \times 10^{4} \mathrm{~cm}^{2} / \mathrm{g}$ to $2.8 \times 10^{4} \mathrm{~cm}^{2} / \mathrm{g}$ from 80-600 A.

3d. Actual spectra are presented.

(19) T

Vainshtein, E. E., R. L. Barinski i and K. I. Narbutt, THE THEORY OF THE PRINCIPAL $X-R A Y$ ABSORPTION EDGE OF ATOMS IN MOLECULES. (In Russian.)

Doklady Akad. Nauk S.S.S.R. 77, 1003-1006 (1951).

1. The first two absorption lines were assumed to be due to the transition of $K$ electrons to $4 p$ and $5 p$ levels.

3a. If this assumption is true the quantum defect, $\Delta$, is then 1.77 .

3b. The potassium $4 p$ absorption line is $2.7 \mathrm{eV}$ from the true absorption edge -- in good agreement with experimental data.

(20)E

Vainshtein, E. E., R. L. Barinskii and K. I. Narbutt, STRUCTURE OF THE X-RAY ABSORPTION EDGE IN MOLECULES. (In Russian.)

Doklady Akad. Nauk S.S.S.R. 28, 39-42 (1951).

1. The $\mathrm{K}$ edge of $\mathrm{S}$ in $\mathrm{H}_{2} \mathrm{~S}, \mathrm{CS}_{2}$, and $\mathrm{SO}_{2}$ and the $\mathrm{K}$ edge of $\mathrm{Cl}$ in $\mathrm{HCl}$ were measured.

2. A bent crystal spectrograph was used, and intensities were photographically recorded.

3a. The polarizability was $20-50 \%$ below optical values.

$3 b$.

$\begin{array}{ll}\text { Compounds } & \text { Edge (eV) } \\ \mathrm{S} \text { in } \mathrm{H}_{2} \mathrm{~S} & 182.49 \\ \mathrm{~S} \text { in } \mathrm{CS}_{2} & 182.37 \\ \mathrm{~S} \text { in } \mathrm{SO}_{2} & 182.65 \\ \mathrm{Cl} \text { in } \mathrm{HCl} & 208.36\end{array}$

$(\mathrm{C}-1) \mathrm{T}$

Fletcher, G. G. and E. P. Wohlfarth, CALCULATION OF THE DENSITY OF STATES CURVE FOR 3d ELECTRONS IN NICKEL.

Phil. Mag. (7) 42, 106-110 (1951).

1,2. Results of $N(E)$ tight binding approximation for the FCC lattice using $\mathrm{Ni}$ as an example are presented.

3a. A value of $2.70 \mathrm{eV}$ for the total width of the $\mathrm{Ni}-3 \mathrm{~d}$ band was obtained.

3b. An $N(E)$ vs. energy curve for $M i$ is given.

$(C-2) T$

Kichenassamy, S., ON THE WIDTHS OF THE K $\alpha_{1}$ LINES. (In French.)

Compt. Rend. (French Academy) 232, 1074-1076 (1951).

1. Data (chiefly that of Gokhale) for elements of atomic number 36-50 are evaluated.

3. These data, as a function of $z^{3}$ and $z^{4}$ are plotted; the line width is a function of $Z^{3}$.

4. The reason for this $Z^{3}$ dependence can be explained by Auger transitions.

$(c-3) T$

Senent, S. and $Y$. Senent, CALCULATION OF THE ORBITAL DENSITIES AND THE ORIENTATION OF THE VALENCE BANDS IN THE HYBRIDIZED STATE. (In Spanish.)

Anales de la Real Sociedad Espanola de Fisica Y Quimica 47a, 197-220 (1951).

1,3. Values of orbital intensities and the orientation of directed valences are tabulated for all pure hybridizations.

$(c-4) T$

Torkington, P., THE GENERAL VALENCE ORBITALS DERIVABLE BY $s P^{3}$ HYBRIDIZATION. J. Chem. Phys. 19, 528-533 (1951).

1. Sets of four $s p^{3}$ hybrid orbitals satisfying the symmetry requirements of point groups $C_{2 v}$ and $C_{3 v}$ were examined; studies of deviations from the ideal tetrahedral valence angle found in systems of symmetry lower than $T_{d}$ were made.

3. Tables of allowed interorbital angles are presented.

\section{2}

(1)T

Agarwal, B. K., NOMENCLATURE OF X-RAY DIAGRAM LINES.

Science and Culture (India) 17, 479-480 (1952).

1,2. The author suggests a new standard nomenclature system based on Somerfeld's energy level configuration.

3. A diagram of transitions using this system is shown. 
(2) $E$

Barinski i, R. L., X-RAY ABSORPTION SPECTRA OF MOLYBDENUM IN COMPLEXES. (In Russian.)

Doklady Akad. Nauk S.S.S.R. 83, 381-384(1952).

1. The $\mathrm{L}$ absorption of $\mathrm{Mo}$ in $\left(\mathrm{NH}_{4}\right)_{2} \mathrm{MOO}_{4}$,

$\mathrm{K}_{4} \mathrm{Mo}(\mathrm{CN})_{8}$, and $\mathrm{MoS}_{2}$ was studied.

3a. The $L_{3}$ absorption lines of Mo are due to transitions of $2 p$ electrons to excited states near the 4d level.

3b. Where 4d levels are used for bonding, there are no intense $L_{3}$ lines.

4. The structure of the $L_{3}$ absorption edge of Mo depends on the valence of Mo and also on the type of compound.

(3)E

Shattacharjee, S. B., THE LOW-ENERGY SATELLITE OF THE VALENCE BAND SPECTRA OF SOME INSULATORS. J. Sci. E Indust. Research (India) 11B, 199-200 (1952).

1. Work on insulators and their spectra is presented.

3a. A table of bandwidths for some insulators is given.

3b. A schematic representation of the origin of low energy satellites in insulators is also given.

(4)E

Cauchois, Y., REMARKS ON THE TECHNIQUE FOR OBSERV ING THE $K$ SPECTRUM OF ALUMINUM. (In French.) Acta. Cryst. 2, 348-350 (1952).

1. The special features needed in a bent crystal spectrograph in order to study $\mathrm{Al}$ are outlined.

3a. The mica or gypsum crystals used must be absolutely free from traces of Al.

3b. For the 2-20A region, Kodak 1357 plates were found to be best.

3c. Attenuation tables for various windows, i.e., $C, B e$, and $L i$ are given; the attenuation from a $25 \mu \mathrm{Be}$ window is $55 \%$.

(5)E

Cauchois, $Y_{.}$, A STUDY OF THE $K$ ABSORPTION SPECTRUM OF METALLIC ALUMINUM. (In French.)

Acta. Cryst. 5, 351-356 (1952).

1. The $K$ absorption spectrum for $A$ l down to $190 \mathrm{eV}$ from the edge was measured.

2. A curved crystal (mica or gypsum) spectrometer was used and intensities were photographically recorded.

3a. The main edge is narrow and similar to the emi ssion edge.

3b. Spectra and a tabulation of all results are presented.

4. The absorption bands are interpreted according to the Kronig theory for electrons traveling in an Al crystal.

(6)E

Cauchois, Y., PRELIMINARY REMARKS ON THE L-SPECTRUM, CONDUCTIVITY BAND AND COLOR OF SILVER.

(In French.)
Compt. Rend. (French Academy) 235, 613-615 (1952).

2. A bent crystal spectrometer was used and intensities were photographically recorded.

3a. The LB $B_{2}$ line of $\mathrm{Ag}$ at $3695.6 \mathrm{XU}$ is accompanied in the high frequency direction by a weak emission, attributed to the conduction band, with a short wave limit equal to the $L_{3}$ absorption edge.

3b. The distance from the edge of this band to the center of the $L B_{2}$ was $4 \mathrm{eV}$.

(7) $T$

Cauchois, Y., ENERGY LEVELS OF HEAVY ATOMS. J. Phys. Radium 13, 113-121 (1952).

1. Results are based on X-ray data for elements of $Z=73-92$.

2. The energy zero was the $L_{3}$ discontinuity.

3. The mechanism of the photoelectric absorption of $x$-rays and the origin of discontinuous absorption is discussed.

(8) $T$

Curie, D., WIDTH OF SPECTRAL LINES AND HYPERFINE STRUCTURE IN THE X-RAY SPECTRA. (In French.) J. Phys. Radium 13, 505-515 (1952).

1. The fact that the absence of line broadening or hyperfine structure of $\mathrm{K}$ lines occurs due to a nuclear magnetic moment is discussed.

4. This result is explained by postulation that the usual theory of spectral line width is not valid when photons of the same frequency are emitted by two distinct levels whose separation is less than their width.

(9) $E$

Deodhar, G. B. and C. Mande, NEW FORBIDDEN LINES IN THE L SPECTRUM OF MERCURY. J. Sci. \& Indust. Research (India) 11B, 1-4 (1952).

1. Forbidden lines in $\mathrm{Hg}$ spectra were studied.

2. The vacuum line to the anti-cathode was sealed wi th Apiezon $Q$ sealing compound.

3. Results are tabulated and a method for setting up the $\mathrm{Hg}$ specimen on the anti-cathode is given.

(10)E

Deodhar, G. B. and C. Mande, NON-QUADRUPOLE LINES IN $X$-RAY SPECTRA.

Nature 169, 889 (1952).

1. Some lines not obeying quadrupole selection rules in the L spectra of $\mathrm{Pt}$ and $\mathrm{Hg}$ were found.

3. Some of the energy of non-quadrupole lines is dissipated in the process of emission itself.

4. Only those non-quadrupole lines for which $\Delta l$ or $\Delta \mathrm{j}$ both are simultaneously zero can be observed and if $\Delta l$ or $\Delta j$ is 3 , one cannot observe a non-quadrupole line. 
(11)E

Doughty, D. D. and J. $W$. McGrath, THE $M_{5}$ and $M_{4}$ $X$-RAY ABSORPTION EDGES OF Ta.

Phys. Rev. 85, 1040 (1952).

1. The edge wavelengths and $V / R$ for the $M_{4}$ and $\mathrm{M}_{5}$ edges of Ta are tabulated.

2. A $13.94 \mathrm{~cm}$ radius Siegbahn spectrograph was used to study thin $\left(4 \times 10^{-5} \mathrm{~cm}\right)$ evaporated films of $\mathrm{Ta}$; photographic exposures were 50 hours long.

\begin{tabular}{|c|c|c|}
\hline & 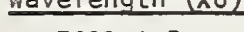 & $v / R \pm 0.1$ \\
\hline $\begin{array}{l}M_{5} \\
M_{4}\end{array}$ & $\begin{array}{l}7033 \pm 5 \\
6845 \pm 5\end{array}$ & $\begin{array}{l}129.3 \\
132.8\end{array}$ \\
\hline
\end{tabular}

(12)E

Faessler, A. and M. Goehring, X-RAY SPECTRA AND CHEMICAL BONDING. (In German.)

Die Naturwissenschaften 8 , 169-177 (1952).

1. The $k \alpha$ for sulfur in many organic and inorganic compounds was investigated.

2. A crystal spectrometer was used and spectra were obtained by photographic photometry.

3. All spectra are presented.

(13) $\mathrm{T}$

Friedel, J., $X$-RAY TRANSITION PROBABILITIES WITH SPECIAL REFERENCE TO K ABSORPTION IN LITHIUM. Phil. Mag. (7) 43, $1115-1139$ (1952).

1. Formulae for total jump in absorption coefficients at $K, L$, and $M X$-ray absorption edges are given.

2. It was assumed that the positive hole created in an inner shell is screened by a bound electron and encloses the metal in a finite sphere in order to apply physico-mathematical computations.

3. Projected spectra based on the computational results are given.

(14)E

Gokhale, B. G., STUDY OF THE WIDTH OF LINES IN $X$-RAY SPECTRA. (In French.)

Annales de Physique Z, 852-902 (1952).

1. The K spectra for elements of atomic number 37-50 were studied.

2. A bent crystal (mica) transmission spectrograph was used and intensities were obtained by photographic photometry.

3a. If the magnetic moment of an atomic nucleus produces hyperfine splitting of X-ray levels, the effect is small.

3b. The line width increases as $z^{3}$.

(15)E

Gyorgy, E. M. and G. G. Harvey, THE SPECTROSCOPY OF THE SOLID STATE: COPPER AND CHROMIUM. Phys. Rev. 87, 861-862 (1952).

1. The $3 p_{3 / 2,1 / 2}$ (valence to $M_{2,3}$ ) emission bands in $\mathrm{Co}_{0}$ and $\mathrm{Cr}$ were obtained.
2. A glass grating spectrograph at grazing incidence was used. The bombarding voltage was $500 \mathrm{v}$. for $\mathrm{Cu}$ and $600 \mathrm{v}$. for $\mathrm{Cr}$, wi th a resultant target current of $3 \mathrm{ma}$. Intensities were measured with a Be-Cu photomultiplier.

3a. Both curves show high energy satellites.

3b. Spectra and density of states curves are given.

3c. Ele- Bandwidth $M_{2,3}$ emission $M_{2,3}$ separament (eV) edge (eV)

Cu $7.1 \pm 0.5 \quad 75.9 \pm 0.2 \quad 1.2 \pm 0.1$

Cr $7.2 \pm 1.0742 .1 \pm 0.2 \quad 0.45 \pm 0.1$

(16)A

Hill, R. D., E. L. Church and J. W. Mikelich, THE DETERMINATION OF $Y$-RAY ENERGIES FROM $B$ RAY SPECTROSCOPY AND A TABLE OF CRITICAL X-RAY ABSORPTION ENERGIES.

Rev. Sci. Instr. 23, 523-528 (1952).

1. A complete table of critical X-ray absorption energies is given with interpolations and extrapolations for $Z=3-100$.

(i 7 )

Hirsh, Jr., F. R., AUGER ENHANCEMENT OF THE MQ $X$-RAY SATELLITE LINES.

Phys. Rev. 85, 685-686 (1952).

1. Photometer traces of plates for M $\alpha$ lines of $\mathrm{Pt}, \mathrm{Au}, \mathrm{Tl}, \mathrm{Pb}, \mathrm{Bi}$, Th, and $\mathrm{U}$ are presented.

3a. The spectra shown have a complete absence of sharp satellite maxima caused by Auger broadening of the satellites.

3b. The relative energy of double to single ionization vs. atomic number is plotted.

4. The results favor the theory of Coster and Kronig.

(18)E

Kiyono, S., K-ABSORPTION SPECTRA OF POTASSIUM IN $\mathrm{KF}, \mathrm{KCl}, \mathrm{KBr}$, and $\mathrm{Kl}$.

Sci. Repts. Tohoku Univ. First Ser. 36, 1-17 (1952).

1. $\mathrm{KCl}, \mathrm{KBr}, \mathrm{Kl}$, and $\mathrm{KF}$ were studied.

2. A bent crystal (quartz - $50 \mathrm{~cm}$ radius) vacuum spectrograph with a Sandstrom (dry air discharge) tube equipped with a $W$ anticathode was used to make 10-40 hour photographic exposures with a dispersion of $5.5 \mathrm{eV} / \mathrm{mm}$.

3. Photometer traces are presented.

4. Values of $\lambda, \Delta \lambda, v / R, \Delta v / R$ and $\Delta V$ are tabulated from this and earlier work.

(19)E

Mitchell, G. and W. W. Beeman, THE X-RAY K ABSORPTION EDGES OF COVALENTLY BONDED $\mathrm{Cr}, \mathrm{Mn}, \mathrm{Ni}$ and $\mathrm{Fe}$.

J. Chem. Phys. 20, 1298-1301 (1952).

1. Spectra and bonding data are presented.

2. Crystal spectrography was employed.

3a. The metal ion is nearly neutral in a complex. 
3b. Low energy absorption is observed in all complexes where an empty $4 p$ orbital is expected, but when the $4 p$ orbital is completely used in bonding no low energy absorption is observed.

4. The results may be used as a check on bonding orbitals.

(20)E

Nilsson, N., K ABSORPTION LIMIT IN ANTIMONY. Arkiv Fysik 3, 167-169 (1952).

1. Absorption data for Sb are tabulated.

2. A bent crystal (quartz) spectrograph was used and intensities were recorded photographically.

3. The $K$ edge is at $4.7 \mathrm{~A}$ for $\mathrm{Sb}$.

(21) A

Ohlin, P., SPECTROMETER TO INVESTIGATE THE ANGULAR DEPENDENCE OF STRUCTURE IN THE CONTINUOUS $X$-RAY SPECTRUM.

Arkiv Fysik 4, 387-390 (1952).

1. A new quartz crystal spectrograph is described in detail.

3. Preliminary data on $\mathrm{Cu}$ are presented.

(22)A

Piore, E. R., G. G. Harvey, E. M. Gyorgy and R. H. Kingston, A HIGH VACUUM RECORDING SPECTROGRAPH FOR THE STUDY OF RADIATION FROM SOLIDS IN THE 100-800 A range.

Rev. Sci. Instr. 23, 8-12 (1952).

1. A description of the M.1.T. spectrometer is given. See Ref. No. 8 (1953) for details.

(23)A

Sandstrom, A. E., A LARGE BENT CRYSTAL VACUUM SPECTROGRAPH.

Arkiv Fysik 4, 517-534 (1952).

1a. A complete description of all phases of design and building of a bent crystal spectrograph is given.

lb. Photographs and diagrams of the apparatus are presented.

(24)E

Shinoda, G., T. Suzuki and S. Kato, ELECTRONIC SPECTROSCOPY FOR THE SOFT X-RAY REGION. J. Phys. Soc. Japan 7, 644-645 (1952).

1. The method of photoelectronic spectroscopy coupled with electronic differentiation is discussed.

2. The circuit diagram for the apparatus is given.

3a. Resolution was calculated to be

$$
=3.52(\mathrm{kT} / \mathrm{ch}) \lambda^{2}
$$

where $k=$ Boltzmann constant, $T=$ absolute temperature, $c=$ speed of $1 \mathrm{ight}, \mathrm{h}=\mathrm{Planck}$ constant, $\lambda=$ wavelength

3b. The emission band for $A l-L_{3}$ is shown.

(25) $T$

Vainshtein, E. E., THE X-RAY ABSORPTION EDGE OF TRANSITION ELEMENTS IN COMPOUNDS. (In Russian.)
1. Lines on the long wavelength side of the edge are discussed; these 1 ines are connected with the existence of vacancies in nd and $n f$ electron shells.

3. The positions of these lines vary less from compound to compound for a given element than do other features of the absorption edge.

4. This is attributed to transitions of the absorber to energy levels of the solid which are close to nd and to $n f$ levels of the free atom of the transition metal.

(26)E

Zandy, H. F., THE MIV AND MV ABSORPTION EDGES OF $\mathrm{Pr}, \mathrm{Nd}, \mathrm{Sm}$, and Eu.

Proc. Phys. Soc. (London) 65A, 1015-1022(1952).

1. Tables of spectra for $\mathrm{Pr}, \mathrm{Nd}, \mathrm{Sm}$, and Eu are presented.

2. A curved crystal (mica) spectrometer evacuated to $10^{-5} \mathrm{~mm} \mathrm{Hg}$ was used to study thin evaporated films of the specimens and to record spectra photographically; the instrument had a dispersion of $40 \mathrm{XU} / \mathrm{mm}$ at $10,000 \mathrm{XU}$.

3. Fine structure was found on both edges for $\mathrm{Pr}$, Nd and $\mathrm{Sm}$ but for Eu fine structure was observed only at the $M_{V}$ edge.

$(c-1) T$

Antoncik, E. and M. Trlifaj, GROUP ANALYSIS OF THE WAVE FUNCTIONS OF VALENCE ELECTRONS IN A CRYSTAL AND THE ELECTRONIC THEORY OF METALLIC Mg. (In English).

Czech. J. Phys. 1, 97-120 (1952).

1,2. Group analysis of the wave functions of valence electrons in the first Brillouin zone was performed.

3a. The binding energy of $\mathrm{Mg}$ was calculated.

3b. Explanation of the Mg soft X-ray emission spectrum is based on the calculated data.

$(\mathrm{C}-2) \mathrm{T}$

AOki, $Y_{.}$, NUMERICAL TABLES OF OVERLAP INTEGRALS FOR $3 \mathrm{~s}, 3 P$ HYBRID ATOMIC ORBITALS. J. Phys. Soc. Japan 7, 451-457 (1952).

$1,2,3$. Numerical calculations for $3 s, 3 p$, and $I_{s}$, $2 s, 3 s$, Sp hybrid orbitals are tabulated; slater's atomic orbitals were employed for the calculations.

$(\mathrm{C}-3) \mathrm{T}$

Baldock, G. R., ELECTRONIC BOUND STATES AT THE SURFACE OF A METAL.

Proc. Cambridge Phil. Soc. 48, 457-469(1952).

1. Bound states for all atoms in a metal surface and for particular small groups of atoms in a simple cubic lattice were determined.

2. The tight binding method was used to find the bound states associated with atoms in the surface of a metal.

3. Most simpler crystals do not exhibit surface states without modifications in the parameters of certain atoms. 
AND RELATED COMPOUNDS: 1. ELECTRONIC BAND STRUCTURE IN GRAPHITE.

Proc. Phys. Soc. (London) 65A, 815-825 (1952).

1,2. The 8loch (tight binding) theory is used to calculate the density of states in graphite.

3a. Density of states curves with and wi thout use of overlap integrals are presented.

3b. The density of states curve calculated is compared favorably with Chalkin's experlmental $X$-ray emission curve.

4. The $\sigma$ electrons play an important role in determining the band shape.

$(\mathrm{C}-5) \mathrm{T}$

Fletcher, G. C., DENSITY OF STATES CURVE FOR THE 3d ELECTRONS IN NICKEL.

Proc. Phys. Soc. (London) 65A, 192-202 (1952).

1. A density of $3 \mathrm{~d}$ states in metallic $\mathrm{Ni}$ was calculated.

2. The method of tight binding (Bloch) was used.

3a. The secular equation for the energy as a function of wave vector was solved exactly.

3b. Bandwidth is $2.7 \mathrm{eV}$; degeneracy temperature is $1.45 \times 10^{3} \mathrm{~K}$.

3c. A density of states curve is presented.

$(C-6) T$

Friedel, J., THE DISTRIBUTION OF ELECTRONS ROUND IMPURITIES IN MONOVALENT METALS. Phil. Mag. (7) 43, 153-189 (1952).

1. The distribution of a positively charged impurity such as dissolved hydrogen or atoms like $\mathrm{Zn}$ or $\mathrm{Ga}$ was investigated.

3a. The positive charge must be screened; this may often occur through the formation of bound states below the Fermi level.

3b. An X-ray vacancy was treated as a positive impurity.

3c. Many diagrams illustrating these points are presented.

$(\mathrm{C}-7) \mathrm{T}$

Lee-Whiting, G. E., X-RAY ABSORPTION LINE-WIDTH AND ELECTRON STOPPING POWER CALCULATED WITH A SCREENED COULOMB INTERACTION.

Proc. Roy. Soc. (London) A212, 362-376(1952).

1. It was assumed that the polarization of a free electron gas about an electron moving through it gives rise to an exponential screening of the coulomb potential.

3a. With such an interaction, a method was found for calculating the frequency of collisions and the rate of energy loss of an excited electron.

3b. The X-ray absorption line width and the stopping power of the electron cloud were deduced to be high energy asymptotic expansions.
( 1 ) $E$

Al exopoulos, K. and G. Brogren, EVIDENCE OF A BAND STRUCTURE IN THE COMPTON RADIATION FROM SOLIDS. Arkiv Fysik 6, 213-222 (1953).

1. The Compton bands of Be and diamond were studied.

2. The X-ray scattering was monitored.

3a. Diamond has an energy gap of $7 \mathrm{eV}$.

3b. Spectra and tabular results are presented.

(2)E

Borovski i, 1. 8. and T. M. Golovner, MULTIPLICITY IN X-RAY EMISSION SPECTRA.

Doklady Akad. Nauk S.S.S.R. 88, 233-236

(1953). Trans: NSF-tr-7, 3 pp. (1953).

Available from Library of Congress.

1. Data on electron configurations and transitions in the rare earth elements (Ce to Lu) are presented.

(3)E

Cauchois, Y., THE L SPECTRA OF NICKEL AND COPPER . Phi 1. Mag. (7) 嵌, 173-186 (1953).

1. Both the absorption and emission bands of $\mathrm{Ni}$ and $\mathrm{Cu}$ were studied.

2. A bent crystal spectrograph (mica or gypsum) was employed, and spectra were recorded photographically.

3a. Complete tables of results are given as well as the experimental spectra.

3b. The band for $\mathrm{Cu}$ is in agreement with Mott's theory of the behavior of electrons in $\mathrm{Cu}$.

4. Density of states curves are postulated on the basis of the data.

(4)E

Cauchois, $Y$., THE K EMISSION SPECTRUM OF ALUMINUM IN THE REGION OF THE CONDUCTION BAND.

(In French.)

Acta Cryst. 6. 352-356 (1953).

2. A bent crystal (mica) spectrometer was used and intensities were photographically recorded.

3a. Spectra are presented and their features are listed.

3b. The $K$ emission bandwidth was found to be $10 \pm$ I eV with one feeble minimum and two maxima; the width of the discontinuity was $1.5 \mathrm{eV}$.

4. The band shape was explained in terms of the transition probabilities of conduction electrons to bound states of the atom. The mechanism is carefully diagramed.

(5) $T$

Deodhar, G. B. and B. K. Agarwal, NOMENCLATURE OF $X$-RAY LINES.

J. Sci. \& Indust. Research (India) 12B, 639-641 (1953).

1. A system of nomenclature was proposed.

3. Tables comparing the new satellite notation with old are given. 


\section{(5) T Cont'd.}

4. New system is easier to work with and to understand.

(6) $T$

Eisenlohr, H. and G. L. Muller, X-RAY SCATTERING IN REGION OF $K$ AND L EDGES OF HEAVY ATOMS. (In German.)

Z. Naturforsch, 3a, 42y-432 (1953).

1. The dispersion for a spectral region reaching from wavelengths through the $K$ and $L$ absorption edges was calculated.

2. Wave-mechanical dispersion theory was used.

3a. Atomic scattering factor curves are plotted for $T e$ and $W$.

3b. These show systematic deviations from other curves.

(7) E

Gyorgy, E. M., M-EMISSION BANDS OF THE TRANSITION METALS IN THE SOLID STATE.

Research Lab. Of Electronics M.I.T. Tech. Rept. 254, 34 pp. (1953).

1,2. $\mathrm{Cu}, \mathrm{Ni}, \mathrm{Fe}, \mathrm{Mn}$, and $\mathrm{Cr}$ were studied wi th a grazing incidence grating spectrograph at a pressure of $10^{-6} \mathrm{~mm} \mathrm{Hg}$; radiation was produced by bombarding the target with 300-500 volt electrons at 2-6 ma, and photons were counted by a Be-Cu photomultiplier.

3a. The radiation studied was produced in the evaporated targets by transitions of valence electrons into the excited $3 p_{3 / 2}, 1 / 2$ states of the atom.

3b. All spectra and the density of states curves derived from them are presented.

3c. Bandwidth and emission edge data are tabulated.

(8)E

Hartman, P. L. and D. H. Tomboulian, FAR ULTRAVIOLET RADIATION FROM THE CORNELL SYNCHOTRON. Phys. Rev. 21, 1577-1578 (1953).

1. This letter describes the use of the synchotron as a source of continuous radiation for the 50-400 A spectral region.

2. The synchrotron energy was 220 and $310 \mathrm{MeV}$; both settings produced a strong continuum.

3. The photographic negatives over the 50-400 A region showed no marked density variations, and no sudden drop over the short-wavelength region available under the particular conditions of detection.

(9) E

Herglotz, H., SECONDARY EXCITATION OF THE K $\alpha_{3}$ SATELLITE OF Cr. (In German.)

Oster. Akad. Wiss. Math. Maturiv. Kl. Sitzber Abt. Ila 162, 235-252 (1953).

1,2a. The $\mathrm{K}_{3}$ satellite was excited from $\mathrm{Cr}$ which was the anticathode in a $\mathrm{Cu} X-$ ray tube and also from $\mathrm{Cr}$ exposed to $\mathrm{Fe}-\mathrm{K} \alpha$ radiation in air.

2b. The $K \alpha_{1}$ and $K \alpha_{2}$ lines were exposed such that they were of equal density on a calibrated photographic film.
3. The ratio of $K \alpha_{3}$ primary to $K \alpha_{3}$ secondary was 2.5 as determined by microphotometry.

(10)E

Morlet, J., CONSTRUCTION OF A SPECTROGRAPH FOR SOFT $X$-RAYS OF WAVELENGTH 2-20 A; L EMISSION SPECTRA OF WAVELENGTH 9-14 A. (In French.) Bull. Classe Sci. Acad. Roy. Belg. 32, 205216 (1953).

1. The L series spectra for $\mathrm{Zn}, \mathrm{Cu}$, and $\mathrm{Cu}-\mathrm{Zn}$ alloys are presented.

2. Details of the construction of the curved crystal spectrometer used are given; the spectrometer records intensities photographically.

3. The effects of alloying on the spectra were tested.

(11)E

Nilsson, A., A PRECISION DETERMINATION OF THE K EXCITATION POTENTIAL OF SOME 3d ELEMENTS. Arkiv Fysik $\underline{6}, 513-592$ (1953).

1. This is a thesis in toto.

2. A complete discussion of apparatus and techniques is given.

3. Tables and discussion, in full, of results and their implications are presented.

(12)E

Rogosa, G. L. and G. Schwarz, MOLYBDENUM K AND URANIUM L X-RAY TRANSITIONS FROM SEPARATED ISOTOPES.

Phys. Rev. 22, 1434-1437 (1953).

1. The $K \alpha\left(K \rightarrow L_{3}, K \rightarrow L_{2}\right)$ lines of Mo and the $L \beta_{1}\left(L_{2} \rightarrow M_{4}\right)$ of $U$ were measured in separated i sotopes.

2. A double crystal spectrometer was used; experimental technique is briefly outlined.

3. Results are tabulated.

(13)E

Sakellaridis, P., ENERGY LEVELS AND WEAK EMISSIONS IN THE RARE EARTHS Tm, Ho, Tb, Gd, and Eu. (In French.)

Compt. Rend. (French Academy) 236, 1767-1769 (1953).

1. The Lm was used as the absorption reference; data were taken from the work quoted in Refs. $14,15,16$ (1953).

2. To obtain the value for each level, all frequency differences possible were calculated from the measured transitions.

3. Wavelengths and energies are tabulated for the five rare earths concerned.

(14)E

Sakellaridis, P., L EMISSION AND ABSORPTION SPECTRA OF EU AND Tb. Compt. Rend. (French Academy) 236, 1547-1549 (1953) (In French).

1. Eu and $\mathrm{Tb}$ in $\mathrm{Eu}_{2} \mathrm{O}_{3}$ and $\mathrm{Tb}_{2} \mathrm{O}_{3}$ respectively were studied.

2. A bent crystal (mica) spectrograph was used and intensities were photographically recorded. 
(14)E Cont'd.

3. Wavelengths for $L_{1}, L_{2}$, and $L_{3}$ absorption edges (max. and $\min$. ) and the dipole and quadrupole emission lines due to transitions between the $L, M, N$, and 0 levels are tabulated.

(15)E

Sakellaridis, P., L EMISSION AND ABSORPTION SPECTRA OF GADOLINIUM AND THULIUM. (In French.) Compt. Rend. (French Academy) 236, 1244-1246 (1953).

1. Gd and $\mathrm{Tm}$ in $\mathrm{Gd}_{2} \mathrm{O}_{3}$ and $\mathrm{Tm}_{2} \mathrm{O}_{3}$ respectively were studied.

2. A bent crystal (mica) spectrograph was used and intensities were photographically recorded.

3. Wavelengths for $L_{1}, L_{2}$, and $L_{3}$ absorption eciges (max. and min.) and the dipole and quadrupole emission lines due to transitions between the $L, M, N$, and 0 levels are tabulated.

(16)E

Sakellaridis, P., L EMISSION AND ABSORPTION SPECTRA OF HOLHIUM. (In French.)

Compt. Rend. (French Academy) 236, 1014-1016 (1953).

1. Ho in a very pure sample of $\mathrm{HO}_{2} \mathrm{O}_{3}$ was studied.

2. A bent crystal (mica) spectrograph was used and intensities were photographically recorded.

3. Wavelengths for $L_{1}, L_{2}$, and $L_{3}$ absorption edges (max. and min.) and the dipole and quadrupole emission lines due to transitions between the $L, M, N$, and 0 levels are tabulated.

(17) E

Schwarz, G. and G. L. Rogosa, ELECTRONIC EXCITATION OF THE LIII STATE OF 5 d ELEMENTS.

Phys. Rev. 22, 88-89 (1953).

1. The ratio h/e was measured from the electronic excitation potential of one of the x-ray levels and a structure in the $K$ excitation curves for $\mathrm{Ta}, \mathrm{Pt}_{\mathrm{t}}$, and $W$ was found.

2. A double crystal spectrometer was used; trouble with target contamination occurred.

3. The $L_{3}$ excitation curves for $T a, P t$, and $W$ are given.

4. The observed structure can be related to the density of states in the conduction band.

(18)E

Townsend, J. R., SOLID STATE ABSORPTION SPECTRA OF Mg AND MgO.

Phys. Rev. 22, 556-560 (1953).

1. The linear absorption coefficients for $M g$ and $\mathrm{MgO}$ in the spectral region 80-350 A were determined.

2a. A glass grating spectrometer was used at a grazing angle of $5^{\circ}$ to study the evaporated specimens (Mg0 was made by oxidizing the Mg foil); intensities were recorded photographically. 2b. The source of radiation was a condensed spark discharge.

3a. The absorption coefficient ranges from $1.8 \times$ $10^{4} \mathrm{~cm}^{-1}$ (at 80A) to $12 \times 10^{4} \mathrm{~cm}^{-1}$ (at 350A) in $\mathrm{Mg}$.

3b. A gap of about $4 \mathrm{eV}$ exists between the top filled level and the proposed conduction band in MgO.

3c. An electronic energy level scheme for MgO was proposed and a diagram of it presented.

$(c-1) T$

Friedel, J., ANOMALY OF MIV,V ABSORPTION IN HEAVY ELEMENTS.

Proc. Phys. Soc. (London) 66A, 333-340 (1953).

1,2. The Wigner-Seitz method was used to compute energies.

3a. An anomaly was observed for the $4 \mathrm{f}$ band in the second long period.

3b. The anomaly disappears from Ra through U; therefore, the conduction band of these elements must contain some $5 \mathrm{f}$ states.

4. The transition probability of a 3 d electron to the top of the conduction band is small; strong absorption begins only when the ejected electron reaches the bottom of the $5 \mathrm{f}$ band.

(C-2) $\mathrm{T}$

Hume-Rothery, W., METALLIC CARBIDES AND NITRIDES OF THE TYPE MX.

Phil. Mag. (7) 公, 1154-1160 (1953).

1. Structures of MX types with the $\mathrm{NaCl}$ configuration were examined to see if this configuration was formed in order to provide the non-metal with an octahedral interstice.

4. The NaCl structure is formed to provide the metal with mutually perpendicular bonds to six neighbors.

$(c-3) E$

Johnson, F. A. and J. S. Foster, AUGER TRANSITIONS IN SILVER.

Can. J. Phys. 31, 469-471 (1953).

1. Some $20 \mathrm{~K}$-Auger lines of Ag were recorded.

2. A permanent-magnet spectrograph was used, and intensities were recorded on Kodak X-ray film.

3. The results disagree with theory, the greatest discrepancy occurring for $K \rightarrow$ LL transition lines.

4. The authors feel that the theory is quantitatively incorrect.

$(C-4) E$

Lander, J. J., AUGER PEAKS IN THE ENERGY SPECTRA OF SECONDARY ELECTRONS FROM VARIOUS MATERIALS. Phys. Rev. 21, 1382-1387 (1953).

1. The energy spectra of secondary electrons from C, Be, $\mathrm{Al}, \mathrm{Ni}, \mathrm{Cu}, \mathrm{Ba}, \mathrm{Pt}, \mathrm{BeO}, \mathrm{Al}_{2} \mathrm{O}_{3}$, $N, 0$, CuO, and $B a 0$ were measured.

2. A spherical electron velocity analyzer which could be evacuated to $1 \times 10^{-8} \mathrm{~mm} \mathrm{Hg}$ was used.

3a. Characteristic peaks due to Auger electrons were observed in all the materials examined. 
$(c-4)$ E cont'd.

3b. Spectra and tabular results are presented.

4. Structure in the peaks can be related to the dlstribution in energy of electrons in the valence band, and it complements that observed in soft $X$-ray emission studies.

$(c-5) \mathrm{T}$

Laskar, W., SEMIDIRECT DETERMINATION OF COEFFICIENTS OF FLUORESCENCE FOR THE K LEVEL OF CERTAIN ATOMS FROM MEASUREMENTS OF THE WIDTH OF X-RAYS. (In French.)

Compt. Rend. (French Academy) 236, 2149-2150 (1953).

1,2. Gokhales values for the $K \alpha$, shell width were used to calculate the fluorescence coefficient of the $K$ shell for eight elements.

3. Element Fluorescence Coefficient

$\begin{array}{ll}\mathrm{Sr} & 0.65 \\ \mathrm{Zr} & 0.69 \\ \mathrm{Mo} & 0.73 \\ \mathrm{Rh} & 0.78 \\ \mathrm{Pd} & 0.80 \\ \mathrm{Ag} & 0.81 \\ \mathrm{Cd} & 0.828 \\ \mathrm{Sn} & 0.83\end{array}$

$(c-6) T$

Meerson, G. A. and Ia. S. Umanski i, ON THE HARDNESS OF REFRACTORY CARBIDES. (In Russian.) Izvestia Sektora Fiziko-Khimicheskogo Analiza 22, $104-110$ (1953).

Trans. AEC-tr-3629, 6 pp. (1960).

1. The hardness of carbides in general terms of directional bonds is discussed.

3. Tables of carbide types and of the free energy of carbide formation are presented.

$(\mathrm{c}-7) \mathrm{T}$

Sato, M., CRITICAL POTENTIALS OF SOFT X-RAYS AND OF SECONDARY ELECTRONS FROM COPPER AND THEIR PHYSICAL SIGNIFICANCE.

Sci. Rep. Res. Inst. Tohoku Univ. A5, 533553 (1953).

1. Critical potentials for soft $x$-rays and for secondary electrons from copper, as determined by several workers, were discussed and correctlons for their critical potentials were determined.

3. Tabulated results for critical potentials in copper are presented.

4. The critical potentials are explained as being the dissociation potentials of chained molecules of copper into component atoms, either with or without accompanying ionization.

1954

(1) $T$

Agarwal, B. K., A FORMULA FOR THE K AND L ABSORPTION DISCONTINUITIES.

Current Sci. (India) 23, 357 (1954).

$1,2,3$. The general formula $T_{a}=C Z^{P} \lambda^{n}$ was used to lead to the conclusion that the magnitude of the $K$ absorption jump ratio, $R_{k}$, is:

$$
R_{k}=a Z^{b}
$$

where $\log _{10} a=1.805283$ and $b=-0.6207$.

(2) $E$

Bedo, D. E . and D. H. Tomboulian, THE L ABSORPTION SPECTRUM OF SILICON AND SILICON DIOXIDE. Phys. Rev. 25, 621 (1954).

1. Si and $\mathrm{SiO}_{2}$ were studied over a range of $60-$ $200 \mathrm{~A}$.

2. Thin evaporated films were employed in a grating spectrometer.

3. The $L_{2,3}$ edge for $S i$ is at $124.5 \mathrm{~A}$ and the $\mathrm{L}_{2}, 3$ edge of $\mathrm{SiO}_{2}$ is at $116.5 \mathrm{~A}$.

4. The energy gap in the semiconductor is about $0.8 \mathrm{eV}$.

(3)E

8lokhin, M. A., X-RAY K ABSORPTION OF TITANIUM IN BARIUM AND LEAD TITANATES. (In Russian.) Doklady Akad. Nauk S.S.S.R. 25, 965-968(1954).

1. $\mathrm{Ba}$ and $\mathrm{Pb}$ titanates and $\mathrm{TiO}_{2}$ and $\mathrm{Ti}_{2} \mathrm{O}_{3}$ were investigated.

2. A bent crystal spectrograph was used; the $\mathrm{Cu}$ anode was covered wi th $\mathrm{Bi}$-oxide for observational purposes.

3a. The separation from the $3 d$ level to the edge is $5 \mathrm{eV}$.

3b. In $\mathrm{BaTiO}_{3}$ there are $1 \mathrm{~s}$ to $4 \mathrm{sp}$ bands for $\mathrm{Ti}^{3+}$ and $\mathrm{Ti}^{4+}$ in addition to a partially filled $3 \mathrm{~d}$ band.

3c. The average number of electrons in a $\mathrm{Ti}$ ion is 0.35 .

3d. The $\mathrm{Ti}$ and oxygen bonds are $25 \%$ covalent.

3e. The 4 sp band separation between $\mathrm{Ti}^{3+}$ and $\mathrm{Ti}^{4+}$ is $4.5 \mathrm{eV}$.

(4)E

Blokhin, M. A., THE INFLUENCE OF TEMPERATURE AND PHASE TRANSFORMATIONS ON THE X-RAY ABSORPTION SPECTRUN OF TITANIUM IN BARIUM AND LEAD TITANATES. (In Russian.)

Doklady Akad. Nauk S.S.S.R. 95, 1165-1167 (1954).

1. $8 \mathrm{a}$ and $\mathrm{Pb}$ ti tanates were studied between 25 and $200^{\circ} \mathrm{C}$ by observing their $\mathrm{K}$ X-ray absorption spectra.

2. A focusing spectrograph of the crystal type was used.

3a. The 3d absorption maximum is unaffected by temperature; however, elevation of the temperature shifts the complex absorption edge toward lower energies.

3b. The $\mathrm{Ti}^{4+}$ 4sp absorption maximum decreases by $0.6 \mathrm{eV}$ suddenly at the Ba ti tanate Curie point $\left(128^{\circ} \mathrm{C}\right)$; this is explained by the transition from tetragonal to cubic structure.

(5)E

Brogren, G., A NOTE ON THE WIDTHS OF X-RAY EMISSION LINES.

Arkiv Fysik $8,391-400$ (1954).

1. The $\mathrm{Cu}-K \alpha_{1}$ width was studied in detall as were the widths of the $\mathrm{K} \alpha$ in $\mathrm{Ti}, \mathrm{Fe}$ and Mo.

2. A double crystal (quartz or calcite) spectrometer was used. 
(5)E Cont'd.

3a. Line width was a function of the spectrometer resolving power; increasing the resolving power caused the line width to decrease asymptotically.

$3 b$.

\begin{tabular}{cc} 
Element & $K \alpha \mid$ Width (XU) \\
\cline { 1 - 2 } $\mathrm{Cu}$ & 0.43 \\
$\mathrm{Ti}$ & 0.85 \\
$\mathrm{Fe}$ & 0.80 \\
$\mathrm{Mo}$ & 0.24
\end{tabular}

4. The true width is the difference of measured width and the width of the spectrometer diffraction pattern.

(6)E

Cauchois, Y., X-RAY SPECTRA AND CHEMICAL BONDING. J. Chim. Phys. (Paris) 51, 76-88 (1954). (In French.)

1. S in several inorganic compounds, Re in Re oxides, $U$ in $U$ oxides, Co in Co complexes, $\mathrm{Al}$ in $\mathrm{Al}_{2} \mathrm{O}_{3}$, and $\mathrm{Al}-\mathrm{Mg}$ alloys were studied.

2. A bent crystal spectrometer was used and intensities were photographically recorded.

3a. Spectral shifts due to compound formation are tabulated and the author suggests some bonding schemes based on these data.

3b. Actual spectra are presented.

(7)E

Cauchois, Y., I Manescu and F. LeBerquier, THE LSPECTRA OF PLUTONIUM. (In French.)

Compt. Rend. (French Academy) 239, 1780-1782 (1954).

1. The L spectra of $\mathrm{Pu}$ in a $10 \mathrm{mg}$ sample of $\mathrm{PuO}_{2}$ were obtained.

2. A bent crystal spectrograph was used and intensities were photographically recorded.

3. Spectra and tabular results are presented; a precision of better than $2 \mathrm{eV}$ is claimed.

(8) $T$

Eisenlohr, H. and G. L. J. Muller, ANOMALOUS X-RAY SCATTERING OF HEAVY ATOMS IN THE REGION OF $K$ AND L EDGES ACCORDING TO WAVE-MECHANICAL DISPERSION THEORY. (In German.)

Z. Physik 136, 491-533 (1954).

1. Both the angular and frequency dependence for $T i$, and only the frequency dependence for $W$ were studied.

2. The treatment is Honl's procedure in which the radiation field of the scattering atom is developed in a series of multipoles and each is given a characteristic frequency dependence.

3. The influence of $L$ electrons is great in a large region above the $\mathrm{K}$ edge.

(9)E

Faessler, A. and E. D. Schmid, STRUCTURE OF THE X-RAY K SPECTRUM OF SULFUR. (In German.)

Z. Physik 133, 71-79 (1954).
1. Rhombic S, CaS, SrS, $\alpha-M n S, \mathrm{~K}_{2} \mathrm{SO}_{4}$, and $\mathrm{CaSO}_{4}$ were studied.

2. A vacuum spectrograph was used and results were photographically recorded.

3. The spectrum consists of a broad band in the case of the element and the sulfide, but it is a very sharp line for the sulfates.

4. The $K-\beta$ spectrum cannot be treated as line displacements (such as the K $\alpha$ doublet).

(10)E

Ferreira, J. G., CONTRIBUTION TO THE STUDY OF THE SATELLITE BAND INTENSITY OF THE L $\alpha_{1}$ LINES FOR ELEMENTS OF ATOMIC NUMBER 73-92. (In Portuguese) Rev. Fac. Cienc. Univ. Lisboa 2, Ser. 3B$65-140$ (1954).

1. Elements of atomic number 73-92 were investigated.

2. A curved crystal spectrometer was used and intensities were photographically recorded.

3a. The high frequency $L \alpha_{1}$ line satellite increases with atomic number to a maximum at TI and then decreases.

$3 b$. The $L \alpha_{2}$ line widths for these elements were al so measured.

(11) E

Gyorgy, E. M. and G. G. Harvey, SPECTROSCOPY OF THE SOLID STATE: SOME OF THE TRANSITION ELEMENTS.

Phys. Rev. 93, 365-369 (1954).

1. The $3 P_{3 / 2,1 / 2}$ (Valence to $M_{2,3}$ ) emission bands of $\mathrm{Ni}, \mathrm{Mn}$, and $\mathrm{Fe}$ were obtained.

2. A glass grating spectrograph was used at grazing incidence; the bombarding voltage was 500 volts with a resultant target current of 4 ma and intensities were measured with a BeCu photomultiplier.

3a. All spectra and density of states curves for the elements studied are presented.

3b. Ele- $3 P_{1 / 2}$ emis- $3 P_{3 / 2,1 / 2}$ sepa- Bandment sion edge \pm 0.2 ration \pm 0.1 width eV

$\begin{array}{llll}\mathrm{Mn} & 46.8 & 0.6 & 5.8 \pm 1.0 \\ \mathrm{Fe} & 52.3 & 0.6 & 3.7 \pm 1.0 \\ \mathrm{Ni} & 66.7 & 0.9 & 5.8 \pm 0.5\end{array}$

(12)E

Johnston, R. W. and D. H. Tomboulian, ABSORPTION SPECTRUM OF BERYLLIUM IN THE NEIGHBORHOOD OF THE K EDGE.

Phys. Rev. 24, 1585-1589 (1954).

1. The absorption spectrum of Be was studied in the spectral region 60-250A.

2. A grating spectrometer was used; the Be was irradiated wi th the bremstrahlung from the Cornell synchrotron.

3a. Spectra and tabular data are presented.

$3 b$. The mass absorption coefficient, $\mu / \rho$, varies from $0.25 \times 10^{5} \mathrm{~cm}^{-1}$ to $2.8 \times 10^{5} \mathrm{~cm}^{-1}$.

3c. The absorption edge was found at $111 \mathrm{~A}$ which is coincident with the emission edge. 
(13) $\mathrm{T}$

Jones, H., SCFT X-RAY EMISSION BANDS IN METALS. Phys. Rev. 24, 1072 (1954).

1,3. Excess bandwidths for $\mathrm{Li}, \mathrm{Na}$, and $\mathrm{Al}$ are tabulated.

2. The use of the Bohm-Pines treatment for valence band calculations rather than the Hartree-Fock method is suggested; a semiempirical equation for excess bandwidth is given.

(14) $T$

IVIgam, A. W., FINE STRUCTURE OF X-RAY ASSORPTIOI. SPECTRA IN HOMOPULAR CRYSTALS.

Current Sci. (India) 23, 117-110 (1954).

1. The dissimilarities in X-ray absorption fine structure between two elements in the same crystal lattice were considered.

2,3. A proof of Kronig's suggestion that the fields around positive and negative ions in an ionic crystal give rise to different fine structures is presented in mathematical form.

(15)E

Parratt, L. G. and E. L. Jossem, X-PAY SPECTROSCOPY OF VALENCE AND CONDUCTION BAINDS OF POTASSIUM CHLORIDE.

Physica 20, 1135-1137 (1954).

1. The KB emission bands in solid KCl were studied.

2. Crystal spectroscopy was used; the emission curves were recorded with high resolving power $(\lambda / \Delta \lambda \approx 11,000)$ and intensities were measured with a proportional counter.

3a. Corrected half-maximum widths of the is states are $0.33 \mathrm{eV}$ for $\mathrm{Cl}-3 \mathrm{p}$ and $0.22 \mathrm{eV}$ for $K-3 p$.

3b. Spectra and an energy level diagram are presented.

4. Discrete atomic-1ike levels exist below the filled bands in the solid in the immediate neighborinood of the ls vacancy.

(16)E

Parratt, L. G., THEORETICAL AND EXPERIMENTAL. INVESTIGATIONS OF THE ATOMIC PHENOMENA OCCURRING ON AND NEAR THE SURFACES OF SOLIDS: 1. SURFACE STUDIES OF SOLIDS BY TOTAL REFLECTION OF X-RAYS AND 11 . STRUCTURE OF THIN EVAPORATED COPPER FILMS BY TOTAL REFLECTION OF $X$-RAYS.

Air Force Office of Scientific Research, Contract AF-18(600)-674 Tech. Rept. \#1, AFOSR-TK-54-13, 68 Pp. (1954).

1,2. Analysis of the reflected X-ray intensity vs. grazing angle curve was performed by extending dispersion theory to treat any small number of stratified homogeneous media. 3a. Such a plot for Cu evaporated onto glass was explained by assuming the air exposed (at $300^{\circ}$ ii) $\mathrm{Cu}$ is oxidized to a depth of $150 \mathrm{~A}$.

3b. If oxidation is less deep, there probably exists an electron density minimum just below an internal oxide seal.

(17) E

Rogers, J. L. and F. C. Chalkin, A GEIGER COUNTER VACUUM SPECTROMETER AND ITS USE FOR THE STUDY OF SOFT $X$-RAY LINES.

Proc. Phys. Soc. (London) 673, 348-356 (1954).

1. The MS line of Mo and the $N$ doublet of $W$ were studied.

2. The range of the instrument is 20-200A; the grating has 15,000 1 ines/inch and radiation is detected by means of a Geiger counter.

3a. Details of design and construction are given as are diagrams.

3b. X-ray line widths are discussed.

(18)E

Sakellaridis, P., THE L ABSORPTION AND EMISSION SPECTRA OF ERBIUM AND ITS ENERGY LEVELS. (In French.)

Compt. Rend. (French Academy) 238, 2296-2298 (1954).

1. The absorption and emission $L$ spectra of $E r$ were measured.

2. A bent crystal (mica) spectrograph was used and intensities were photographically recorded.

3. Energy levels for Er are tabulated.

(19)E

Shinoda, G., T. Suzuki and S. Kato, ELECTRONIC SPECTROSCOPY IN THE SOFT X-RAY REGION. Tech. Repts. Osaka Univ. 4, 1-5 (1954).

1. This is chiefly a description of apparatus and technique although the $L_{2}, 3$ spectrum of Al is shown.

2a. See Ref. \#22-1956 for the method of photoelectronic spectrometry employed.

2b. Diagrams of the $X$-ray tube and circuit are given.

3a. Results for Al agreed with those made on a grating spectrometer.

3b. The photoelectronic method gives less resolution than the grating method.

(20)E

Shinoda, G., T. Suzuki and S. Kato, TwO TYPES OF BAIND EMISSION CURVES FOR COPPER IIN THE SOFT $X$-RAY REGION.

Phys. Rev. 25, 840-841 (1954).

1. Emission spectra are obtained directly on an oscilloscope; the authors show actual oscillograms for the $\mathrm{M}_{2}, 3$ band of $\mathrm{Cu}$.

2. Voltages applied to the anticathode are varied gradually and the soft $X$-rays emitted are detected with a photoelectric device; the resulting voltage vs. photocurrent curves are 
(20)E Cont'd. differentiated electronically.

3. The $M_{2,3}$ band of $\mathrm{Cu}$ oscillated between a band of the shape of Skinner and a two-humped band corresponding to J. C. Slater's theoretical curve.

(21)E

Skinner, H. W. B., T. G. Bullen and J. E. Johnston, NOTES ON SOFT X-RAY SPECTRA, PARTICULARLY OF THE Fe GROUP ELEMENTS.

Phil. Mag. (7) 45, 1070-1080 (1954).

1. Old unpublished work on $\mathrm{Ca}, \mathrm{Mn}, \mathrm{Co}, \mathrm{Ti}, \mathrm{Cr}$, $\mathrm{Fe}, \mathrm{Ni}, \mathrm{Cu}, \mathrm{Cr}_{2} \mathrm{O}_{3}, \mathrm{TiO}_{2}, \mathrm{CaO}$, and $\mathrm{MnO}_{2} \mathrm{~L}$ and $M$ bands is presented and compared with Gyorgy, Harvey's and Cauchois' results.

2a. Two grating spectrometers were used: one for $M$ studies at $150-400 \mathrm{~A}$ and the other for $L$ studies at 13-40A.

2b. Targets were evaporated foils put down every 15-20 minutes during the long photographic exposures; the system was evacuated to $10^{\infty 6}$ $\mathrm{mm} \mathrm{Hg}$.

2c. The target power input was 600 watts ( $3 \mathrm{kv}$ and $200 \mathrm{ma}$ ).

3. All spectra are shown and a tabulation of $L_{3}$ and $M_{3}$ bandwidths for $\mathrm{Ca}, \mathrm{Ti}, \mathrm{U}, \mathrm{Cr}, \mathrm{Mn}, \mathrm{Fe}$, $\mathrm{Co}, \mathrm{Ni}, \mathrm{Cu}$, and $\mathrm{Zn}$ is given.

(22)A

Smi th, G. L. and L. G. Miller, MTR CRYSTAL SPECTROMETER AND DATA PRINTING SYSTEM.

Phys. Rev. 26, 849 (1954).

1. This is a setup for a large computer installation.

2. Some 1500 separate measurements on 6-digit tape with $0.3 \%$ statistics and 106 counts per minute are accumulated.

(23)A

Tournaire, M., CORRECTION OF ERROR RESULTING FROM CONTINUOUS X-RAY RECORDING. (In French.) J. Phys. Radium 15, Suppl. to \#1 - 16A-22A (1954).

1. The change in the line profiles during continuous automatic recording was studied analytically.

3. Corrections necessary to reconstruct a true profile were determined.

$(C-1) T$

BrOWn, E., CALCULATION OF ENERGY BANDS IN CRYSTALS. Univ. Microfilms PUBL $9735,72 \mathrm{pp}$. (1954). Diss. Abs. $14-2096$.

1. Electronic energy eigenvalues as a function of wave vector $k$ for valence and conduction bands were calculated.

2a. The usual approximations leading to the oneelectron Schroedinger equation in a periodic potential were made.

$2 b$. The Schroedinger equation was replaced with an equivalent variation principle and a solution was approximated by expansion in a finite number of plane waves plus an auxiliary function.

3. This led to a simple matrix equation for the coefficients.

$(\mathrm{C}-2) \mathrm{T}$

Craig, D. P., A. Maccoll, R. S. Nyholm, L. E. Orgel and L. E. Sutton, CHEMICAL BONDS INVOLVING d-ORBITALS .

J. Chem. Soc. (London), 332-357 (1954).

1. Bonds which may require the use of d orbitals were investigated.

2. Overlap integrals involving $3 \mathrm{~s}, 3 \mathrm{p}, 3 \mathrm{~d}$, and 45 orbitals are used as criteria for determining bond strengths.

3a. The results do not agree with those of Pauling.

3b. The importance of the conditional stability of $d$ orbitals ( $\sigma$ and $\pi$ ) resulting from the polar nature of bonds formed by $s$ and $P$ orbitals is stressed.

$(\mathrm{C}-3) \mathrm{T}$

Friedel, J., ELECTRONIC STRUCTURE OF PRIMARY SOLID SOLUTIONS IN METALS.

Advances in Physics 3, 446-507 (1954).

1. A review of band structure calculations with 125 references is presented. Some of the topics reviewed are:

(1) The perturbed metallic lattice-insulators and metals.

(2) Self consistent solution in an alloy screening, displacement of the Fermi surface.

(3) Molecular orbitals - overlapping bands, physical properties, Born approximation, parabolic and full bands.

(4) Atomic orbitals - X-ray and optical transitions.

$(\mathrm{C}-4) \mathrm{T}$

Herman, F., SOME RECENT DEVELOPMENTS IN THE CALCULATION OF CRYSTAL ENERGY BANDS - NEW RESULTS FOR THE GERMANIUM CRYSTAL. Physica 20, 801-812 (1954).

1,2. A Ge band structure calculation based on the orthogonalized plane wave method is presented.

3a. The band structure depends critically on the assumed crystal potential.

3b. A lowest conduction band minimum at positions along the $[111]$ axis is predicted.

$(c-5) T$

Igo, G. and M. S. Werthein, ISOTOPIC SHIFT IN THE $X$-RAY SPECTRA OF HEAVY ELEMENTS. Phys. Rev. 25, 1097 (1954).

1,3. Isotopic shifts in U, Pb and Mo are tabulated.

2. The Fermi-Thomas field approximation is used. 
$(c-6) T$

Kiessling, R., THE NITRIDE, CAREIDE, BORIDE, AND SILICIDE OF TRANSITION METALS. (In German.) Fortschrift Chem. Forschung 3, 41-69 (1954).

1. Both binary and ternary systems are dealt with; bonding is discussed and illustrations given.

3. Metallic properties are associated with compounds having a value of 0.59 or less for the ratio of the atomic radius of the non-metal to that of the metal.

Note: 128 references are appended.

$(\mathrm{C}-7) \mathrm{T}$

Raimes, S., ENERGY BAND SHAPES AND BAND WIDTHS IN METALS.

Phil. Mag. (7) 45, 727-734 (1954).

1. The Bohm-Pines density of states curve was compared with the Sommerfield and HartreeFock approximations for $\mathrm{Na}, \mathrm{Mg}$, and $\mathrm{Al}$.

3. The $80 h m-P i n e s$ curve shows a rudimentary tail but it is a great improvement over the HartreeFock method; however, the Bohm-Pines bandwidth is still much larger than the observed width.

4. This defect may be partially due to the neglect of the short range correlation energy.

$(C-8) E$

ROOS, C. E., A NEW METHOD FOR MEASURING AUGER TRANSITIONS.

Phys. Rev. 23, 401-405 (1954).

1. The K-fluorescence yield of $\mathrm{Zr}, \mathrm{Nb}, \mathrm{Mo}, \mathrm{Rh}$, $\mathrm{Pd}, \mathrm{Ag}, \mathrm{Cd}$, and $\mathrm{Sn}$ was measured.

2a. X-rays were detected over a solid angle of $2 \pi$ steradians, the tube voltage was stabilized to $100 \mathrm{ppm}, 35-40 \mathrm{kv}$ at $10 \mathrm{ma}$ was used. Radiation was passed through two sets of collimating slits and then to a Nal-Ti scintillation counter.

2b. Targets were $3 \mathrm{~mm}$ foils.

3.

\begin{tabular}{|c|c|}
\hline remen & $w_{k}( \pm 3 \%)$ \\
\hline $\mathrm{Zr}$ & 0.645 \\
\hline $\mathrm{Nb}$ & 0.713 \\
\hline Mo & 0.714 \\
\hline $\mathrm{Rh}$ & 0.779 \\
\hline Pd & 0.782 \\
\hline $\mathrm{Ag}$ & 0.814 \\
\hline$c d$ & 0.819 \\
\hline Sn & 0.840 \\
\hline
\end{tabular}

(C-9) T

Shoemaker, D. P. and T. C. Huang, A SYSTEMATIC METHOD FOR CALCULATING VOLUMES OF POLYHEDRA CORRESPONDING TO BRILLOUIN ZONES. Acta Cryst. Z, 249-259 (1954).

1. The volume and number of quantum states in Brillouin polyhedra were calculated.

2. A geometrical treatment was employed.

3. The method was applied to cubic, tetragonal, and orthorhombic systems and the results are shown.

$(\mathrm{C}-10) \mathrm{T}$

Slater, J. C. and G. F. Koster, A SIMPLIFIED LCAO METHOD FOR THE PERIODIC POTENTIAL PROBLEM. Phys. Rev. 24, 1498-1524 (1954).

1,2. It is proposed that various LCAO integrals be obtained as disposable constants; then one can force the LCAO results to agree wi th accurate results at symmetry points in the 8 rillouin zone.

3. Tables of matrix components of energy are given for all cubic structures.

$(c-11) T$

Wertheim, M. S. and G. Igo, ISOTOPE SHIFT IN THE $X$-RAY SPECTRA OF HEAVY ELEMENTS

Air Force office of Scientific Research, Contract AFI 8(600)771, Tech. Rept. \#8 AFOSR-TN-54-347, 16 PP. (1954).

1. Isotope shifts in the X-ray levels due to the nuclear volume effect were calculated for three different nuclear potentials.

2,3a. Screening effects of atomic electrons were accounted for by comparison of the FermiThomas field wave function at the nuclear radius with that of a coulomb field.

3b. An upper limit of the change in screening of other atomic electrons occurs when a K or L shell electron is removed or replaced.

\section{5}

(1) T

Agarwal, B. K., PRESSURE OF ABSORBING GAS FOR OPTIMUM X-RAY ABSORPTION USE. (In English.) Z. Physik 142, 161-162 (1955).

1,4. For absorption experiments in the soft $x$-ray region, the following formula for gas pressure giving maximum intensity difference at absorption edge was deduced:

$P d=A a Z^{b} \log a Z^{b} / Z(\mu e)_{k} L\left(a Z^{b}-1\right)$

$P=$ density of absorber, $A=$ atomic weight of absorber, $d$ = thickness of absorber, $Z=$ atomic number of absorber, ( $\mu)_{k}=$ absorption coefficient of 1 electron, $L=$ Loschmidt's number, $\log _{10} a=1.80283, b=0.6207$.

3. Pd for $O=0.79996$, for $N=0.58173$, for $C=0.39613$.

(2)E

Amrehn, H. and H. Kulenkampff, ENERGY DISTRIBUTION IN SPECTRUM OF X-RAY BREMSTRAHLUNG AS A FUNCTION OF THE ATOMIC NUMBER. (In German.) . Z. Physik 140, 152-164 (1955).

1. $\mathrm{Al}, \mathrm{Ni}$, and $\mathrm{Sn}$ were observed at potentials of 25,34 , and $40 \mathrm{kv}$.

2. The direction of the proportional counter was $90^{\circ}$ with respect to the electron beam.

3. Intensities were inversely proportional to the potential. 
(3)E

Barinski $i, R$. L., X-RAY SPECTRA AND THE ELECTRONIC STRUCTURE OF THORIUM IN Th $\left(\mathrm{NO}_{3}\right)_{4}$ AND $\mathrm{ThO}_{2}$.

Izvest. Akad. Nauk S.S.S.R. Ser. Fiz. 20,

133-135 (1955). (In Russian.)

Trans: Bull. Acad. Sci. U.S.S.R. Phys. Ser.

20, 120-122 (1956).

1. The $\mathrm{M}_{4}$ and $\mathrm{M}_{5}$ absorption edge of Th in $\mathrm{Th}\left(\mathrm{NO}_{3}\right)_{4}$ and $\mathrm{ThO}_{2}$ was studied.

2. A $500 \mathrm{~mm}$ radius quartz crystal spectrograph with a dispersive power of $9 \mathrm{eV} / \mathrm{mm}$ was used; intensities were recorded photographically, and the spectrograms were processed visually wi th a microphotometer.

3. The electronic structural changes were postulated from the spectra.

4. The results show that it is most "advantageous" for the electrons in the Th atoms to fill the $5 f$ states first since the absorption lines in the $M_{4}$ and $M_{5}$ spectra are located energetically below all the other unoccupied levels of the Th atoms in the crystal.

(4)E

Beckman, 0., RELATIVE INTENSITIES OF X-RAY K LINES OF HEAVIER ELEMENTS.

Arkiv Fysik 2, 495-529 (1955).

1. Elements of atomic number $73-83,90$, and 92 were studied.

2. A Van de Graef generator was employed as a source of $800 \mathrm{kv}$ exciting potential for use with a curved crystal (quartz) spectrometer giving a dispersion of $0.382 \mathrm{XU} / \mathrm{mm}$.

3. Spectra and complete tabular results are given.

(5) T

Blokhin, M. A., INVESTIGATION OF THE DENSITY OF ELECTRONIC STATES IN A SOLID AND THE WIDTH OF THE INTERNAL ATOMIC LEVELS. (In Russian.) Izvest. Akad. Nauk S.S.S.R. Ser. Fiz 20, 142-151 (1955).

Trans: Bull. Acad. Sci. U.S.S.R. Phys. Ser. 20, $127-138$ (1956).

1. A mathematical development is presented from which series functions can be deduced to correct distorted emission and absorption spectra obtained with a double crystal spectrometer to their true shapes.

3a. Corrections for $\mathrm{K}$ level width determinations in the iron group transition series are given.

3b. The application of these results to the density of states curve for nickel is discussed.

(6)E

Blokhin, M. A. and A. N. Gusantinski, SELECTION OF OPTIMUM SPECIMEN DENSITY FOR THE INVESTIGATION OF X-RAY ABSORPTION SPECTRA. (In Russian.) Izvest. Akad. Nauk S.S.S.R. Ser. Fiz. 128-133 (1955).

Trans: Bull. Acad. Sci. U.S.S.R. Phys. Ser. 20, $113-120$ (1956).

1. Cu-Zn alloy specimens were studied in order to determine the absorber thickness giving the greatest difference between the directly observed quantities on both sides of the absorption edge.

2. Ionization and photographic techniques were used.

3. Equations and conditions for using them in order to obtain optimum absorber densities under a variety of conditions are given.

(7) $\mathrm{T}$

Cauchois, Y., ENERGY LEVELS FOR ATOMIC NUMBERS 2-69. (In French.)

J. Phys. Radium 16, 253-262 (1955).

1. The energy levels were calculated from characteristic X-ray frequencies.

3. A table of energy levels for $Z=2-69$ is given.

(8)E

Cormack, D. V., J.E. Till, G. F. Whitmore and H. E. JohnS, MEASUREMENT OF CONTINUOUS X-RAY SPECTRA WITH A SCINTILLATION SPECTROMETER. Brit. J. Radiol. 28, 605-609 (1955).

1. The spectral distribution of half-value layers of $1.7,2.5$, and $3.1 \mathrm{~mm} \mathrm{Cu}$ strips was measured.

2a. A scintillation spectrometer was used.

$2 b$. The spectral distributions were corrected for crystal and instrumental effects by comparison with spectra obtained wi th monochromatic radiation.

3. Corrected distributions are compared with those obtained by analysis of absorption data.

(9)E

Das Gupta, K., A. K. Sen and S. B. Bhattacharjee, STUDY OF CARBON K $\alpha$ AND ALUMINUM $L_{2}, 3$ BANDS BY A NEWLY CONSTRUCTED SOFT X-RAY RULED GRATING SPECTROGRAPH.

J. Sci. \& Indust. Research (India) 148, $129-130$ (1955).

1. The content is primarily an equipment description.

2a. A 1 -meter radius grating is used at a $5.5^{\circ}$ grazing angle. An oxide coated $\mathrm{Ni}$ wire electron gun was used to excite the specimen.

2b. All vibration from the spectrograph was damped out.

2c. The target temperature was maintained at $300^{\circ} \mathrm{C}$ for 30 minutes before the sample was evaporated on to it.

2d. A 40-400 A range is covered.

3. The $L_{2,3}$ bandwidth of $A 1$ is $13.0 \mathrm{eV}$ with an emissión edge at 170.5A.

(10)E

Das Gupta, K. and E. Wood, SOFT X-RAY SPECTRA OF MAGNESIUM-ALUMINUM, MAGNESIUM-SILICON, AND ALUMINUM-SILICON ALLOYS.

Phil. Mag. (7) 46, 77-86 (1955).

1. L spectra for the alloys were obtained; these were compared to the spectra from the respective pure elements. 
(10)E Cont'd.

3a. The emission edge broadens on alloying.

3b. Structural changes in the shapes of the bands occur.

3c. No case of identity of the bands of the two constituents is found; this would be the case for a perfectly ordered single phase alloy.

(11) E

Ferreira, J. G., DETERMINATION OF THE INTENSITY OF L $\alpha$ SATELLITE BANDS FOR $Z=73-92$. (In French.) Compt. Rend. (French Academy) 241, 1929-1932 (1955).

1,2. A curved crystal (mica) spectrograph with a dispersion of $5.5 \mathrm{XU} / \mathrm{mm}$ was used to obtain the L spectra; intensities were recorded photographically.

3a. Results are presented as a table with satellite intensities shown as a percentage of the L $\alpha$ 1 primary maximum.

3b. A plot of satellite intensity versus atomic number $r$ ises to a maximum at $Z=83$ and then drops off.

(12)E

Fine, S. and C. F. Hendee, X-RAY CRITICAL ABSORPTION AND EMISSION ENERGIES IN EKV. Nucleonics 13, (3), 36-37 (1955).

1. Tables are given for $z=1-100$.

2. Values were obtained by a conversion of tabulated experimental wavelength values to keV using one of the following equations:

$E(\mathrm{keV})=12.39644 \pm 0.00017 / \lambda(\mathrm{A})$ or

$E(\mathrm{keV})=12.39644 / 1.002020 \lambda(\mathrm{kx})$

(13)E

Fobberth, 0. G., SOLID SOLUTIONS IN $A^{3} B^{5}$ COMPOUNDS. (In German.)

2. Naturforsch. 10a, 502-503 (1955).

1,3. $A^{3} B^{5}$ forbidden band values are found. $A^{3} B^{5}$ compounds with values of forbidden band energy, $\Delta E$, between 0.33 and $1.25 \mathrm{eV}$ and $1.45-2.22$ eV were prepared.

2. Pseudobinary systems InAs-InP and GaAs-GaP form a complete series of solid solutions.

(14)E

Hempstead, C. F., LOCALIZED ENERGY STATES IN CRYSTALLINE ALKALI CHLORIDES BY SOFT X-RAY ABSORPTION SPECTROSCOPY.

Univ. Microfilms, PUBL 10,744, 108 pp.(1955). Diss. Abs. 15, $280(1955)$.

1. The structure $20 \mathrm{eV}$ from both sides of the $K$ absorption edge of $\mathrm{KCl}$ and $\mathrm{NaCl}$ was investigated.

2. A double crystal (calcite) spectrometer having a resolution of $0.1 \mathrm{eV}$ was used; a proportional counter was used to obtain intensity data. 3a. The structure observed is temperature sensitive and differs from $\mathrm{NaCl}$ to $\mathrm{KCl}$.

3b. The inner vacancy resulting when a K-electron is photoejected causes a perturbation of the normal periodic potential in the vicinity of the ionized atom; this atom of atomic number $Z$ appears as a $Z+1$ impurity in the solid.

(15)E

Herglotz, H., A NEW X-RAY MICROFOCUS TUBE.

(In German, English summary.)

Mikrochim Acta 1955, 684-695.

1. Secondary activation of $\alpha_{3}$ satellites in $\mathrm{Cr}$, and the chemical bonding influence on the $K \beta_{1}$ $\mathrm{l}$ ine of $\mathrm{Fe}$ and $\mathrm{Co}$ in compounds were studied.

2. A tube with a radiating anode for convenient external excitation of $X$-ray spectra was used; the tube is diagramed and described.

3. The spectra of $\mathrm{Al}$ and $\mathrm{Al}_{2} \mathrm{O}_{3}$ from $170-220 \mathrm{~A}$ are shown.

(16)E

Kazantsev, V. A., INVESTIGATION OF THE X-RAY SPECTRA OF ALLOYS OF THE Mn-Ni SYSTEM. (In Russian.)

Izvest. Akad. Nauk S.S.S.R. Ser. Fiz. 20, 107-111 (1955).

Trans: Bull. Acad. Sci. U.S.S.R. Phys. Ser. 20, 97-102 (1956).

1. The $\mathrm{K}_{5}$ lines during magnetic transformation over a range of $20-300^{\circ} \mathrm{C}$ were studied.

2. A curved crystal spectrometer was used and intensities were photographically recorded.

3a. The experimental results for all observed phenomena are listed.

3b. Transition to the paramagnetic state shifts the $\mathrm{KB}_{5}$ of $\mathrm{Ni}$ to higher energies and does the opposite to the $\mathrm{KB}_{5}$ of $\mathrm{Mn}$.

4. A mechanism for the magnetic transition (based on the observed data) is postulated.

(17) T

Ku ryl enko, C., BRILLOUIN ZONES, ELECTRICAL CONDUCTIVITY OF METALS, AND X-RAY $K$ ABSORPTION SPECTRA. (In French.) Cahiers de Physique 2, (54), 1-36 (1955).

1. The electronic properties of $\mathrm{Cu}, \mathrm{Ca}, \mathrm{Ni}, \mathrm{Al}$, $\mathrm{Cr}, \mathrm{Fe}, \mathrm{K}, \mathrm{Na}, \mathrm{Li}, \mathrm{Zr}, \mathrm{Ag}, \mathrm{In}, \mathrm{W}, \mathrm{Au}, \mathrm{Mg}, \mathrm{Zn}$, $\mathrm{Sn}$, and $\mathrm{Pb}$ were studied.

3a. Many Brillouin zone diagrams and energy level diagrams are presented.

3b. A linear relationship was established between $\left[\left(V_{0}-\varphi\right)-E\right]_{n}$ and $\log \sigma$ where $V_{0}=$ mean potential in the crystal, $\varphi=$ Richardson potential,

$E$ = maximum energy of levels occupied by free electrons,

$\mathrm{n}=$ number of valence electrons,

$\sigma=$ electrical conductivity.

Landolt-Bornstein Tables - See Review (R-5). 
(18)E

Mande, C., ON THE L-ABSORPTION SPECTRA OF GOLD IN THE PURE METAL AND IN GOLD-PALLADIUM ALLOYS. (In French.)

Compt. Rend. (French Academy) 240, 1205-1207 (1955).

1. The $L$ absorption of $A u$ in pure $A u$ and in two Au-Pd alloys was studied.

2. A curved crystal spectrometer was used and intensities were photographically recorded.

3a. The three L discontinuities are shifted to longer wavelengths, and the form of the $L_{3}$ discontinuity is changed in the alloys.

3b. $V / R, E(e V)$ and $\Delta E(e V)$ quantities are tabulated.

(19)E

Mande, C., THE L ABSORPTION SPECTRA OF GOLD IN GOLD-SILVER ALLOYS. (In French.)

Compt. Rend. (French Academy) 240, 2222-2224 (1955).

1. The $L_{1}, L_{2}$, and $L_{3}$ absorption spectra in pure $\mathrm{Au}$ and in $\mathrm{Ag}-50 \mathrm{w} / \mathrm{o} \mathrm{Au}$ and $\mathrm{Ag}-75 \mathrm{w} / \mathrm{o} \mathrm{Au}$ were studied.

2. A bent crystal spectrograph was used and intensities were photographically recorded.

3. Values of $\lambda(x U), V / R$ and $E(e V)$ are tabulated for the observed features; the $A_{u} L_{1}$ and $L_{2}$ absorption edges were displaced $1.2 \mathrm{eV}$ and the $L_{3} 1.8 \mathrm{eV}$ toward higher energies.

(20)E

Moore, H. R. and F. C. Chalkin, THE K SERIES EMISSION SPECTRUM OF NEON.

Proc. Phys. Soc. (London) 68A, 717-7.25 (1955).

1. Tabular data and spectra for Ne are presented.

2. An electrodeless discharge source was used and spectra were photographically recorded with the aid of a bent crystal spectrometer.

3a. One diagram line, one semi-optical line, and twenty satellites were obtained.

3b. The shape of the diagram line and the satellite structure were analyzed.

(21) E

Narbutt, K. 1., ON THE STRUCTURE OF X-RAY EMISSION LINES OF IONS IN SOLUTION. (In RUSSian.) Izvest. Akad. Nauk S.S.S.R. Ser. Fiz. 20 , 118-121 (1955).

Trans: Bull. Acad. Sci. U.S.S.R. Phys. Ser. 20, $107-110$ (1956).

1,2. A special fluorescent spectrometer at 200 ma and $50 \mathrm{kv}$ was used to study the $k \alpha$ lines of $\mathrm{Zn}$ in dissolved complexes by photographic means.

3a. Tables of results and idealized spectra are presented.

3b. The $\mathrm{K} \alpha_{1}$ line for $\mathrm{Zn}$ ions in solution is broadened by a factor of $1.5=1.8$ over $\mathrm{Zn}$ in solid compounds; the $K \alpha_{1}$ is also highly asymmetric.

4. The $L_{2}, 3$ levels in $Z_{n}$ are split by the process of ionization.

(22) T

Nigam, A. N., THE ORIGIN OF FINE STRUCTURES IN $X$-RAY ABSORPTION SPECTRA OF IONIC SOLUTIONS. Proc. Phys. Soc. (London) 68B, 472-473(1955).
1. The situation was examined from the point of view that an ion is confined for a short time in a potential space due to attraction on all sides which prevents the ion from escaping.

3a. The intensity distribution depends upon the dielectric constant of the solvent $\mathrm{H}_{2} \mathrm{O}$ molecule.

3b. A table comparing the position of structures in solids and in solutions for several inorganic substances is. presented.

(23) E

Nordfors, B., A NOTE ON Al $-\mathrm{K} \alpha_{3,4}$ LINES IN METAL AND

Proc. Phys. Soc. (London) 68A, 654-656 (1955).

1. Wavelengths of $\mathrm{K} \alpha_{2}, 4$ in $\mathrm{Al}$ and $\mathrm{Al}_{2} \mathrm{O}_{3}$ are listed.

2. A curved crystal spectrometer evacuated to $1 \times 10^{-5} \mathrm{~mm} \mathrm{Hg}$ was used to study $20 \mu$ layers and spectra were recorded with a Geiger counter. 3. Spectra and tables are shown.

(24)E

Parratt, L. G. and E. L. Jossem, X-RAY SPECTROSCOPY OF THE SOLID STATE: POTASSIUM CHLORIDE. Phys. Rev. 27, 916-926 (1955).

1,3. Emission and absorption data for $\mathrm{K}$ and $\mathrm{Cl}$ in solid $\mathrm{KCl}$ are presented and at tempt to correlate the theoretical model was made.

2a. A double crystal (calcite) spectrometer was used in the $(1,+1)$ position and also a single crystal (mica) focusing spectrometer with a slit width of $0.1 \times U$.

2b. The vacuum was $10^{-6}=10^{-7} \mathrm{~mm} \mathrm{Hg}$ but there was still some contamination.

4a. The one-electron model is not valid for this case.

4b. It is possible that the strong emission line involving the valence band electrons does not, in general, give much information about the normal unperturbed valence band itself.

(25)E

Sakellaridis, P., EMISSIONS IN THE NEIGHBORHOOD OF ABSORPTION EDGES IN THE L REGION OF THE $X$-RAY SPECTRA OF RARE EARTHS. (In French.)

J. Phys. Radium 16, 271-273 (1955).

1. Eu, Gd, Tb, Ho, and Tm in their trivalent oxide form were studied.

2. Used bent crystal spectrograph and results were photographically recorded.

3. The spectra are only discussed; no interpretation of them is offered.

(26)E

Sakellaridis, P., CHARACTERISTIC MULTIPLETS OF RARE EARTHS IN THEIR X-RAY EMISSION SPECTRA. (In French.)

J. Phys. Radium 16, 422-427 (1955).

1. Eu, Gd, Tb, Ho, and Tm, in their trivalent oxide form were studied.

2. A bent crystal spectrograph was used and results were photographically recorded.

3a. Characteristic anomalies due to the incomplete $4 \mathrm{f}$ shell were found.

3b. Tables and spectra showing the characteristic multiplets are presented. 
(26)E Cont'd.

4. The results are not interpreted in detail.

(27)E

Sato, M., METHOD FOR ACCURATE DETERMINATION OF ABSOLUTE VALUES OF $X$-RAY LEVELS IN COPPER. Sci . Repts. Tohoku Univ. Series A-7, 56-66 (1955).

1. Evaporated thin films of Cu were investigated.

3a. Some 2.6 volts was found as the critical soft $x$-ray and secondary electron emission potential.

3b. 01 der work is tabulated and calculation and tabulation in terms of $v / R$, of the absolute $X$-ray levels, is presented.

(28)E

Sawada, M., K. Tsutsumi, 1. Shiraiwa and M. Obashi, $X$-RAY NON-DIAGRAM LINES $K B_{n}$ and $K B_{L}$ FROM $\mathrm{Cr}^{24}$ to $\mathrm{Zn} 30$.

J. Phys. Soc. Japan 10, 647-650 (1955).

1. The $K \beta_{\eta}$ and $K \beta_{L}$ lines for $Z=24-30$ are tabulated.

2. A bent crystal (quartz) spectrograph was used and results were photographically recorded.

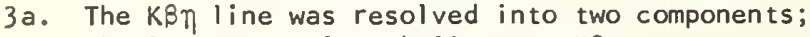
the longer wavelength line was $K \beta_{L}$.

3b. $K \alpha$ is $10^{4}$ as intense as $K \beta \eta$ or $K \beta_{L}$.

4a. The $K \beta \eta$ comes from $K L_{2}-L_{1} M_{1}$ and $K B_{L}$ from $K_{3}-L_{1} M_{1}$.

4n. The origin of $K B \eta$ is ascribed to a twoelectron jump (1s2p) and (2s3s).

(29)E

Shinoda, G., SOFT X-RAY SPECTRA DUE TO ENERGY BANDS IN THE SOLID STATE. (In Japanese.) $x$-Sen (X-rays) 8, 55-60 (1955).

1. The $L$ and $M$ spectra of $\mathrm{Cu}, \mathrm{Ni}, \mathrm{Mn}, \mathrm{Fe}$, and CuAl, were studied.

2. The photoelectronic method described in Ref. \#22 (1956) was used.

3a. Values of $\lambda, v / R$, and energies for $C u-L_{l}$, $L_{2}, L_{3}$ and $M_{2,3}$ and for $N i-L_{3}, M_{2,3}$ are tabulated.

3b. Actual oscillograms for the $\mathrm{Cu}-\mathrm{M}_{2,3}$ are presented showing a double peaked curve and a single peaked curve which al ternate, one dissolving into the other.

3c. The grating and photoelectric methods are compared; the photoelectric method is virtually as good as that of the grating.

(30) T

Sokolov, A. V., ON THE ABSORPTION AND EMISSION OF $X$-RAYS BY FERROMAGNETIC METALS. (In Russian.) Izvest. Akad. Nauk S.S.S.R. Ser. Fiz. 20, $113-117$ (1955).

Trans: 8ull. Acad. Sci. U.S.S.R. Phys. Ser. 20, 103-107 (1956).

1,2. A model of exchange interaction between the outer s electrons and inner d electrons was used to compute the density of states curve. 4a. The existence of quasi-particles which are essentially elementary excitations is postulated.

4b. The density of conduction electron states is a quadratic function of spontaneous magnetization.

(31) E

Sprague, G., D. H. Tomboulian and D. E. Bedo, CALCULATIONS OF GRATING EFFICIENCY IN THE SOFT $X$-RAY REGION.

J. Opt. Soc. Am. 45, 756-761 (1955).

1. Expressions for predicting the energy distribution among spectral orders produced by a grating near grazing incidence were derived.

2. Theoretical calculations were checked by means of a 30,000 lines/in. grating at a grazing angle of $4.64^{\circ}$.

3a. Curves for the reflecting power as a function of wavelength for an unblazed glass grating are presented.

3b. Grating interference conditions, phase amplitude relations, and boundary conditions are discussed.

(32)E

Tomboulian, D. H., ON THE SPECTRA AND ANGULAR DISTRIBUTION OF ULTRAVIOLET RADIATION FROM THE 300 MEV CORNELL SYNCHROTRON.

U.S. At. Energy Comm. NP-5805, 16 Pp. (1955).

1,2. A grazing incidence spectrograph was used to record the power spectrum in the 60-450A region; the results were recorded photographically.

3. The use of the continuous synchrotron radition as a source for absorption measurements in the extreme ultraviolet is suggested.

(33) E

Tomboulian, D. H., THE EXTREME ULTRAVIOLET SPECTRA OF SOLIDS.

U.S. At. Energy Comm. NP-5803, 24 pP. (1955).

1,2a. A grazing incidence grating vacuum spectrograph was used to study the absorption spectra of $\mathrm{Be}, \mathrm{BeO}, \mathrm{Si}, \mathrm{SiO}, \mathrm{SiO}_{2}, \mathrm{P}, \mathrm{S}, \mathrm{Cr}, \mathrm{Mn}, \mathrm{Ni}$, and $\mathrm{Ge}$ in the spectral region 60-450A.

2b. A synchrotron power spectrum was used as the source of continuous radiation.

3. Results are presented graphically at various wavelength positions.

(34)E

Tomboulian, D. H. and D. E. Bedo, METAL FOILS AS FILTERS IN THE SOFT $X$-RAY REGION.

Rev. Sci. Instr. 26, 747-750 (1955).

1. Evaporated foils, 500-2000A thick, of Be, Mg, and $\mathrm{Al}$ were used as filters in the 50-500A region.

2. Procedures for the preparation of plastic backing films (Zapon, Formvar, Mylar, etc.) are outlined.

3. Absorption curves for $\mathrm{Be}, \mathrm{Mg}, \mathrm{Al}$, and Zapon vs. wavelength are shown in order that one may choose the proper filter and thickness.

4. Filters may be used to exclude visible light, sort out overlapping orders, and to transmit narrow bands of radiation by reducing the 
(34)E Cont'd.

intensity of undesirable portions of the spectrum.

(35)E

Vainshtein, E. E., REGULARITIES IN THE STRUCTURE OF THE MAIN X-RAY ABSORPTION OF ATOMS OF ALKALI HALIDES. (In Russian.)

Doklady Akad. Nauk S.S.S.R. 105, 1196-1199 (1955).

1. The $\mathrm{K}$ absorption of potassium in $\mathrm{KCl}, \mathrm{KBr}, \mathrm{Kl}$, and KF was measured.

2. A curved crystal spectrometer was used and intensities were photographically recorded. Spectra were corrected for the irregular intensity distribution of the continuous spectrum.

3. The $K$ absorption spectrum for KF differed from that of the other halides greatly.

4. No reasons for this difference are given, but it is proposed that the difference is of a qual itative nature.

(36)E

Vainshtein, E. E., THE FINE STRUCTURE OF $K$ LINES OF THE TITANIUM SPECTRUM IN DIELECTRICS. Doklady Akad. Nauk S.S.S.R. 105, 943-946 (1955). (In Russian.)

1. Preliminary work on $\mathrm{TiO}_{2}$, ilmenite, and perovskite is presented. See Ref. \#25 (1956) for results.

(37)E

Van Den Berg, C. G. and H. Brinkman, HIGH LUMINOSITY SPECTROMETRY IN THE SOFT X-RAY REGION. I. THE CYLINDER SPECTROMETER. Physica 21, 85-102 (1955).

1. Complete calculations for the design of a crystal spectrometer are given.

2. A mica crystal was bent to a cylindrical shape and the spectra were observed along the cylinder axis; the radius of curvature was $200 \mathrm{~mm}$ and the reflecting surface was $14 \times 4 \mathrm{~cm}$ (56 sq. $\mathrm{cm}$.).

3a. The intensity gain was 60-90 over other crystal spectrometers; the wavelength range is 9 - 19A.

3b. Spectra for $\mathrm{W}, \mathrm{Cl}$, and Si are presented.

(38)E

Wagner, B., H. Witte and E. Wolfel, X-RAY DETERMINATION OF THE ELECTRON DISTRIBUTION IN CRYSTALS: 1, 11 . (In German.)

Z. Physik Chem. 3, 273-329 (1955).

1. The energies of $X$-rays reflected by the crystal were measured.

2. These energies were recorded on moving photosensitized paper with a $1-2 \%$ error.

3. The results for rock salt were 10.05 electrons for $\mathrm{Na}^{+}$and 17.70 electronc for $\mathrm{Cl}^{-}$ions.
(39)E

Woodruff, R. W. and M. P. Givens, SOFT X-IRRADIATION OF Te THIN FILMS.

Phys. Rev. 27, 52-54 (1955).

1. The linear absorption coefficient of Te was measured from 100-400A.

2. A grating spectrometer evacuated to $5 \times 10^{-5}$ $\mathrm{mm} \mathrm{Hg}$ was used.

$2 b$. The radiation source was a spark caused by a capacitor $(0.15 \mu \mathrm{f})$ charged to $3 \times 10^{4}$ volts between $\mathrm{Ag}$ or $\mathrm{Cu}$ electrodes.

3a. A large peak at $155 \mathrm{~A}$ was observed.

3b. A double peak was observed at $300 \mathrm{~A}$.

4. The double peak was due to $N_{4}$ and $N_{5}$ transitions to the conduction band.

$(c-1) T$

Candlin, D. J., ON THE IDENTIFICATION OF X-RAY SATELLITES.

Proc. Phys. Soc. (London) 68A, 322-328 (1955).

1. The wave numbers of $K \alpha$ sets for $Z=19-42$ were calculated.

2. Analytical wave functions were used.

3. Transitions are listed and results are tabu= lated.

$(c-2) T$

Dehlinger, U., H. Schenk and W. Weser, BONDING IN METALLIC PHASES. (In German.)

Z. Metallkunde 46, 647-650 (1955).

I. Ga, MoSi $i_{2}$ diamond, $Z n, A s, B i, S b$, and $W S i_{2}$ were studied.

3a. Band structures for $\mathrm{As}$ and $\mathrm{Sb}$ are presented.

Bb. Bonding is examined by Bloch theory and also by Sommerfeld-Gramm theory.

$(c-3) T$

Koster, G. F. DENSITY OF STATES CURVE FOR NICKEL. Phys. Rev. 98, $901-902$ (1955).

1,3. The density of states curve for $\mathrm{Ni}$ was extended over the entire energy range of the "d" bands.

$(c-4) T$

Laskar, W., LINE WIDTHS FROM DIPOLE AND QUADRUPOLE TRANSITIONS. (In French.)

J. Phys. Radium 16, 644-649 (1955).

1. Radiative line widths and intensities were calculated.

3. Transition probabilities for the $K, L_{1}, L_{2}$, $\mathrm{L}_{3}$ levels of $\mathrm{Bi}, \mathrm{Pb}, \mathrm{Pt}$, and $\mathrm{W}$ are tabulated.

$(C-5) T$

Lewis, M. N., L. C. Green, M. M. Mulder, and P. C. Milner, COMPUTED TRANSITION PROBABILITIES FOR $X$-RAY CONTINUA OF POTASSIUM.

Phys. Rev. 98, 1020-1028 (1955). 


\section{(c-5)T cont'd.}

1. The moment, momentum, and acceleration matrix elements for $K$ were computed.

2. Hartree-Fock one-electron wave functions were used.

3a. All data are tabulated.

3b. The momentum matrix element gives the best values as compared wi th experiment.

$(\mathrm{c}-6) \mathrm{T}$

Rubenstein, R. A. and J. N. Snyder, NEW TREATMENT OF THE AUGER EFFECT AND THE FLUORESCENCE YIELD IN THE LIGHTER ELEMENTS. Phys. Rev. 27, 1653 (1955).

1,2 The yield, $u_{k}$, was computed from transition rates.

3. The yield, $\omega_{k}$ for $\mathrm{A}, \mathrm{Kr}$, and $\mathrm{Ag}$ were $0.13,0.67$, and 0.85 respectiveiy. This compares favorably with experimental data.

$(c-7) T$

slater, J.C., ONE ELECTRON ENERGIES OF ATOMS MOLECULES AND SOLIDS.

Phys. Rev. 98, 1039-1045 (1955).

1. Tables of ionization energies of the atoms and of revised $X$-ray term values are presented.

3. The Fermi surface in alkali metals was found.

(c-8)T

Wolfsberg, M. and M. L. Perlman, MULTIPLE ELECTRON EXCITATION IN AUGER PROCESSES.

Phys. Rev. 92, 1833-1835 (1955).

1. The work was done on chlorine atoms.

3,4. The atom gets a greater charge from an Auger cascade than that obtainable by conventional two-electron theory.

1956

(1) $E$

Bedo, D. E. and D. H. Tomboulian, STUDY OF SILICON AND GERMANIUM IN THE SOFT X-RAY REGION. Phys. Rev. 104, 590-597 (1956).

1. Absorption spectra of thin evaporated foils in the spectral region 70-200A and emission spectra of $\mathrm{Ge}$ in the 60-600A region are presented; absorbers were several hundred to several thousand $( \pm 10 \%)$ angstroms thick.

2a. A grating spectrometer at a pressure of $10^{-6}$ $\mathrm{mm} \mathrm{Hg}$ was used.

2b. Absorption procedures are described as well as the spark rate used as a "light" source
(16 sparks/minute).

3a. Actual spectra and band shapes are shown.

3b. The $L_{2,3}$ edge of $S i$ is at $123 A$ and the $M_{2,3}$ edge of $\mathrm{Ge}$ is at $101.5 \mathrm{~A}$.

3c. For $\mathrm{Si}$ and $\mathrm{Ge} \mu / \mathrm{p}$ is $1.4 \times 10^{5} \mathrm{~cm}^{-1}$ and $1.8 \times$ $10^{5} \mathrm{~cm}^{-1}$ respectively.

3d. The range of forbidden energies is $1.0 \mathrm{eV}$ for $\mathrm{Si}$ and $0.8 \mathrm{eV}$ for Ge.

4. Valence bandwidths are $16.7 \mathrm{eV}$ for $\mathrm{si}$ and 7.0 eV for Ge.

(2) $T$

Brentano, 3. C. M., THE CYLINDER X-RAY SPECTROMETER. Physica 22, 705-706 (1956).

1,2. A discussion is given of a mica crystal spectrometer for the sof $\mathrm{x}$-ray region in which the crystal is bent to a cylindrical radius.

3. Details for alignment of such a spectrometer are given.

(3) E

Carter, D. E. and M. P. Givens, SOFT X-RAY ABSORPTION OF THIN FILMS OF IRON AND IRON OXIDE. Phys. Rev. 101, 1469-1472 (1956).

1. The absorption of thin (about 440A) films of Fe and $\mathrm{Fe}_{2} \mathrm{O}_{3}$ between 170 and 340A was studied.

2a. A $2 \mathrm{~m}$ grating $(30,000$ lines per inch) spectrograph with a grazing angle of $5^{\circ}$ was used; spectra were recorded photographically; the vacuum was $5 \times 10^{-5} \mathrm{~mm} \mathrm{Hg}$; slit width was $0.03 \mathrm{~mm}$.

$2 b$. The radiation source was a Cu spark operated in vacuo with a DC voltage of 30,000 volts; sparking rate was 1000 per hour.

3a. The $\mathrm{Fe}$ edge is 225A and the $\mathrm{Fe}_{2} \mathrm{O}_{3}$ edge is 218A.

3b. Spectra are shown and a density of states curve for $\mathrm{Fe}$ is postulated.

(4)E

Cauchois, Y.; SPECTRAL DISTRIBUTION IN THE REGIONS OF CHARACTERISTIC ABSORPTION OF VARIOUS CRYSTALS. (In French.)

Compt. Rend. (French Academy) 242, 100-102 (1956).

1. Anomalous absorption and stray line effects in quartz, mica, and gypsum were studied.

2. The crystals from a bent crystal spectrograph were used.

3. The anomalies were due to heavier atom impurities such as $\mathrm{Al}$ and $\mathrm{Si}$ in mica, Si in quartz, and $\mathrm{S}$ and $\mathrm{Ca}$ in gypsum.

(5) E

Cauchois, $Y$. and 1 . Manescu, THE FLUORESCENCE L SPECTRUM OF PLUTONIUM. (In French.)

Compt. Rend. (French Academy) 242, 1433-1436 (1956).

1. Some twenty lines of the Pu spectrum were measured.

2. A curved crystal spectrograph was used and intensities were photographically recorded.

3. Wavelength positions of the lines are tabulated.

(6) T

Cotton, F. A., and C. J. Ballhausen, SOFT X-RAY ABSORPTION EDGES OF METAL IONS IN COMPLEXES. I. THEORETICAL CONSIDERATIONS. 
(6) T Cont'd.

J. Chem. Phys. 25, 617-619 (1956).

1. The effect of crystal field symmetry and bond type on the appearance of $K X$-ray absorption edges of metal ions in complexes is considered.

2. In complexes where the interaction of the metal ion and ligands can be regarded as primarily ionic, an adequate description of the essential features of the fine structure of the edge may be obtained by considering the crystal field splitting of the $p$ orbitals of the metal ion.

3. The splitting of the $15-4 p$ absorption for fiest row transition elements is related to the splitting of the degeneracy of the $4 p$ energy levels in the ion by the crystal field.

(7) $E$

Cotton, F. A. and H. P. Hanson, SOFT X-RAY ABSORPTION EDGES OF METAL IONS IN COMPLEXES. 11 . CUK EDGE IN SOME CUPRIC COMPLEXES.

J. Chem. Phys. 25, 619-623 (1956).

1. X-ray absorption measurements were made on salts and solutions of copper complexes in the region of the $K$ absorption edge.

2. A double crystal (calcite) X-ray spectrometer was used. The $(1,-1)$ width at the Cuk $\alpha$ line was slightly less than a volt. The data were taken with a commercial end-window Gieger tube and recorded by a decade scaling unit. A water-cooled tungsten target $X$-ray tube, supplied by a 10 KVA stabilized AC source was used.

3. It is shown that the crystal field splitting of the $4 p$ orbitals of $\mathrm{Cu}(11)$ in some complexes can be correlated with the splitting of the $1 s-4 p$ transition observed in studies of the $k$ absorption edges of these complexes, provided the ligand-metal bonding is not appreciably covalent.

4. The results obtained are in agreement with the theory developed in part 1 of this paper (preceding abstract).

(8)E

Das Gupta, K., ELECTRON TRANSFER SMEKAL LINES IN $X$-RAY SCATTERING ON THE LONG AND SHORT WAVELENGTH SIDE OF THE MONOCHROMATISED INCIDENT $X-R A Y$ BEAM.

Science and Culture (India) 21, 624-626(1956).

1. The scattering of weak X-rays by $\mathrm{Si}, \mathrm{Na}, \mathrm{Al}$, and oxygen excited by $\mathrm{Cu}-\mathrm{K} \alpha$ radiation was studied.

2. A bent crystal (mica) spectrograph was used and intensities were photographically recorded.

3a. Smekal lines were clearly present on both the long and short wavelength sides of the incident radiation.

3b. Smekal positions are tabulated.

(9)E

Deodhar, G. B. and R. C. Karnatak, THE L-EMISSION SPECTRUM OF $\sin 62$.

J. Sci. \& Indust. Research (India) 15B, 615618 (1956).

1. The spectra ( $L$ emission) of $S \mathrm{~m}^{62}$ are presented.

2. A transmission curved crystal (mica) spectrometer was used and spectra were photographi - cally recorded.

3a. Lines at 1.7 and $1.8 \mathrm{~A}$ from $L_{2}: 0_{4}$ and $L_{3}: 04,5$ transitions respectively were found.

3b. Derived energy levels are tabulated.

4. The 1.7 and 1.8A lines indicate an 04,5 level.

(10) T

Fujimoto, H., K ABSORPTION SPECTRUM OF METALLIC AI. Sci. Repts. Tohoku Univ. First Ser. 39, 189-193 (1956).

1. Theoretical absorption maxima for metallic Al are derived and tabulated, and previous experimental results are tabulated.

3. Widths of the quasi-stationary states in $\mathrm{Al}$ were calculated and tabulated.

4. From these calculations an attempt was made to resolve the maxima into individual absorp$\mathrm{ti}$ ion bands.

(11) E

Gale, B. and J. Trotter, SOFT X-RAY SPECTRA OF SOLID SOLUTIONS OF ALUMINUM AND MAGNESIUM. Phi 1. Mag. (8) I, 759-770 (1956).

1. The $\mathrm{L}_{2}, 3$ bands of $\mathrm{Al}-\mathrm{Mg}$ al loys were examined.

2. A grating spectrometer evacuated to $10-5 \mathrm{~mm} \mathrm{Hg}$ was used and spectra were photographically recorded.

3a. The widths and shapes of the solute bands in the alloys differed greatly from those of the solvents and pure metals.

3b. These changes were examined in the light of the Thomas-Fermi treatment of fields around impurity atoms.

3c. The spectra for the alloys are presented.

(12)E

Kamada, 0., SPECTRAL INTENSITY DISTRIBUTION OF BREMSTRAHLUNG .

Sci. Repts. Tohoku Univ. First Ser. 40 , 152-160 (1956).

1. Using only a $W$ target, the spectral intensity for a condenser discharge tube was derived.

3. Curves for the distribution based on the formulae of Nicholas and of Kulenkampff are presented.

4. Extension of these formulae into the soft $X-$ ray region was assumed.

(13) E

Karal'nik, S. M., X-RAY SPECTRA AND INTERATOMIC BONDS IN ALLOYS. (In Russian.)

Izvest. Akad. Nauk S.S.S.R. Ser. Fiz. 20, 815-819 (1956).

1. Alloys of $\mathrm{Fe}-\mathrm{Cr}, \mathrm{Co}-\mathrm{Cr}, \mathrm{Ni}-\mathrm{Cr}$, and $\mathrm{Ni}-\mathrm{Mn}$ were studied.

2. A crystal spectrograph was used.

3. The $K$ absorption edge of the metals in the alloys is shifted toward shorter wavelengths as compared to the parent metals.

4. This shift is due to an increase in the interatomic bond strength on alloying. 
(14) $T$

Karal'nik, 5. M., ASYMMETRY OF $K \alpha_{1}, 2$ LINES AND THE INTERATOMIC BOND IN METALS AND ALLOYS OF THE IRON GROUP. (In Russian.)

Nauk Providomlennya Kiev Univ. 1956 \#1, $41-42$. Annotation from Referat. Zhur. Met. 1957 Abstr. 8635. (In English.)

la. It was postulated that bonding exists by degrees and examination of $K \alpha$ lines on this basis was undertaken.

1b. The index of asymetry rises in transition metals up to iron and then decreases; the index al so changes on alloying.

3. These asymmetry effects are explained by the screening of $\mathrm{K}$ electrons by outer electrons in the interatomic bond.

4. The stronger the interatomic bond the less the screening effect, this causes the $K \alpha_{1}, \alpha_{2}$ lines to adopt a position more towards short wavelengths than the position for weaker bonding.

(15)E

Kazantsev, V. A., BEHAVIOR OF THE KB GROUP X-RAY SPECTRA IN THE Fe-Cr SYSTEM. In Russian.) Sbornik. Nauch. Trudov. Kuibyshev. Ind. Inst. 2. 187-190, (1956).

Annotation from Chem. Abs. 53, 850a.

1. The $\mathrm{K} \beta$ group in $\mathrm{Fe}-\mathrm{Cr}$ alloys containing 11.4$14.23 \%$ of $\mathrm{Fe}$ was studied.

2. Primary excitation in a crystal spectrometer was employed; intensities were recorded photographically.

3a. The $K \beta_{1}$ wavelength of $\mathrm{Fe}$ and $\mathrm{Cr}$ in ferromagnetic alloys is independent of composition, while in the paramagnetic state the $\mathrm{Fe}-\mathrm{K} \beta_{1}$ is unchanged but the $\mathrm{Cr}-K \beta_{1}$ increases to $0.53 \mathrm{XU}$.

3b. The $\mathrm{K}_{5}$ zone width for $\mathrm{Fe}$ and $\mathrm{Cr}$ varies discontinuously on transition into the paramagnetic region.

4. Complete pooling of electrons does not occur in $\mathrm{Fe}-\mathrm{Cr}$ alloys.

(16)E

KiyOno, S., KB LINES OF POTASSIUM IN COMPOUNDS. Sci. Repts. Tohoku Univ. First Ser. 39, $129-144(1956)$.

1. Crystalline $\mathrm{KCl}, \mathrm{KBr}, \mathrm{KI}, \mathrm{K}_{2} \mathrm{CO}_{3}$, and $\mathrm{K}_{2} \mathrm{SO}_{4}$ were studied.

2. A bent crystal (50 cm radius quartz) spectrograph with a Sandstrom (dry air discharge) tube, was used to make 50 hour photographic exposures with a dispersion of $5.2 \mathrm{eV} / \mathrm{mm}$.

3. With fresh compound being added every $1-2$ hours, $\lambda$ and $\Delta \lambda$ of the $K \beta_{1}$ were measured and from these $\nu / R, \Delta \nu / R, \& \Delta V$ are calculated and tabulated; all other results from 19141955 are also tabulated for comparison.

4. The wavelength of the $\mathrm{KB}_{5}$ changes slightly with compounding, but the other lines appeared to be independent of crystal structure or form.
(17)E

Kotlyar, B. I., INVESTIGATION OF ASYMMETRY AND WIDTH OF $K \alpha_{1}$ LINES OF $\mathrm{CU}$ AND Mn IN GEISLER ALLOYS. (In Russian.)

Izvest. Akad. Nauk S.S.S.R. Ser. Fiz. 20, 790-793 (1956).

1. The asymmetry of the $K_{\alpha} \alpha_{1}$ line of $\mathrm{Cu}$ and $\mathrm{Mn}$ was examined in ferromagnetic $\mathrm{Cu}-\mathrm{Mn}-\mathrm{Al}$ alloys and paramagnetic Cu-Mn alloys.

2. Measurements were made wi th a demountable $X$-ray tube at $50-700^{\circ} \mathrm{C}$.

3a. The asymetry index differed with magnetic state and increased with temperature.

3b. The width of the $K \alpha_{1}$ lines remained the same when the magnetic state was changed.

(18)E

Noble, R. and L. Jacob, CONTINUOUS INTENSITIES IN THE SOFT $X$-RAY REGION.

Nature 178, 814 (1956).

1. The relationship $1=k Z V^{2}$ (constant current) was investigated in the 13-62A range (200$8000 \mathrm{~V}$ ).

2. The $\mathrm{C}$ and $\mathrm{Cu}$ targets were outgassed at red heat in vacuo, a 15 stage Be-Cu photomultiplier was used to count photons, and reproducible results were obtained.

3. Results showed that for any fixed voltage, the $x$-ray output is directly proportional to the current, but for fixed current, the output is approximately proportional to the first power of the voltage.

(19)E

Nordfors, B., THE K SPECTRUM OF AI AND ITS OXIDES. Arkiv Fysik 10, 279-289 (1956).

1. The $K \alpha_{1}, K \alpha_{2}, K \alpha_{3}, K \alpha_{4}$, and $K \beta$ for $A l$ and Its oxides were recorded.

2a. An $X$-ray tube was constructed with 2 targets in order to obtain suitable reference lines.

2b. Difficulty in keeping the Al target oxygenfree was encountered.

3. A change in the intensity and line shape of the satellites $\alpha_{3}$ and $\alpha_{4}$ in the oxide as compared to the metal was found.

(20)E

Sen, A. K., $\mathrm{L}_{2,3}$ AND K EMISSION SPECTRA FROM Mg, Al, AND Li?.

Indian J. Phys. 30, 415-422 (1956).

1. The band width band structure and edge breadths were determined in $\mathrm{Mg}, \mathrm{Al}$, and $\mathrm{Li}$; the data agree with those of Skinner.

2. A 1 meter grating with 1152 lines/mm was used at a grazing angle of $5.5^{\circ}$ with a slit width of $0.02-0.03 \mathrm{~mm}$. The intensities were photographically recorded; the evaporated specimen is excited with a $3 \mathrm{kv}$ beam of electrons. All operations were carried out at a pressure of $10^{-5} \mathrm{~mm} \mathrm{Hg}$. 
(20)E Cont'd.

3a. Spectra and tabular results are presented.

3b. The position of the Fermi surface based on the data obtained is discussed.

Shaw, C. H., - See Review $(R-13)$ and $(R-14)$.

(21)E

Shaw, C. H., SOFT X-RAY SPECTRA OF METALS AND ALLOYS.

U.S. At. Energy Corm. AECU-3578, 81 pp. (1956).

1. Characteristic emission and absorption spectra of $\mathrm{Ti}, \mathrm{Zr}, \mathrm{HF}, \mathrm{Th}$, and their alloys are presented.

(22)E

Shinoda, G., T. Suzuki and S. Kato, THE SOFT X-RAY SPECTROSCOPY OF THE SOLID STATE BY THE ELECTRONIC DIFFERENTIATING METHOD: ALUMINUM $L_{3}$. J. Phys. Soc. Japan 11, 657-661 (1956).

1,3a. The $A 1-L_{3}$ was studied; a bandwidth of 10.5 eV was obtained.

2a. A photoelectronic spectrometer in which soft $X$-rays are detected by a photosensitive surface (copper sheet in this case) was used with a retarding potential having a sawtooth waveform (100 cps). Photoelectric currents on the order of $10^{-9}$ to $10^{-12}$ amperes were electronically differentiated 3 times in order to represent the intensity of soft $x-r a y$ emission (the sawtooth voltage corresponds to reciprocal wavelength.

2b. The differentiated current was placed on an oscilloscope, thus giving the band structure in 0.01 second.

3b. The resolving power of this method vs. the grating method is shown; the latter is better up to $225 A$.

3c. The tube and circuit are diagramed and an actual oscillogram of the $A 1-L_{3}$ is presented.

(23)E

Trapneznikov, V. A. and S. A. Nemnonov, BOND STRENGTH IN Fe-MO SOLID SOLUTIONS FROM THE FINE STRUCTURES OF X-RAY ABSORPTION SPECTRA. (In Russian.)

Fiz. Metal. i Metallovedne 3, 314-320 (1956).

1. The K absorption spectra of $\mathrm{Fe}$ alloyed with $0,0.5,1.0,2$, and $4 \% \mathrm{MO}$, pure $\mathrm{Co}$, and $\mathrm{Ni}$ were studied over a temperature range of 20$800^{\circ} \mathrm{C}$.

2. Bent crystal spectrography was used.

3a. At $20^{\circ} \mathrm{C}$ the amplitude fluctuation ratio of fine structure absorption limits as a function of concentration (AFR $f(C)$ ) begins to increase at $1 \%$ Mo - increases from $1-2 \%$ Mo and then remains essentially constant to $4 \%$ Mo.

3b. At higher temperatures, the bond strength of Fe-Mo alloys is greater than that of Fe.

4. The AFR $f(C)$ is a measure of the bond strength between the atoms involved.
(24)E

Trapneznikov, V. A., THE K ABSORPTION EDGE POSITION IN Fe AND Ni FOR PURE METALS IN FERROMAGNETIC AND PARAMAGNETIC STATES.

Fiz. Metal. i Metallovedne 3, 561-562 (1956).

1,2. A vacuum $x$-ray spectrograph with a linear dispersion of $2.45 \mathrm{XU} / \mathrm{mm}$ and $3.87 \mathrm{XU} / \mathrm{mm}$ for $\mathrm{Fe}$ and $\mathrm{Ni}$ respectively was used.

3. A point " $b$ " was defined as the Fermi surface; no change in this point was observed on passing through the Curie point of $\mathrm{Fe}$ and $\mathrm{Ni}$.

4. The Fermi surface position is fixed in this transformation of $\mathrm{Fe}$ and $\mathrm{Ni}$.

(25)E

Vainshtein, E. E., THE K SERIES IN TITANIUM METAL AND IN SOME DIELECTRIC MATERIALS. (In RusSian.) Izvest. Akad. Nauk S.S.S.R. Ser. Fiz 20, 784-789 (1956).

1. The fine structure in the $K$ absorption spectrum of $\mathrm{Ti}$ in $\mathrm{Ti}$ metal, $\mathrm{TiO}_{2}$, ilmenite and perovskite was studied.

2. A bent crystal (quartz) spectrograph was used and intensities were photographically recorded.

3a. The $K \alpha$ width was unchanged, but the $K \beta_{1}$ is $30 \%$ broader in the compounds and a satellite K $\beta$ " was present in the compounds but absent in the metal.

3b. The asymmetry index was 1.19 in compounds and 1.42 in the metal.

4. The $K \beta^{\prime \prime}$ satellite was attributed to transitions from the " $O$ " level to the free $K$ level in the $\mathrm{Ti}$ atom.

(26)E

Vainshtein, E. E. and 8. I. Kotlyar, X-RAY EMISSION SPECTRA OF Mn AND CU IN HEUSLER ALLOYS IN THE MAGNETIC TRANSITION TEMPERATURE RANGE. (In Russian.)

Doklady Akad. Nauk S.S.S.R. 110, 44-47 (1956). Trans: Sov. Phys. "Doklady" I, 527-529 (1956).

1. The $K \alpha_{1}, 2$ lines and the $K \beta$ group in $\mathrm{Cu}$ and $\mathrm{Mn}$ in the alloy $\mathrm{Cu}_{2} \mathrm{MnAl}$ were studied over a temperature range of $40-300^{\circ} \mathrm{C}$.

2. A curved crystal (quartz) spectrograph having a dispersive power of $2-3.8 \mathrm{XU} / \mathrm{mm}$ was used; intensities were recorded photographically.

3a. Spectra and a plot of the $K \alpha_{1}$ and $K \alpha_{2}$ lines of the Mn asymmetry index vs. temperature are presented.

$3 b$.

$$
\text { Magnetic State }
$$

$\mathrm{MnK}_{1} \frac{\overline{\lambda(\mathrm{XU})}}{1906.12} \frac{\mathrm{E}(\mathrm{eV})}{6463.48} \frac{\overline{\lambda(\mathrm{XU})}}{1906.15} \frac{\mathrm{E}(\mathrm{eV})}{6463.37}$

$\begin{array}{lllll}M n K \beta_{5} & 1892.93 & 6508.52 & 1893.30 & 6507.30\end{array}$

$\begin{array}{lllll}\text { CuKB1 } & 1389.42 & 8867.15 & 1389.38 & 8867.41\end{array}$

$\begin{array}{lllll}\text { CuKR }_{5} & 1378.55 & 8937.22 & 1378.48 & 8938.09\end{array}$

$(C-1) E$

Amrehn, H., ENERGY DISTRIBUTION IN SPECTRUM OF $X$-RAY BREMSTRAHLUNG AS A FUNCTION OF THE ATOMIC NUMBER. (In German.)

Z. Physik 144, 529-537 (1956).

1. $\mathrm{C}, \mathrm{Al}, \mathrm{Ni}, \mathrm{Ag}$ and $\mathrm{Au}$ were studied at potentials of 25 , and $34 \mathrm{kv}$. 


\section{(c-1)E Cont'd.}

2. The direction of the observational proportional counter was $90^{\circ}$ with respect to the electron beam.

3. Results agreed satisfactorily with Sommerfeld Theory.

(C-2) T

Biberman, L. M. and E. M. Novodvorskaya, THE EFFECT OF REABSORPTION ON SPECTRAL LINE WIDTH. (In Russian.)

Doklady Akad. Nauk S.S.S.R. 106, 35-38 (1956).

1. An equation expressing the width (w) of a spectral line in the presence of a Doppler effect was derived.

3a. The equation is:

$$
w=2 \sqrt{\ln 2}\left[\frac{\nu-\nu_{0}}{\Delta \nu_{\theta}}\right]
$$

$\nu_{0}$ is the emission frequency.

$\nu$ is the frequency of the center of the line. $v_{D}$ is the Doppler frequency.

3b. Comparison with other Russlan experimental data was favorable.

$(\mathrm{C}-3) \mathrm{T}$

Blokhin, M. A., TRUE SHAPE OF X-RAY SPECTRA. Dokl ady Akad. Nauk S.S.S.R. 107, 33-36 (1956). Trans: Sov. Phys. "Doklady" I, 145-148 (1956).

1,2,3. A correction scheme for spectra obtained with a double crystal spectrometer was postulated; the scheme assumed a dispersion function for instrumental broadening and continued from that assumption.

$(\mathrm{C}-4) \mathrm{T}$

Blokhin, M. A., INSTRUMENTAL DISTORTION OF X-RAY SPECTRA.

Doklady Akad. Nauk S.S.S.R. 107, 229-232(1956). Trans: Sov. Phys. 'Doklady'l, 165-168 (1956).

1. The case of nondispersive asymmetric distortions in a double crystal spectrometer was developed.

3. A "true line shape" was assumed and corrections were developed for a distorted line of any shape but not of any width.

(C-5) T

Eisenstein, J. C. USE OF $f$ ORBITALS IN COVALENT BONDING.

J. Chem. Phys. 25, 142-146 (1956).

1. The compounds $\left(\mathrm{UO}_{2}\right)^{++}, \mathrm{UCl}_{6}$, and $\mathrm{UCl}_{4}$ were discussed and the use of $f$ uranium orbitals for covalent bonding in these compounds was postulated.

3. Tables showing whlch atomic orbitals can be combined to form bonding orbitals for a number of different spatial arrangements of the bonds are presented.

$(C-6) E$

Harrower, G. A., ENERGY SPECTRA OF SECONDARY ELECTRONS FROM MO AND $W$ FOR LOW PRIMARY ENERGIES. Phys. Rev. 104, 52-56 (1956).

1. Energy spectra were measured using primary voltages of $0-100 \mathrm{~V}$.
2. An electrostatic analyzer was used at $127^{\circ}$; specimens were at a vacuum of $5 \times 10^{-10} \mathrm{~mm} \mathrm{Hg}$ and were cleaned by flashing.

3. Monolayer adsorption time on the targets was inversely proportional to the pressure; it was 1 second at $10^{-6} \mathrm{~mm} \mathrm{Hg}$.

$(\mathrm{C}-7) \mathrm{T}$

Karnatak, R. C. and Y. P. Varshni, SCREENING CONSTANTS IN X-RAY SPECTRA. (In English.)

Z. Physik 145, 341-346 (1956).

1. The $X-$ ray screenlng constant $\sigma_{2}$ for $L_{2} L_{3}, M_{2} M_{3}$ and $M_{4} M_{5}$ is calculated.

2. Sommerfeld theory was used.

3. Values of $\sigma_{2}$ for elements of $z=23-92$ are tabulated.

(C-8)E

Katamadze, V. R., REFRACTIVE INDEX OF X-RAYS IN METALS. (In Russian.)

Trudy Stal inirsk. gosudarst. Inst. 3, 589598 (1956).

Annotated from Abs. J. Met. (U.S.S.R.) 1958 $(3-4) 44$ (Abs. 8106).

1. The energy of reflected $X$-rays from mirror surfaces of $\mathrm{Al}, \mathrm{Fe}, \mathrm{Ni}$, and $\mathrm{Cu}$ was studied in the wavelength reglon 0.710 to $1.933 \mathrm{~A}$.

2. These energies were found from photographs taken at angles of incidence less than a factor of 1.3 of the critical angle.

3. The index of refraction is then found; the results agree within $2 \%$ of the theoretical values predicted by the Kalman-Mark formula.

$(c-9) \mathrm{T}$

Richardson, J. W. and R. E. Rundle, THEORETICAL STUDY OF ELECTRONIC STRUCTURES OF TRANSITION METAL COMPLEXES. U.S. At. Energy Comm. ISC-830, 118 pp. (1956).

1. New findings on metal-ligand interactions and on extra valence shell orbitals for the ligand are listed.

2a. A semi-empirical theory based on Roothan's self-consistent field molecular orbital procedures and on Mulliken's approximations for certain molecular integrals was devised.

2b. Only valence shell atomic orbitals were used.

3. Tables of results are presented.

4. It is possible to use these methods in bonding problems in intermetallic compounds and other alloys.

$(C-10) E$

Takeishi, Y., AUGER EJECTION OF ELECTRONS FROM BaO BY INERT GAS ATOMS.

J. Phys. Soc. Japan 11, 676-689 (1956).

1. Auger transitions are tabulated.

3. The total Auger yield was found to be about 0.475 for Inert gas atoms of several energies.

4a. The energy gap is $0.8-1.0 \mathrm{eV}$ in BaO.

4b. The top of the filled band is $5.1 \mathrm{eV}$ or more 
$(c-10)$ E Cont'd.

below the vacuum level and the width is 6-9 eV.

(C-11)E

Tomboulian, D. H. and P. L. Hartman, SPECTRA AND ANGULAR DISTRIBUTION OF ULTRAVIOLET RADIATION FROM THE 300-MEV CORNELL SYNCHROTRON. Phys. Rev. 102, 1423-1447 (1956).

1,2a. A grazing incidence grating spectrograph was used wi th photographic means in order to record the average power spectrum emitted over a partial or full synchrotron acceleration interval in which the electron energy was 233 or 321 MEV.

2b. The grating reflecting power was determined wi th monochromatic sources; this enabled the synchrotron continuum to be evaluated from 60-200A.

3a. Results are in good agreement with the theory of accelerated electrons.

3b. The Be-K and the $A 1-L_{2}, 3$ absorption edges were obtained by use of the synchrotroncontinuum as the radiation source. The Be-K edge is $111 \mathrm{~A}$ and the $\mathrm{Al}-\mathrm{L}_{2,3}$ edge is $170 \mathrm{~A}$.

1957

(1)E

Agarwal, B. K. and M. P. Givens, SOFT X-RAY ABSORPTION BY THIN FILMS OF CHROMIUM.

Phys. Rev. 107, 62-64 (1957).

1. Absorption and emission spectra of $\mathrm{Cr}$ were studied in the spectral region of 250-300A.

3. The observed absorption band was interpreted as a combination of $M_{3}$ and $M_{2}$ bands in the ratio $3: 2$ and separated by $1.5 \mathrm{eV}$.

4. The absorption produced is from the transition $3 P_{3 / 2} \cdot 1 / 2$ to the unfilled portion of the conduction band.

(2)E

Agarwal, B. K. and M. P. Givens, SOFT X-RAY ABSORPTION BY THIN VANADIUM FILMS.

Phys. Rev. 108, 658-659 (1957).

1. The absorption of sof $t X$-rays by $V$ over $a$ spectral region of 190-250A was measured.

2. Films 25-300A thick deposited at a pressure of $10^{-4} \mathrm{~mm} \mathrm{Hg}$ were employed.

3. Soft X-ray data for $\mathrm{Fe}, \mathrm{Cr}$, and $\mathrm{V}$ are compared; total (emission and absorption) width and absorption spectra for $\mathrm{Fe}$ and $\mathrm{V}$ are given.

4. The observed absorption band for $v$ is interpreted as a combination of $M_{3}$ and $M_{2}$ bands in the ratio of $2: 1$ and separated by $1.5 \mathrm{eV}$.

(3) $T$

Barinskii, R. L., E. E. Vainshtein and K. E. Narbutt, DEPENDENCE OF X-RAY ATOMIC ABSORPTION SPECTRA IN COMPOUNDS ON THE CHARACTER OF THE CHEMICAL BOND. (In Russian.)

Izvest. Akad. Nauk S.S.S.R. Ser. Fiz. 21, 1351-1361 (1957).

Trans: Bull. Acad. Sci. U.S.S.R. Phys. Ser. 21, 1341-1350 (1957).

1. The $K$ absorption edge fine structure of $\mathrm{Zn}$,
$\mathrm{K}$, and $\mathrm{Cl}$ in ionic compounds as a function of the nature of the chemical bond is discussed.

3a. Rules are established permitting the prediction of the position and relative intensity of the lines of one component in a compound provided these data are available for the other component.

3b. All spectra are presented.

(4)E

Barinskii, R. L., K ABSORPTION SPECTRA OF CHLORINE IN ALKALI METAL CHLORIDES. (In Russian.) Izvest. Akad. Nauk S.S.S.R. Ser. Fiz. 21, 1381-1386 (1957).

Trans: Bull. Acad. Sci. U.S.S.R. Phys. Ser. 21, 1369-1374 (1957).

1. Sintered $\mathrm{LiCl}, \mathrm{NaCl}, \mathrm{KCl}, \mathrm{RbCl}$, and $\mathrm{CsCl}$ were studied.

2. A bent crystal (quartz) spectrograph was used and intensities were photographically recorded.

3. The line widths increased with the decrease of the ionic radius of the cation; the spectra are shown.

4. The effective quantum number of the series is directly proportional to the polarizeability of the cation.

(5)E

Barinskii, R. L. and E. E. Vainshtein, X-RAY $A B-$ SORPTION AND EMISSION L SPECTRA OF MO IN THE CARBIDE AND SOME OTHER COMPOUNDS. (In Russian.) Izvest. Akad. Nauk S.S.S.R. Ser. Fiz. 2l, 1387-1396 (1957).

Trans: Bull. Acad. Sci. U.S.S.R. Phys. Ser. 21, 1375-1384 (1957).

1. The $L_{3}$ absorption edge and the $L_{2}$ emission line of $\mathrm{Mo}$ in $\mathrm{MoC}_{2},\left(\mathrm{NH}_{4}\right)_{2} \mathrm{MoO}_{4}, \mathrm{MOO}_{3}$, and $\mathrm{MoS}_{3}$ and $\mathrm{MoS}_{2}$ were investigated.

2. A bent crystal (quartz) spectrograph was used; Intensities were recorded photographically.

3a. A group of very intense selective lines were found $11-15 \mathrm{eV}$ from the edge in all absorption spectra obtained.

$3 b$. The results show that the $4 d$ band is free in $\left(\mathrm{NH}_{4}\right)_{2} \mathrm{MoO}_{4}$, that there is a $d^{4}$ sp hybridization in $\mathrm{MOS}_{2}$ and a partial bond hybridization in $\mathrm{MoC}_{2}$.

3c. All spectra are presented.

(6)E

Baurmann, $E$. and $K$. Ulmer, THE ABSORPTION OF SOFT $X$-RAYS IN THE NEIGHBORHOOD OF THE K EDGE IN Mg. (in German.)

Z. Naturforsch, 12a, 670-671 (1957).

1. The absorption was measured between 7 and $24 \mathrm{~A}$.

3a. The mass absorption coefficients are presented.

3b. The Bragg-Pierce law constant for this case is given.

(7)E

Bedo, D. E., THE K SPECTRUM OF LITHIUM. Univ. Microfilms PUBL 21074, 93 pP. (1957). Diss. Abs. 17, 1097-1098.

1. The 60-600A region was investigated.

2. A grating spectrometer at grazing incidence, evacuated to $1 \times 10^{-6} \mathrm{~mm} \mathrm{Hg}$, was used to detect the astigmatically focused image by 
(7) E Cont'd.

photographic means.

3a. The band does not show a high energy cut-off.

3b. A satellite band with a maxlmum at $82.83 \mathrm{eV}$ was found.

4. The experimental intensity distribution as a function of the energy of photons is proportional to the product of the transition probability for allowed transitions and the level density functions for the specific excited solid.

(8) $\mathrm{T}$

Blokhin, M. A. and V. P. Sachenko, WIDTHS OF INTERNAL LEVELS AND ENERGY-DENSITY DISTRIBUTIONS OF ELECTRON STATES OF THE IRON GROUP TRANSITION ELEMENTS. (In Russian.)

I zvest. Akad. Nauk S.S.S.R. Ser. Fiz. 21, 1342-1350 (1957).

Trans: Bull. Acad. Sci. U.S.S.R. Phys. Ser. 21, 1333-1340 (1957).

1,2. The widths of $K$ levels for $Z=12-79$ (35 elements shown) were calculated from transition probabilities and the fluorescence yield. Similar calculations were made of the $\mathrm{L}_{2}, 3$ levels for $Z=22-47$ ( 19 elements shown).

3a. Calculated data agree wi th Beeman and Friedman for the density states for copper.

3b. Complete tables of the line widths obtained by the calculations are presented.

3c. "Corrected" spectra for Beeman and Friedman's data (Ref. \#1, 1939) are shown.

(9)E

BOke, K., K ABSORPTION EDGE FINE STRUCTURE. (In German.)

2. Physik Chem., Frankfurt (NF) 10, 45-82 (1957).

1. The $K$ absorption edge was studied in transition metal complexes, chiefly carbonyl and cyano complexes, both at liquid oxygen temperature and at $300^{\circ} \mathrm{K}$.

2. A double crystal spectrometer was used.

3a. An extrapolation method allowing one to get the absorption curve for the pure element from material of lower purity is described.

3b. Results at liquid $\mathrm{O}_{2}$ temperature were the same as at $300^{\circ} \mathrm{K}$.

4. For the absorption edge of the ions, the experimental values with respect to the position and distances of $p$ levels conformed to theory.

(10)E

BOKe, K., K EDGE FINE STRUCTURE OF TRANSITION ELEMENT COMPLEXES OF Cr AND $\mathrm{Zn}$. (In German.) Z. Physik Chem. Frankfurt (NF) II, 326-336 (1957).

1. The slope of absorption curves is discussed in connection with molecular level theory.

3. Empirical statements which can be deduced from the data are tabulated.

(11)E

Bonnelle, C. and C. Mande, THE L SPECTRUM OF PALLADIUM. (In French.)
Compt. Rend. (French Academy) 245, 2253-2256 (1957).

1. Weakly bound electrons and vacant states near the Fermi level were investigated by means of the $\mathrm{LB}_{2}$ spectrum of $\mathrm{Pd}$.

2. A curved crystal spectrometer wl th a dispersive power of $5.4 \mathrm{eV} / \mathrm{mm}$ was used and intensities were photographically recorded.

3a. The emission band is unsymmetrical on the high energy side with secondary maxima due to satellites.

3b. The $L_{3}$ absorption edge was found to be $1 \mathrm{eV}$ above the emission maximum.

(12)E

BOrisOV, M. D., SELECTION OF THE OPTIMUM CONDITIONS FOR EXPOSURE AND PHOTOMETRY OF X-RAY BANDS. Voprosy Fiz. Metal. i Metalloved. Akad. Nauk Ukr. S.S.R. Sbornik Nauch. Rabot 1957 (8) 209-214. Annotation from Chem. Abs. 55,7030c

1. The resolving power of a crystal spectrograph is discussed from the point of view of the effect of the slit width and the film grain size.

(13)E

Bori sov, M. D., V. V. Nemoshkalenko and A. M. Fefer, $X$-RAY INVESTIGATION OF THE DISTRIBUTION OF ELECTRONS AMONG STATES IN METALS AND ALLOYS. (In Russian.) Izvest. Akad. Nauk. S.S.S.R. Ser. Fiz. 21, 1424-1434 (1957).

Trans: Bull. Acad. Sci. U.S.S.R. Phys. Ser. 21, 1412-1422 (1957).

1. The $\mathrm{K}_{5}$ and $K \beta_{1}$ lines of $\mathrm{Cr}-\mathrm{Fe}$ alloys containing $4,5.8,8,20,30,45,50$, and $75 \mathrm{w} / \mathrm{o} \mathrm{Cr}$ were investigated at $1000^{\circ} \mathrm{C}$.

2. A bent crystal (quartz) spectrograph was used; intensities were recorded photographically.

3. The $F e-K \beta_{1}$ and $K \beta_{5}$ and the $\mathrm{Cr}-\mathrm{K} \beta_{1}$ were not affected by concentration, but the $\mathrm{Cr}-\mathrm{KB}_{5}$ was displaced to longer wavelengths while the absorption edge was shifted to lower wavelengths with increasing iron concentration.

4. The conduction bandwidth reaches a maximum for intermediate concentrations of $\mathrm{Fe}$ and $\mathrm{Cr}$.

(14)E

Borovikova, G. P., and M. I. Korsunski i, X-RAY SPECTRUM OF THE L SERIES OF Ge.(In Russian.) Izvest. Ak'ad. Nauk S.S.S.R. Ser. Fiz. 2l, 1438-1444 (1957).

Trans: Bull. Acad. Sci. U.S.S.R. Phys. Ser. 21, 1426-1431 (1957).

1. The $L$ spectra of both $\mathrm{Ge}$ and $\mathrm{GeO}_{2}$ were studied.

2. A bent crystal (mica) spectrograph was used; intensities were recorded photographically.

3a. The $L \alpha_{x}$ and $L \beta_{x}$ disappeared in $\mathrm{GeO}_{2}$ owing to the loss of $\mathrm{Ge}$ electrons to oxygen.

3b. Actual spectra are presented.

(15)E

Borovski i, I. B. and G. N. Ronami, THE INFLUENCE OF THERMAL VIBRATIONS OF ATOMS ON THE ELECTRON ENERGY SPECTRUM OF METALS AND ALLOYS. 
(15)E Cont'd.

(In Russian.)

Izvest. Akad. Nauk S.S.S.R. Ser. Fiz. 21, 1397-1400 (1957).

Trans: Bull. Acad. Sci. U.S.S.R. Phys. Ser. 21, 1385-1388 (1957).

1. The $L_{3}$ absorption spectra of $\mathrm{Pb}$ with $0.2,0.5$, 2.0 and $10 \mathrm{w} / 0 \mathrm{Sn}, \mathrm{PbO}$, and $\mathrm{PbO}_{2}$ were investi= gated at -190 to $300^{\circ} \mathrm{C}$.

2. A bent crystal spectrograph was used, and intensities were photographically recorded.

3a. The fine structure in $\mathrm{Pb}$ and $\mathrm{Pb}=10 \% \mathrm{Sn}$ disappears at $200^{\circ} \mathrm{C}$, but it still persists at $300^{\circ} \mathrm{C}$ in $\mathrm{Pb}$ with $0.2-0.5 \% \mathrm{Sn}$.

3b. Fine structure data and the experimental spectra are tabulated.

(16)E

Cauchois, Y. and C. Bonnelle, NEW STUDY OF THE L SPECTRA OF NICKEL AND COPPER. (In French.) Compt. Rend. (French Academy) 245, 1230-1233 (1957).

1. Both the emission and absorption spectra of $\mathrm{Ni}$ and $\mathrm{Cu}$ were obtained.

2. A bent crystal (gypsum or mica) spectrograph was used and intensitles were recorded photographically.

3a. Strong white rays were found in the absorption spectra of $\mathrm{Ni}$ (absent in $\mathrm{Cu}$ ) and these rays were attributed to " $d$ " shell vacancies.

3b. Emission bandwidths of $2.2 \mathrm{eV}$ for $\mathrm{Ni}$ and 3.8 $\mathrm{eV}$ for $\mathrm{Cu}$ (in agreement wi th Shaw) were found.

(17)E

Dilmore, B. L., G. L. Rogosa and G. Schwartz, THE NP L X-RAY ABSORPTION SPECTRUM. Bull. Am. Phys. Soc. (2) 1, 258 (1957).

2. A double crystal spectrometer was used to study an $\mathrm{HNO}_{3}$ solution of $\mathrm{Np}^{237}$ and intensities were recorded with a scintillation counter.

3.

$\begin{array}{cc}\text { L edge } & \text { Value }(\mathrm{keV} \pm 5 \mathrm{eV}) \\ L_{1} & 22.432 \\ L_{2} & 21.594 \\ L_{3} & 17.610\end{array}$

(18) E

Doran, D. G. and S. T. Stephenson, THE K ABSORPTION EDGE IN A SINGLE CRYSTAL OF Ge. Phys. Rev. 105, 1156-1157 (1957).

1. The extended fine structure on the short wavelength side of the Ge-K edge was studied; measurements extended $300 \mathrm{eV}$ from the edge.

2. A double crystal spectrometer was used to examine the 100 thick crystal.

3. The spectrum and tabular results are presented.
(19)E

Eberbeck, W., K EDGE STRUCTURES OF ELEMENTS IN $A^{3}$ $B^{5}$ COMPOUNDS. (In German.)

Z. Physik 149, 412-424 (1957).

1. The K absorption spectra of GaP, GaAs, GaSb, InAs and $Z n S$ were studied, and absorber

thicknesses and absorption maxima and minima were tabulated.

3. The separation of the closest absorption maximum from the edge was:

$\begin{array}{ll}\text { GaSb } & 5.8 \mathrm{eV} \\ \text { GaAs } & 7.1 \mathrm{eV} \\ \text { GaP } & 8.6 \mathrm{eV}\end{array}$

4. These separations correspond to decreasing electrical conductivity of the compounds as the conduction band is shifted to higher energies and becomes more nearly empty.

(20)E

Henke, B. L., R. White and B. Lundberg, MASS ABSORPTION COEFFICIENTS FOR 5-50A X-RAYS. J. Appl. Phys. 28, 98-105 (1957).

1,2. The mass absorption coefficients for $z=1-36$ were determined by a semi-empirical relationship.

3a. A universal function was set up and from it tables were computed for absorption by $K$ shell electrons and also for absorption by $L$ and extra L shell electrons.

3b. Tables of mass absorption coefficients are given for $Z=1-36$ at $8.34,13.3,17.6,21.7$, $23.7,27.4,31.6,36.3$ and $44.0 \mathrm{~A}$.

(21) A

Jaegle, P., DIFFRACTION OF SOFT X-RAYS PRODUCED BY TWO GRATINGS. (In French.)

Compt. Rend. (French Academy) 245, 1412-1415 (1957).

1,2. Two consecutive concave gratings were used to disperse $20 \mathrm{~A} X$-rays.

3a. A series giving the amplitude of the diffraction spot in the final pattern was obtained.

3b. The diaphragm projecting the intermediate spot is capable of modifying the shape of the diffraction pattern.

(22) T

Karal'nik, S. M., EXTERIOR SCREENING AND THE FINE STRUCTURE OF X-RAY SPECTRA. (In RUssian.) Izvest. Akad. Nauk S.S.S.R. Ser. Fiz. 21 , $1445-1457$ (1957).

Trans: Bull. Acad. Sci. U.S.S.R. Phys. Ser. 21, 1432-1439 (1957).

1. The effect of bonding in solid compounds on the screening of electrons appears as $K a b$ sorption edge displacement.

2. The value of the screening of the is shell by a single outer electron was calculated from the displacement per unit valence of 
(22) T cont'd.

the $\mathrm{K}$ edge in inorganic compounds of $\mathrm{V}, \mathrm{Cr}$, $\mathrm{Mn}, \mathrm{Fe}, \mathrm{Ni}$, and $\mathrm{Na}$.

3a. The screening value was about 0.008 in the Fe group and 0.018 in sodium.

3b. In $\mathrm{Cr}_{2} \mathrm{O}_{3}, \mathrm{MnO}, \mathrm{Fe}_{2} \mathrm{O}_{3}$, and $\mathrm{Ni}_{2} \mathrm{O}_{3}$, the $\mathrm{K}$ edge shifts to shorter wavelengths and the $\mathrm{KB}_{5}$ to longer wavelengths.

4. This shift is attributed to $4 \mathrm{~s}$ and $3 \mathrm{~d}$ electrons both being active in the chemical bond.

(23)E

Kazantsev, V. A., CHROMIUM K EDGE ABSORPTION IN $\alpha$ AND $\sigma$ PHASES OF THE Fe-Cr ALLOY SYSTEM.

(In Russian.)

Doklady Akad. Nauk S.S.S.R. 115, 501-503 (1957)

1. Data on the $3 d$ and $45 p$ bands in the alloys in the $\alpha$ and $\sigma$ phases was obtained.

2. A curved crystal spectrometer was used and intensities were photographically recorded.

$3 a$. On the formation of the $\sigma$ phase, the $K$ edge shifted towards lower energies - the inflection point of the $3 \mathrm{~d}$ band by $3.2 \mathrm{eV}$ and the midpoint of the $4 \mathrm{sp}$ band by $4.6 \mathrm{eV}$.

3b. Phase-band Width Phase-band Width

$\begin{array}{cccc}\frac{\alpha}{3 d} & \frac{(\mathrm{eV})}{1.2} & \frac{\sigma}{3 d} & \frac{(\mathrm{eV})}{7.0} \\ 4 \mathrm{sp} & 17.0 & 4 \mathrm{sp} & 13.0\end{array}$

3c. Actual spectra are presented.

(24)E

Korsunski i, M. I. and Ya. E. Genkin, NIOBIUM LB 2 AND LYI EMISSION FIELOS IN NIOBIUM NITRIDE, NIOBIUM CARBIDE, AND NIOBIUM BORIDE.

Trudy Seminara po Zharostoikim Materialam, Akad. Nauk Ukr. S.S.R. Inst. Metallokeram. i Spetsial. Splavov, Kiev. 1957 (5) 15-20. (Pub. 1960) Annotation from Chem. Abs. 25, 12025 e.

1. The shapes and intensities of the $L$ lines of $\mathrm{NbN}, \mathrm{NbC}$, and $\mathrm{NbB}_{2}$ are compared to those of pure $\mathrm{Nb}$.

2. Crystal spectrometry was used.

3. The compounds showed less intensity and different shapes than did the parent metal due to line splitting.

4. The alteration in shape was due to electronic transitions from the $\mathrm{d}$ level of $\mathrm{Nb}$.

(25)E

Lucasson-Lemasson, A., L EMISSION SPECTRA OF COPPER IN ALLOYS. (In French.)

Compt. Rend. (French Academy) 245, 1794-1797 (1957).

1. The L $\alpha$ band of $\mathrm{Cu}$ alloyed with $\mathrm{Ni}, \mathrm{Zn}$, and Al was studied.

2. A bent crystal (gypsum) spectrograph having a dispersive power of $2.1 \mathrm{eV} / \mathrm{mm}$ was used and intensities were photographically recorded.

3a. A satellite $\alpha^{\prime \prime \prime}$ was found in all alloys.

3b. Spectra and a table showing the characteristics of all alloys studied are presented.
(26) A

Lukirski i, A. P., A VACUUM X-RAY SPECTROGRAPH WITH GEIGER COUNTER FOR THE INVESTIGATION OF THE ENERGY LEVELS IN SOLIOS. (In Russian.) Radiotekh. i Elektron. 2, 328-333 (1957). Trans: Radio Engineering and Electronics (U.S.S.R.) 2 (3), 99-106 (1957).

1. A 600 lines/mm (15,000 lines/in) grating spectrograph was constructed for use in the 20-120A spectral region.

3a. A $2.5^{\circ}$ grazing angle was employed.

3b. A Geiger counter was used to measure the intensities.

3c. The vacuum was $10^{-5} \mathrm{~mm} \mathrm{Hg}$.

3d. The apparatus is described and illustrated.

3e. Calibration-type spectra of $\mathrm{Be}$ and $\mathrm{Pb}$ are shown.

(27) $E$

Mande, C., K ABSORPTION SPECTRA OF PALLADIUM AND PALLADIUM-GOLD ALLOYS. (In French.)

Compt. Rend. (French Academy) 244, 747-749 (1957).

1. The second order spectra of Pd pure and in $\mathrm{Pd}-67 \mathrm{w} / \mathrm{O} \mathrm{Au}$ and $\mathrm{Pd}-45 \mathrm{w} / \mathrm{o}$ Au were studied.

2. A curved crystal spectrometer was used and intensities were photographically recorded. Resolution was better in the pure metal than in the alloy.

3a. The edge discontinuity was resolved into two branches, $K_{1}$ and $K_{2}$.

3b. $K_{1} / K_{2}$ increased wi th Pd additions in the alloys.

$3 c$. The $K$ edge width was found to be $7.5 \mathrm{eV}$.

(28)A

Mitra, B. and K. Das Gupta, NEW BENT CRYSTAL SOFT $X$-RAY SPECTROGRAPH.

J. Sci. Indust. Research (India) 168, 524527 (1957).

1. A curved mica crystal spectrometer is described.

3a. The crystal and cassette were fixed; the target was movable.

3b. The vacuum was $5 \times 10^{-6} \mathrm{~mm} \mathrm{Hg}$.

3c. Photographic photometry was used to determine intensities.

3d. A dispersion of $16 \mathrm{xU} / \mathrm{mm}$ for 8 th order $\mathrm{Cu}-\mathrm{K} \alpha_{1}$, $\alpha_{2}$ can be obtained.

(29) E

Moore, H. R., L SERIES EMISSION SPECTRUM OF KRYPTON. Proc. Phys. Soc. (London) 70A, 466-473 (1957).

1. Tabular data and spectra for $\mathrm{Kr}$ are presented.

2. An electrodeless discharge source was used and spectra were photographically recorded with the aid of a bent crystal spectrometer.

3a. One quadrupole line, seven diagram lines, and ten satellites were obtained.

3b. The $x$-ray energy levels found were:

\begin{tabular}{lr} 
Level & Energy $(\mathrm{eV})$ \\
\hline$L_{1}$ & 1920 \\
$M_{4}, 5$ & 87 \\
$\mathrm{~N}_{1}$ & 20
\end{tabular}


(30) $\mathrm{T}$

Nigam, A. N., X-RAY SPECTRA OF POTASSIUM HALIDE CRYSTALS AND COLOR CENTERS IN THEM.

Z. Physik 147, 264-270 (1957).

1,4. Possible correlations of the energy levels arising from color centers with the fine structure of $X$-ray absorptions of the potassium ion are postulated.

(31) T

Nikiforov, I. Ya., CALCULATION OF THE ENERGY DISTRIBUTION DENSITY OF ELECTRONIC STATES FROM $X$-RAY SPECTRA. (In Russian.)

Izvest. Akad. Nauk S.S.S.R. Ser. Fiz. 21, 1362-1366 (1957).

Trans: Bull. Acad. Sci. U.S.S.R. Phys. Ser. 21, 1351-1355 (1957).

1,3a. A new method is proposed in order to approximate the experimental spectrum mathematically.

3b. The results are tabulated and a test spectrum obtained by applying the method is shown.

(32) $T$

Orlov, A. N. and A. V. Sokolov, STRUCTURE OF X-RAY EMISSION SPECTRA OF ORDERED ALLOYS. (In RuSSian) Fiz. Metal. i Metallovedne 5, 390-394 (1957). Trans: Phys. Of Metals and Metallography 5 (3) $7-11(1957)$.

1. The intensity of $X$-rays emitted when electrons transfer from the conduction band to the Llevel was calculated.

2. The one-electron theory of ordered solution forming BCC alloys was used.

3. Values for limits of conduction band and Fermi surface in eV were derived.

(33)E

Parratt, L. G., C. F. Hempstead and E. L. Jossem, THICKNESS EFFECT IN ABSORPTION SPECTRA NEAR THE ABSORPTION EDGE.

Phys. Rev. 105, 1228-1232 (1957).

1,2. The role of the spectral window as it affects the details of the observed absorption spectrum (which the authors show, depend's upon absorber thickness) is discussed for the 2crystal spectrometer.

3a. The window effect may be serious when the window tails are extensive.

3b. Measurement of widths and of relative intensities are most sensitively involved, but wavelengths are also slightly affected.

3c. An optimum thickness equation is derived:

$$
x_{d}=\frac{\ln \left(\mu_{1} / \mu_{2}\right)}{\mu_{1}-\mu_{2}}
$$

and values of $x_{d}$ are tabulated.

3d. Spectra are presented, the thickness effect explained and the spectral window shape discussed and evaluated.

4. The details of the absorption spectrum depend upon the absorber thickness.

(34)E

Parratt, L. G. and E. L. Jossem, WIDTH OF THE VALENCE BAND IN KCl.

J. Chem. Phys. Solids 2, 67-71 (1957).

1. Values for the effective dielectric constant and for the effective mass of the $\mathrm{K}-\mathrm{ls}$ first excited state in $\mathrm{KCl}$ are obtained.

2. Crystal spectrography was used.

3. The chlorine-3p valence band is about $2 \mathrm{eV}$ wide.

4. The base width of the valence band may be of the order of $1 \mathrm{eV}$ and the half maximum width of the density of states curve for this band may be about $0.3 \mathrm{eV}$.

(35)E

Rumyantsev, I. A. and $M$. I. Korsunski $i$, LINES LB $_{6}$ AND L $Y_{5}$ IN COPPER AND ZINC SPECTRA. (In Russian) Izvest. Akad. Nauk S.S.S.R. Ser. Fiz. 21, 1435-1437 (1957).

Trans: Bull. Acad. Sci. U.S.S.R. Phys. Ser. 21, 1423-1425 (1957).

1,2. A bent crystal (mica) spectrograph was used to study $\mathrm{Cu}, \mathrm{Zn}$, and their oxides and the spectra were photographically recorded.

3a. Oxidation increased the intensity of the lines due to the $4 \mathrm{~s}$ transition to the oxygen atom.

3b. The actual experimental spectra are presented.

(36)E

Smirnova, 1. S. and $K$. I. Narbutt, INVESTIGATION OF THE FINE STRUCTURE OF X-RAY ABSORPTION SPECTRA IN ALKALI HALIDES. (In Russian.) Izvest. Akad. Nauk S.S.S.R. Ser. Fiz. 21, 1375-1380 (1957).

Trans: Bull. Acad. Sci. U.S.S.R. Phys. Ser. 21, 1363-1368 (1957).

1. The fine structure of the $L_{3}$ absorption of iodine in Lil, $\mathrm{Nal}, \mathrm{Kl}, \mathrm{Rbl}, \mathrm{Csl}$ and of $\mathrm{Cs}_{5}$ in $\mathrm{CsF}, \mathrm{CsCl}, \mathrm{CsBr}$, and $\mathrm{Csl}$ was studied.

2. A curved crystal (quartz) spectrometer was used and the spectra were photographically recorded.

3a. The $L_{3}$ spectrum is a superposition of two series - the $s$ and $d$.

$3 b$. For the $d$ series of $C_{5}$, the principal quantum numbers are 1.41 and 1.55 based on the resul ts for Csl.

3c. All spectra and a graphical analysis of them are presented. 
(37)E

Tomboulian, D. H., D. E. Bedo and W. M. Neupert, $M_{2}, 3$ ABSORPTION SPECTRA OF THE ELEMENTAL SOLIDS Cr THROUGH Ge.

J. Chem. Phys. Solids 2, 282-302 (1957).

1. The elements $\mathrm{Cr}$ through Ge were studied in the 80-300A region; thin evaporated films were used as absorbers.

2a. A grazing incidence grating spectrograph was used and intensities were recorded photographically.

$2 b$. The radiation source was produced by a condensed discharge in a pyrex capillary.

3. All spectra and tabulated results including secondary structure and characteristic electron energy losses are presented.

(38) T

Trapeznikov, V. A., THEORY OF FINE STRUCTURE OF $X$-RAY ABSORPTION SPECTRA OF SOLIDS.

Fiz. Metal. i Metallovedne 2, 8-14 (1957). Trans: Phys. of Metals and Metallography 5, (1) $5-12$ (1957)

1. Temperature and concentration dependence of fluctuations in the fine structure are dlscussed.

2. Kostarev's theory was used.

4. Bonding forces can be studied by means of X-ray absorption spectra.

(39)E

Tsutsumi, K., A. Hayase and M. Sawada, FINE STRUCTURE OF X-RAY CU-K ABSORPTION SPECTRA OF CU IN COMPOUNDS.

J. Phys. Soc. Japan 12, 793-801 (1957).

1. Some 12 organo-metallics and inorganic $\mathrm{Cu}$ compounds were studied.

2. A standard Norelco diffractometer was used.

3. Actual spectra and tabular results are presented.

4. The observed fine structure is due to the immediate surroundings of the atom.

(40)E

Vainshteln, E. E. and Iu. N. Vasil'ev, THE INFLUENCE OF CHEMICAL BONDS ON THE FINE STRUCTURE OF TITANIUM K LINES IN COMPOUNDS. (In RUSSian.) Doklady Akad. Nauk S.S.S.R. 114, 53-56 (1957). Trans: Sov. Phys. "Dokl ady" $\underline{2}$, 207-209 (1957).

I. TiC and $\mathrm{TiWC}_{2}, \mathrm{TIN}, \mathrm{TIH}$, and $\mathrm{TiO}_{2} \mathrm{~KB}$ groups were studied with special emphasls on the $\mathrm{KB}_{5}$.

2. A curved crystal spectrograph (quartz) was used and intensitles were photographically recorded.

3. All spectra are shown but no bonding scheme is postulated.

(41)E

Vainshtein, E. E. and Iu. N. Vasil'ev, THE TITANIUM $K$ GROUP IN TITANIUM CARBIDE. (In Russian.) Dokl ady Akad. Nauk S.S.S.R. 114, 1-3 (1957). Trans: Sov. Phys. "Doklady" $\underline{2}, 251-254$ (1957).

1. Carbides wi th carbon content varying from $9-24 \%$ were studied.
2. A bent crystal (quartz) spectrograph wl th a dlsperslve power of $5.7 \mathrm{XU} / \mathrm{mm}$ was used; the observed second order intensities were recorded photographically.

3a. All spectra are presented.

3b. The separation of the $K \beta$ and $K \beta_{5}$ peaks was $7.9 \mathrm{eV}$ In carbides of different compositions.

Vasil'ev, lu. N., - See E. E. Vainshtein.

White, R., - See B. L. Henke.

(42) $E$

Zwerdling, S. and R. S. Hal ford, K ABSORPTION EDGES IN COMPLEXES OF $\mathrm{Cr}$, Mn, Fe AND Co. J. Chem. Phys. 26, 1758-1759 (1957).

1. Spectra for 10 complexes are given.

3. Is $\rightarrow 4 p$ can occur with and $w$ l thoyt change of the $3 d$ conflguration from $3 F$ to $3 p$.

(C-1) T

AdamS, E. N., DEFINITION OF ENERGY BANDS IN THE PRESENCE OF AN EXTERNAL FORCE FIELD. Phys. Rev. 107, 698 (1957).

1,3. An electron moving in a periodic potential perturbed by a weak electric field has different physical energy bands than it has when it moves In the absence of a field.

$(C-2) T$

Al tmann, S. L., C. A. Coulson and W. Hume-Rothery, ON THE RELATION BETUEEN BOND HYBRIDS AND THE METALLIC STRUCTURES.

Proc. Roy. Soc. (London) A-240, 145-160 (1957).

1. A qualitative means of determining the bondlng in FCC, HCP, and BCC type structures is presented.

3a. The metallic bond has certain directionality; this directionallty is related to symetries of known hybrid bonds.

3b. Hybrids of gerade and ungerade orbitals $\left(s p^{3}\right)$ bias the electron cloud to one side of the atom giving $\mathrm{rlse}$ to directional strong bonding; gerade orbitals double the possible number of I igands.

$(c-3) T$

Borovskii, I. B., and K. P. Gurov, THEORY OF SOLID SOLUTIONS. (In Russian.)

Fiz. Metal. i Metallovedne 4, 187 (1957). Trans: Phys. of Metals and Metallography 4 , (1) 154-5 (1957).

1,4. Electron energy spectra of solld solutions are discussed from the viewpolnt that impurities and temperature must be carefully controlled in order to get reproducible $\mathrm{X}$-ray results.

$(c-4) T$

Brout, $K$., WIDTH AND SHIFT OF SPECTRAL LINES DUE TO DISSIPATIVE INTERACTION.

Phys. Rev. 107, 664-668 (1957). 
$(c-4) T$ Cont'd.

1,3. The width of a spectral line is the difference in widths of the two microscopic states before and after the transition. The natural line width is the sum of the two states involved.

$(C-5) T$

Callaway, J. and E. L. Haase, ELECTRON ENERGY BANDS IN Cs.

Phys. Rev. 108, 217-221 (1957).

1. Energy levels are calculated and an estimate is made of the magnitude, at a nucleus, of the wave function of an electron on the Fermi surface.

2a. Orthogonal plane wave and cellular methods were applied to calculate the energy levels.

2b. The same crystal potential was used for all states and the wave functions of the core electrons for this potential were found.

3. Energies of 24 states at four Brillouin zone symetry points are calculated.

$(C-6) E$

Fairbrother, J. A. V., D. G. Parkyn and B. M. O'CONNOR, THE K-AUGER YIELO FOR TIN.

Proc. Phys. Soc. (London) 70A, 262-274 (1957).

1. The fluorescent yield uK is determined for Sn.

3. Burhop's probability values give $0.164 \pm 8 \%$ as the $\mathrm{K}$-Auger yield or $0.836 \pm 1.5 \%$ as uk.

4. One can compute Auger transition probability.

$(c-7) T$

Greiner, H., and E. Schaffer, SAYA'S THEORY OF THE CONCAVE GRATING SPECTROMETER. (I n German.) Optik 14, 263-276 (1957).

1. Concave grating spectrometers giving single reflections were investigated.

2. The Saya theory, providing a basis for a spectrometer design embodying fixed slits and a rotatable grating in order to vary the wavelengths is extended.

3a. An equation for the best angle between incident and reflected beams at small angles of grating rotation is derived.

3b. Focal curve plots for the angular defocusing vs. grating rotation are presented.

(C-8)E

Hanson, H. P. and J. Herrera, SELF-ABSORPTION IN

THE X-RAY SPECTROSCOPY OF VALENCE ELECTRONS. Phys. Rev. 105, 1483-1485 (1957).

1. Target self-absorption modified $K \beta_{5}$ emission profiles in $W, C u$, and Fe are presented.

2. Commercial Norelco equipment was used.

3a. Actual spectra are shown. 3b. The effect produces an exaggerated asymetry, depresses certain satellites, and produces an apparent coincidence of the absorption and enission edges.

$(c-9) T$

Lehman, G. H., ELECTRONIC PROPERTIES OF Th, U, AND PU-ENERGY BAND STRUCTURE OF METALLIC PHASES. U.S. At. Energy Comm. NAASR-1839, 50 pp. (1957).

1. Band data calculations are presented for Th, $U$, and Pu; numerical data are given for the three lowest bands in Th.

2a. A simplified Slater-Koster interpolation method based on a cellular model was used.

$2 b$. The energy matrix of the $6 \mathrm{~d}$ band in Th was constructed from Bloch sums and the energy levels were found to be doubly degenerate at every point in the zone.

3a. Spin=orbit interaction modifies energy levels at points of Brillouin zone symetry.

$3 \mathrm{~b}$. The $6 \mathrm{~d}$ bandwidth of Th is about $3.4 \mathrm{eV}$.

4. The valence electrons of Th occupy the $6 \mathrm{~d}$ band while those of $U$ and Pu occupy the $5 f$ and $6 \mathrm{~d}$ bands.

$(\mathrm{C}-10) \mathrm{T}$

Lomer, W. M. and W. Marshall, ELECTRONIC STRUCTURE OF METALS IN THE FIRST TRANSITION PERIOD. Phi 1. Mag. (8) 3, 185-203 (1957).

1. It is postulated that the electron distribution around atoms in a metal is greatly different from that in a free atom.

2. Using $X$-ray results, neutron diffraction data and magnetic measurements, an electronic structure is inductively reasoned.

3. Density of states data are proposed but no curves are given.

4a. Elements of atomic number less than $\mathrm{Fe}$ have few $3 d$ electrons and many conduction electrons; while for those above Fe, this situation is reversed. This seems to be the case no matter what the crystal structure or alloy composition may be.

4b. The variation of saturation magnetic moment of all the binary ferromagnetic alloys can be explained on this basis.

$(\mathrm{C}-11) \mathrm{E}$

Patronis, E. T., C. H. Braden and L. D. Wyly, FLUORESENCE YIELDS OF $\mathrm{Ni}, \mathrm{Cu}, \mathrm{Zn}, \mathrm{AND} \mathrm{Pb}$. Phys. Rev. 105, 681-682 (1957).

1,2. The source was a radioactive excitant; detector was a proportional counter.

\begin{tabular}{|c|c|c|}
\hline & & \\
\hline $\mathrm{Ni}$ & $\begin{array}{l}k \\
k\end{array}$ & $\begin{array}{l}0.33 \\
0.39\end{array}$ \\
\hline $\mathrm{Zn}$ & $k$ & 0.44 \\
\hline $\mathrm{Pb}$ & $L$ & 0.39 \\
\hline
\end{tabular}


$(\mathrm{C}-12) \mathrm{E}$

Sokolowski, E., C. Nordling, and K. Siegbahn, MAGNETIC ANALYSIS OF X-RAY PRODUCED AUGER ELECTRONS.

Arkiv Fysik 12, 301-318 (1957).

1. Photo-electrons expelled from thin evaporated layers of $\mathrm{Cu}$ were studied by $\mathrm{X}$-irradiation.

2. These were magnetically analyzed.

3a. Seven KLL-KLM Auger 1 ines were resolved.

3b. Peaks due to electrons having suffered discrete energy losses were observed on the low energy flanks of the photo lines.

$3 c$. Auger spectra and transition configurations are presented.

3d. $K$ and $L$ binding energies in Cu are $8985.5 \mathrm{eV}$ and $1 / 100 \mathrm{eV}$ respectively.

$(\mathrm{C}-13) \mathrm{E}$

Zinke, O. H., AUGER ELECTRONS IN MAGNESIUM. Phys. Rev. 106, 1163-1164 (1957).

1,3. Auger transitions in Mg are tabulated.

2. Mg was continuously evaporated onto the target surface at $3 \times 10^{-6} \mathrm{~mm} \mathrm{Hg}$ pressure in an $X$-ray tube equipped with a stainless steel anode and a gun to excite the Mg with 3-5 $\mathrm{kV}$ electrons at 5-20 ma: the Mg temperature was $345^{\circ} \mathrm{C}$.

$(\mathrm{C}-14) \mathrm{E}$

Zinke, 0. H., AUGER EFFECTS IN METALS. Univ. Microfilms PUBL 19976, 137 pp. (1957). Diss. abs. 17, 657 .

1. Secondary electron spectra were studied.

2. These spectra were induced by primary electron bombardment.

3. The effects of varying surface treatments on these spectra are discussed.

1958

(1) $\mathrm{E}$

Agarwal, B. K. and M. P. Givens, SOFT X-RAY $A B-$ SORPTION BY Mn AND $\mathrm{MnO}_{2}$.

J. Chem. Phys. Solids $\underline{6}, 178-179$ (1958).

1. Mn and $\mathrm{MnO}_{2}$ were studied between 45 and $60 \mathrm{eV}$.

2. Thin evaporated films 35-85 A thick were used as absorbers.

3a. $\mathrm{Mn}$ and $\mathrm{MnO}_{2}$ both showed an absorption edge near $50 \mathrm{eV}$.

3b. On the low energy side of the edge, $\mathrm{MnO}_{2}$ has a larger absorption coefficient than Mn; it is also noted that this effect is present for $\mathrm{Fe}_{2} \mathrm{O}_{3}$ over $\mathrm{Fe}$.

3c. Actual absorption spectra are shown and results are compared to those of Tomboulian.

(2)E

Beckman, 0., THE $K X$-RAY SPECTRUM OF MERCURY. Phys. Rev. 109, 1590 (1958).

1,3. K spectral observations in $\mathrm{Hg}$ are tabulated.

2a. A 2.5 meter radius bent crystal (quartz) spectrograph which focused rays on a slit $0.1 \mathrm{~mm}$ in front of an $\mathrm{Nal}$ scintiliation counter was employed.

2b. A Van de Graeff machine was used as a source of $600 \mathrm{kV}$ on the $\mathrm{X}$-ray tube.

2c. Measurements were taken for twelve hours after depositing $\mathrm{Hg}$ on a silver-amalgam anticathode.

(3) E

Borisov, M. D., V. V. Nemoshkalenko and A. M. Fefer, ELECTRONIC BAND STRUCTURE OF $\mathrm{Fe}-\mathrm{Cr}$ ALLOYS. (In Russian.)

Doklady Akad. Nauk S.S.S.R. 121, 264-267 (1958) Trans: Sov. Phys. "Doklady" $3,826-829$ (1958).

1. Pure $\mathrm{Fe}, \mathrm{Cr}$, and 35,45 , and $55 \mathrm{w} / \mathrm{o} \mathrm{Cr}$ alloys homogenized at $1150^{\circ} \mathrm{C}$ for 50 hours were studied; specimens were tablets sealed to the $X-r a y$ tube anode.

2. A bent crystal spectrograph was used in order to photograph $\alpha$ and $\sigma$ phase lines of the KB group in the third and fourth orders.

3a. Spectra, tables, and a diagram of overlapping $\mathrm{Cr}$ and $\mathrm{Fe}$ energy bands in $\mathrm{Fe}-\mathrm{Cr}$ alloys are presented.

3b. The energy band characteristics in the 600$1200^{\circ} \mathrm{C}$ temperature range are given.

3c. The Fermi energy in $\alpha \mathrm{Fe}-\mathrm{Cr}$ is $0.183 \pm 0.003$ $\nu / R$ and $i t$ is not concentration dependent.

4. The shape of the $K \beta_{5}$ band of a metal is determined by the distribution function of the states occupied by electrons in the conduction band.

(4) E

Brummer, O., KIKUCHI BANDS FROM SOFT X-RAYS AND INFLUEIICE OF CRYSTAL IMPERFECTION ON SUCH $X$-RAY INTERFERENCES. (In German.) Z. Naturforsch. 13a, 571-572 (1958).

1. Kikuchi patterns of etched $\mathrm{Fe}$ and $\mathrm{Al}$ single crystal spheres were produced.

2. A microfocus $X-$ ray tube wi th Mo or Pt anodes was used; lines were recorded on photographic plates held 0.8 to $40 \mathrm{~mm}$ from the anode.

3. Band intensities decrease with increasing crystal perfection.

4. Kikuchi bands are limited by short wave interference from continuous radiation.

(5)A

Catterall, J.A., L. F. Wilson and J. Trotter, SOFT $X$-RAY SPECTROSCOPY USING AN ELECTRON MULTIPLIER.

J. Sci. Instr. 35, 393-395 (1958).

1. A Be-Cu electron multiplier which was insensitive to radiation above 3000 A was used to record intensities in a grating spectrometer.

2a. Spectra were excited with 500-1000 volt electrons with 5-10 ma emission current at a pressure of $6-7 \times 10^{-6} \mathrm{~mm} \mathrm{Hg}$.

3a. The slit width of the photomultiplier was chosen as $0.1 \mathrm{~mm}$.

3b. A glass window was inserted in the spectrometer wall in order to observe the Rowland circle during the experiment. 
(6) $E$

Cotton, F. A. and H. P. Hanson, SOFT X-RAY ABSORPTION EDGES OF METAL IONS IN COMPLEXES. III. ZINC (1I) COMPLEXES.

J. Chem. Phys. 28 (1), 83-87 (1958).

1. The $\mathrm{K} X$-ray absorption edges of the $\mathrm{Zn}^{+2}$ ion in various complexes were measured.

2. A calcite double crystal X-ray spectrometer was used.

3. The significance of the fine structure of the $K$ absorption edges with regard to the stereochemistry and electronic structure of the complexes is discussed.

(7) $E$

Crisp, R. S., SOFT X-RAY $L_{2}$, EMISSICN SPECTRA OF Mg FROM SOLID AND EVAPORATED TARGETS. Australian J. Phys. 11, 449-452 (1958).

1. The $M g-L_{2}, 3$ was studied at $250 A$.

2. A one meter grazing incidence grating spectrograph equipped with a scraper to clean the solid metal surface was used; the electron gun was operated at $4 \mathrm{kV}$ with a target current of $4 \mathrm{ma}$. A maximum counting rate of 4000 counts/sec. was obtained.

3a. After 35-40 minutes of bombardment a brownish film was visible on the target due to the deposition of carbon from residual organic vapors.

3b. A spectrum is shown but no calculated density of states curve is presented.

3c. A constant spectral window was obtained.

(8)E

Deodhar, G. B. and A. N. Nigram, X-RAY $L_{3}$ ABSORPTION EDGES OF Pt AND AU IN COMPLEXES.

(In English.)

Naturwissenschaften 45, 309 (1958).

1. The wavelength of $\mathrm{L}_{3}$ edge in $\mathrm{Pt}$ and $\mathrm{Au}$ is tabulated for the materials studied.

3a. The effect of substitution is to shift the $L_{3}$ edge toward lower frequencies.

3b. The shift was greatest for $\mathrm{NaAuCl}_{4}, \mathrm{KAuCl}_{4}$, $\mathrm{K}_{2} \mathrm{Pt}(\mathrm{CN})_{6}$ and $\mathrm{K}_{2} \mathrm{PtCl}_{3}$.

(9) $E$

El-Hussaini, J.M. and S. T. Stephenson, SINGLECRYSTAL ORIENTATION EFFECTS IN K X-RAY ABSORPTION SPECTRA OF Ge.

Phys. Rev. log, 51-59 (1958).

1a. The extended fine structure on the short wavelength side of the edge was studied for three different orientations of the crystal.

1b. A single crystal of $7 \% \mathrm{Si}$ in Ge was also investigated. Data were taken to $60 \mathrm{eV}$ from the Ge-K edge and many changes noted.

2. For the Ge crystal, shifts in position of structure were observed between 75 and 280 eV from the edge; the polarization was only $7 \%$.

3. Observed shifts are tabulated.
(10)E

Fisher, P., R. S. Crisp and S. E. Williams, A PHOTON COUNTING SPECTROMETER FOR THE 50-1000A RANGE.

Optica Acta (Paris) 2, 31-39 (1958).

1. The apparatus is described in detail and preliminary spectra for $\mathrm{Mg}, \mathrm{Al}, \mathrm{Na}, \mathrm{Be}, \mathrm{Cu}, \mathrm{K}$, and $L i$, are shown.

2a. The instrument employs 1 m gratings of 570 or $1150 \mathrm{lines} / \mathrm{mm}(15,000$ and $30,000 \mathrm{lines} / \mathrm{in}$. respectively) at a $5^{\circ}$ grazing angle; a $\mathrm{Cu}-\mathrm{Be}$ photomultiplier with a potentiometer recorder is used for intensity determinations.

2b. Four kv electrons are used to excite the specimen; the specimen is scraped in vacuo to clean the surface.

3a. Curves of intensity vs. time are presented for various targets; contamination by oxygen and carbon is considered.

3b. Skinner's shape of the $\mathrm{Cu}-\mathrm{M}_{2}, 3$ band was obtained.

(11)A

Hanson, H. P. and R. Economy, CONTINUOUSLY ALIGNED GEARING SYSTEM FOR A SPECTROMETER. Rev. Sci. Instr. 29, 421-424 (1958).

1. A gearing system for a double crystal spectrometer which scans Bragg angles of $10-45^{\circ}$ continuously is described.

2. Appropriate angular changes of the components are effected through a planetary gear system.

3. Design and description are detailed.

(12)E

Hayashi, T., T. Nishimura and M. Suzuki, TEST FOR THE RESOLVING POWER OF A CURVED CRYSTAL SPECTROGRAPH.

Sci. Repts. Tohoku Univ. 41, First Ser. 183187 (1958).

1. The image of a $W$ wire was used to experimentally measure the resolving power of a quartz crystal spectrometer set in the Johann mounting.

2a. A 25 micron diameter $W$ wire was placed such that $i$ ts spectral image was formed at the central portion of the $K \alpha$, line of $\mathrm{Cu}$.

2b. Spectral images were obtained by photographic means; the spectrograms were analyzed microphotometrically.

3a. The half-width $\Delta \lambda$ of the $W$ image is found to be 1/40.6 of the interval between the $K \alpha_{1}$ and $\mathrm{K} \alpha_{2}$ of $\mathrm{Cu}, \mathrm{i} . \mathrm{e} ., \Delta \lambda=0.095 \mathrm{XU}$.

3b. For the $\mathrm{Cu}-\mathrm{K} \alpha_{1} \lambda / \Delta \lambda=1537 / 0.095=1.62 \times 10^{4}$ for the spectrometer investigated.

(13)E

Jacobs, E. S., X-RAY PHOTOELECTRIC SPECTRA FROM THIN METAL FILMS. Univ. Microfilms, PUBL MIC-58-3076, $105 \mathrm{pp}$. (1958). Diss. Abs. 19, 547. 
(13)E Cont'd.

1. The photoelectron spectra of $\mathrm{Ni}, \mathrm{Cu}, \mathrm{Rh}, \mathrm{Pt}$, and $\mathrm{Au}$ were measured and values for each peak tabulated.

2. Monochromatic $X$-rays were used to excite the target; this permitted only photoelectrons from the innermost shells of the surface atoms to escape.

3. A general relationship to predict relative efficiency of varying the wavelength of monochromatic $X$-radiation for the generation of photoelectrons from the surface of any material is given.

(14)E

Korsunskii, M. 1. and 1. A. Rumyantsev, LINES $L_{6}$ ANO $L_{5}$ in $X$-RAY SPECTRA OF COPPER ANO $Z$ ! NC. (In Russian.)

Issledovaniya. po Zharoproch. Splavam, Akad. Nauk S.S.S.R., Inst. Met. im. A. A. Baikova 3. 249-251 (1958).

Annotation from Chem. Abs. 55, $1176 \mathrm{~g}$.

1. Pure $\mathrm{Cu}$ and $\mathrm{Zn}$ were studied in order to establish the lines related to the transition of valence electrons.

3a. The short wave components of $L \alpha_{1,2}$ and $L \beta_{1}$ doublets are $65 \mathrm{XU}$ from the basic ${ }^{2}$ line.

3.j. These components are $L \beta_{6}$ and $L \gamma_{5}$ lines with transitions $L_{3}-N_{1}$ and $L_{2}-N_{1}$ respectively.

3c. The wavelength aifference between $L \alpha_{2}$ and $L \beta_{6}$ and also between $L Y_{5}$ and $L \beta_{1}$ is $4.6 \mathrm{eV}$ in $\mathrm{Cu}$ and $5.6 \mathrm{eV}$ in $\mathrm{Zn}$.

(15)E

Kotlyar, B. 1. and G. A. Shapi ro, INVESTIGATION OF THE KB GROUP OF THE X-RAY EMISSION SPECTRUM OF Mn AND CU IN SOME ALLOYS OF THE Cu-Mn AND Cu-Mn-Al SYSTEMS.

Nauch. Zap. Fiz. - mat. fak, Odessk, gos. ped. inst. 22, (1) 71-76 (1958).

Ref: Abstracts Journal of Metallurgy Part $A$, No. 1-2, 1961 Abstract \#46 (annotated from Abstract).

1. Binary $\mathrm{Cu}$ alloys containing 9.6 to 33.5 at. $\%$ $\mathrm{Mn}$, and ternary alloys containing (in at.\%) $22.7,24.6 \mathrm{Mn}$ and $3.2,24.6 \mathrm{Al}$, respectively, were investigated. The latter alloy corresponds to $\mathrm{Cu}_{3} \mathrm{MnAl}$ and is very ferromagnetic.

2. A Johann vacuum spectrograph was used, in a first order of reflection from the (1340) plane of quartz by primary method.

3a. The $\mathrm{MnK}_{1}$ wavelength in $\mathrm{Cu}_{2} \mathrm{MnAl}$ is displaced $0.61 \mathrm{eV}$ towards long wavelengths.

3b. The max displacement of $K \beta_{1}$ of $\mathrm{Cu}$ towards long wavelengths is observed for an alloy with 8.2 at.\% $\mathrm{Al}$. In this alloy the max displacement of $\mathrm{KB}_{5}$ of $\mathrm{Mn}$ is towards short wavelengths.

3c. For an alloy with 23.9 at.\% $\mathrm{Mn}$, the $\mathrm{KB}_{5}$ of $\mathrm{Cu}$ is displaced $0.94 \mathrm{eV}$ towards long wavelengths. Al (8.2 at.\%) added to a binary alloy displaces this line towards short wavelengths by $1.67 \mathrm{eV}$ compared wi th pure $\mathrm{Cu}$. In $\mathrm{Cu}_{2} \mathrm{MnAl}$ alloy this displacement towards short wavelengths is equal to $0.94 \mathrm{eV}$.

3d. For $\mathrm{Cu}_{2} \mathrm{MnAl}$ alloy, the wavelength of the $\mathrm{MnK} \mathrm{B}_{1}$ max is displaced $1.89 \mathrm{eV}$ towards long wave- lengths when passing through the curie point.

(16)E

Kotlyar, B. 1., X-RAY SPECTROSCOPIC INVESTIGATION OF MAGNETIC TRANSFORMATIONS IN HEUSLER ALLOYS. (In Russian.)

Nauch. Zapiski Kafidr. Mat. Fiz. i Estestvoznan Odess. Gosudarst. Pedagog. Inst. 22 (2) 60-61 (1958). Annotation from Referat. Zhur. Met. 1960 Abs. \#3625.

1. The $\mathrm{KB}_{5}$ line of $\mathrm{Mn}$ and $\mathrm{Cu}$ in $\mathrm{Cu}_{2}{ }^{\prime} \mathrm{MnAl}$ in the transition from ferromagnetic to paramagnetic states was investigated.

3. The short wave edge of the $K \beta_{5}$ shifted to higher energies in $\mathrm{Mn}$ and vice versa in $\mathrm{Cu}$ on transition to ferromagnetism.

4. This may be due to the transfer of some delectrons from $\mathrm{Cu}$ to $\mathrm{Mn}$.

(17) E

Lucasson-Lemasson, A., K AND L ABSORPTION SPECTRA OF COPPER IN VARIOUS ALLOYS. (In French.) Compt. Rend. (French Academy) 246, 94-97(1958).

1. The $L_{3}$ absorption spectrum of $\mathrm{Cu}$ alloyed with $\mathrm{Ni}, \mathrm{Zn}$ and $\mathrm{Al}$, and the $\mathrm{K}$ absorption spectrum of $\mathrm{Cu}$ alloyed with $\mathrm{Ni}$ and $\mathrm{Zn}$, pure $\mathrm{Cu}$ and $\mathrm{CuO}$ were studied.

2. A bent crystal (mica) spectrograph with a dispersive power of $83.5 \mathrm{eV} / \mathrm{mm}$ was used; intensities were recorded photographically.

3. No spectra are shown but all results giving the position and observed characteristics of the features studied are tabulated.

(18)E

Merrill, J. J. and J.W. M. DuMond. THE L X-RAY SPECTRA OF URANIUM AND PLUTONIUM. Phys. Rev. 110,79-84 (1958).

1,3a. L spectral data for $U$ and Pu are tabulated and compared wi th earlier work.

2a. A double crystal spectrometer was used.

2b. Target temperature was maintained at a constant value.

2c. All observed line breadths were corrected.

3b. A definition of the "X-unit" is given in an appendix.

(19)E

Nemnonov, S. A. and $V$. V. Kliushin, $L_{3}$ ABSORPTION SPECTRA OF CERIUM IN Ce-AI ALLOYS. (In Russian.) Fiz. Metal. i Metallovedne 6, $951-952$ (1958). Trans: Physics of Metals and Metallography $\underline{6}$, $183-185$ (1958).

1. The $L_{3}$ absorption edge in pure $\mathrm{Ce}, \mathrm{CeAl}_{2}$ and $\mathrm{CeAl}_{4}$ was studied.

2. An logani bent crystal (quartz $-38 \mathrm{~cm}$ radius) spectrograph with a linear dispersion of 2.48 $\mathrm{XU} / \mathrm{mm}$ was used.

3a. Spectra for $\mathrm{Ce}$ and $\mathrm{CeAl}_{2}$ are shown.

3b. The $2 p \rightarrow 5 d$ absorption line is displaced $1.6 \mathrm{eV}$ in $\mathrm{CeAl}_{2}$. 
(19)E Cont'd.

4. The main ce contribution to the bonding is due to $6 s$ and $5 d$ electrons.

(20)E

Nemnonov, S. A. and A. Z. Men'shikov, THE K ABSORP-

TION SPECTRUM OF CHROMIUM IN BORIDES, CARBIDES, NITRIDES, AND OTHER COMPOUNDS.

Trudy Seminara po Zharostoikim Materialam Akad. Nauk Ukr. S.S.R., Inst. Metallokeram. i Spetsial, Splavov, Kiev. 1958 (5), 21-27 (Pub.

1960). Annotation from Chem. Abs. 25, 12025b.

1. The $\mathrm{K}$ edge in pure $\mathrm{Cr}, \mathrm{Cr}_{2}\left(\mathrm{SO}_{4}\right)_{3}, \mathrm{CrCl}_{3}$, $\mathrm{Cr}_{2} \mathrm{O}_{3}, \mathrm{CrN}, \mathrm{CrB}_{2}, \mathrm{Cr}_{3} \mathrm{C}_{2}, \mathrm{CrB}, \mathrm{Cr}_{2} \mathrm{C}_{3}$, and $\mathrm{Cr}_{2} \mathrm{~N}$ was studied.

3. Bonding between $\mathrm{Cr}$ and the hard metalloids changes from ionic-covalent to covalentmetallic.

4. It is not possible to refer metalloids to a metallic state.

(21) $\mathrm{T}$

Parratt, L. G., NOTES ON THE PROSPECTIVE USE OF THE ORBIT RADIATION OF A HIGH ENERGY SYNCHROTRON IN X-RAY PHYSICS IN THE 0.1 TO 20A REGION. Office of Technical Services, PB135404, Tech. Note \#1, 14 pp. (1958).

1. Results of the classical predictions of Schwinger concerning electromagnetic radiation from high energy electrons in circular orbits were put into practical form for 40-800A. (See Tomboulian, Phys. Rev. 102, 1423-1477 (1956).

3. These results were extended to the 0.1-20A region and the total power radiated and the spectral distribution were calculated; beam geometry was discussed.

(22)E

Rudstrom, $L$. and $S$. Sjoberg, $L$ X-RAY ABSORPTION SPECTRUM OF Se AND Se OXIDE.

Arkiv Fysik 13, 297-302 (1958).

1. Metallic and vitreous $\mathrm{Se}$ and $\mathrm{Se}$ oxide were investigated at $7.5 \mathrm{~A}$.

2. A crystal spectrometer and photographic recording were used.

3a. Values for vitreous se and se oxide were in close agreement, but the Se metal edge was not.

3b. The energy shift between vitreous $\mathrm{Se}$ and Se oxide is $4.2 \mathrm{eV}$.

3c. Spectra and tabular data are presented.
(23) T

Sachenko, V. P., WIDTH OF INTERNAL LEVELS OF ATOMS. Uchenye Zapiski Rostov-Na-Donu Univ. 68 (8) 91-104 (1958). (In Russian.)

Annotation from Chem. Abs. 55, 14049 d.

1,3a. The widths of $k$ levels for $z=12-79$ and of the $L$ levels for $Z=22-47$ were obtained by interpolating experimental data.

3b. The basis for these interpolations is presented.

(24)E

Sakellaridis, P., ADSORPTION STATES IN K ABSORPTION SPECTRA OF COBALT. (In French.)

Compt. Rend. (French Academy) 247, 876-879 (1958).

1. The K absorption spectra of co in $\mathrm{CoSO}_{4} \cdot 7 \mathrm{H}_{2} \mathrm{O}$; $\mathrm{CoCl}_{2} \cdot 6 \mathrm{H}_{2} \mathrm{O} ; \mathrm{Co}\left(\mathrm{NO}_{3}\right)_{2} \cdot 6 \mathrm{H}_{2} \mathrm{O}$, and $\mathrm{Co}\left(\mathrm{CH}_{3} \mathrm{COO}\right)_{2}$ pure and adsorbed on $\mathrm{MgO}$ are compared.

3. The discontinuity of $K$ absorption of the co adsorbed on MgO shifts toward shorter wave lengths.

4. Adsorption on $\mathrm{MgO}$ is a chemical reaction.

(25)E

Sakellaridis, P., CHARACTERISTIC MULTIPLETS IN THE $X$-RAY EMISSION SPECTRUM OF ERBIUM. (In French) Compt. Rend. (French Academy) 247, 921-923 (1958).

1. The $L \beta$ and $L Y$ series in $E r$ were studled.

2. A curved crystal spectrometer was used.

3. The frequencies and wavelengths for all maxima are tabulated; intensity curves for the transitions $L_{1}-N_{1}, L_{1}-N_{4}, L_{3}-N_{5}$, associated wi th the $L \gamma_{10}, L \gamma_{9}$, and $L \beta_{14}$ respectively, are given.

4. The results can be attributed to the existence of an incomplete $4 \mathrm{f}$ layer, i.e., the $\mathrm{N}_{6}, 8$.

(26)E

Sakellaridis, P., MICROPHOTOMETRIC MEASUREMENTS OF $X$-RAY ABSORPTION IN RARE EARTHS. (In French.) Chim. Chronika 23, (8-9), 231-235 (1958).

1. The $L_{1}, L_{2}$, and $L_{3}$ absorption spectra of Eu, $\mathrm{Gd}, \mathrm{Tb}, \mathrm{Ho}, \mathrm{Er}$, and $\mathrm{Tm}$ combined as the $\mathrm{M}_{2} \mathrm{O}_{3}$ oxide were studied.

2. A curved crystal (mica) spectrograph was used; intensities were recorded photographically.

3. The exact wavelength values due to $L_{2}$ and $L_{3}$ 


\section{(26)E Cont'd.}

white ray satellites could not be located; no spectra are presented.

(27) $E$

Samylov, S. V., V. A. Tsukerman and I. S. Model, GLOW OF GASES IRRADIATED WITH SOFT X-RAYS. (In Russian.)

Zhur. Eksptl. i Teoret. Fiz. 34, 599-608 (1958)

Trans: Sov. Phys. "JETP" I, 414-420 (1958).

1. Plates of $\mathrm{Be}, \mathrm{Cu}, \mathrm{Mo}, \mathrm{Sn}$, and Pt were studied in a gas chamber containing air, A, or A-air, $\mathrm{N}$ or 0 mixtures.

2. An intensity of $600 \mathrm{r} / \mathrm{sec}$ was obtained wi th the tube at $50 \mathrm{kv}, 40 \mathrm{ma}, W$ anode, Be window, and gas chamber at $10 \mu \mathrm{Hg}$ pressure.

3. The gases glowed at the metal surface. A photograph of the airglow is shown.

4. The glow was attributed to electrons freed by $x$-rays which excited a thin gas layer at the metal surface.

Shapiro, G. A., - See 8. I. Kotlyar.

(28)T

Shi raiwa, T., T. I shimura and $M$. Sawada, THEORY OF FINE STRUCTURE OF X-RAY ABSORPTION SPECTRUM. J. Phys. Soc. Japan 13, 847-859 (1958).

1. The lifetime of the state of the electron ejected by absorption of a photon was considered.

2. Kronig's method for the molecule was used and applied to the solid; this gave reasonable transition probabilities.

3. Detailed calculations are given and results compared with tabulated experimental data.

(29)E

Sokolowski, E., C. Nordling and K. Siegbahn, CHEMICAL SHIFT IN iNNER ELECTRON LEVELS OF CU DUE TO OXIDATION.

Phys. Rev. 110, 776 (1958).

1. A preliminary discussion of the data presented in Ref. \#31 (1958) is given.

(30) E

Sokolowski, E., C. Nordling and K. Siegbahn, CHEMICAL SHIFTS IN INNER ELECTRON LEVELS IN A METAL RELATIVE TO ITS OXIDES. Arkiv Fysik 13, 483-500 (1958).

1. Thin (100A) evaporated layers of $\mathrm{Cu}, \mathrm{Cu}_{2} \mathrm{O}$ and CuO were studied.

2a. A magnetic analysis of $\mathbf{X}$-ray produced photoelectrons in these substances was performed.

2b. Electron diffractograms of the oxides were obtained in order to check their composition.

3a. Natural line widths changed with oxidation.

3b. A shift toward greater binding energies was observed in the order $\mathrm{Cu}_{2} \mathrm{Cu}_{2} \mathrm{O}, \mathrm{CuO}$; the shift is $4.4 \mathrm{eV}$ for $1 \mathrm{~s}$ and $2 \mathrm{~s}$ in CuO. 3c. The Cu0-KLL Auger line was much lower in energy than the Cu-KLL Auger I ine.

3d. Spectra and tabular data are presented, and transitions are discussed.

4. The K Auger yield may depend on the chemical composition of the source.

(31)E

Taft, E. A., PHOTOELECTRIC EMISSION FROM THE VALENCE BAND IN AgBr.

Phys. Rev. 110, 876-878 (1958).

1,3. For photoelectric emission in Ag8r, the threshold energy is about 6-7 eV and the band gap is $2.5 \mathrm{eV}$.

4a. The excited photoelectrons are scattered by the valence band electrons.

4b. The valence band lies $6 \mathrm{eV}$ below vacuum energy.

(32) E

Tomboulian, D. H. and D. E. Bedo, THE K-EMISSION SPECTRUM OF METALLIC LITHIUM. Phys. Rev. 109, 35-40 (1958).

1. The $K$ emission $(2 s \rightarrow K)$ spectrum of an evaporated $\mathrm{Li}$ target was investigated over a region of $60-600 \mathrm{~A}$.

2a. A grating spectrometer was used at $5.5^{\circ}$ grazing angle and intensities were photographically recorded; the vacuum was $2 \times 10^{-6} \mathrm{~mm} \mathrm{Hg}$.

2b. Li was excited with 600 volts and 100 ma which raised the temperature to $26^{\circ} \mathrm{C}$ below the $\mathrm{Li}$ melting point.

3. The band has a maximum at $229.50 \mathrm{~A}(54.02 \mathrm{eV})$, the distribution drops to half its maximum on the high energy side at $54.58 \mathrm{ev}$, and the decay intensity from the peak to the high-energy limit of the band occurs in an energy interval of $1.18 \mathrm{eV}$.

(33) E

Troneva, N. V., I. D. Marchukova and I. 8. Borovski, L-SERIES OF CERIUM IN $\mathrm{CeB}_{6}$ and $\mathrm{CeO}_{2}$.

Fiz. Metal. i Metallovedne 6 , 141-147 (1958). Trans: Physics of Metals and Metallography $\underline{6}$, 125-131 (1958).

1. $L_{3}$ absorption bands and $L \beta_{2} \beta_{10}$ emission 1 ines were studied.

2. A bent crystal (quartz) spectrograph was used and intensities were photographically recorded.

3a. Spectra and tabular data are presented.

3b. The effect of a chemical bond on the $x$-ray spectra was obtained for the rare earths.

3c. Transitions are discussed.

(34) $E$

Tsutsumi, K., FINE STRUCTURES OF X-RAY K ABSORPTION SPECTRA OF $\mathrm{NI}$ IN OXIDES OF $\mathrm{Wi}$. J. Phys. Soc. Japan 13 (6), 586-590 (1958). 


\section{(34)E Cont'd.}

1. $\mathrm{Ni}$ in $\mathrm{NiO}, \mathrm{Ni}_{2} \mathrm{O}_{3}$, and $\mathrm{NiO}_{2}$ in $\mathrm{H}_{2} \mathrm{O}$ were studied.

2. A bent crystal (quartz) spectrograph was used and the spectra were photographically recorded.

3a. The first absorption maximum increased in intensity with increasing oxygen content while other features of the spectra remained essentially unchanged.

3b. The results are tabulated and spectra are presented.

4. The results support the Coster and Kiestra theory of absorption spectra.

(35)E

Vainshtein, E. E., M. N. Bril and 1. B. Staryi, FINE STRUCTURE OF THE K ABSORPTION SPECTRA OF Ti IN TITANATES. (In Russian.)

Doklady Akad. Nauk S.S.S.R. 122, $201=204$ (1958). Trans; Sov. Phys. "Doklady" $3,947-948$ (1958).

1. Titanates of $\mathrm{Mg}, \mathrm{Ca}, \mathrm{Ba}, \mathrm{Sr}, \mathrm{Fe}$, and $\mathrm{Zn}$ were studied.

2. A bent crystal (quartz) spectrograph was used to study absorbers $3-14 \mathrm{mg} / \mathrm{cm}^{2}$ thick; spectra were recorded photographically.

3a. The long-wave absorption band resulting from is electron transitions to $3 d$ free levels is a singlet.

3b. All spectra are presented.

4. In perovskite types, the $\mathrm{Ti}$ edge depends strongly on the polarization of atoms in the compound.

(36)E

Vainshtein, E. E., I. B. Staryi and E. A. ZhurakovSKI $i$, THE FINE STRUCTURE OF TITANIUM K ABSORPTION SPECTRA IN CARBIDES. (In RUSSian.)

Dokl ady Akad. Nauk S.S.S.R. 122, 365-366 (1958)

Trans: Sov. Phys. "Doklady" $3,960-961$ (1958).

1. Titanium with a carbon content varying from $12-24 \%$ and also $\mathrm{TiO}_{2}$ were studied.

2. A bent crystal (quarts) spectrograph was used; intensities were recorded photographically.

3. The fine structure of the titanium $K$ absorption remains unchanged over the range of carbon contents where a single phase FCC metallic atom lattice exists.

4. The bonds in TiC are not metallized.

1958 (c)

$(c-1) T$

Bilz, H., ELECTRONIC STATES OF HARD SUBSTANCES WITH THE NACI STRUCTURE. (In German.) Z. Physik 153, 338-358 (1958).

1. Band structure data for MX compounds of the transition metals is presented.

2. The one electron model was used for hard phase electronic bands.

3a. Band structure data and bonding models are shown.

3b. Calculated data for $T i, Z r, H f, V, C b, T a$ and their carbides, oxides, and nitrides are tabulated and compared with experimental results where possible.

$(C-2) T$

Brooks, H., and F. S. Ham, ENERGY BANDS IN SOLIDSTHE QUANTUM DEFECT METHOD

Phys. Rev. 112, 344-361 (1958).

1. Electron energy bands in $\mathrm{Na}, \mathrm{Li}, \mathrm{K}, \mathrm{Rb}$, and Cs were calculated from spectroscopic data for the free atom.

2a. Explicit construction of one-electron potential was avoided in representing the interaction between valence and core electrons.

2b. Interaction between the valence electrons and an ion in the crystal was assumed to be about the same as in the free atom.

3. Tables of the data including improved polarization corrections are given.

\section{$(c-3) T$}

Callaway, J., ELECTRON ENERGY BANDS IN SODIUM. Phys. Rev. 112, 322-325 (1958).

1. Energy levels of $s$ and $p$ type symmetry were determined at four points in the Brillouin zone.

3. The potential energy of valence electrons is represented in $\mathrm{Na}$ by: $V(r)=-2 / r+A[\exp (-\beta r) / r]$, $A[\exp (-\beta r) / r]$ is repulsive and represents core electrons, $A$ and $\beta$ are obtained from spectral data.

$(C-4) E$

Chupp, E. L., J. W. M. DuMond, F. J. Gordon, R. C. Jopson and H. Mark, K SERIES X-RAY WAVELENGTHS IN RARE EARTH ELEMENTS. Phys. Rev. 112, 1183-1186 (1958).

1. The K series in Nd, Sn, Gd, Tb, Dy, Ho, Er, $T m, Y b$, Lu was studied.

2. A 2-meter radius bent crystal (quartz) spectrograph was used, wi th photographic recording, and a $3.7 \mathrm{MEV}$ proton accelerator for excitation.

3a. $K \alpha_{1}, K \alpha_{2}, K \beta_{1}$, and $K \beta_{3}$ lines are tabulated. 3b. Weak transitions, $\mathrm{KB}_{5}{ }^{3}$ and $\mathrm{K}_{2} \mathrm{O}_{3}$, were found.

$(C-5) \mathrm{T}$

Deslattes, R. D., 3d ELECTRONS IN TRANSITION METALS. Phys. Rev. 110, 1471 (1958).

1. The Weiss-DeMarco data (Ref. \#C-24, 1958) are discussed.

$(c-6) T$

Dutta, A. K., SOFT X-RAY EMISSION SPECTRUM OF GRAPHITE AND THE SUGGESTION OF A SUITABLE BRILLOUIN ZONE FOR IT.

Indian J. Phys. 32, 397-399 (1958).

1. Skinner's spectrum for graphite was used.

3. The 4 electron zone was suggested as most suitable.

4. Known $\sigma$ and $\pi$ electron interaction in $\mathrm{C}-\mathrm{C}$ bonds of graphite supports the 4 electron zone view. 
(c-7) T

Flodmark, S., ELECTRON DISTRIBUTION AND ENERGY BANDS IN CRYSTALS OF METAL BORIDES OF THE TYPE MB 6 .

Arkiv Fysik 14, 513-550 (1958).

1. The distribution of the boron valence electrons in $\mathrm{MB}_{6}$ metal borides is described.

2a. Hybridized $s, p$ and d orbitals of the atomic $L$ and $M$ shells were used to construct Bloch wave functions.

2b. The one-electron approximation equations were solved numerically.

3a. Energy eigenvalues and eigenvectors for bonding orbitals in L and LM approximations are tabulated.

3b. Several diagrams of the $\mathrm{MB}_{6}$ bonding orbitals and structures are shown; an energy level diagram is al so included.

4. The M shell orbitals are essential for many of the strongly bonded orbital sites.

$(c-8) T$

Friedel, J., ELECTRONIC STRUCTURE OF TRANSITION METALS AND ALLOYS AND OF HEAVY METALS.

(In French.)

J. Phys. Radium 19, 573-581 (1958).

1. Electronic structures of transition metals dissolved as impurities in Cu or Al are discussed and these metals are compared with those of the $4 \mathrm{f}$ and $5 \mathrm{f}$ series.

4. Magnetic properties of transition metals and rare earths are the result of an equilibrium of exchange couplings.

$(C-9) E$

Gauthe, B., ENERGY LEVELS OF ELECTRONS PASSING THROUGH METAL FOILS - COMPARISON WITH RESULTS OF X-RAY SPECTROSCOPY. (In French.) Ann. Phys. (13) 3, 915-964 (1958).

1. Selected metal foils were studied to find if a relation exists between spectral distribution of energy losses observed in electrons and the absorption pattern of X-ray spectra.

3. Two elementary interactions producing energy losses exist - individual collisions and plasma oscillations.

4a. Correspondence of the X-ray absorption maximum with respect to the peak of the emission band and the value of the electron loss indicates individual character originating in the elementary interaction.

4b. Non-correspondences indicate plasma oscillations.

$(\mathrm{C}-10) \mathrm{T}$

Horak, Z., CALCULATIONS OF EXCITED STATES OF ATOMS. Czech. J. Phys. 8, $271-276$ (1958). (In English.)

1. Approximate wave functions of the excited states of a many electron atom and also the $K$ $X$-ray state of neon were calculated.

2a. The many electron calculations were made by means of the extremalization of the variation functional.

2b. The X-ray state calculations were made by radial wave functions in Morse's analytical form.
4. The method can be used to interpret some results of soft $X$-ray spectroscopy.

$(\mathrm{c}-11) \mathrm{T}$

Kittel, C. and W. Marshall, 3d ELECTRONS IN IRON. J. Chem. Phys. Solids 6 , 99 (1958).

1,2. The Weiss-DeMarco data (Ref.\#C-24, 1958) is discussed in terms of spectroscopic splitting factor $(g)$ and the magneto-mechanical ratio $\left(g^{\prime}\right)$.

4. It may be possible to reconcile $(g-2)$ and $\left(2-g^{\prime}\right)$ values from other sources with the Weiss-DeMarco data.

$(C-12) T$

Lesnik, A. G., INTERATOMIC INTERACTION IN Fe-Cr SYSTEM ALLOYS. (In Russian.)

Dokl ady Akad. Nauk S.S.S.R. 122, 385-388 (1958).

Trans: Sov. Phys. "Doklady" 3, 1006-1009 (1958).

1. It was hypothesized that the formation of a polar state of atoms in alloys occurs.

2. Statistical theory was used to support this hypothesis.

3. Features of the disintegration of the solid solution accompanied by separation of an intermetallic compound of the $\sigma$ phase type are postulated.

$(\mathrm{C}-13) \mathrm{T}$

Mokhov, V. N. and M. G. UrIn, AUGER EFFECT IN HEAVY ATOMS. (In Russian.)

Zhur. Ekspt1. Teoret. Fiz. 30, 209-210 (1958). Trans: Sov. Phys. "JETP" 3, 133 (1958).

1. A new equation for $w_{k}$, the coefficient of the Auger effect, was derived.

3. For $\mathrm{Ag}$, the formula gives $\mu_{k}=1.14 \times 10^{6}$ and experiment gives $\omega_{k}=1.12 \times 10^{6}$.

$(\mathrm{c}-14) \mathrm{T}$

Morin, F. J., OXIDES OF 3d TRANSITION METALS. Bell System Technical Journal 37, 1047-1084 (1958).

1. Magnetic, electrical, and optical properties were examined in 3d metal oxides and an energy band scheme is proposed for the oxides of Sc, $T i$, and $V$, suggesting that the non-bonding $3 d$ orbitals of neighboring cations overlap to form a $3 d$ conduction band.

3a. The 3d orbitals do not overlap in the other $3 \mathrm{~d}$ elements, so that the $3 \mathrm{~d}$ electrons are in isolated energy states and electron transport occurs by electron exchange between cation neighbors and involves an activation energy.

3b. Energy level diagrams are presented.

$(C-15) T$

Onaka, R., GRATING MOUNTING FOR A VACUUM ULTRAVIOLET MONOCHROMATOR. Science of Light (Tokyo) Z, (2) 23-27 (1958).

1,3a. The rotation of a concave grating about a point displaced from the center of the grating is applicable to a monochromator of any angle of deflection. 
(c-15) Cont'd.

3b. A general analysis of such a mounting is presented and its usefulness down to $510 \mathrm{~A}$ is illustrated.

3c. The optical arrangement for the monochromator is presented.

(C-16) T

Pearson, W. B., GROUP VB TO VIIB INTERMETALLIC CRYSTAL STRUCTURES.

J. Chem. Phys. Solids I (1), 65-77 (1958).

1. Crystal structures of VB and VIlB elements and compounds are discussed on the basis of valence bond theory.

2. A bond scheme is proposed and it is used to derive qualitative bond structures for these elements.

3a. The derived bond structures deviate from the usual semiconductor model.

3b. Bonding is discussed in detail.

$(C-17) \mathrm{T}$

Plass, G. N., MODELS FOR SPECTRAL BAND ABSORPTION. J. Opt. Soc. Am. 48, 690-703 (1958).

1. Models used to represent band absorption are compared and regions of validity for each model are given.

3. Absorption of a statistical model including effects of overlapping is shown to depend only on an average equivalent width for a single line.

(C-18)T

Robins, D. A., BONDING IN CARBIDES, SILICIDES AND BORIDES.

Powder Metallurgy $1958(1,2) \quad 172-188$.

1. A relationship between the coordination of the metal atoms and the number of bonding electrons per atom is proposed.

3a. The crystal structure and stability of carbides is discussed in terms of the electron concentration.

3b. In silicides $5 i-s i$ bonds are important; in the disilicides no metal-metal bonds remain.

3c. Boron-boron bonds are responsible for boride bonding.

3d. Tables of calculating parameters are presented.

$(\mathrm{c}-19) \mathrm{T}$

Takeishi, Y., AUGER EJECTION BY NICKEL.

J. Phys. Soc. Japan 13, 766 (1958).

1. The total electron yield for $\mathrm{He}^{+}, \mathrm{Ne}^{+}, \mathrm{A}^{+}$, and $\mathrm{Xe}^{+}$was computed.

3a. Results are tabulated.

3b. Secondary electrons are discussed.

$(C-20) T$

Tomboulian, D. H. and D. E. Bedo, SPECTRAL CHARACTERISTICS OF THE RADIATION EMITTED BY ELECTRONS ACCELERATED IN A SYNCHROTRON.

J. Appl. Phys. 29 (5) 804-809 (1958).

1,2. Expressions were developed for the average power radiated by a high-energy electron moving in a circular orbit. The instantaneous electron energy $E(t)$ is assumed to vary with the time in accordance with $E(t)=E_{m} \sin ^{2}$ $(\pi t / 2 T)$.

3a. The results are presented in a form which is applicable to any synchrotron in which the time dependence of electron energy is as stated above.

3b. Spectral distributions are obtained corresponding to the radiation emitted over a partial or full acceleration interval.

$3 c$. The numerical results predicted from the general relations are examined for a particular value of the peak energy $E_{m}=6.0 \mathrm{Bev}$ and the orbital radius $R=86.14 \mathrm{ft}$. In the case of these parameters, the continuous spectrum attains a peak at $0.36 \mathrm{~A}$.

4. Calculations related to the case where the radiation is collected only over the lowenergy portion of the acceleration interval, indicate that it is feasible to utilize the continuum as a source for measurements in problems of interest to astrophysics and solid state spectroscopy.

$(C-21) \mathrm{T}$

TOYOzawa, Y., LINE SHAPES OF EXCITON ABSORPTION BANDS.

Prog. Theoret. Phys. (Kyoto) 19, 214 (1958).

la. Theoretical considerations and experimental difficulties are discussed.

1b. Earlier work is reviewed.

$(C-22) \mathrm{T}$

Toyozawa, Y., LINE SHAPES OF EXCITON ABSORPTION BANDS.

Prog. Theoret. Phys. (Kyoto) 20, 53-81 (1958).

1. The general theory of these line shapes is developed.

2. A generating function method is used.

3a. The absorption band is Lorentzian if the temperature is not too high and the coupling is weak.

3b. If the coupling is strong and the temperature is high, the band is Gaussian.

$(C-23) T$

Trost, W. R., ORBITAL THEORY IN THE TRANSITION METALS.

Canadian Dept. Mines Tech. Surveys, Mines Branch Res. Repts. R42, 77 Pp. (1958).

1. See Ref.\#C-25 (1959) for annotation.

$(C-24) E$

Weiss, R. J. and J. J. Demarco, 3d ELECTRONS IN $\mathrm{Cu}, \mathrm{Ni}, \mathrm{Co}, \mathrm{Fe}$, and $\mathrm{Cr}$.

Revs. Modern Phys. 30, 59-62 (1958).

1. Data on 3d electron population in the iron group transition metals is presented.

2a. Absolute $X$-ray scattering factors are measured.

2b. The argon core as calculated by the selfconsistent field method for the free atom is subtracted from the measured scattering data leaving only the unbound electron contribution.

3a. The radial extension of 45 and $4 p$ electrons is such that all their scattering factors are negligible at all Bragg angles; this leaves 
(c-24)E Cont'd.

only the $3 d$ contribution.

$3 b$. The $3 d$ populations found are tabulated.

1959

(1) $E$

Bally, D. and L. Benes, FINE STRUCTURE OF X-RAY ABSORPTION DISCONTINUITIES OF NICKEL AND IRON IN Ni-Fe ALLOYS. (In French.) Compt. Rend. (French Academy) 248, 2327-2329 (1959).

1. Alloys ranging from $50-100 \% \mathrm{Ni}$ were studied.

2. A bent crystal (mica) spectrograph was used in the second order and intensities were photographically recorded.

3. Results are tabulated but no spectra are shown; nine features of the observed spectra are listed.

(2) $E$

Bally, D. and L. Muller, FIINE STRUCTURE OF THE K ABSORPTION EDGE OF NICKEL AND IRON IN NI-Fe ALLOYS AT LOW TEMPERATURES. (In French.) Compt. Rend. (French Academy) 249, 1099-1101 (1959).

1. The fine structure was determined at $113^{\circ} \mathrm{K}$.

2. A crystal spectrograph was used.

3a. For the Fe-Ni alloys a general shift of the $\mathrm{K}$-absorption structure towards longer wavelengths was observed.

3b. Detailed results are tabulated.

(3) $E$

Bedo, D. E. and D. H. Tomboulian, THE M 2,3 EMISSION BAND OF COPPER.

Phys. Rev. 113, 464.-470 (1959).

1. The $M_{2,3}$ band in thin evaporated films of high purity $\mathrm{Cu}$ was studied.

2a. A grating spectrometer was used at grazing incidence with 200 ma at $1500 \mathrm{~V}$ ( 300 watts) power input to the target which was at a pressure of $10^{-6} \mathrm{~mm} \mathrm{Hg}$.

2b. Fresh Cu was put down every 15 minutes, and the total time for the photographic exposure was 6 hours.

3a. The distortion of the band due to window effects, self-absorption, the presence of contaminants, and the nature of the target is discussed as are satellites.

3b. Spectra are shown and data are tabulated: The band has a maximum at $72 \mathrm{eV}(172 \mathrm{~A})$, and a width of $7.8 \mathrm{ev}$; at the high energy end the intensity rises gradually and no sharp bands are noticeable.

(4) $E$

Bonnelle, C., L SPECTRA OF COPPER IN $\mathrm{Cu}_{2} \mathrm{O}$ and CuO. Compt. Rend. (French Academy) 248, 2324-2326 (1959). (In French.)

1. Both the emission and absorption spectra were studied.

2. A curved crystal spectrometer was used. 3a. The $L \alpha$ is narrower and displaced $0.7 \mathrm{eV}$ toward lower energies in $\mathrm{Cu}_{2} \mathrm{O}$ as compared with $\mathrm{Cu}$.

3b. In CuO, the displacement is $0.3 \mathrm{eV}$ toward lower energies.

(5) $E$

Borisov, M. D. and V. V. Nemoshikalenko, THE STRUCTURE OF THE ENERGY SPECTRA OF ELECTRONS IN $\mathrm{Fe}-\mathrm{Cr}$, AND Fe-Cr-Ni ALLOYS. (In Russian.) Fiz. Metal. i Metallovedne 8, 211-215 (1959). Trans: Physics of Metals and Metallography 8 (In Process)

1. The $K \beta_{5}$ line of $\mathrm{Cr}, \mathrm{Fe}$, and $\mathrm{Ni}$ and also the $K \beta_{1}$ were studied.

2. A crystal spectrometer was used.

3a. The $\mathrm{K}_{5}$ is dependent upon electron transitions from the conduction band to the $K$ level, and the $K B_{l}$ is dependent upon electron transitions from the $3 p$ level to the $K$ level.

3b. The Fermi energies of $\mathrm{Fe}-\mathrm{Cr}$ alloy and Fe-Cr-Ni alloy were $0.19 \mathrm{~V} / \mathrm{R}$ and $0.22 \mathrm{~V} / \mathrm{R}$ respectively.

(6) T

Borovski i, I. B. and K. P. Gurov, EFFECT OF IMPURITIES ON X-RAY SPECTRA OF TRANSITION METALS. (In Russian.)

Zhur. Eksptl. i Teoret. Fiz. 36, 1203-1206 (1959).

Trans: Sov. Phys. "JETP" 2, 856-858 (1959).

1. Regional perturbation is created from impurity charges in the electron shells of transition metals. This amounts to induced surplus charge, opposite in sign to that of the impurity and forming a dipole with it.

2. An integral equation is set up for this surplus charge.

3. This equation is applied to the particular case of $\alpha-\mathrm{Fe}$.

(7) $E$

Borovskii, I. B. and K. P. Gurov, ELECTRONIC SPECTRA OF DILUTE SOLID SOLUTIONS. (In Russian.) Fiz. Metal. i Metallovedne I, 225-284 (1959). Trans: Physics of Metals and Metallography $Z$, (2), 61-70 (1959).

1. $\mathrm{Cr}$, and $\mathrm{Pb}-\mathrm{Sn}$ and $\mathrm{Cr}-\mathrm{Mo}$ alloys were studied at $-196^{\circ}$ and $300^{\circ} \mathrm{C}$ by investigating the $\mathrm{K}$ absorption spectrum of these materials.

2. A bent crystal transmission spectrograph with a dispersive power of $4 \mathrm{XU} / \mathrm{mm}$ was used; intensities were recorded photographically.

3a. Addition of Mo to $\mathrm{Cr}$ increased the energy of $\mathrm{M}_{2,3}$ levels in $\mathrm{Cr}$ and did not affect the $\mathrm{K}$ spectrum.

3b. An atom block formation is postulated for dilute solid solutions at $0^{\circ} \mathrm{K}$.

4. The formation of interatomic bonds in alloys causes energy state distribution changes for the valence shell, and thermal vibrations exert a very large influence on the entire electron-energy spectrum.

(8)E

Borovski i, I. B. and $V$. V. Shmidt, INVESTIGATION OF THE TEMPERATURE DEPENDENCE OF THE FINE STRUCTURE OF THE MAIN K EDGE IN THE ABSORPTION SPECTRUM OF IRON. (In Russian.) 


\section{(8)E Cont'd.}

Doklady Akad. Nauk S.S.S.R. 127, 997-1001 (1959). Trans: Sov. Phys. "Doklady" 4 , $855-858$ (1960).

2. A double crystal (calcite) spectrometer was used in the $(1,+1)$ position to study $7 \mathrm{micron}$ iron foils heated by self-resistance at $5 x$ $10^{-6} \mathrm{~mm} \mathrm{Hg}$ pressure; spectra were recorded electronically.

3a. The energy loss of an electron was $7.5 \pm 0.7$ $\mathrm{eV}$ for $\alpha-\mathrm{Fe}$ and $1.0 \pm 0.6 \mathrm{eV}$ for $\gamma-\mathrm{Fe}$; these values were temperature independent.

3b. Actual and corrected spectra are shown.

4. The fine structure of the short wave region and $i$ ts temperature dependence can be ascribed to the excitation of plasma oscillations in the electron cloud of the metal.

(9) $E$

Catterall, J. A. and J. Trotter, INTERPRETATION OF $X$-RAY EMISSION SPECTRA.

Phil. Mag. (8) 3, 1424-1431 (1959).

1. The $K$ satellite emission bands in $\mathrm{Li}$ and $\mathrm{Be}$ were studied.

2. A grating spectrometer was used and the spectral intensities were recorded by means of a $\mathrm{Be}-\mathrm{Cu}$ photomultiplier.

3. There is probably a hole occurring in the core-level when the soft $\mathrm{X}$-ray emission process takes place.

4. This hole is unlikely to have a great effect on the intensity distribution of the spectra.

(10)E

Catterall, J.A. and J. Trotter, SOFT X-RAY EMISSION SPECTRA FROM LITHIUM AND Li-Mg ALLOYS. Phil. Mag. (8) 4, 1164-1170 (1959).

2. A grating spectrometer was used at grazing incidence and photons were counted with a Be-Cu photomultiplier.

3a. In the alloys, electron transfer took place from $\mathrm{Mg}$ to $\mathrm{Li}$.

3b. The shape of the high energy edge of the $L i-K$ emission spectrum was explained by broadening of the Is ionic level in the crystal.

(11)E

Callon, P., STUDY OF THE K-EMISSION BAND OF MAGNESIUM. (In French.)

Compt. Rend. (French Academy) 248, 19851987 (1959).

1. Both metallic $\mathrm{Mg}$ and $\mathrm{MgO}$ were studied.

2. A curved crystal $(25 \mathrm{~cm}$. radius mica in the second order) spectrograph was used and intensities were photographically recorded.

3a. Spectra and tabular results are presented.

3b. oxide and metal bands are compared and effects of oxidation on the emission band of metallic Mg were found.

(12)E

Callon, P., EMISSION LB 2 AND ABSORPTION $L_{3}$ OF MOLYBDENUM. (In French.) Compt. Rend. (French Academy) 248, 20852087 (1959).
1. Samples of $1000 \mathrm{~A}$ films of Mo evaporated on to Al supports were studied.

2. A curved crystal spectrograph was used and intensities were photographically recorded.

3a. The half-width value of the $L B_{2}$ diminished as the excitation potential was increased; the hal f-width maximum was $5 \pm 0.2 \mathrm{eV}$ with an index of asymmetry of 1.2 .

3b. Superimposed on the $L \beta_{2}$ was a strong "whi te" line attributed to vacancies in the $4 \mathrm{~d}$ band.

3c. The minimum was $6 \mathrm{eV}$ from the $L \beta_{2}$ peak.

(13) E

Collet, V., THE $L_{3}$ X-RAY ABSORPTION SPECTRA OF COMPLEX SALTS OF PLATINUM. (In French.) Compt. Rend. (French Academy) 248, 1314-1316 (1959).

1. Some 20 complex salts of Pt were studied.

2. A special $X$-ray tube at $20 \mathrm{kV}, 7.5 \mathrm{ma}$ equ i pped with a Ta target was used; the spectra were recorded photographically.

3. All results are tabulated.

$(14) E$

Collet, $V .$, CONTRIBUTION TO THE STUDY OF THE NATURE OF TRANSITION METAL COMPLEXES BY X-RAY SPECTROGRAPHY. (In French.)

These Doct. Sci. Phys. Paris 1959, 52 pp. (1959)

1. The $K$ spectra of $\mathrm{Ni}, \mathrm{CO}$, and the $L$ spectra of $\mathrm{Pt}, \mathrm{Au}$, and Re in complexes were studied.

2. A Cauchois (bent crystal) spectrograph was used; intensities were recorded photographically.

3. The electronic configuration for the transition metals when they are in complexes was determined.

(15) E

Deslattes, R. D. and H. S. DeBen, THE K ABSORPTION EDGE OF SELENIUM.

Phys. Rev. 115, 71-74 (1959).

1. Thin unsupported films of Se which had been evaporated on to rock salt and which were amorphous were investigated.

2. A double crystal (quartz) spectrometer was used; intensities were measured with a $\mathrm{Nal}$ scintillation counter.

3. The gap energy is about $4 \mathrm{eV}$ indicating that the lower portion of the conduction band contains low p type symmetry.

4. The edge absorption maximum arises from transitions to $x$-ray excitation states in the region of the forbidden energy gap.

(16) E

Dowdey, J.E., FINE STRUCTURE OF THE X-RAY ABSORPTION EDGE OF CUBIC FERRITES.

Univ. Microfilms MIC-59-154, 99 PP. (1959). Diss. Abs, 12, 2365.

1. The $\mathrm{M}-\mathrm{Fe}_{2} \mathrm{O}_{4}$ spinel structure type ferrites were studied.

2. A double crystal spectrometer equipped wi th a scaler was used to obtain intensities. 


\section{(16)E Cont'd.}

3. The fine structure is interpreted as a composite of electron transitions from is to $3 d$, 45, 4p, and np levels.

4. Hybridization of the orbitals gave some $p$ character to the $3 \mathrm{~d}$ and $4 \mathrm{~s}$ bands so that no violation of the selection rules occurred.

(17) $\mathrm{T}$

Dutta, A. K., AN ANALYSIS OF THE SOFT X-RAY EMISSION SPECTROSCOPY OF GRAPHITE AND AN APPROPRIATE ELECTRONIC PICTURE OF IT. Proc. Phys. Soc. (London) 24, 604-608 (1959).

2. Skinner's soft $X$-ray spectrum for graphite was used in performing the analysis.

3a. The Brillouin zone is bounded by two independent sets of planes with overlapping electrons (into the next zone).

3b. The total bandwidth is $24 \pm 3 \mathrm{eV}$.

4. The zone is of the four electron variety because a correlation of $k$ states with the sof $t$ $x$-ray spectra gives the correct value for the Fermi surface boundary.

(18)E

DYSOT, N. A., CONTINUOUS X-RAY SPECTRUM FROM ELECTRON OPAQUE TARGETS.

Proc. Phys. Soc. (London) 73 (6) \#474, 924-936 (1959).

1. The angular and energy distributions for the continuous $x$-ray spectrum were investigated in the forward hemisphere.

2a. Exciting voltages were 6 and $12 \mathrm{kv}$.

2b. The technique and conditions are carefully described.

3a. The angular distribution was greatly affected by $X$-ray scattering.

3b. The absolute efficiency of $x$-ray production was $20 \%$ greater than that predicted by the Compton-Allison formula.

3c. The results are tabulated.

(19)E

Guseva, L. N. and B. I. Ovechkin, ATOMIC SCATTERING OF X-RAYS IN SOLID SOLUTIONS OF COPPER AND NICKEL. (In Russian.)

Izvest. Akad. Nauk S.S.S.R. - Otdel. Tekh. Nauk, Met. i Toplivo 1952 (2), 82-85.

Annotation from Chem. Abs. $23-17661$.

1. Only the technique is discussed - data are not interpreted.

2. Data are obtained from $X$-ray powder photograms taken by the exchange method at angles of $20,35,40$, and $60^{\circ}$ at $2-3$ hour exposure times.

(20)E

Hayashi, T. and H. Kawaharada, CRITICAL POTENTIALS OF SOFT X-RAYS EMITTED FROM IRON.

Sci. Repts. Tohoku Univ. First Ser. 43, 1-5 (1959).

1. The critical potentials were measured and the excitation voltages were calculated; good agreement was obtained.
2. The energies of quasi-stationary states were determined from the measured find structure of $K$ and $M$ spectra of iron.

3. Exciting voltages of the $s$ or $p$ core electrons to the quasi-stationary states of $s, p$, or $d$ symmetry are estimated.

4. The absorption maxima in the fine structure of the soft $\mathrm{X}$-ray absorption spectrum of a solid are caused by the excitation of core electrons to quasi-stationary states. There is a close relationship between the quasi-stationary states and the critical potentials.

(21) T

Kakuschadse, T. I., SATELLITES OF $K \alpha_{3}$ and $K B_{1}$ IN $X$-RAY SPECTRA. (In German.)

Ann. Physik (7) 2, 352-359 (1959).

1. The effective interaction of the electrons with thermal lattice vibrations is considered.

2,3 . The Bloch theory is extended to explain the occurrence of $K \alpha_{3}$ and $K \beta_{1}$ satellites.

(22)E

Kawaharada, H., CRITICAL POTENTIALS OF SOFT $X$-RAYS EMITTED FROM NICKEL.

Sci. Repts. Tohoku Univ. First Ser. 43, 143147 (1959).

1. The energies of quasi-stationary states were determined from the measured fine structure of $\mathrm{K}$ and $\mathrm{M}_{2}, 3$ absorption spectra of $\mathrm{Ni}$.

3a. Excitation voltages of the $s$ or $p$ core electrons to the quasi-stationary states of $s, p$, or d symmetry are estimated.

3b. The critical potentials and the calculated excitation voltages are tabulated; these are in good agreement.

4. There is a close relationship between the quasi-stationary stated and the critical potentials.

(23)E

Kazantsev, V. A., STUDY OF THE Mn-KB SPECTRUM IN THE Mn-Ni SYSTEM. (In Russian.) Doklady Akad. Nauk S.S.S.R. 123, 449-452 (1959) Trans: Sov. Phys. "Doklady" $3,1249-1253$ (1959)

1. Alloys with a $\mathrm{Ni}$ content varying from 40.1 92.43 w/o were studied.

2a. A bent crystal spectrograph was used; samples were in the shape of tablets pressed into the $\mathrm{Cu}$ head of the $\mathrm{X}$-ray tube anode.

$2 b$. The specimen temperature was measured during the run, and $x$-ray intensities were recorded photographically.

3. Tables and spectra showing the behavior of $\mathrm{Mn}-\mathrm{KB}_{5}$ bands as a function of composition, temperature and magnetic state of the alloy are presented.

4. The $M n-K B_{5}$ is not affected by compositional changes, but the $M n K \beta_{5}$ shifts $1.2-1.8 \mathrm{eV}$ toward lower energies as the temperature is elevated and the magnetic transition affects the Mn-KB drastically. 
(24)E

Kazantsev, V. A., STUDY OF THE KB ${ }_{5}$ BAND AND $\mathrm{K}$ ABSORPTION EDGE IN NICKEL ON PASSING THROUGH THE CURIE POINT. (In Russian.) Doklady Akad. Nauk S.S.S.R. 123, 667-670 (1959) Trans: Sov. Phys. "Doklady" $3,1262-1265$ (1959)

1. Tablets of $99.99 \% \mathrm{Ni}$ pushed into the anode of the $\mathrm{X}$-ray tube were investigated; work was carried out at $300-400^{\circ} \mathrm{C}$ and not in immediate proximity to the Curie point.

2a. A bent crystal spectrograph of $3.92 \mathrm{xU} / \mathrm{mm}$ dispersive power was used; microphotograms of the spectra were obtained in the first and second order.

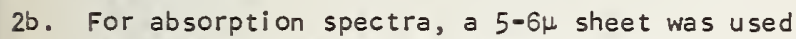
and the temperature was measured wi th a nichrome-constantan the rmocouple; temperatures used were 22,320 , and $400^{\circ} \mathrm{C} \pm 5^{\circ}$.

3. The transition to the paramagnetic state shifts the $\mathrm{KB}_{5} 2.1 \pm 0.2 \mathrm{eV}$ toward higher energies and decreases the bandwidth by 1.8 $\pm 0.4 \mathrm{eV}$.

4. The Ni-K edge shifts about $1.2 \mathrm{eV}$ toward higher energies as the temperature is increased.

(25)E

Lucasson-Lemasson, A., A NEW STUDY OF THE L ABSORPTION SPECTRUM OF GERMANIUM. (In French.) Compt. Rend. (French Academy) 248, 1156-1158 (1959).

1. Both the L absorption and emission spectra of evaporated films of Ge were studied.

2a. A bent crystal (gypsum) spectrograph was used and intensities were pnotograpnically recorded.

2b. The ausorber tnickness ranged from 0.1 to 1 micron; the temperature varied from $20-400^{\circ} \mathrm{C}$.

3. Results and spectra are tabulated.

4. The spectra are greatly influenced by the crystalline state of Ge, which was checked by electron diffraction; evidence of this is presented.

(26)E

Nemnonov, S. A. and K. M.Kolobova, THE X-RAY KABSORPTION SPECTRUM OF IRON AT LIQUID NITROGEN TEMPERATURE. (In Russian.)

Fiz. Metal. i Metallovedne 8 , 478-480 (1959). Trans: Physics of Metals \& Metallography $\underline{8}$. (In Process.)

2. A crystal spectrometer was used.

3. The middle of the basic K-edge curve shifted into the long wavelength region.

4. As a result of lattice parameter decrease, the $3 \mathrm{~d}, 4 \mathrm{~s}$ and $4 \mathrm{p}$ band overlap of metallic iron increases. Thus, the d state redistribution is altered according to the energy and probability of the corresponding transformations. As a result, the Fermi surface energy can also decrease.
(27)E

Nikolaeva, L. G. and S. M. Karal 'nik, CHARACTERISTIC ABSORPTION OF X-RAYS IN BINARY ALLOYS OF IRON WITH Ni, CO, AND Cr. (In Ukrainian.) Ukrain. Fiz. Shur. 4, 260-267 (1959). Annotation from Chem. Abs. $53-21133 \mathrm{~h}$.

1. The change in the $K$ absorption edge of $\mathrm{Fe}$ upon alloying wi th $\mathrm{Ni}, \mathrm{Cr}$, and Co was investigated.

3a. The greatest change in the spectra of these alloys occurs at the $K$ edge.

3b. An attempt is made to interpret the results on the basis of external screening occurring when the interatomic bond changes.

(28)E

Nordling, C., ENERGY SHIFTS IN 5TH PERIOD L SHELLS DUE TO OXIDATION AND ALLOYING.

Arkiv Fysik 15 (3), 241-250 (1959).

1,2,3,4. cd-cdo: Thin transmission and thick reflection sources were prepared. The evaporated metal layers were heated in air for 12 hrs. at $200^{\circ} \mathrm{C}$ to obtain CdO. To check compositions, electron diffraction patterns were taken; these showed pure $\mathrm{Cd}$ and complete oxidation in the Cdo samples. The $L_{1}$ and $L_{3}$ energy shifts were measured with $\mathrm{Cu}-\mathrm{K} \alpha_{1}$ radiation (to produce photoelectrons). Results: $L_{1}$ : shift $=-0.8 \pm 0.3 \mathrm{eV}$ $L_{3}$ : shift $=-0.6 \pm 0.3 \mathrm{eV}$

Minus sign indicates that the electron binding energies are smaller in Cdo than in Cd. sn-sno: $L_{1}, L_{2}, L_{3}$ shifts were measured. Samples were prepared as above. Samples were pure.

Results: $L_{1}:$ shift $=+1.3 \pm 0.3 \mathrm{eV}$

$L_{2}$ : shift $=+1.1 \pm 0.3 \mathrm{eV}$

$L_{3}:$ shift $=+1.3 \pm 0.2 \mathrm{eV}$

Plus sign indicates an increase in $L$ binding energies due to oxidation contrary to the case of $\mathrm{Cd}$.

$\mathrm{Sn}-\mathrm{SnO}_{2}$ : Reflection samples only:

$L_{3}$ only: shift $=+1.1 \pm 0.3 \mathrm{eV}$

Samples contained less than $0.3 \%$ impurities. Sn-SnAu: In the case of an alloy, it is most advantageous to have thick converters since the techniques of evaporating or electroplating alloys without changing the composition are not too reliable. The alloy was prepared by heating $50 \mathrm{a} / \mathrm{O} \mathrm{Sn}$ and $50 \mathrm{a} / \mathrm{O} \mathrm{Au}$ in evacuated pyrex tube to well above M.P. $\left(418^{\circ} \mathrm{C}\right)$. In $\mathrm{SnL}_{3}$, no shift was observed due to alloying. Conclusions: The magnitude of the shifts in $\mathrm{Cd}$ and $\mathrm{Sn}$ are less than in $\mathrm{Cu}_{\mathrm{u}}$ and the $\mathrm{L}_{1}$ shifts are not significantly greater than $L_{2}$ or $L_{3}$ shifts. For $\mathrm{Cu}$, the widths of $L$ photo lines are a few tenths of an eV greater in the oxide; this is also true in $5 n$ and is always less than $0.5 \mathrm{eV}$. The Fermi level in cdo 1 ies about $0.4 \mathrm{eV}$ below the conduction band. 
Parrat, L. G., - See Review $(R-9)$ and $(R-10)$.

(29)E

Porteus, J. 0., THE K ABSORPTION SPECTRA OF ALKALI METAL CHLORIDES.

Univ. Microfilms MIC 59-135, 155 pp. (1959). Diss. Abs. $19-2368$.

1. LiCl, $\mathrm{RbCl}$, and CsCl were studied.

2. A double crystal spectroneter equipped with a proportional counter was used.

3a. Spectra and tabular data are presented.

3b. The spectra are discussed from the point of view of $X$-ray excitation states.

(30)E

Porteus, J. O. and L. G. Parratt. AN OPTIMIZED METHOD FOR CORRECTING FOR SMEARING ABERRATIONS: COMPLEX X-RAY SPECTRA.

Office of Technical Services PB143952,130 pp. (1959).

1,2. A convolution integral is set up in order to obtain the true spectrum $T(V)$ from the observed spectrum $0\left(V_{n}\right)$ for $\mathrm{KCl}$.

2a. The observed spectrum was assumed to come from a spectrometer having a smearing function equal to $M\left(V_{n}-V\right)$. An attempt is made to correct for this smearing effect also.

3a. It is shown that

$$
O\left(V_{n}\right)=\int_{-D}^{\infty} T(V) M(V n-V) d V
$$

3b. The correction method is applied to the $K$ absorption and emission spectra of solid KCl.

(31)E

Rumyantsev, I. A. and M. I. Korsunski i, INVESTIGATION OF THE L SPECTRA OF $Z n$ IN ALLOYS OF THE Cu-Zn SYSTEM. (In Russian.) Optika i Spektoskopiia, 2, 850-852 (1959). Trans. Optics and Spectroscopy Z, 498-500 (1959).

1. Alloys comprised of each phase of the $\mathrm{Cu}-\mathrm{Zn}$ system and pure $\mathrm{Cu}$ and $\mathrm{Zn}$ were studied.

2. A bent crystal spectrograph (mica) was used; intensities were recorded photographically with exposure times ranging from 2-6 hours.

3. Spectra for each alloy studied are presented showing the differences observed; no explanation or discussion of the data is given.

Sandstrom, A. E., - See Review (R-12).

(32) E

Sokolowski, E., ELECTRON BINDING ENJERGIES OF IV AND VI PERIOD ELEMENTS BY PHOTOELECTRON MET'HOD.

Arkiv Fysik 15, 1-30 (1959).

$1,2,3,4$. The binding energy of an inner electron shell is the energy associated with an electron transition from that inner shell to the lowest unoccupied level in the conduction band. Under the assumption of a constant density of states around the first unoccupied level, the absorption edge should follow an arc tan function, the inflection point of which should correspond to transitions to the lowest unoccupied state in the conduction band. since the binding energy corresponds to a transition from the given shell to the lowest unoccupied level in the atom, the quantum numbers vary for the final state and a discontinuity must be expected in the modified Moseley diagram each time an outer shell is filled and the symmetry of the lowest unoccupied level is changed. The $K$ binding energy of 4 th period elements is a scnsitive function of the crystal parameters.

(33)E

Sokolowski, E. and C. Mordling, EXPERIMENTAL STUDIES OF KLL AUGER SPECTRA OF CU AivD Ge. Arkiv Fysik 14, 557-564 (1959).

$1,2,3,4$. The sample was an evaporated metal layer $100 \mathrm{~A}$ thick. The intensity of the satellites was found to be a function of source thickness. Table 1 gives KLL Auger energies for $\mathrm{Cu}$ (p. 560 of paper); Table 11 gives KLL Auger energies for $\mathrm{Ge}(p .561)$; a table giving relative energy and intensity of lines is presented (p. 562). For the energies, a set of general equations are given which depend on B.E. of the atomic shells involved and a group of functions $F$ and $G$, accounting for screening and exchange energy:

$$
F(o r G)=A\left(Z-Z_{S}\right)\left(1-\alpha Z^{2}\right)
$$

where $A, Z_{S}$ and $\alpha$ are constants (values not given). A comparison between theory and experiment regarding absolute energies for the Auger lines is not good, the calculated energies being 40 and $50 \mathrm{eV}$ too low for $\mathrm{Cu}$ and $\mathrm{Ge}$ respectively. The discrepancy must be sought in the functions $F$ and $G$, to which the absolute energies are more sensitive than the relative values.

(34)E

Soules, J. A. and C. H. Shaw, X-RAY K ABSORPTION SPECTRA OF SOLID ARGON AND KRYPTON.

Phys. Rev. 113, 470-472 (1959).

1. The absorption edge of $A$, and $K r$ in the solid and gaseous states was studied.

2. A double crystal (calcite) spectrometer was used; photons were counted by a $\mathrm{Xe}^{-\mathrm{CH}_{4}}$ proportional counter.

3a. A great deal of fine structure was found in the solid state samples.

3b. The broad absorption maxima are correlated with valence bands; the extremely sharp initial rise indicates the existence of excitation states.

3c. The argon level width is $0.58 \mathrm{eV}$.

3d. Actual spectra are presented.

Tomboulian, D. H., - See Review $(R-16)$. 
(35)E

Tomboulian, D. H., A PHOTON COUNTING SPECTROMETER FOR ATTENUATION MEASUREMENTS IN THE SOFT X-RAY REGION.

U.S. At. Energy Comm. NP-7906, 20 pp. (1959).

1,2. Aluminum and zapon absorber foils were used under normal illumination at $180 \mathrm{~A}$ and a Be-Cu photomultiplier was rotated from $0-22^{\circ}$ wi th respect to the foil axis to receive photons scattered at various angles from the absorber's front surface.

3. The scattered intensity was too small to be observed.

4. For incident photon energies of about $70 \mathrm{eV}$, attenuation may be associated with processes which absorb energy within the foils.

(36)E

Trapeznikov, V. A., CALCULATION OF THE REABSORPTION FOR THE SHORTEST WAVELENGTH LINE OF AN X-RAY EMISSION SERIES. (In Russian.)

Fiz. Metal. i Metallovedne I, 294-295 (1959). Trans: Physics of Metals and Metallography $I$ (2), 130-132 (1959).

1. The $L B_{2}$ absorption spectrum in Mo was studied.

2. A bent crystal (quartz) spectrograph was used to study the 1 micron thick absorbers; $5 \mathrm{kV}$ electrons at $3-4$ ma caused the excitations.

3. The reabsorption accounting resulted in considerable changes in the form and position of the 1 ines in the emission series.

Tsutsumi, K., et al, - See Review $(R-17)$.

(37)E

Tsutsumi, K., X-RAY NON-DIAGRAM LINES KB' OF SOME COMPOUNDS OF THE IRON GROUP.

J. Phys. Soc. Japan 14, 1696-1706 (1959).

1. The $\mathrm{K \alpha}_{3,4}$ of $\mathrm{Fe}$ and the $\mathrm{KB}$ ' from $\mathrm{Cr}_{2}\left(\mathrm{SO}_{4}\right)_{3}$ in $\mathrm{H}_{2} \mathrm{O} ; \mathrm{Cr}_{2} \mathrm{O}_{3} ; \mathrm{MnO}_{2} ; \mathrm{MnSO}_{4} \cdot 4 \mathrm{H}_{2} \mathrm{O} ; \mathrm{Fe}\left(\mathrm{NH}_{4}\right)_{2}$

$\left(\mathrm{SO}_{4}\right)_{2} \cdot 6 \mathrm{H}_{2} \mathrm{O}$, and $\mathrm{Fe}_{2} \mathrm{O}_{3}$ were studied.

2. Samples were excited by $\mathrm{Ni}-\mathrm{K}$ and then by $\mathrm{Cu}-\mathrm{K}$ radiation in a bent crystal (quartz) spectrograph; intensities were recorded photographically.

3a. Spectra are shown and results are tabulated.

$3 b$. No difference could be found for the $K \beta^{\prime} l i$ ine for energies higher or lower than $K(Z)+$ $L(Z+1)$.

4. The $K B^{\prime}$ line is due to a single ionization and $i t$ can be derived from the difference of the exchange interactions of the states having different total spins $(s+1 / 2)$ and $(s-1 / 2)$ where $S$ is the total spin of the incomplete $3 \mathrm{~d}$ shell and $1 / 2$ is that of the incomplete $3 p$ shell in the final state.

(38)E

Vainshtein, E. E., B. I. Kotlyar and G. A. Shapiro, STUDY OF FINE X-RAY ABSORPTION SPECTRA OF IRON IN SOME ANTIFERROMAGNETIC SUBSTANCES AND

FERRITES. (In Russian.)

Doklady Akad. Nauk S.S.S.R. 125, 55-58 (1959).
Trans: Sov. Phys. "Doklady" 4, 316-318 (1959).

1. The materials $\mathrm{Fe}_{2} \mathrm{O}_{3} ; \mathrm{SrO} \cdot 6 \mathrm{Fe}_{2} \mathrm{O}_{3} ; \mathrm{MnO} \cdot \mathrm{Fe}_{2} \mathrm{O}_{3}$; $\mathrm{ZnO} \cdot \mathrm{Fe}_{2} \mathrm{O}_{3} ; \mathrm{COO} \cdot \mathrm{Fe}_{2} \mathrm{O}_{3}$; and $\mathrm{NiO} \cdot \mathrm{Fe}_{2} \mathrm{O}_{3}$ were studied.

2. A Johann bent crystal (quartz) spectrograph was used and intensities were recorded photographically.

3a. The $K$ absorption edge wavelength is independent of the magnetic state in the compounds studied.

3b. All spectra are shown.

4. "Tentative" conclusions concerning the chemical bonding in the compounds studied are reached.

(39)E

Vainshtein, E. E. and E. A. Zhurakovski i, NEW DATA ON THE X-RAY EMISSION SPECTRA OF TITANIUM IN CERTAIN HYDRIDES, CARBIDES, AND NITRIDES. (In Russian.)

Doklady Akad. Nauk S.S.S.R. 128, 695-697 (1959)

Trans: Sov. Phys. "Doklady" $\underline{4}, 1050-1052$ (1959)

1. The $K \beta_{5}, K \alpha_{1}$, and $K \alpha_{2}$ groups were studied in stoichiometric TiC, $\mathrm{TiN}$, and 1,2 , and $3 \% \mathrm{H}$ in $\mathrm{Ti}$ and pure $\mathrm{Ti}$.

2. A curved crystal (quartz) spectrograph wi th a dispersive power of $2.5 \mathrm{XU} / \mathrm{mm}$ was used; data were recorded photometrically at five crosssections along the lines and averaged.

3a. All spectra are presented.

3b. The $\mathrm{KB}_{5}$ was displaced about $1 \mathrm{eV}$ toward shorter wavelengths in the hydrides as compared with the pure metal although the shapes were very similar.

(40)E

Vainshtein, E. E. and E. A. Zhurakovski i, THE FINE STRUCTURE OF THE $K$ ABSORPTION SPECTRA OF TiHYDRIDE, BORIDE, AND SILICIDE. (In RUSsian.) Izvest. Akad. Nauk S.S.S.R. Otdel. Khim. Nauk 1959, $1493-1495$.

Annotation from Chem. Abs. 54, 6295c.

2. A crystal spectrometer was used.

3. As the specific number of boron and silicon atoms is increased, a tendency toward the formation of individual structural elements from the metalloid atoms appears and the bond between the atoms acquires a more covalent character.

(41)E

Vainshtein, E. E., E. A. Zhurakovskii and 1. B. Staryi, ON SOME RESULTS OF X-RAY SPECTRAL INVESTIGATIONS OF THE PHYSICAL NATURE OF INTERSTITIAL PHASES. (In Russian.) Zhur. neorg. khim. 4, 245-246 (1959). Trans: Russian Journal of Inorganic Chemistry 生 (1), 104-105 (1959).

1. The $K$ absorption of Titanium in $\mathrm{TiN}, \mathrm{Ti}-\mathrm{C}$ $(9-24 \% \mathrm{C}), \mathrm{TiB}_{2}$ and 1.2 and $2 \%$ hydrogen $\mathrm{Ti}-$ hydrides was studied.

2. Crystal spectrometry coupled wi th photographic means was used to obtain the spectra.

3a. The longwave absorption line in the hydrides disappears when the $H$ content is equal to or greater than $2 \%$; this line indicates the 


\section{(41)E Cont'd.}

existence of vacancies in the $3 \mathrm{~d}$ shell of $\mathrm{Ti}$.

3b. Large differences were found in hydride bonding as compared wi th bonding of carbides and nitrides.

3c. The fine structure of the $K$ edge of $\mathrm{Ti}$ in borides is more complex than for nitrides and carbides.

(42)E

Zhurakovski i, E. A. and E. E. Vainshtein, X-RAY K ABSORPTION SPECTRA OF VANADIUM IN HYDRIDES, NITRIDES, BORIDES, AND CARBIDES. (In Russian.) Doklady Akad. Nauk S.S.S.R. 127, 534-537 (1959) Trans: Sov. Phys. 'Doklady" 4 , 826-828 (1960).

2. A Johann bent crystal spectrograph was used and intensities were photographically recorded.

3a. In going from oxide to nitride, the intensity of the longwave white absorption line changes, but its position does not.

3b. All spectra obtained are shown but are not interpreted.

$(c-1) T$

Asaad, W. N., RELATIVISTIC CALCULATION OF THE K-LL AUGER SPECTRUM.

Proc. Roy. Soc. (London) A-249, 555-573 (1959).

1. A calculated K-LL Auger spectrum for $\mathrm{Hg}$ is presented.

2. Moller's treatment for the interaction of radiation with electrons was used in order to make the calculations.

3a. Relativistic effects increase the Auger transitions by about $84 \%$ and decrease the radiative transitions by about $75 \%$.

3b. The $K$ series fluorescence yield, $w_{k}$, was estimated to be 0.961 for $\mathrm{Hg}$.

3c. Tables of transition probabilities for $\mathrm{Hg}$ are presented.

$(C-2) E$

Batterman, B. W., X-RAY MEASUREMENT OF THE DISTRIBUTION OF ELECTRONS IN IRON AND COPPER.

Phys. Rev. Letters 2, 148 (1959).

1,2. The X-ray intensities for Fe (carbonyl) and $\mathrm{Cu}$ (smooth molded powder 0-60,000 PSI) were measured wi th $\mathrm{Fe}-\mathrm{K}$ radiation.

3. The number of $3 \mathrm{~d}$ electrons was the same as for the free atom in both $\mathrm{Fe}$ and $\mathrm{Cu}$.

$(\mathrm{C}-3) \mathrm{T}$

Belding, E. F., THE 3d BAND STRUCTURE OF SOME TRANSITION ELEMENTS.

Phil. Mag. (8) 4 , (46) $1145-1149$ (1959).

1. The 3d band structure for $\mathrm{Cr}, \mathrm{Fe}$, and $\mathrm{Ni}$ was calculated.

2a. A tight binding approximation was used, taking into account the interaction of first and second neighbors.

2b. A table of the overlap integrals used is given.

3a. The 3d band showed a broadening at the lower energy limit for $\mathrm{BCC} \mathrm{Cr}$ and $\mathrm{Fe}$, but only a negligible effect for FCC-Ni.

3b. A density of states curve for $\mathrm{Fe}$ is presented.

$(\mathrm{C}-4) \mathrm{E}$

Bergval 1, P., PRECISION MEASUREMENT OF K $\alpha$ X-RAY LINES FROM RARE EARTH ELEMENTS. Arkiv Fysik 16, 57-68 (1959).

1. Elements of $Z=57-60$ and $62-71$ were studied; $\mathrm{La}, \mathrm{Ce}, \mathrm{Pr}$, and $\mathrm{Nd}$ were metals and the remainder of the elements were oxides.

2. A curved crystal (quartz) spectrometer equipped with a scintillation counter was used.

3. The $K \alpha$ line wavelengths in $X U$ are tabulated to six significant figures.

$(\mathrm{C}-5) \mathrm{T}$

de Carvalho, A. P., THE BAND STRUCTURE OF TELLURIUM. (In French.)

Compt. Rend. (French Academy) 248, 778-781 (1959).

$1,2,3$. The secular Reitz equation was used to calculate the band structure.

$(\mathrm{C}-6) \mathrm{T}$

Elliott, R. J., and R. Loudon, ABSORPTION EDGE SPECTRUM OF DIAMOND.

J. Chem. Phys. Solids $\underline{8}, 382$ (1959).

1. The effect of magnetic fields and excitons on the absorption edge in semiconductors was examined.

2. Simple spherical bands were assumed and spin effects were neglected.

$(\mathrm{c}-7) \mathrm{T}$

Faulkner, J. S., ELECTRON ENERGY BANDS OF ONE DIMENSIONAL RANDOM ALLOYS.

Univ. Microfilms, L.C. Card \#MIC 59-5891, 93 pp. (1959).

1. A model consisting of two different types of symmetric potential wells equally spaced in a "random" sequence with a fixed concentration was used.

2. The method of Korringa and a method in which electron scattering is characterized by a 2 by 2 matrix expressing traveling waves on one side in terms of those on the other side were both employed.

3. An attempt to predict density of states curves was made.

(c-8)E

Frey, W. R., R. E. Johnston and J. 1. Hopkins, $K$ SERIES FLUORESCENCE YIELDS ( $\left.u_{k}\right)$ FOR $v$, $\mathrm{Mn}$, AND Ne.

Phys. Rev. 113, 1057-1060 (1959).

2. A proportional counter was used to measure $w_{k}$; counting gas was $\mathrm{P}-10$ and the counter was Al.

3a. The Auger electron spectra are presented. 
$(c-8) E$ Cont'd.

3b.

$\frac{\text { Element }}{\mathrm{V}}$

$\frac{u_{k}}{0.304 \pm 0.013}$

3c. These data are compared with earlier results.

$(C-9) E$

Fujiki, Y., VACUUM DEPOSITION OF ALLOYS J. Phys. Soc. Japan 14, 913-917 (1959).

1. The formation of alloy phases by successive deposition of constituent metal vapors in vacuum was studied by electron diffraction for the alloys of $\mathrm{Au}-\mathrm{Pb}, \mathrm{Bi}-\mathrm{Pb}, \mathrm{Cu}-\mathrm{Sn}, \mathrm{Ag}-\mathrm{Sn}$, and $\mathrm{Cd}-\mathrm{Sn}$.

2. The total amount of metal used was $10 \mathrm{mg}$, and the evaporation rate was $25 \mathrm{mg} / \mathrm{min}$.; the pressure was $2 \times 10^{-5} \mathrm{mr} \mathrm{Hg}$.

3. The temperature of the surface layer of the primary deposit is elevated by depositing the second metal, and this rise contributes to the formation of true alloy phases; this is due to the latent heat of condensation of the metal deposited on the substrate.

4. Metal pairs having large heats of condensation may form alloys easily.

$(C-10) T$

Greiner, H. and E. Schaffer, ASTIGMATISM OF THE CONCAVE GRATING WITH SPHERICAL OR TOROIDAL SURFACES. (In German.) Optik 16, 288-303 (1959).

1. The toroidal and spherical gratings are compared with reference to the incident light density (spectrograph) of the radiant flux leaving the exit slit (spectrometer).

3. A procedure is given so that the ratio of the radi $i$ of curvature for the toroidal grating and the incident angle can be found so that departure from a stigmatic image is a minimum.

4. The density of incident light or radiant flux depends on the length of entrance and exit slits.

$(C-11) E$

Hass, G. and R. Tousey, REFLECTING COATINGS FOR THE EXTREME ULTRAVIOLET.

J. Opt. Soc. Am. 49, 593-602 (1959).

1. Conditions for preparing evaporated films of Al for use on the grating are summarized and the effect of thin overcoatings on the efficiency of ruled gratings is discussed.

3a. Data on $\mathrm{Pt}, \mathrm{ZnS}$, and $\mathrm{Al}_{2} \mathrm{O}_{3}$ for use as overcoatings below 1200 A are presented.

3b. From 0-400A, extrapolation of the curves of reflectance vs. wavelength given shows that $\mathrm{Pt}$ has about $15-20 \%$ reflectivity while $\mathrm{Al}$ has about 5-10\% reflectivity.

$(C-12) T$

Henke, Burton L. and Jack C. Miller, ULTRASOFT $X$-RAY INTERACTION COEFFICIENTS. REPORT NO.3 ON ULTRASOFT X-RAY PHYSICS.

Office of Technical Services PB144965, 84 pp. (1959).
1. Interaction coefficients for ultrasoft $X$ radiation were derived by semi-empirical methods.

2. Semi-empirical relations, based on quantummechanical theory wi th certain simplifying assumptions applicable in the soft $X$-ray region (10-100A) were determined by interpolation of available data.

3. Results obtained for photoelectric absorption coefficients, atomic scattering factors, ultrasoft $x$-ray scattering, and ultrasoft $x$ ray reflection are presented graphically and in tabular form.

$(C-13) \mathrm{T}$

Kanamori, J., SUPEREXCHANGE INTERACTION AND SYMMETRY PROPERTIES OF ELECTRON ORBITALS. J. Chem. Phys. Solids 10, 87-98 (1959).

1. In some cases, the sign of the superexchange interaction is determined by symmetry relations; cases in which the cation is subject to an octahedral cubic field and in which lines connecting interacting cations to the intervening anion make an angle of 90 or $180^{\circ}$ are discussed.

3. Examples for perovskite, $\mathrm{NaCl}, \mathrm{TiH}_{2}$, and some anhydrous chlorides are given.

$(C-14) T$

Kelley, R. L., VACUUM ULTRAVIOLET EMISSION LINES BELOW 2000A.

U.S. At. Energy Comm. UCRL-5612, 520 pp. (1959)

1. Lines below 2000A are tabulated.

2. Data were taken from 811 references.

$(c-15) T$

Kleinman, L. and J. C. Phillips, SELF-CONSISTENT CALCULATIONS FOR DIAMOND.

Phys. Rev. 116, 880-884 (1959).

1. Approximate self-consistent potentials with exchange included are obtained.

2. The Slater free electron approximation was used.

3a. Inclusion of the momentum dependence of the exchange potential alters the valence band width.

3b. Tables of calculated energies are presented.

$(C-16) R$

Kurylenko, C., TECHMIQUE FOR OBTAINING ABSORPTION AND EMISSION SPECTRA BY MEANS OF X-RAYS. (In French.)

Cahiers de Physique 13, No. 106, 237-256 (1959).

1. A general description of the methods of crystal spectrometry and photographic photometry including historical background, general solid state and $X$-ray excitation theory and photoelectric theory is given. A few spectra, notably $W$ and $A g$, are presented. 
$(c-17) T$

Lohmann, A., CONTRAST TRANSFER IN THE GRATING SPECTROGRAPH.

Optica Acta (Paris) 6. 175-185 (1959).

1. Calculations are based on the theory of contrast transfer for optical image formation.

2. The spectral distribution of the light falling into the entrance slit is calculated from the measured intensity by Fourier methods.

3. General formulae for the intensity distribution in a grating spectrograph with various types of grating errors, aperture diffraction, aberrations, and amplitude filters are given. Note: A comprehensive bibliography on contrast transfer is given. spectra are presented; a modified Mosely diagram for the $\mathrm{K}$ binding energies of the fourth period elements is also given.

$(\mathrm{C}-21) \mathrm{E}$

Nordling, $C$, and $S$. Hagstrom, ELECTRON BINDING ENERGIES IN URANIUM.

Arkiv. Fysik 15, 431-443 (1959).

1. The $\mathrm{L}_{3}, \mathrm{M}_{2}, M_{5}$, and $\mathrm{N}_{1}, \mathrm{~N}_{5}$ level energies were measured in uranium by the photo-electron method.

2a. A magnetic spectrometer equipped wi th a $G-M$ counter was used to observe the evaporated (onto an Al backing) $U$ targets; no value for the pressure of the system was given.

2b. The $\mathrm{K} \alpha_{1}$ lines of $\mathrm{Ag}, \mathrm{Pd}, \mathrm{Ge}$, and $\mathrm{Cu}$ were used to excite the desired photo-lines.

3. All data are tabulated and $L$ and $M$ photoemission spectra are presented.

$(C-18) A$

Namioka, T., THEORY OF THE COINCAVE GRATINE I, II, III.

J. Opt. Soc. Am. 49, 1:446-459, 11:460-465, 111:951-960, (1959).

1,2. The concave grating theory is examined in terms of geometrical optics and astigmatism, and other aberrations are treated with respect to the finite length of slit illumination, grating size, and deviations of optical components from the Rowland plane, but still on the Rowland cylinder.

3a. The aberrations in an off-plane Eagle mounting can be corrected by rotating the slit perpendicular to the optical axis.

3b. Tables and graphs for the optimum grating size of a 21-foot radius grating with 30,000 lines/inch and for a l-meter grating with 15,000 lines/inch are given.

$(C-19) A$

Namioka, T., DESIGN OF A HIGH RESOLUTION MONOCHROMATOR FOR THE VACUUH ULTRAVIOLET.

J. Opt. Soc. Am. 49, y61-965 (1959).

1. The off-plane Eagle mounting is chosen as that most suitable for the vacuum ultraviolet.

3a. The resolving power of the grating with this mounting is calculated numerically for a 3meter grating wi th $30,000 \mathrm{lines/inch,0-5800 \textrm {A }}$ (1st order) and a distance of the entrance slit from the Rowland plane of $6 \mathrm{~cm}$.

30. A tentative instrumental design is presented.

$(C-20) E$

Nordling, C., $K$ AND L ENERGY LEVELS IN SOME FOURTH AND FIFTH PERIOD ELEMENTS.

Arkiv. Fysik 15, 397-429 (1959).

1. The $K$ and $L$ binding energies in $\mathrm{Cu}, \mathrm{Zn}, \mathrm{Ga}$, $\mathrm{Ge}$, and $\mathrm{Se}$, and the $L$ binding energy in elements from $R$ h through $T e$ were studied by the photo-electron method.

2. The kinetic energy of the photo-electrons was determined with an iron-free, double focusing $\beta$ spectrometer equipped with a G-M counter; a schematic diagram of the apparatus is given.

3. All results are tabulated and all photo
$(\mathrm{C}-22)$

Posener, D. W., THE SHAPE OF SPECTRAL LINES - A TABLE OF THE VOIGT PROFILE

$$
\frac{a}{\pi} \int_{-\infty}^{+\infty} e^{-y^{2}} d y\left(1 / a^{2}+[v-y]^{2}\right)
$$

Australian J. Phys. 12, 184-196 (1959).

1. The line shape which results when any spectral line is broadened simultaneously by Gaussian and Lorentzian effects is computed.

2. The equation for this effect is solved with a digital computer.

3. Tables of results for values of the titular function are presented.

$(C-23) T$

Robins, D. A., AN INITERPRETATION OF SOME OF THE PROPERTIES OF THE TRAISITION METALS AND THEIR ALLOYS.

J. Less Cormon Metals 1, 396-411 (1959).

1. Many of the properties of the transition metals can be interpreted in terms of a relationship between the coordination number and the number of bonding electrons per atom.

4a. The electron resonance bond strength is a maximum when the number of bonding electrons per atom is equal to half the coordination number; "effective" coordination numbers must be invoked to support this view.

4b. The stability of this arrangement dictates the alloying behavior and the crystal structure of the transition metal in question.

$(C-24) T$

Suoninen, E. J., INFLUENCE OF INDIRECT EXCITATION ON THE INTENSITY OF A FLUORESCENT X-RAY LINE IN TWO PARTICULAR CASES. (In English.) Ann. Acad. Sci. Fennicae, Ser. A VI \#15, 12 pp. (1959).

1,3. An expression for the intensity of a fluorescent line in terms of true and total absorption 
(c-24)T Cont'd.

coefficients in which the primary beam is assumed to be able to excite a line $\lambda_{A}$ of element $A$ and $\lambda_{B}$ of element $B$, is given.

$(C-25) T$

Trost, W. R., ORBITAL CONSTRUCTIONS AND ELECTRON POPULATIONS IN TRANSITION ELEMENTS. Can. J. Chem. 37, 460-474 (1959).

1. Orbital constructions and electron populations for the bands in transition metals are presented.

3a. It is possible to predict the crystal structure of the elements if there is a uniform density of states in delocalized bands among nearest neighbors.

3b. Numerical values for electron populations in the $s, p, d$, and hybrid bands including their bonding, antibonding, and non-bonding levels are presented.

3c. Density of states curves are given for 1, 5, 9 , and 12 electron atoms.

Note: Excellent drawings of hybrid bonds are included.

$(\mathrm{C}-26) \mathrm{T}$

Waldron, F. D., IMTENSITY AND DAMPING DEPENDENCE OF VARIOUS PARAMETERS DESCRIBING SPECTPAL LINE SHAPES.

J. Opt. Soc. Am. 49, 609-618 (1959).

1. Expressions for several properties of a damped harmonic oscillator system are given.

3. Equations for the displacement maxima of these properties as a function of line width and strength are also given.

$(\mathrm{C}-27) \mathrm{E}$

Walker, W. C., O. P. Rustgi and G. L. Weissler, OPTICAL AND PHOTOELECTRIC PROPERTIES OF THIN METALLIC FILISS IN THE VACUUM ULTRAVIOLET. J. Opt. Soc. Am. 49, 471-475 (1959).

1. Evaporated films of Al, Sn, In, Bi, Au, Ag, and $C d$ were studied in order to correlate optical transmission, reflection, and photoemission between 411 and 2072A.

3a. The frequency at which the reflection-transmission transition occurs is compared to that predicted by the Bohm-Pines theory.

3b. New absorption transitions were observed and related to X-ray absorption edges.

3c. Results for each film studied are plotted.

$(C-28) T$

Watson, R. E., IRON SERIES HARTREE-FOCK CALCULATIONS.

M.I.T. Solid State and Molecular Theory Group, Tech. Rept. 12, 258 pp. (6-15-1959).

1. It was assumed that there is a common oneelectron radial function for all electrons in any given shell and that all ion states have a common one-electron radial function for each shell.

2. Slater two-electron integrals were used to find the interaction between the ion and the crystalline field.

3. Equations and data for ions in cubic fields are tabulated.

$(C-29) E$

Weiss, R. J. and J. J. DeMarco, X-RAY MEASUREMENT OF THE DISTRIBUTIONS OF ELECTRONS IN IRON AND COPPER.

Phys. Rev. Letters 2, 47 (1959).

1,2. The (110) peak of iron relative to Al for $\mathrm{Fe}-\mathrm{K} \alpha$ and $\mathrm{Mo}-\mathrm{K} \alpha$ radiation was measured.

3. Results indicate that iron has only $2.5 \pm 1.5$ electrons of $d$ type.

$(C-30) E$

Weiss, R. J. and A. J. Freeman, $X$-RAY AND NEUTRON SCATTERING FRON ELECTRONS IN A CRYSTALLINE FIELD AIND THE DETERMINATION OF OUTER ELECTRON CONFIGURATIONS IN IRON AND NICKEL.

J. Chem. Phys. Solids 10, 147-161 (1959).

1. The effect of non-spherical charge distributions on $x$-ray and neutron scattering factors is calculated for $d$ and $f$ electrons in hexagonal, cubic, and tetrahedral crystalline fields.

3a. Polarized neutron data show that double and triply degenerate orbitals are equally populated in iron.

3b. In nickel, the holes are $75 \%$ in triply degenerate orbitals and $25 \%$ in doubly degenerate orbitals.

4a. In BCC iron, the spin density arises from $2.23 \mathrm{~d}$ atom-like electrons in one spin direction.

4b. In nickel, the spin density is from 5.0 ed atom-like electrons wi th spin up and 4.3 wi th spin down.

\section{0}

(1) E

Averbukh, E. D., USE OF X-RAY SPECTROSCOPIC DATA IN THE STUDY OF THE ENERGETIC STRUCTURE OF SOLID BODIES.' (In Russian.)

Vestnik Leningrad. Univ. 15, \#16; Ser. Fiz. i Khim. (3), 36-4l (1960).

Annotation from Chem. Abs. 55, 3188d.

1. Polarization effects in the initial and final states of an ionic crystal undergoing $x$-ray emission were studied.

3a. These polarizations are important in determining the cross transitions belonging to different ions.

3b. The energy structure of $\mathrm{KCl}$ and $\mathrm{NaCl}$ is explained by this theory.

(2) $E$

Axel rod, N. N. and M. P. Givens, OPTICAL MEASUREMENT OF THE PLASMA FREQUENCY AND THE $\mathrm{M}_{2,3}$ BAND OF CHROMIUM.

Phys. Rev. 120, 1205-1207 (1960).

1,2. A grating equipped vacuum spectrograph was used to study vacuum deposited $\mathrm{Cr}$ at a pressure of $5 \times 10^{-5} \mathrm{~mm} \mathrm{Hg}$; intensities were recorded photographically. 
(2)E cont'd.

3a. The $\mathrm{Cr}$ films became transparent at $500 \mathrm{~A}$ $(24.8 \mathrm{eV})$.

3b. A soft X-ray absorption plot for $C r$ ( $\mu v s \lambda)$ is given for the 200-800A region, but no $\mathrm{M}_{2,3}$ band is shown.

(3) $T$

Barinski i, R. L. and E. G. Nadzhakov, CALCULATION OF THE CHARGE OF ATOMS IN MOLECULES FROM X-RAY K ABSORPTION SPECTRA. (In Russian.)

Izvest. Akad. Nauk S.S.S.R. Ser. Fiz. 24, 407-414 (1960).

Trans: Bull. Acad. Sci. U.S.S.R. Phys. Ser. 24, (In Process.)

1. Using data for $\mathrm{Cl}, \mathrm{Br}, \mathrm{Ge}, \mathrm{Zn}, \mathrm{Fe}$, and $\mathrm{Cr}$ in halides and oxides as measured by various other workers, a series of equations are derived describing the absorption edge from line width data, charge of the absorber and effective quantum number.

3. The secondary absorption maximum of $\mathrm{Br}, \mathrm{Zn}$, $\mathrm{Cl}$, and $\mathrm{Ge}$ in certain compounds is explained by hole formation in the $K$ shell.

(4) $E$

Bergval 1, P. and S. Hagstrom, ATOMIC LEVEL ENERGIES II RARE EARTH ELEMENTS.

Arkiv Fysik 17, 61-79 (1960).

1. The $L_{1}, L_{2}, L_{3}$ level energies in the oxides of stable lanthanides were measured.

2. Photoelectronic spectrometry was used.

3. All results are tabulated.

(5) T

Borisov, M. D. and V. V. Nemoshkalenko, ENERGY DETERMINATION OF X-RAY PHOTOHS AND THE ENERGIES OF ELECTRONIC LEVELS IN ATOMS. (In Russian) Izvest. Akad. Nauk. S.S.S.R. Ser. Fiz. 24, 393-396 (1960).

Trans: Bull. Acad. Sci. U.S.S.R. Phys. Ser. 24, (In Process.)

1. All previous tabular data made wi th spectrometers using calcite crystals is corrected due to an improved value determination of the calcite lattice.

2,3 . Corrected energies are calculated by means of the following equation:

$E$ (Rydbergs) $=5.9587650-\log \lambda(\mathrm{XU})$

(6) E

Sorisov, M. D., V. V. Wemoshkalenko and A. M. Fefer, INFLUENCE OF THE NICKEL CONCENTRATION ON THE STRUCTURE OF THE EIERGY SPECTRUM OF ELECTROISS IN IRON-CHROMIUIA ALLCYS. (In RuSSian) Izvest. Akad. Nauk. S.S.S.R. Ser. Fiz. 24, 443-446 (1960).

Trans: Bull. Acad. Sci. U.S.S.R. Phys. Ser. 24, (In process.)

1. The $K \beta_{5}, K \beta$, and $K \beta^{1.1}$ of $C r, F e$ and $40 \mathrm{w} / 0$ $\mathrm{Fe}-\mathrm{Cr}-\mathrm{Ni}$ alloys containing $0,2,5,7$, and $10 \mathrm{w} / \mathrm{O} \mathrm{Ni}$ were studied at $1000^{\circ} \mathrm{C}$.

2. A crystal spectrometer was used.

3. A curve showing the $3 d$ band in Fe-Cr-Ni alloys is presented.

(7) $T$

Borisov, M. D. and V. A. Batiev, FINE STRUCTURE OF THE FU:IDAMENTAL K EDGE OF THE X-RAY ABSORPTION SPECTRA OF IRON GROUP ELEMENTS. (In RUSSian.) Izvest. Akad. Nauk S.S.S.R. Ser. Fiz. 24, $441-442(1960)$

Trans: Bull. Acad. Sci. U.S.S.R. Phys. Ser. 24, (In Process.)

1,3a. Long wave structure gradually decreases in the order $\mathrm{Ti}, \mathrm{V}, \mathrm{Cr}, \mathrm{Fe}, \mathrm{Co}, \mathrm{Ni}$, and $\mathrm{Cu}$; this corresponds to the unfilled portion of the $d$ band.

3b. The horizontal portion of the structure is ascribed to 4 sp photoelectric transitions.

4. The fundamental $\mathrm{K}$ edge is a superposition of two absorption edges.

(3) $E$

Borovski i, I. B. and V. V. Schmidt, THE FINE STRUCTURE OF X-RAY ABSORPTION SPECTRA AND CHARAC TERISTIC LOSSES OF ELECTRON ENERGY. (In Russian) Izvest. Akad. Nauk S.S.S.R. Ser. Fiz. 24 428-432 (1960)

Trans: Bull. Acad. Sci. U.S.S.R. Phys. Ser. 24, (In Process.)

1. K absorption spectral measurements were made on a foil of iron heated by self-resistance over a temperature range of $20-950^{\circ} \mathrm{C}$.

2. A crystal spectrometer was used.

3. Changes in the fine structure occurring during the $\alpha \rightarrow \gamma$ phase change are listed.

(9) $E$

Bril, M. N., AN INVESTIGATION ON THE TEMPERATURE DEPENDENCE OF THE FINE STRUCTURE OF THE FUI:DAIENTAL REGION OF THE X-RAY AESORPTION SPECTRA OF TITANIUM IN BARIUM TITANATES NEAR THE CURIE POINT OF BaTiO. (In Russian.) Doklady Akad. Hauk S.S.S.R. 131, 535-537 (1960) Trans: Sov. Phys. "Doklady" $5,310-312$ (1960).

2. A bent crystal (quartz) spectrograph was used; intensities were recorded photographically with exposure times of $3-5$ hours.

3a. The diffuseness of the fine structure increases in a monotonic manner up to the Curie point; above this point the fine structure of $\mathrm{Ti}$ in a compound is much lower than in a ferroelectric.

3b. In the nonferroelectric Ba-tetratitanate, no temperature dependence is observed.

3c. Spectra vs. temperature curves for $\mathrm{BaTiO}_{3}$ and $\mathrm{BaO} \cdot 4 \mathrm{TiO}_{2}$ are given.

(10)E

CrisP, R. S., SOFT X-RAY EMISSION FROM POTASSIUM METAL IN THE 40-1000A RANGE. Phil. Mag. (3) 5, 1161-1169 (1960).

1,2. A grazing incidence grating vacuum spectrometer capable of being evacuated to a pressure of $1 \times 10^{-6} \mathrm{~mm} \mathrm{Hg}$ was used to study evaporated $K$ metal; intensities were measured by a Be-Cu photomultiplier. 
(10)E cont'd.

3a. Seven lines and bands were found, of which two are deduced to be the $L$ and $M$ valence band spectra, 3 are diagram 1 ines and 2 (very broad) are not identified; all spectra are shown, and the data pertinent to the observed features are tabulated.

3b. A density of states curve is deduced from the potassium $M$ enission band and an energy level diagram is constructed based on the observed data.

(11) E

Crisp, R. S. and S. E. Williams, THE K-EMISSION SPECTRUM OF METALLIC LITHIUM. Phi 1. Mag. (8) 5, 525-527 (1960).

1. The third order $L$ spectrum was studied with a "virtually uncontaminated target surface."

2. A spectrometer having a grating with 576 lines $/ \mathrm{mm}$ was employed which when used with a $40 \mu$ slit width gave a resolution of $0.07 \mathrm{eV}$.

3a. An actual spectrum which shows a high energy edge and an anisotropic Fermi surface is presented; the edge width is $0.30 \mathrm{eV}$.

3b. Edge widths for $\mathrm{Na}-L$ and potassium $M$ were $0.21 \mathrm{eV}$ and $0.19 \mathrm{eV}$ respectively.

(12) E

Crisp, R. S. and S. E. Williams, THE SOFT X-RAY SPECTPA OF LITHIUM, MAGNESIUM AND ALUMINUM AND THEIR ALLOYS.

Phil. Mag. (8) 5, 1205-1216 (1960).

1. Pure $\mathrm{Li}, \mathrm{Mg}$, and $\mathrm{Al}$ and solid $\mathrm{Mg}-\mathrm{Li}$ specimens containing 15,40 , and 70 a/o Li respectively were studied.

2a. A glass grating, grazing incidence, spectrometer capable of being evacuated to $1-2 \times 10^{-6}$ $\mathrm{mm} \mathrm{Hg}$ was used. Specimens were cooled to $\left(-100^{\circ} \mathrm{C}\right)$ by a liquid air finger; this virtually excluded carbonaceous contamination.

$2 b$. Intensities were obtained by a Be-Cu photomultiplier; a tungsten carbide scraper was used to clean the targets which were irradiated at $4 \mathrm{kV}$ and $8-11 \mathrm{ma}$ target current.

3a. Electron transfer from Mg was observed in the alloys.

3b. The $\mathrm{Mg}$ band contracted and the $\mathrm{Li}$ band extended on the low energy side.

3c. Li deposited on $\mathrm{Al}$ yields a $\mathrm{K}$ spectrum having no metal edge.

3d. Spectra of all substances studied, and a "time-contamination" curve for the targets are shown.

4a. The changes in the $K$ and $L$ level screening compensate almost exactly for the electron transfer effect.

4b. For Li deposited on $\mathrm{Al}$, the first zone is full and there is no zone overlap.

(13) E

Curry, C. and D. J. MCNeill, SOFT X-RAY EMISSION SPECTRA OF SOME TRANSITION AND NOBLE METALS. Proc. Phys. Soc. (London) 76, 791-793 (1960).

1. $\mathrm{Al}$ and the $M_{2,3}$ of $\mathrm{Cu}$ and $\mathrm{Ni}$ and the $\mathrm{N}_{2,3}$ of Ph, Pd, and Ag were studied.

2. A l-meter grating with $1152 \mathrm{lines/mm}$ was used at a grazing angle of $53 / 4^{\circ}$ to study targets which were scraped in a vacuum of $5 \times 10^{-6} \mathrm{~mm}$ $\mathrm{Hg}$; intensities were recorded on 11 ford Q-1 plates with exposure times of 2-6 hours.

3a. Skinner's Cu-M 2,3 band shape was obtained.

3b. Element

$\begin{array}{ll}\text { Rh } & 1.3 \\ \text { Pd } & 1.3 \\ \text { Ag } & 2.1\end{array}$

(14) T

Deodhar, G. B. and S. T. H. Abidi, NEW RELATIONS IN THE X-RAY $K$ AND L SATELLITES. Naturwi ssenschaften 47, 319 (1960).

1. Empirical relations are obtained for both the high and low frequency satellites for X-ray emission I ines.

3a. The pertinent relationships for $Z=11-53$ are listed.

3b. The high frequency $k$ satellites arise from the $\mathrm{x}$-ray term difference for multiply ionized atoms.

3c. L shells are multiply ionized in the final state by the radiationless transition $k \rightarrow L_{1}$.

(15)E

Ganeev, A. S. and 1. M. Izrailev, INTERACTION CROSS SECTIONS OF SOFT X-RAYS WITH LITHIUM. (ln Russian.)

Zhur. Tekh. Fiz. 30, 1085-1086 (1960).

Trans: Soviet Phys."Tech. Phys." 5, 10161017 (1960).

1. The values of $\mu / p$ for $\mathrm{Li}$ were measured in the region of $X$-ray energies 5.5 to $20 \mathrm{k} \mathrm{eV}$.

2. A quartz crystal spectrometer was used to obtain data from a Li specimen of $0.553 \mathrm{~g} / \mathrm{cm}^{2}$ thickness containing small amounts of some sixteen known impurities.

3. Data are presented graphically and a comparison with Slater's theoretical data is made.

(16)T

Gorak, Z., ORIGIN OF SOME SATELLITES IN X-RAY SPECTRA. (In Russian.)

Izvest. Akad. llauk S.S.S.R. Ser. Fiz. 24, 422-423 (1960).

Trans: Bull. Acad. Sci. U.S.S.R. Phys. Ser. 24, (In Process.)

1. Satellites of the $K \alpha$ of $\mathrm{Ne}$ and the $K \alpha$ of $\mathrm{Fe}^{+++}$were studied.

3a. Lines $K \alpha^{\prime}$ and $K \alpha^{\prime \prime}$ of $\mathrm{Ne}$ are caused by the interaction of vacancies in the 15 and $2 p$ shells.

3b. The K $\beta^{i}$ line of $\mathrm{Fe}^{+++}$is caused by the interaction of a $3 p$ vacancy with the partially filled $3 d^{5}$ shell. 
(17) A

Holliday, J. E., A SOFT X-RAY SPECTRCHETER USING A FLON PROPORTIONAL COUITER.

Rev. Sci. Instr. 31, 891-895 (1560).

1. The $i$ emission spectra of $c$ and $\varepsilon e$ and the $1 u_{1}, 5$ emission spectra of $H o$ and $\mathrm{Nb}$ were studied.

2. A blazed grating spectrometer equipped with a P-lo flow proportional counter having a $1000 \mathrm{~A}$ window which transmits $17 \%$ of incident radiation at 200A was used; the spectrometer operates in the range $30-200 \mathrm{~A}$ and can be evacuated to $10^{-7} \mathrm{~mm} \mathrm{Hg}$.

3. All spectra are presented.

$(13) A$

Jacob, L., R. Noble and H. Yee, PHOTOMULTIPLIER SOFT K-RAY SPECTROMETEK.

J. Sci. Instr. 37, 460-462 (1960).

1. A new soft X-ray spectrometer at the University of Liverpool is described.

2a. The spectrometer has a 15 stage Be-Cu photomultiplier mounted on a radial arm rotating about the Rowland circle, a 30,000 lines/inch grating is used and the slit width is $0.004 \mathrm{in}$. with a resolution of $1 \mathrm{~A}$.

2b. The pulses are integrated by using a direct current amplifier to amplify the average current from the multiplier.

3a. The spectrometer, grating mounting and amplifier circuits are diagramed.

3b. Preliminary emission band spectra of $\mathrm{Al}, \mathrm{Mg}$, $\mathrm{Na}$ and Li are presented.

(19)E

Johansson, P., AiN EXPERIMENTAL IINVESTIGATION OF $X$-RAY EXCITATION STATES IN SOLIDS. Arkiv. Fysik 18 (4), 289-303 (1960).

1. The $K \alpha_{1}$ line of metallic $\mathrm{Cr}$ and of $\mathrm{Cr}_{2} \mathrm{O}_{3}$ is recorded at only a few volts above the excitation potential.

2. A bent crystal (topaz) spectrometer evacuated to $10^{-6} \mathrm{~mm}$ ig was used; intensities were determined with a commercial G-M counter.

3a. A small ( $0.1 \mathrm{eV})$ wavelength shift is found by using this "low" excitation voltage.

4. Three major conclusions are reached:

(a) The position in the spectrum of an $x$-ray line is dependent upon the voltage for excitation energies slightly above the threshold value; (b) The energy shift between threshold curves and ordinary curves is small; (c) The emission energy is lower for the threshold line than for the ordinary line.

(20) E

Karal'nik, S. H., I. G. Nikolaeva and N. H. Llefedov, HIGH TEMPERATURE X-RAY SPECTRAL INVESTIGATION IiI liNVAR ALLOYS. (In Russian.) Izvest. Akad. Nauk S.S.S.R. Ser. Fiz. 24, 473-475 (1960).

Trans: 3ull. Acad. Sci. U.S.S.R. Phys. Ser. 24, (In process.)

1. The displacement of the $i$ ron $K$ absorption edge was measured in Fe-Pt alloys containing $25,48,56$, and $75 \mathrm{w} / \mathrm{o} \mathrm{Pt}$; the 25,48 , and
$56 \mathrm{w} / \mathrm{O} \mathrm{Pt}$ alloys were also measured between 70 and $930^{\circ} \mathrm{C}$; an alloy containing $\mathrm{Fe}-34 \mathrm{w} / \mathrm{O} \mathrm{Ni}$ was also investigated.

2. A crystal spectrometer was used.

2. The $K$ edge in the $48 \% \mathrm{Pt}$ alloy was displaced to longer wavelengths with rising temperature while the reverse was true in the $56 \% \mathrm{Pt}$ alloy.

(21)E

Kern, B., THE Si KB BAND FROM X-RAY EMISSION SPECTRA OF ELEMENTARY SILICON, CARBORUNDUN AND QUARTZ. (In German.)

Z. Physik 152, 178-193 (1960).

1,2. A bent crystal vacuum spectrograph with a dispersive power of $0.498 \mathrm{~mm} / \mathrm{eV}$ was used to study the SiKB emission bands of Si, SiC, and $\mathrm{SiO}_{2}$; intensities were recorded photographically.

3a. All spectra and a table giving the energy values of the structural features are presented.

3b. Comparison of the results with results for diamond indicate that these are valence band spectra and that they are only slightly influenced by unusual perturbed states.

4. The bonding is essentially covalent in all cases.

(22)E

Korsunski i, M. I. and Ya. E. Genkin, FLUORESCENCE SPECTRA OF NIOBIUH IN THE COMPOUNDS NBB32, NbC, NbN, AND IN PURE Nb. (In Russian.) Izvest. Akad. Nauk S.S.S.R. Ser. Fiz. 24, $461-464$ (1960).

Trans: Bull. Acad. Sci. U.S.S.R. Phys. Ser. 24, (In Process.)

2. A curved crystal (mica) spectrograph was used to study $L B_{2}$ and $L Y 1$ lines, and the spectra were photographically recorded.

3a. Satellite lines of ilb are changed in the compounds due to $\mathrm{L}_{2} \rightarrow \mathrm{N}_{4}$ and $\mathrm{L}_{3} \rightarrow \mathrm{N}_{5}$ transitions.

3b. The density of $d$ states is discussed.

(23) $T$

Korsunskii, M. I. and Ya. E. Genkin, INTENSITY FATI 10 OF THE $L \beta_{2}, L \beta_{15}$, and $L \gamma_{1}$ LINES IN THE L SERIES OF SUESTANCES WITH AN UNFILLED N SHELL. (In Russian.)

Izvest. Akad. Wauk S.S.S.R. Ser. Fiz. 24, 465-469 (1960).

Trans: Bull. Acad. Sci. U.S.S.R. Phys. Ser. 24, (In Process.)

1,2. The number of transitions for $L \alpha_{1}, L \alpha_{2}, L \varepsilon_{1}$, $L \beta_{2}, L \beta_{15}$, and $L \gamma_{1}$ lines are computed on the basis of the degree of filling of the $N$ shell.

3. The density of $d_{3 / 2}$ and $d_{5 / 2}$ states in $\mathrm{Nb}, \mathrm{Mo}$, $\mathrm{Rh}, \mathrm{Pd}$, and $\mathrm{Ag}$ is calculated.

(24)T

Kurylenko, C., ISOLATED BREAIS IN THE X-RAY K DISCONTINUITY OF COPPER. (In French.) Cahiers de Physique 14 No. $113,25-28$ (1960). 
(24) T Cont'd.

1,2. T. Hayashi's theory of absorption spectra is examined and Veldkamp's mass absorption coefficient measurements on Cu are explained on this basis.

3a. The isolated breaks (fine structure) are asymmetric with respect to the energy positions $E_{(200),} E_{(220)}$.

3b. The respective mass absorption coefficient symmetry variations indicate that perturbed energy states predominate over non-perturbed states.

3c. Detailed diagrams of the fine structure and the $\mu / \rho$ variation vs. wavelength are given.

(25) T

Kurylenko, C., FINE STRUCTURE IN THE HEIGHBORHOOD CF THE $K X$-RAY DISCONTINUITY IN ZINC.

Cahiers de Physique 14, No. 115, 119-123 (1960). (In French.)

1. The probability of electron transfer between perturbed and non-perturbed energy zones is examined.

2. The theories of Brillouin, Bethe and Hayashi concerning the variation of the mass absorption coefficient, $\mu / P=P(E)$ where $P(E)$ is the electron transport probability for perturbed and non-perturbed energy zones are used.

3. The probability vs. the actual $\mu / \rho$ curve is plotted, and perturbed and non-perturbed energy contours in $\mathrm{Zn}$ are shown.

(26)E

Liefield, R. J., L SERIES X-RAY EMISSION AND ABSORPTION SPECTRA IN ZIRCONIUN.

Univ. Microfilms LC card \#MIC 60-1197, 99 pp. (1960). Diss. Abs. 20, 4147 (1960).

1. The $L B_{2}$ and $L y$ lines of $Z r$ were studied.

2. A double crystal (quartz) spectrometer was used in the $(1,+1)$ position at a pressure of $4 \times 10^{-8} \mathrm{~mm} \mathrm{Hg}$.

3. A density of states curve with a fairly steep high frequency edge, with no evidence of the double peaked structure predicted for d-type states in first period transition elements, is proposed.

(27)E

Lucasson, A., STUDY OF $\mathrm{Zn}, \mathrm{Ga}, \mathrm{Ge}$, and Cu ALLOYS BY $X$-PAY SPECTROGRAPTiY. (In French.) Annales de Physique (13) 5, 509-565 (1960).

1. Both the $L$ absorption and emission spectra in solid $\mathrm{Zn}, \mathrm{Ga}, \mathrm{Ge}$, and the $\mathrm{L}_{3}$ edge of $\mathrm{Cu}$ in alloys of $\mathrm{Cu}-\mathrm{Ni}, \mathrm{Cu}-\mathrm{Zn}$, and $\mathrm{Cu}-\mathrm{Al}$ were investigated.

2. A crystal spectrometer was used.

3a. Spectra and tabular results are presented.

$3 b$. The measured $L_{2}$ edge widths of $\mathrm{Zn}$ and $\mathrm{Ge}$ and the $L \alpha+L \beta$ line widths gave the width of the third band in $\mathrm{Zn}$ and $\mathrm{Ge}$.

3c. The Fermi level shift was obtained from the $L_{3}$ edge shift in the $\mathrm{Cu}$ alloys.
(28)E

Luki rski i, A. P. and Yu. A. Omel'chenko, USE OF THE PHENOMENON OF "TOTAL EXTERNAL REFLECTION" FOR FILTERING THE CONTUOUS SPECTRUM IN THE ULTRA-SOFT X-RAY REGION. (In Russian.) Optica i Spectrosk $\underline{8}(4), 563-568$ (1960). Trans: Optics and spectroscopy $\underline{8}, 297-299$ (1960).

1. The short wavelength component of the $W$ continuum was filtered by means of Be or quartz reflectors at various angles.

2. A $6001 \mathrm{ines} / \mathrm{mm}$ grating was used at a grazing angle of $5.5^{\circ}$ in a vacuum spectrometer to study the radiation obtained; the vacuum was $1 \times 10^{-6} \mathrm{~mm} \mathrm{Hg}$.

3. The $y$ continuum ( $f i l$ tered and unfiltered radiation) and a table of the relative continuum intensities in the 100-150A region are presented.

4. This filtered radiation may be used as the source in the study of soft $x$-ray absorption spectra.

(29) A

Luki rski i, A. P., M. A. Rumsh and L. A. Smirnov, $X$-RAY MONOCHROMATOR FOR ULTRASOFT RADIATION WITH THE RECORDING OF THE ABSOLUTE NUMBER OF QUANTA. (In Russian.)

Optika i Spektoskopiya 2, 505-508 (1960). Trans: Optics and Spectroscopy (U.S.S.R.) 2, (4), 262-265 (1960).

1. A 15,000 lines per inch vacuum $X$-ray monochromator for the spectral region 15-120A is described; the grating is one meter radius and the grazing angle is $2.5^{\circ}$.

2a. The $K l$ ines of $F, O, C, B$ and $B e$ are excited and this $K$ radiation is used to excite the desired spectra; the pressure in the $x$-ray tube is $5 \times 10^{-7} \mathrm{~mm} \mathrm{Hg}$.

2b. A methane quenched argon "Geiger" counter is used to obtain intensity data; a photomultiplier can also be used.

3a. Construction details and diagrams are presented.

3b. The characteristic $K$ spectra of $F, O, C, B$, and $\mathrm{Be}$ are given.

(30)E

Lukirski i, A. P., M. A. Rumsh, and I. A. Karpovich, MEASUREMENT OF THE PHOTOELECTRIC YIELD OF THE EXTERINAL PHOTOEFFECT UNDER THE ACTION OF $X-$ RAYS IN THE WAVELENGTH RANGE 1.54-13.3A. (In Russian.)

Optika i Spektroskopiya 2, 653-657 (1960). Trans: Optics and Spectroscopy (U.S.S.R.) 2, 343-346 (1960).

1,2. An Allen Be-Cu photomultiplier was used to investigate the photoelectric yields of $\mathrm{Ti}$, $W, \mathrm{Pt}, \mathrm{NaBr}, \mathrm{SrF}_{2}$, and $\mathrm{Csl}$.

3a. A complete account of the operating characteristics for the photomultiplier is given for this spectral region.

3b. A table of photoelectric yields for the substances studied is given; the specimens were excited by characteristic $x$-rays of various elements. 
(30)E Cont'd.

3c. The photoelectric yield rose with increasing wavel ength.

4. The authors feel that this rise is due to the decreased penetration of the $x$-rays into the photocathode.

(31) $\mathrm{E}$

Lukirski i, A. P., M. A. Rumsh and L. A. Smirnov, MEASUREMENT OF THE PHOTOELECTRIC YIELD FOR ULTRASOFT X-RADIATION. (In Russian.) Optika i Spe'ctoskopiya 2, 511-513 (1960). Trans: Optics and Spectroscopy (U.S.S.R.) 2 (4), 265-267 (1960).

1,3. Values of the photoelectric yield on a percentage basis are given for Be, Ni, W, LiF, $\mathrm{NaF}, \mathrm{CaF}_{2}, \mathrm{SrF}_{2}$, and $\mathrm{NaCl}$ excited by the $\mathrm{K}$ line of $\mathrm{O}, \mathrm{C}, \mathrm{B}$, and $\mathrm{Be}$, respectively.

2a. Using the apparatus described in Ref. \#29, 1960, a Be-Cu photomultiplier was used to count small numbers of photoelectrons and a Geiger counter was used for absolute counting of quanta.

2b. The electrical apparatus details are given and it is shown that, in general, the number of registered impulses equals the number of photoelectrons if the probability of the appearance of two electrons as a result of the action of a single quantum is neglected.

(32) $E$

Mande, C, CONTRIBUTION TO THE STUDY OF GOLD AND PALLADIUM AND OF THEIR ALLOYS $3 Y X$ X-RAY SPECTROGRAPHY. (In French.)

Ann. phys. 2, 1559-1614 (1960).

1. The $L$ and $M$ absorption spectra of pure $A u$, the $K$ and $L$ absorption spectra of pure $P d$, the $L$ absorption spectra of $A u$ and the $K$ absorption spectra of Pd in Au-Pd alloys and the $L \beta_{2}$ of $\mathrm{Pd}$ and the $L \beta_{5} A u$ emission lines were studied.

2a. A curved crystal (quartz) spectrograph was used. Intensities were recorded photographically, the spectra being obtained by means of microphotometry.

2b. For absorption specimens, Sandstrom's criterion for optimum absorber thickness was used.

3a. All spectra are given and the data are also tabulated.

3b. A density of states curve for pure $\mathrm{Au}$, and Pd, based on the data, is presented.

3c. The changes in the absorption and emission spectra occurring on alloying are presented.

(33)E

Men'shikov, A. Z, and S. A. Nemnonov, X-RAY

ABSORPTIO IS SPECTRA IN COMPOUISDS WITH A NICKELARSENIDE STRUCTURE. (In Russian.)

Fiz. Metal. i Metallovedne 10, 390-396 (1960). Trans: Physics of Metals and Metal lography 10 (3), 74-7) (1960).

1. The $\mathrm{K}$ absorption spectrum for $\mathrm{Cr}$ was studied in the compounds CrS, CrSe, CrTe, and CrSb.

2. A quartz crystal spectrometer was used to study powdered specimens of the compounds; intensities were recorded photographically.

3. All spectra are presented for comparison with the spectrum of pure $\mathrm{Cr}$; many differences are apparent.

4a. The d electrons of transition metals participate only weakly in the chemical bond in NiAs types.

4b. For the substances studied a $p^{3}$ or $s p^{2}$ electron configuration is most likely.

(34) $\mathrm{E}$

Nemnonov, S. A., FINE STRUCTURE OF THE FUNDAMENTAL $\checkmark$ ABSORPTION EDGE OF TRANSITION METALS OF THE IRON GROUP, THEIR ALLOYS, AND COMPOUNDS. (In Russian.)

Izvest. Akad. Nauk S.S.S.R. Ser. Fiz. 24, $4,47-454$ (1960)

Trans: Bull. Acad. Sci. U.S.S.R. Phys. Ser. 24, (In Process.)

1,3a. K absorption measurements are tabulated for $\mathrm{Cr}, \mathrm{Mn}, \mathrm{Fe}, \mathrm{Co}, \mathrm{Ni}, \mathrm{Cu}, \mathrm{Zn}$ and their oxides, sulfides, halides and sulfates; tabular data are also presented for Fe containing 17, 25, 50 , and 75 a/o Al.

3b. In the compounds the fundamental $K$ edge is shifted $8-15 \mathrm{eV}$ towards higher energies than in the pure metal.

4. With increasing Al content, the superposed $3 d-4 s$ bands of iron are filling with $p$ type electrons.

(35)E

Nemnonov, S. A. and L. D. Finkel'shtein, THE CHARACTER OF THE INTERATOMIC INTERACTION OF HYDRIDES OF SOME TRANSITION METALS. (In Russian) Fiz. Metal. i Metallovedne 2, 530-534 (1960). Trans: Physics of Metals and Metallography 2 (4), 48-5i (1960).

1. The $K$ absorption edge of $V$ pure and alloyed with 45 a/O $H$ was studied.

2. A bent crystal (quartz) spectrograph was used.

3a. The long wave VH lines were considerably less intense than those of pure $V$.

3b. The $V$ and $H$ bond in $V H$ is nonlocalized (mixed covalent and ionic).

4. The VH long wave spectra are explained by a screening loss in the $3 \mathrm{~d} 4 \mathrm{~s}$ band by the $4 p$ band due to the interatomic distance increase on alloying.

(36) E

Nemnonov, S. A. and A. Z. Menshikov, X-RAY ABSORPTION SPECTRA OF CHROMIUM IN CHROMIUM SILICIDES. (In Russian.)

Fiz. Metal. i Metallovedne 2, 385-389 (1960). Trans: Physics of Metals and Metallography 2 (3), 57-61 (1960).

1. The silicides $\mathrm{Cr}_{3} \mathrm{Si}, \mathrm{Cr}_{3} \mathrm{Si}_{2}, \mathrm{CrSi}$ and $\mathrm{CrSi}_{2}$ were studied. 
(36)E Cont'd.

3. Changes in the $k$ edge showed that the number of electrons participating in the $\mathrm{Cr}-\mathrm{Cr}$ bond decreased while the $\mathrm{Cr}-\mathrm{Si}$ bond electrons increased with increasing Si content.

4. The bond is a mixed covalent-metallic up to $\mathrm{CrSi}_{2}$ when covalency becomes prevalent.

(37)E

Nemnonov, S. A. and M. F. Sorokina, THE FUNDAMENTAL K-ABSORPTION EDGE OF IHICKEL IN NICKELALUMINUM ALLOYS. (In Russian.) Izvest. Akad. Nauk SS.S.R. Ser. Fiz. 24 , 455-460 (1960) Trans: Bull. Acad. Sci. U.S.S.R. Phys. Ser. 24, (In Process).

1. Pure Ni, $\mathrm{Ni}_{3} \mathrm{Al}, \mathrm{NiAl}$ and $\mathrm{NiAl}_{3}$ were studied.

2. A bent crystal spectrograph was used.

3. The 3d band is full in $\mathrm{NiAl}$ and $\mathrm{NiAl}_{3}$ and nearly so in $\mathrm{Ni}_{3} \mathrm{Al}$.

(38)E

Nemnonov, S. A., M. F. Sorokina and L. D. Fin, INVESTIGATION OF THE K ABSORPTION SPECTRUM OF SMALL ADDITIONS OF ZINC IM ZINC ALIMINUM ALLOYS. (In Russian.)

Fiz. Metal. i Metallovedne 10, 148-150 (1960). Trans: Physics of Metals and Metallography 10 (1), 142-144 (1560).

1. The $K$ absorption edge of $A l$ and of $Z n$ in an alloy of Al containing 1.7 weight percent $\mathrm{Zn}$ was studied.

2. A film of alloy $210 \mu$ thick was photographed using a bent crystal (quartz) spectrometer as the dispersing agent.

3a. A comparison curve for the absorption edges of $\mathrm{Al}$ and $\mathrm{Zn}$ in the alloy vs. the $k$ edge of pure $\mathrm{Zn}$ is given; the $\mathrm{Zn}$ edge is shifted to $0.8 \mathrm{eV}$ toward lower energies.

3b. Details or the observed fine structure are tabulated.

4. The conduction band of the alloy is common to both elements.

(39) E

Neupert, W. M., PHOTON ABSORPTION BY VALENCE ELECTRONS IN ALUMINUM, NICKEL, AND COPPER. Thesis, Cornell University (1960). Univ. Microfilms MIC 60-830, 107 Pp. Diss. Abs. 20, 41 $42-4143$ (1960).

1. Maxima near L absorption edges in Al and near $M$ absorption edges in $\mathrm{Cu}$ were investigated.

2a. A normal incidence vacuum spectrograph was modified to operate in the energy region 50 to $15 \mathrm{eV}$ (200-900A); the resolution near the high energy end is better than $0.1 \mathrm{eV}$.

2b. Thin films formed directly in the chamber were investigated; the area densities ranged from 15 to $34 \mu \mathrm{g} / \mathrm{cm}^{2}$.

3. All observed absorption maxima in the three metals are tabulated.

4. Collective oscillations (plasmons) as well as interband transitions may participate in the attenuation of the incident beam; how- ever, it is felt that the dominating process is the interband transition.

(40) E

Nigam, A. N. and K. S. Srivastava, FORBIDDEN TRANSITICN LIMI IN THE SPECTRUM OF PLATINUM (78). J. Sci. E Ind. Research (India) 198, 111-112 (1960).

1,2. A curved crystal (mica) spectrograph having a dispersive power of $5.8 \mathrm{XU} / \mathrm{mm}$ was used to study the L emission spectrum of Pt; intensities were recorded photographically with exposure times of $6-\overline{8}$ hours.

3. A faint line was observed at $1167.3 \times U(\nu / R=$ 730.66) which is believed to be due to the $\mathrm{L}_{1} \mathrm{H}_{1}$ transition in $\mathrm{Pt}$.

(41) E

Nikolaeva, L. G. and S. M. Karal'nik, THE BASIC KEDGE ABSORPTION OF $X$-RAYS OF IRON AND VANADIUM IN THEIR ALLOYS AND TWO MODIFICATIONS.

(In Ukrainian.)

U'srain. Fiz. Zhur. 5, 231-234 (1960). Annotation from Chem. Abs. 55, 1176 i.

1. The $k$ edges in FeV alloys and in $\alpha$ and $\sigma$ phase modifications were studied.

3. The short wave displacement in the alloys attained a peak of 4 to $5 \mathrm{eV}$ in the middle concentration range.

4. The $\alpha \rightarrow \sigma$ transformation was attended by the transfer of $\mathrm{Fe} 3 \mathrm{~d}$ electrons to $V$ atom outer levels.

(42) E

Ovsyannikova, I. A. and I. B. Borovski i, FINE STRUCTURE OF THE X-PAY $K$ SPECTRA OF SOME SULFIDES. (In Russian.)

Izvest. Akad. Nauk S.S.S.R. Ser. Fiz. 2/4, 435-4:4:0 (1960).

Trans: Bull. Acad. Sci. U.S.S.R. Ser. Phys. 24, (In Process.)

1. The $K$ absorption edges and satellites in $\mathrm{Cu}$, $S$, CuS, Ni, NiBi, and Nis were studied.

2. A bent crystal spectrometer was used and the spectra were photographically recorded.

3a. Copper in Cus changes in the direction of a zinc spectrum indicating the promotion of a $3 p$ electron in sulfur to a conduction electron of the $4 \mathrm{~s}$ variety.

4. Both copper and sulfur contribute electrons to the conduction band.

Pike, E. R., - See Review (R-11).

(43) A

Rumsh, M. A., A. P. Lukirski i and V. N. Shchemelev, PHOTOEFFECT FOR METALLIC CATHODES IN THE WAVELENGTH REGION FROM 1.39 TO $13.3 \mathrm{~A}$. 
(43) A Cont'd.

Doklady Akad, ilauk U.S.S.R. 135, 55-57 (1960). (In Russian.)

Trans: Soviet Physics "Doklady' 5, 1231-1233 (1960).

1. The quantum yield, $K$, measured at $\theta=10^{\circ}$, where $\theta$ is the angle of incidence, is given for $\mathrm{W}, \mathrm{Ni}$, and $\mathrm{Be}$ photocathodes in the range $1.339 \mathrm{~A}$ to $13.33 \mathrm{~A}$

2. See Ref. \#30 (1960) for a description of the methods used.

3. Results for each photocathode are tabulated at nine points within the stated wavelength region.

$(44) A$

Rumsh, M. A., A. P. Lukirski i and V. H. Shchemelev, A VACUUM $X$-RAY MONOCHROMATOR FCR DETERMIIING TIIE A.ESOLUTE EFFICIENCY OF RADIATION RECEIVERS. (In Russian.) Pribory i Tekhnika Eksperimenta No. 5, 67-73 (1960).

Trans: Instruments and Experimental Techniques 1960, 755-761.

1. A flat crystal Bragg type monochromator capable of being used in the $1 \mathrm{~A}$ to $19.3 \mathrm{~A}$ region is described in great detail; a cutaway isometric view is also provided.

3a. Using the expression

$$
\text { No }=\frac{K_{4} K_{5}}{K_{1} K_{2}\left(1-K_{3}\right)} \mathrm{N}
$$

where No is the number of quanta falling on a flow proportional type counter per second, $N$ is the observed counting rate,

$K_{1}$ is the transmittance of the entrance window, $K_{2}$ and $k_{3}$ are the transmittances of the gas in the tube,

$K_{4}$ is the counting loss factor, and

$K_{5}$ is a factor for extraneous pulses, a special counter tube is designed which enabled the authors to measure $K_{1}, K_{2}$, and $K_{3}$. The terms for $K_{4}$ and $K_{5}$ were calculated.

3b. Results for $\mathrm{Cu}, \mathrm{Ti}, \mathrm{Cl}, \mathrm{Al}, \mathrm{Na}$, and $\mathrm{F}$ are shown graphically.

(45) T

Shiraiwa, T., THEORY OF THE FINE STRUCTURE OF THE $X$-RAY ABSORPTION SPECTRUM.

J. Phys. Soc. Japan 15, 240-250 (1960).

1. State lifetimes are considered. It is assumed that the inelastic cross-section of collision between the electron and an atom is of the order of I square A.

2. Using this assumption, Kronig's method is applied in order to obtain transition probabilities.

3a. The scattering amplitude for the Hartree field of the atom is numerically calculated.

$3 b$. The method is applied to the $K$ absorption spectra of $\mathrm{Cu}, \mathrm{Ti}$, rutile, and anatase, and good agreement with experimental results is obtained except for the Ti-oxides.

3c. Calculated spectra are presented in detail.

$(46) T$

Shmidt, V. V., ON THE EFFECT OF INTERELECTRCN INTERACTION II METALS ON THE FINE STRUCTURE OF $X$-RAY SPECTRA. (In Russian.)

Zhur. E'ssptl. i Teoret. Fiz. 39, 1269-1275 (1960).

Trans: Soviet Physics "JeTP" 12, 886-390 (1961).

1. An attempt is made to solve the problem of finding the absorption coefficient taking into account the interaction between an electron which has absorbed an X-ray quantum with all the free electrons of the metal.

2. The free electron theory of slater is used to determine the ratio of the absorption coefficient with plasma production to that given by the single-electron theory.

3a. The ratio is given as $\mathrm{Ti}=5, \mathrm{Cr}=1$, and $\mathrm{Fe}=0.1$.

3b. The results are confirmed by the fact that, in experimental work, the fine structure details decreased in the order $\mathrm{Ti}, \mathrm{V}, \mathrm{Cr}$, Fe and disappeared in li i .

(47) $T$

Shuvaev, A. T., INTERPRETATION OF X-RAY SPECTRA. (In Russian.)

Izvest. Akad. Nauk S.S.S.R. Ser. Fiz. 24, $424-427$ (1960).

Trans: Bull. Acad. Sci. U.S.S.R. Phys. Ser. 24, (In Process.)

1. A change in the $K$ edge is assumed to be due to a change in the is level upon removal of a is electron by valence bonding.

2. Ey using a self-consistent field method, a value of $0.15 \mathrm{eV}$ is calculated for the screening constant change of $\mathrm{Ca}, \mathrm{Fe}$, and $\mathrm{Zn}$.

3. The magnitude of $K B_{5}$ (conduction $\rightarrow K$ band transitions) line displacement is about $2 \mathrm{eV}$ for removal of a d electron and $\mathrm{I} \mathrm{eV}$ for $s \rightarrow d$ and $s \rightarrow p$ changes.

4. Inner screening by $3 p$ and $4 s$ levels in elements of $Z=20-29$ increases because the $d$ levels are filling.

(48)E

Singh, J. N., FINE STRUCTURE OF THE $K X$-RAY ABSCRPTION EDGE OF GERMANIUM.

Thesis to !lashington State University. Univ. Microfilms MIC 60-5350, $92 \mathrm{pp}$.

Diss. Abs. $21,2343(1961)$.

1. A thin (12.5 $\mu$ ) single crystal of Ge was investigated by means of the transmission method; only the high energy side of the $K$ edge was studied.

2. A double crystal (quartz and calcite) spectrometer was used; a proportional counter was employed to obtain intensity data.

3a. New features were observed in the absorption structure; the results could be explained by Hayashi's theory and by Kronig's theory.

3b. A necessary proof of the $\cos ^{2} \theta$ dependence in the kronig theory is provided by the results. 
(49) $T$

Taylor, G. R. and $W$. B. Payne, RETARDATION AND K $X$-RAY RELATIVE IIITEIISITIES.

Phys. Rev. 118, 154-1551 (1960).

1. The matrix elements are numerically evaluated for electric dipols transitions with retardation for transitions between the $1 \mathrm{~s}$ and higher states of a single Dirac electron in a coulomb field.

3a. The relative intensities of the principal K $x$-ray lines in elements of high atomic number are tabulated.

3b. Data on the relative intensity of $K \alpha_{2}: K \alpha_{1}$; $K \beta_{3}: K \beta_{1}$; and $K \beta_{1}: K \alpha_{1}$ are presented.

4. The effect of retardation is more significant than screening effects only when the total angular momentum of the electron changes; this effect shows itself in the $: \alpha_{2}: k \alpha_{1}$ intensity ratio in lead.

(50)A

Tomboulian, D. H., THE PERFORMAIICE OF A Be-Cu PHOTOMULTIPLIEF, IN THE 100 A TO 300 A REGION. U.S. A.t. Energy Comm. UP-8475, 29 PP. (1960).

1,2. A Be-Cu photomultiplier was used to count quanta in absorption coefficient determinations in the 100-300A region.

3. The reliability of the photomultiplier is carefully outlined.

(51) $T$

Tomboulian, D. H., THE ANGULAR DISTRIBUTION OF THE SYNCHROTROAI RADIATION IN THE EXTREME ULTRAVIOLET AIID X-RAY REGIONS.

Office of Ordnance Research, Project \#2486, Tech. Rept. \#1, (1960).

1. Classical and quantum theories of electromagnetic radiation of high energy electrons in circular motion are explored.

2. The classical equation for the power radiated per unit solid angle into the Nth harmonic of the circular frequency is put into a form suitable for calculations, and the results of the quantum theory are compared with this classical expression.

3a. Curves of the angular power distribution for four wavelengths (108.6, 10.86, 1.086 and $0.1036 \mathrm{~A}$ ) in the region of most intense radiation are computed for a Cambridge-like accelerator at maximum energy (orbital radius = 26.26 meters, energy $=6$ Bev).

3b. The polarization of this radiation is also calculated, as well as the angular distribution of the total power radiated into all wavelengths.

(52) E

Tomboulian, D. H., SOFT X-RAY PHOTON COUNTERSTAEILIZATION OF SOURCE.

Office of Technical Services, PO 158025,

Tech. Rept. \#4, 14 pp. (1960).
1. The methods adopted for regulating the $x-r a y$ tube current and potential are described.

2. Circuitry and behavior of the voltage and current regulators are discussed.

3a. The $\mathrm{X}$-ray potential is regulated by a commercial 1 ine voltage regulator.

The regulator is modi fied so that the controlling signal is derived directly by sampling a fraction of the $D C$ target voltage.

3b. The X-ray tube current is regulated by an electronic circuit which, in effect, changes the impedance in the primary circuit of the $\mathrm{X}$-ray $\mathrm{filament}$ heater transformer to compensate for changes in the $x$-ray tube current.

(53)E

Vainshtein, E. E., E. A. Zhurakovskii, V. S. Neshpor, and G. V. Samsonov, FINE STRUCTURE OF X-RAY K SPECTRAL ABSORPTION AND THE HALL EFFECT IN VANADIUM SILICIDES. (In Russian.) Doklady Akad. Nauk S.S.S.K. 134, 68-70 (1960). Trans: Sov. Phys. 'Doklady" 5, 996-998 (1961).

1. The substances studied were $V_{3} S i, V_{5} S i_{3}$, and VSi ${ }_{2}$ containing not more than $0.6 \%$ free $\mathrm{Si}$; the $K$ absorption edge was investigated.

2. A curved crystal (quartz) spectrograph was used.

3a. The absorption maximum shifts towards higher energies with increasing silicon content.

3b. Spectra are presented and a table of results is given.

4. The short wavelength displacement of the maximum may be connected with the perturbation of the vanadium "d" states by the neighboring silicon atoms.

1960 (C)

$(C-1) A$

Baez, A. V., A SELF-SUPPORTIHG METAL FRESNEL ZONE PLATE TO FOCUS EXTREME ULTRAVIOLET AND SOFT $X$-RAYS.

Nature 186, 958 (1960).

1. A fresnel zone-plate consisting of 19 metal zones held together by thin radial struts was prepared.

2. The zone-plate was produced by $1 \mathrm{i}$ thographic techniques; it is $10 \mathrm{microns}$ thick and the narrowest gold band has a width of 20 microns.

3. Tests were made at 6700,4358 and $2537 \mathrm{~A}$; at $1000 \mathrm{~A}$ the zone-plate is faster than any lens.

4. The zone-plate will give excellent resolution down to 100A.

$(\mathrm{c}-2) \mathrm{T}$

Blokhin, M. A. and V. P. Sachenko, FORM OF THE ENERGY BANDS FOR A SOLID. (In Russian.) Izvest. Akad. Nauk S.S.S.R. Ser. Fiz. 24, 397-406 (1960). 
$(c-2) T$ Cont'd.

Trans: Bull. Acad. Sci. U.S.S.R. Phys. Ser. 24 (10), (In Process.)

1. The amount of level broadening occurring as the free electron state is approached, was calculated.

3. The effect of this broadening on $x$-ray emission bands and on electron distribution within the band is enumerated.

$(\mathrm{C}-3) \mathrm{E}$

Coles, B. R., ELECTRICAL RESISTIVITY AND THE ELECTRONIC STRUCTURE OF $\mathrm{Cu}_{3} \mathrm{Au}$. Physica 26, 143-144 (1960).

1. It is stressed that a direct indication of a reduction, upon ordering, of the freedom of conduction electrons in $\mathrm{Cu}_{3} \mathrm{Au}$ can be found in the electrical resistance.

3. A table of resistivity is given for ordered and disordered types of $\mathrm{Cu}_{3} \mathrm{Au}$ at 273 and $4.2^{\circ} \mathrm{K}$; the temperature effect. on the Brillouin zone structure is discussed.

$(\mathrm{c}-4) \mathrm{T}$

Cornwell, J. F. and E. P. Wohlfarth, AN ENERGY BAND INTEFPOLATION SCHEME WITY APPLICATION TO BCDY-CENTERED CUBIC LITHIUM. Nature 186, 379-380 (1960).

1,2. The energy bands in BCC-Li were calculated using plane wave expansions of the wave functions and accurately known values of the energy levels at high-symmetry points in the Brillouin zone; for valence states having the same symmetry as the ion cores, the expansion includes a repulsive pseudo-potential ( $V r$ ).

3. A calculated band structure and a density of states curve are presented; the Fermi energy was -0.425 Ry and the Fermi surface does not touch the zone boundary.

$(C-5) T$

Curie, D., CALCULATION OF EMISSION STRUCTURE IN THE CONFIGURATION COORDINATE MODEL. (In French) Compt. Rend. (French Academy) 250, 834-336 (1960).

1,3. A simple derivation is presented for emission and absorption bandwidths at $0^{\circ} \mathrm{K}$, for the increase of bandwidth with temperature elevation; and for band displacement due to an elevation of temperature.

$(\mathrm{C}-6) \mathrm{E}$

Dawber, K. R., PHOTOELECTRIC YIELD FROM ADSORBED GAS LAYERS IN THE SOFT X-RAY REGION. Rev. Sci. Inst. 31, 210-211 (Feb. 1960).

1. The photoelectric yield of Allen type photomultipliers was determined as a function of temperature, pressure, and time after firing.

2. A 10-stage photomultiplier assembly was mounted without an envelope in a vacuum system containing a 200-300A X-ray source (A) target). The photosensitive first plate of the photomultiplier was made interchangeable and specimens of Be-Cu both clean and oxidized, $\mathrm{Cu}, \mathrm{Al}, \mathrm{Ta}$ and stainless steel were examined. The metal components could be rf vacuum fired, or the whole high-vacuum section could be baked out. The photomultiplier could be operated immediately after either heat treatment had ceased.

3a. Pyrofilm resistors between multiplier stages stood up well to $400^{\circ} \mathrm{C}$ bakeout or rf heating of the plates to $800^{\circ} \mathrm{C}$.

3b. The results showed that the yield from clean metal or alloy surfaces was negligible compared to that from the adsorbed gas.

3c. Stable multilayer adsorption occurred on $\mathrm{Cu}$ above pressures of $1.5 \times 10^{-5} \mathrm{~mm} \mathrm{Hg}$; below this pressure only monolayer adsorption appeared stable.

3d. Time variations in yield at constant temperature were noted only at pressures below $1.5 \times 10^{-5} \mathrm{~mm} \mathrm{Hg}$ and showed no reproducibility.

4. The method of this experiment offers new means for investigating gas adsorption phenomena.

$(\mathrm{C}-7) \mathrm{E}$

Eley, D. D. and P. R. Wilkenson, ADSORPTION AND OXIDE FORIMATION ON ALUMINUM FILMS.

Proc. Roy. Soc. (London) A-254, 327-343 (1960).

1. The kinetics of oxygen uptake were followed at a pressure of $10^{-2}$ to $10^{-3} \mathrm{~mm} \mathrm{Hg}$.

3a. Place exchange of oxygen and aluminum atoms was deduced to be the governing uptake step.

3b. An equation for the weight uptake (g) was:

$$
\frac{d g}{d t}=\left(a e^{-\frac{\gamma g}{R t}}\right)\left(\rho^{0.6}\right)
$$

where a and $\gamma$ are constants.

$(\mathrm{C}-8) \mathrm{T}$

Flynn, C. P. and E. F. W. Seymour, THE CORRECTION OF SPECTRAL LINE SHAPES FOR INSTRUMENTAL AND OTHER BROADENING.

Proc. Phys. Soc. (London) 75, 337-344 (1960).

1. A rapid method for the correction of line shapes observed in any branch of spectroscopy is presented.

3a. The method is useful for distortions governed by the equation:

$$
f\left(x_{0}\right)=\int_{-\infty}^{+\infty} g(x) h\left(x_{0}-x\right) d x
$$

where $f(x)$ is the observed line shape, $g(x)$ the true line shape, and $h(x)$ an instrumental or intrinsic broadening function provided $h(x)$ is real and finite.

3b. Formulae for the corrections of moments of lines are also given.

$(C-9) T$

Goodenough, J. B., BAND STRUCTURE OF TRANSITION METALS AND THEIR ALLOYS. Phys. Rev. 120, 67-83 (1960).

1. An exhaustive re-examination of the band 
structure of the transition metals is pre-

sented with 95 references.

2. Several theoretical models are used.

3. (1) Density of states curves, (2) qualitative features of the band structures for the various transition metal crystal lattices, (3) the relation between d-orbital vs. neighbor configuration symmetry, band occupation and band characteristics in pure metals are presented.

$(C-10) E$

Hagstrom, H. D. and C. D'Amico, PRODUCTION AND DEMONSTRATION OF ATOMICALLY CLEAN SURFACES. Jour. Appl. Phys. 31, 715-723 (1960).

1. The cleaning of solid surfaces by means of ion bombardment was tested by applying it to the metal tungsten.

2. Surface conditions during the cleaning procedures were observed by means of Auger-type ejection of electrons by slowly moving positive ions.

3. This effect is capable of detecting changes in surface concentration of foreign atoms which amount to a few percent of a monolayer.

4. Ion bombardment produces the same surface as is produced by high-temperature flashing $\left(2200^{\circ} \mathrm{k}\right)$.

$(\mathrm{C}-11) \mathrm{T}$

Horak, Z., ORIGIN OF THE KB' LINE ACCORDING TO THE ANGULAR MOMENTUM COUPLING HYPOTHESIS.

Czech. J. Phys. 10, 405-406 (1960) (In English)

1,2. The Coster-Druyvesteyn theory is used to calculate the $K^{\prime}$ satellite structure in free $\mathrm{Mnt+}$ and $\mathrm{Fe}^{++t+}$ ions.

3. Calculated results are in fair agreement with those measured by other workers; a table is given.

4. The $K \theta^{\prime}$ originates from an angular momentum coupling.

$(C-12) \mathrm{T}$

Jaegle, P., CALCULATION OF THE RESOLVING POWER OF A SPECTROGRAPH WITH THO CONCAVE GRATINGS AT GLANCING INCIDEIICE. (In French.)

Compt. Rend. (French Academy) 250, 3620-3621 (1960).

1. The intensity distribution of the diffracted $x$-ray beam from a double grating spectrograph at grazing incidence is examined.

3. The resolution should be greatly improved without intensity loss by adding the second grating in a suitable position.

$(\mathrm{C}-13) \mathrm{T}$

Klemens, P. G., BAND STRUCTURE OF MONOVALENT METALS AND THEIR ALLOYS.

Australian J. Phys. 13, 233-246 (1960).

1,2. Bloch theory is used in an attempt to evaluate the conduction properties of metals.

3a. The Bloch theory can only be used with a spherical and isotropic Fermi surface.

3b. The Fermi surface of monovalent metals is examined mathematically and the form of the transport equation for electrical and thermal

$(C=14) T$

Lipscomb, is. N. and D. Britton, VALENCE STRUCTURES OF THE HIGHER BORIDES.

J. Chem. Phys. 33, 275-280 (1960).

1. An attempt to systematize the valence orbital structures of the boron frameworks in $\mathrm{MB}_{2}$, $M_{4}, M^{B}, M B_{12}, B_{12} C_{3}$ and pure boron is made.

2. The $B$ framework is isolated into polyhedra connected by localized bonds and the molecular orbitals of the individual polyhedra are investigated. Then electrons are "transferred" from the more electropositive element to the $B$ framework until the bonding orbitals are filled.

3a. Excess valence electrons on the metal atoms are regarded as metallic in character.

3b. The procedure outlined above is carried out in detail, and the results are diagramed.

$(C=15) T$

Murrel 1, J. N., CONSTRUCTION OF HYBRID ORBITALS. J. Chem. Phys. 32, 767-770 (1960)。

1. A method to construct the "best" hybrid orbi= tals is presented.

2. The method is based on the use of the principle of maximum overlap.

3. The method is illustrated by use of the example of $\mathrm{Cl}$ in $\mathrm{ClF}_{3}$.

$(C-16) E$

Nemnonov, S. A., L. D. Finkel'shtein and K. M. Kolobova, AN X-RAY SPECTRAL AND X-RAY DIFFRACTION INVESTIGATION OF THE INTERATOMIC BONDING FORCES IN IRON-ALUMINUM ALLOYS. (In Russian.)

Fiz. Metal. i Metallovedne 2, 243-247 (1960). Trans: Physics of Metals and Metallography 2 (2), 71-75 (1960).

1. I rons containing 2, 4, 10, 17, 25, and 50 atomic percent $\mathrm{Al}$ were annealed at various temperatures ranging from $380^{\circ} \mathrm{C}$ to $470^{\circ} \mathrm{C}$ and the Debye temperature determined.

$3,4 a$. The appearance of the $K$-state on annealing is responsible for the strengthening of the $\mathrm{Fe}-\mathrm{Al}$ bond.

4b. Iron is electronegative to aluminum in $\mathrm{Fe}-\mathrm{Al}$ alloys.

$(c-17) T$

Nordfors, B., THE STATISTICAL ERROR IN $X$-RAY AB= SORPTION MEASUREMENTS.

Arkiv Fysik 18, 37-47 (1960).

1. The case for counter registration is studied; the influence of background radiation is also surveyed.

3a. The optimum conditions for absorber thickness and for the time distribution between measuring $I$ and $I_{0}$ are found, and these values are plotted.

3b. A two-page table giving the optimum conditions for different backgrounds is presented. 
$(\mathrm{C}-18) \mathrm{E}$

Phillip, H., E. A. Taft and L. Apker, PHOTOEMISSION AND VALENCE BAND STRUCTURE OF ALKALI IODIDES.

Phys. Rev. 120, 49-51 (1960).

1. The energy distributions for external photoelectrons ejected from CsI by $11.3 \mathrm{eV}$ photons were studied.

2. Energy distributions were determined in sealed-off phototubes with spherical collectors by retarding potential methods.

3a. All but $5 \%$ of the ejected photoelectrons ranged in energy from 1.5 to $5.3 \mathrm{eV}$.

3b. The energy distributions of intrinsic photoelectrons from KI, Nal, CsBr, CsLi, Csl, and Rbl are presented in graphical form.

3c. Photon energies equal to twice the forbidden band gap are sufficient to eject photoelectrons from the bottom of the balence band.

4. The valence bandwidth is 3 to $4 \mathrm{eV}$ below the vacuum level.

(C-19)E

Rustgi, O. P., THE OPTICAL AND PHOTOELECTRIC PROPERTIES OF METALS IN THE VACUUM ULTRAVIOLET REGION OF THE SPECTRUM.

Thesis, University of Southern California (1960). Univ. Microfi Ims MIC 60-4486, 87 pp. Diss. Abs. 21, 1609 (1960).

1. The metals, Al, Sn, In, $8 \mathbf{i}, \mathrm{Te}, \mathrm{Au}, \mathrm{Ag}, \mathrm{Cd}$, $\mathrm{Sb}, \mathrm{Ti}$, and $\mathrm{Ge}$ were investigated in the region 1600A to $450 \mathrm{~A}$.

2. The transmissivity and the photoelectric yield were observed in thin films of the above metals in the path of a normally incident beam.

3a. The photoelectric yield increased in regions where the reflectivity declined.

3b. Values for the reflection-transmission transition are given.

4. The results lead to a conclusion that plasma oscillations caused by high energy electrons striking a metal are not necessarily excited by photons.

$(C-20) \mathrm{T}$

Wilmshurst, J. K., ORBITAL RADII AND THE DEPENDENCE OF BOND LENGTH UPON IONICITY, HYBRIDIZATION AND SOND ORDER.

J. Chem. Phys. 33, 813-820 (1960).

1. Atomic orbital radi a abe obained for elements in the first four periods except for transition metals.

2. These orbitals were obtained by using known bond length data and a derived expression for bond ionicity.

3. Results are presented in tabular form for about 75 atoms and molecules.

\section{0 - Suppiemental.}

(Papers which did not appear in print until 1961, al thouth they carry a 1960 date.)
$\mathrm{S}-1$

Hayashi, T., THE K AND L 2,3 ABSORPTION SPECTRUM OF ALUMINUM.

Sci. Repts. Tohoku Univ., Ist Ser. 44 (3) 87-94 (1960).

1. The Hayashi theory of quasi-stationary electron states, (See e.g. Refs. 1949 (2), 1950 (9)) is applied to the $K$ and $L_{2,3}$ absorption spectra of Al.

3a. Experimental spectra of other workers are shown along with the corresponding appropriate quasi-stationary states.

3b. The energy of $d$ and $s$ quasi-stationary states of Al is tabulated.

4a. The fine structure of the $L$ spectra is thought to correspond to the absorption process

$\mathrm{L}_{2,3} \rightarrow \mathrm{s}$ quasi-stationary state in the wavelength region greater than the absorption edge.

4b. No fine structure is expected in the wavelength region greater than the absorption edge for the $K$ spectra.

\section{$S-2$}

Hayashi, T. and T. Sagawa, THE ABSORPTION SPECTRUM OF METALLIC ALUMINIUM IN THE WAVELENGTH RANGE OF THE AI-L 2,3 EMISSION BAND. Sci. Repts. Tohoku Univ., ist Ser. 44 (4), $126-134$ (1960).

1. Both the emission and absorption $A 1-L_{2}, 3$ bands were photographed in the wavelength range 170-200A.

2a. See Ref. 1960 (s-3) for details of the experimental procedure.

2b. Absorbers were foils of Al 2,750A thick (determined by weigning and by colorimetric microanalysis).

3a. The ausorption coefficjent $(\mu)$ was found to be about $3.0 \times 10^{4} \mathrm{~cm}^{-1}$ in the range 170-200A.

$3 b$. Fine structure was found on the long wavelength side of the $\mathrm{Al}^{-\mathrm{L}_{2}, 3}$ absorption edge.

$5-3$

Sagawa, T., THE L 2,3 EMISSION SPECTRUM OF METALLIC ALUMINIUM.

Sci. Repts. Tohoku Univ., Ist Ser. 44 (4) $115-125$ (1960).

1. A new grazing incidence grating spectrograph was constructed; Al was the first substance to be studied.

2a. The spectrograph employs a Siegbahn grating having $576 \mathrm{lines} / \mathrm{mm}$ at a grazing angle of $3^{\circ} 29^{\prime}$. Targets were evaporated Al which was excited by radiation from a W filament. Target current was 100 ma at $2 \mathrm{kv}$.

2b. The spectrometer uses photographic photometry to obtain intensity data.

$2 c$. The vacuum was $4-8 \times 10^{-6} \mathrm{~mm} \mathrm{Hg}$.

$2 d$. The resolution in the third order was $0.02 \mathrm{ev}$; carbon $K \alpha_{1}$ was not significant in this order.

3a. The observed band is presented and compared wi th bands obtained by other workers.

3b. The features of the observed band are tabulated; the total band width was $14.8 \mathrm{eV}$.

3c. The experimental Al band was compatible with the results of earlier work. 
ABIDI, S. T. H., 1960 (14).

ADAMS, E. N., 1957 (C-1).

AGARWAL, B. K., 1952 (1); 1953 (5); 1954 (1);

1955 (1); 1957 (1), (2); 1958 (1).

ALEXOPOULOS, K. 1953 (1).

ALTMANN, S. L., 1957 (C-2).

AMREHN, H., 1955 (2); 1956 (C-1).

ANDREW, V. J., 1932 (1).

ANTONCIK, E., 1952 (C-1).

AOKI, Y., 1952 (C-2).

APKER, L., 1960 (C-18).

ASAAD, W. N., 1959 (C-1).

AVERBUKH, E. D.; 1951 (1); 1960 (1).

AXELROD, N. N., 1960 (2).

BAEZ, A. V., 1960 (C-1).

BALDOCK, G. R., 1952 (C-3).

BALLHAUSEN, C. J., 1956 (6).

BALLY, D., 1959 (1), (2).

BARINSKII, R. L., 1951 (19), (20); 1952 (2);

1955 (3); 1957 (3), (4), (5); 1960 (3).

BARRERE, G., 1951 (2).

BATTERMAN, B. W., 1959 (C-2).

BATYIEV, V. A., 1960 (7).

BAURMANN, E., 1957 (6).

BEARDEN, J. A., 1940 (1), (2).

BECKMAN, O., 1955 (4); 1958 (2).

BEDO, D. E., 1954 (2); 1955 (31), (34); 1956 (1);

1957 (7), (37); 1958 (32); (C-20); 1959 (3).

BEEMAN, W. W., 1939 (1); 1940 (1), (3); 1952 (19).

BELDING, E. F., 1959 (C-3).

BENES, L., 1959 (1).

BERGVALL, P., 1959 (C-4); 1960 (4).

BEUTLER, H. G., 1945 (C-1).

BHATTACHARJEE, 1952 (3); 1954 (9).

BIBERMAN, L. M., 1956 (C-2).

BILZ, H., 1958 (C-1).
BLOKHIN, M. A., 1954 (3), (4); 1955 (5), (6): 1956 (C-3), (C-4); 1957 (8); 1960 (C-2).

BOKE, K., 1957 (9), (10).

BONNELLE, C., 1957 (11), (16); 1959 (4).

BORISOV, M. D., 1957 (12), (13); 1958 (3);

1959 (5); $1960(5),(6)$.

BOROVIKOVA, G. P., 1957 (14).

BOROVSKII, 1. B, 1951 (3); 1953 (2); 1957 (15),

$(C-3) ; 1958(33) ; 1959(6),(7) ;(8) ; 1960(7)$,

$(8),(42)$.

BOYCE, J. C., $1941(R-1)$.

BRADEN, C. H., $1957(\mathrm{C}-11)$.

BRENTANO, J. C. M., 1956 (2).

BRIL, M. N., 1958 (35); 1960 (9).

BRINKMAN, H., 1955 (37).

BRITTON, D., 1960 (C-14).

BROGREN, G., 1954 (5).

BROOKS, H., 1958 (C-2).

BROUT, K., 1957 (C-4).

BROWN, E., 1954 (C-1).

BRUMMER, O., 1958 (4).

BULLEN, T. G., 1954 (21).

BURBANK, C. J., 1939 (2).

CADY, W. M., 1941 (2), (3).

CALLAWAY, J., 1957 (C-5); 1958 (C-3).

CALLON, P., 1959 (11), (12).

CANDLIN, D. J., $1955(\mathrm{C}-1)$.

CARTER, D. E., 1955 (3).

CATTERALL, J. A., 1958 (5); 1959 (9), (10); R-4.

CAUCHOIS, Y., 1949 (1); 1950 (1), (2); 1952. (4), (5), (6), (7); 1953 (3), (4); $1954(6),(7)$;

$1955(7) ; 1956(4),(5) ; 1957(16)$.

CHALKIN, F. C., 1954 (17); 1955 (20).

CHIBA, S., 1951 (6).

CHUPP, E. L., 1958 (C-4).

CHURCH, E. L., 1952 (16).

COLES, B. R., 1960 (C-2). 
COLLET, V., 1959 (13), (14).

CORMACK, D. V., 1955 (8).

CORNWELL, J. F., 1960 (C-4).

COSTER, D., 1948 (1); 1950 (3).

COTTON, F. A., 1956 (6), (7); 1958 (6).

COULSON, C. A., 1952 (C-4); 1957 (C-2).

CRAIG, D. P., 1954 (C-2).

CRISP, R. S., 1958 (7), (10); 1960 (10), (11),

(12).

CURIE, D., 1952 (8); $1960($ C -5$)$.

CURRY, C., 1960 (13).

D'AMICO, C., 1960 (C-10).

DAS GUPTA, K., 1950 (4); 1955 (9), (10); 1956 (8); $1957(28)$.

DAWBER, K. R., 1960 (C-6).

DE BEN, H. S., 1959 (15).

DE CARVALHO, A. P., 1959 (C-5).

DEHLINGER, U., 1955 (C-2).

DE MARCO, J. J., 1958 (C-24); 1959 (C-29).

DEODHAR, G. B., 1950 (5); 1951 (4); 1952 (9), (10);

1953 (5); 1956 (9); 1958 (8); 1960 (14).

DESLATTES, R. D., 1958 (C-5); 1959 (15).

DILMORE, B. L., 1957 (17).

DORAN, D. G., 1957 (18).

DOUGHTY, D. D., 1952 (11).

DOWDEY, J. E., 1959 (16).

DU MOND, J.W. M., 1958 (18), (C-4)

DUTTA, A. K., 1958 (C-6); 1959 (17).

DYSON, N. A., 1959 (18).

EBERBECK, W., 1957 (19).

ECONOMY, R., 1958 (11).

EDAMOTO, I., 1950 (6).

EDLEN, B., 1932 (3).

EISENLOHR, H., 1953 (6); 1954 (8).

EISENSTEIn, J. C., 1956 (C-5).

ELEY, D. D., 1960 (C-5).

EL-HUSSAIN I, J. M., 1958 (9).
ELLIOTT, R. J., 1959 (C-6).

FAESSLER, A., 1952 (12); 1954 (9).

FAIRBROTHER, J. A. V., 1957 (C-6).

FAULKNER, J. S., 1959 (C-7).

FEFER, A. M., 1957 (12); 1958 (3); 1960 (6).

FERREIRA, J. G., 1951 (16); 1954 (10); 1955 (11).

FINE, S., 1955 (12).

FINKEL'SHTEIN, L. D., 1960 (35), (C-16).

FIN, L. D., 1960 (38).

FISHER, P., 1958 (10).

FLETCHER, G. C., 1951 (C-1); 1952 (C-5).

FLODMARK, S., 1958 (C-7).

FLYNN, C. P., 1960 (C-8).

FOBBERTH, O. G., 1955 (13).

FOSTER, J. S., 1953 (C-3).

FREEMAN, A. J., 1959 (C-30).

FREY, W. R., 1959 (C-8).

FRIEDEL, J., 1952 (13), (C-6), (C-1); 1954 (C-3); 1958 (c-8).

FRIEDMAN, H., 1939 (1); 1940 (2), (3).

FRILLEY, M., 1951（5).

FUJIKI, Y., 1959 (C-9).

FUJIMOTO, H., 1951 (6); 1956 (10).

GALE, B., 1956 (11).

GANEEV, A. S., 1960 (15).

GAUTHE, B., 1958 (C-9).

GENK IN, YA. E., 1960 (22), (23); 1957 (24).

GIVENS, M. P., 1955 (39); 1956 (3); 1957 (1), (2); $1958(1) ; 1960(2)$.

GLASER, H., 1951（7).

GOKHALE, B. K., 1950 (7); 1951 (5), (8), (9); $1952(14)$.

GOLOVNER, T. M., 1953 (2).

GOODENOUGH, J. B., 1960 (C-9).

GORAK, Z., 1960 (16).

GORDON, F. J., 1958 (C-4)

GREEN, L. C., 1955 (C-5)

GREINER, H., 1957 (C-7); 1959 (C-10). 
GROVEN, L., $1951(10)$.

GUROV, K. P., 1957 (C-3); 1959 (6), (7).

GUSANTINSKI, A. N., 1955 (6).

GUSEVA, L. N., 1959 (19).

GYORGY, E. M., 1952 (15), (22); 1953 (7); 1954

HAASE, E. L, 1957 (C-5).

HAGSTROM, H. D., 1960 (C-10).

HAGSTROM, S., 1959 (C-21); 1960 (4).

HALFORD, R. S., 1957 ( 42 ).

HAM, F. S., 1958 (C-2).

HANSON, H. P., 1956 (7); 1957 (C-8); 1958 (6), (11).

HARROWER, G. A., 1956 (C-6).

HARTMAN, P. L., 1953 (8); 1956 (C-11).

HARVEY, G. G., 1951 (15); 1952 (15), (22); 1954 (11).

HASS, G., 1959 (C-11).

HAYASE, A., 1957 (39).

HAYASHI, T., 1942 (1); 1949 (2); 1950 (8), (9), (10); 1958 (12); 1959 (12).

HEMPSTEAD, C. F., 1955 (14); 1957 (33).

HENDEE, C. F., 1955 (12).

HENKE, B. L., 1957 (20); 1959 (C-12).

HERGLOTZ, H., 1953 (9); 1955 (15).

HERMAN, F., 1954 (C-4).

HERRERA, J., 1957 (C-8).

HILL, R. D., 1952 (16).

HIRSH, JR., F. R., 1933 (1); 1935 (1); 1936 (1);

1942 (2); 1950 (11); 1952 (17).

HOLLIDAY, J. E., 1960 (17).

HOPKINS, J. I., 1959 (C-8).

HORAK, Z., 1958 (C-10); 1960 (C-11).

HOYT, A., 1932 (2).

HUANG, T. C., 1954 (C-9).

HUME-ROTHERY, W., 1953 (C-2); 1957 (C-2).

IGO, G., 1954 (C-5), (C-11).

ISHIMURA, T., 1958 (28).

IZRAILEV, 1. M., 1960 (15).

JACOB, L., 1956 (18); 1960 (18).
JACOBS, E. S., 1958 (13).

JAEGLE, P., 1957 (21); 1960 (C-12).

JOHANSSON, P., 1960 (19).

JOHNS, H. E., 1955 (8).

11). JOHNSON, F. A., 1953 (C-3).

JOHNSTON, J. E., 1937 (1); 1938 (1); 1939 (3); 1954 (21).

JOHNSTON, R. E., 1959 (C-8).

JOHNSTON, R. W., 1954 (12).

JONES, H., 1934 (1); 1954 (13).

JOPSON, R. C., 1958 (C-4).

JOSSEM, E. L., 1951 (14); 1954 (15); 1955 (24);

1957 (33), (34).

KAKUSCHADSE, T. 1., 1959 (21).

KAMADA, 0., 1956 (12).

KANAMOR!, J., 1959 (C-13).

KARAL'NIK, S. M., 1956 (13), (14); 1957 (21);

1959 (27); 1960 (20), (41).

KARNATAK, R. C., 1956 (9), (C-7).

KARPOVICH, I. A., 1960 (30), (44).

KATAMADZE, V. R., 1956 (C-8).

КАTO, S., 1952 (23); 1954 (19), (20); 1956 (23).

KAUFMAN, S., 1933 (2).

KAWAMARADA, H., 1959 (20), (22).

KAZANTSEV, V.A., 1955 (16); 1956 (15); 1957 (23); 1959 (23), (24).

KELLEY, R. L., 1959 (C-14).

KERN, B., 1960 (21).

KICHENASSAMY, S., 1951 (C-2).

KIESSLING, R., 1954 (C-6).

KIESTRA, S., 1950 (3).

KINGSTON, R. H., 1951 (1'1), (12), (15); 1952 (22).

KITTEL, C., 1958 (C-11).

KIYONO, S., 1952 (18); 1956 (16).

KLEINMAN, L., 1959 (C-15).

KLEMENS, P. G., 1960 (C-13).

KLIUSHIN, V. V., 1958 (19).

KLIEVER, W. H., 1939 (4).

KOLOBOVA, К. M., 1959 (26); 1960 (c-16). 
KORSUNSKII, M. I., 1957 (14), (24), (35);

$1958(14) ; 1959(31) ; 1960$ (22), (23).

KOSTAREV, A. 1., 1949 (3).

KOSTER, G. F., 1954 (C-10); 1955 (C-3).

KOTLYAR, B. 1., 1956 (17), (26); 1958 (16), (15); 1959 (38).

KRUTTER, T., 1935 (C-1).

KULENKAMPFF, H., 1955 (2).

KURYLENKO, C., 1955 (17); 1959 (C-16); 1960 (24), (25).

LANDER, J. J., 1953 (C-4).

LASKER, W., 1953 (C-5); 1955 (C-4).

LE BERQUIER, F., 1954 (7).

LEE, P. A., 1951 (17).

LEE-WHITING, G. E., 1952 (C-7).

LEHMAN, G. W., 1957 (C-9).

LESNIK, A. G., 1958 (C-12).

LEWIS, M. N., 1955 (C-5).

LIEFIELD, R. J., 1960 (26).

LIPSCOMB, W. N., 1960 (C-14).

LOHMANN, A., 1959 (C-17).

LOMER, W. M., 1957 (C-10).

LOUDON, R., 1959 (C-6).

LUCASSON, A., 1957 (25); 1958 (17); 1959 (25); 1960 (27).

LUKIRSKII, A. P., 1957 (26); 1960 (28), (29), (30), (31), (43), (44).

LUNDBERG, B., 1957 (20).

MACCOLL, A., 1954 (C-2).

MACK, J. E., 1932 (3).

MANDE, C., 1950 (5); 1951 (4); 1952 (9), (10); 1955 (18), (19); 1959 (12), (27); 1960 (32).

MANESCU, I., 1950 (2); 1954 (7); 1956 (5).

MARCHIKOVA, I. D., 1958 (33).

MARK, H., 1958 (C-4).

MARSHALL, W., $1957(C-10) ; 1958(C-11)$.

McGRATH, J.W., 1939 (5); 1952 (14).

MCNEILL, D. J., 1960 (13).

MEERSON, G. A., 1953 (C-6).

MERRILL, J. J., 1958 (18).
MENSHIKOV, A. Z., 1960 (33), (36); 1958 (20).

MIKELICH, J.W., 1952 (16).

MILLER, G. L., 1954 (22).

MILLER, J. C., 1959 (C-12).

MILNER, P. C., 1955 (C-5).

MITCHELL, G., 1952 (19).

MITRA, B., 1957 (28).

MODEL, I. S., 1958 (28).

MOKHOV, V. N., 1958 (C-13).

MOORE, H. R., 1955 (20); 1957 (29).

MORIN, F. J., 1958 (C-14).

MORLET, J., 1949 (4); 1951 (10); 1953 (10).

MOTT, N. F., 1934 (1); 1949 (1).

MULDER, M. M., 1955 (C-5).

MULLER, G. L., 1953 (6); 1954 (8).

MULLER, L., 1959 (2).

MURRELL, J. N., 1960 (C-15).

NADZHAKOV, E. G., 1960 (3).

NAMIOKA, T., 1959 (C-18), (C-19).

NARBUTT, K. 1., 1951 (20); 1955 (21); 1957 (3), (36).

NEFEDOV, N. N., 1960 (20).

NEFF, H., 1951 (13).

NEMNONOV, S. A., 1956 (23); 1958 (19), (20);

$1959(26) ; 1960(34),(35),(36),(37),(38)$, $(c-16)$.

NEMOSHKALENKO, V. V.:1957（13); 1958 (3); 1959 (5); $1960(5),(6)$.

NESHPOR, V. S., 1960 (51).

NEUPERT, W. M., 1957 (37); 1960 (39).

NIEHRS, H., $1950(R-7)$.

NIGAM, A. N., 1954 (14); 1955 (22); 1957 (30); $1958(8) ; 1960(40)$.

NIKIFOROV, I. YA., 1957 (31).

NIKOLAEVA, L. G., 1959 (27); 1960 (20), (41).

NILSSON, A., 1953 (11).

NILSSON, N., 1952 (20).

NISHIMURA, T., 1958 (12). 
NOBLE, R., 1956 (18); 1960 (18).

NORDFORS, B., 1955 (23); 1956 (19); 1960 (C-17). NORDLING, C., 1957 (C-12); 1958 (30), (31); 1959 $(28),(33),(C-20),(C-21)$.

NOVODVORSKAYA, E. M., 1956 (C-2).

NYHOLM, R. S., 1954 (C-2).

OBASHI, M., 1955 (28).

O'BRYAN, H. M., $1940(4)$.

O'CONNOR, B. M., 1957 (C-6).

OHLIN, P., 1952 (21).

OMEL 'CHENKO, YU. A., 1960 (28).

ONAKA, R., 1958 (C-15).

ORLOV, A. N., 1957 (32).

OVECHKIN, B. I., 1959 (19).

OVSYANNIKOVA, I. A., 1960 (42).

PARKYN, D. G., 1957 (C-6).

PARRATT, L. G., 1936 (2), (3), (4), (5), (7);

1951 (14); 1954 (14), (16); 1955 (24);

1957 (33), (34); 1958 (21); 1959 (30), R-8,

$R-9, R-10$.

PATRONIS, E. T., 1957 (C-11).

PAULING, L., $1947(\mathrm{C}-1)$.

PAYNE, W. B., 1960 (49).

PEARSALL, A. W., 1935 (2).

PEARSON, W. B., 1958 (C-16).

PELL, E. M., 1951 (18).

PERLMAN, M. L., 1955 (C-8).

PHILLIP, H., $1960(C-18)$.

PHILLIPS, J. C., 1959 (C-15).

PIKE, E. R., $(R-11)$.

PIORE, E. R., 1951 (15); 1952 (22).

PLASS, G. N., 1958 (C-17).

PORTEUS, J. 0., 1959 (29), (30).

POSENER, D. W., 1959 (C-22).

RAIMES, S., 1954 (C-7).

RANDALL, C. A., 1940 (5).

RICHARDSON, J. W., 1956 (C-9).

RICHTMYER, F. K., 1929 (1); 1933 (2), (11).
RICHTMYER, R. D., 1929 (1); 1931 (1); 1936 (6); $1939(6)$.

ROBINS, D. A., 1958 (C-18); 1959 (C-23).

ROGERS, J. L., 1954 (17).

ROGOSA, G. L., 1953 (17), (18); 1957 (17).

RONAMI, G. N., 1957 (15).

ROOS, G. E., 1954 (C-8).

RUBENSTE IN, R. A。, 1955 (C-6).

RUDSTROM, L., 1958 (22).

RUMSH, M. A., 1960 (29), (30), (31), (43), (44).

RUMYANTSEV, I. A., 1957 (33); 1958 (13); 1959 (31).

RUNDLE, R. E., 1948 (C-1); 1956 (C-9).

RUSTGI, O. P., 1959 (C-27); 1960 (C-19).

SACHENKO, V. P., 1958 (23); 1960 (C-2).

SAKELLARIDIS, P., 1953 (13), (14), (15), (16);

$1954(18) ; 1955(25),(26) ; 1958(24),(25)$,

(26).

SALGUEIRO, L., 1951 (16).

SANDSTROM, A. E., R-12.

SAMSONOV, G. V., 1960 (53).

SAMYLOV, S. V., 1958 (27).

SATO, M., 1941 (1); 1953 (C-7); 1955 (27).

SAWADA, M., 1955 (28); 1957 (37); 1958 (28).

SCHAFFER, E., 1957 (C-7); 1959 (C-10).

SCHENK, H., 1955 (C-2).

SCHMID, E. D., 1954(9).

SCHWARTZ, G., 1953 (12), (17); 1957 (17).

SEN, A. K., 1955 (9); 1956 (21).

SENENT, S., $1951(\mathrm{C}-3)$.

SENENT, Y., 1951 (C-3).

SEYMOUR, E. F. H., 1960 (C-8).

SHAPIRO, G. A., 1958 (15); 1959 (38).

SHAW, C. H., 1936 (7); 1956 (21); 1959 (34), R-13, $\mathrm{R}-14$.

SHCHEMELEV, V.N., 1960 (43), (44).

SHINODA, G., 1952 (24); 1954 (19), (20); 1955 (29); 1956 (22).

SHIRAIWA, T., 1955 (28); 1958 (28); 1960 (45). 
SHMIDT, V. V., 1959 (8); 1960 (8), (46).

SHOEMAKER, D. P., 1954 (C-9).

SHUVAEV, A. T., 1960 (48).

SIEGBAHN, K., 1957 (C-12); 1958 (30), (31).

SINGH, J. N., 1960 (47).

SJOBERG, S., 1958 (22).

SKINNER, H. W. B., 1934 (1); 1937 (1); 1938 (1);

$1940(4),(6) ; 1954(21),(R-15)$.

SLATER, J. C., 1954 (C-10); 1955 (C-6).

SMIRNOV, L. A., 1960 (29), (31).

SMIRNOVA, I. S., 1957 (36).

SMITH, G. L., 1954 (22).

SNYDER, J. N., 1955 (C-6).

SOKOLOV, A. V., 1955 (30); 1957 (32).

SOKOLOWSKI, E., 1957 (C-12); 1958 (29), (30); 1959 (32), (33).

SOROKINA, M. F., 1960 (37), (38).

SOULES, J. A., 1959 (34).

SPRAGUE, G., 1955 (31).

SRIVASTAVA, K. S., 1960 (40).

STARY I, I. B., 1958 (35), (36); 1959 (41).

STEHN, J. R., 1932 (3).

STEPHANSON, S. T., 1957 (18); 1958 (9).

STEWARDSON, E. A., 1951 (17).

SUONINEN, E. J., 1959 (C-24).

SUTTON, L. E., 1954 (C-2).

SUZUKI, M., 1958 (12).

SUZUKI, T., 1952 (24); 1954 (19), (20); 1956 (22).

TAFT, E. A., 1958 (31); $1960(\mathrm{C}-18)$.

TAKEISHI, Y., 1956 (C-10); 1958 (C-19).

TAYLOR, G. R., 1960 (49).

TAYLOR, R., 1952 (C-4).

TILL, J. E., 1955 (8).

TOMBOUL IAN, D. H., R-16; 1941 (2), (3); 1948 (2); 1951 (18); 1953 (8); 1954 (2), (12); 1955 (31), (32), (33), (34); 1956 (1); (c-11); 1957 (37); 1958 (32), (C-20); 1959 (35), (3); 1960 (50), (51), (52).

TORKINGTON, P., 1951 (C-4).
TOURNAIRE, M., 1954 (23).

TOUSEY, R., 1959 (C-11).

TOWNSEND, J. R., 1953 (18).

TOYAZAWA, Y., 1958 (C-21), (C-22).

TRAPNEZNIKOV, V. A., 1956 (23), (24); 1957 (38); $1959(36)$.

TRLIFAJ, M., 1952 (C-1).

TRONEVA, N. V., 1958 (33).

TROST, W. R., 1958 (C-23); 1959 (C-25).

TROTTER, J., 1956 (11); 1958 (5); 1959 (9), (10).

TSUKERMAN, V. A., 1958 (27).

TSUTSUMI, K., 1955 (28); 1957 (37); 1958 (34); 1959 (37); R-17.

ULMER, K., 1957 (6).

UMANSKII, IA. S., 1953 (C-6).

UNITED STATES ATOMIC ENERGY COMM., 1950 (R-17). URIN, M. G., 1958 (C-13).

VAINSHTE IN, E. E., 1949 (5); 1950 (12), (13), (14); 1951 (19), (20); 1952 (25); 1955 (35), (36); 1956 (25), (26); 1957 (3), (5), (40), (41); 1958 (35), (36); 1959 (38), (39), (40), (41), (42); R-19; 1960 (53).

VALADARES, M., 1951 (5).

VAN DEN BERG, C. B., 1955 (37).

VARSHN I, Y. P., 1956 (C-7).

VASIL'EV, YU. N., 1957 (40), (41).

VICTOREEN, J. A., 1949 (6).

WAGNER, B., 1955 (38).

WALDRON, R. D., 1959 (C-26).

WALKER, W. C., 1959 (C-27).

WATSON, R. E., 1959 (C-28).

WEISS, R. J., 1958 (C-24); 1959 (C-29), (C-30).

WEISSLER, G. L., 1959 (C-27).

WERTHEIM, M. A., 1954 (C-5), (C-11).

WESER, W., 1955 (C-2).

WHITE, R., 1957 (20).

WHITMORE, G. F., 1955 (8).

WILKENSON, P. R., 1960 (C-7).

WILLIAMS, S. E., 1958 (10); 1960 (11), (12). 
WILMSHURST, J. K., 1960 (C-20).

WILSON, L. F., 1958 (5).

WITTE, H., 1955 (38).

WOHLFARTH, E. P., 1951 (C-1); 1960 (C-4).

WOLFEL, E., 1955 (38).

WOLFSBERG, M., 1955 (C-8).

WOOD, E., 1955 (10).

WOODRUFF, R. W., 1955 (39).

WYLY, L. D., 1957 (C-11).

YEE, H., 1960 (17).

YOSHIDA, S., 1936 (8).

ZANDY, H. F., 1952 (26).

ZHURAKOVSK II, E. A., 1958 (36); 1959 (38), (39), $(40),(41),(42) ; 1960(53)$.

ZINKE, O. H., 1957 (C-13), (C-14).

ZWERDLING, S., 1957 (42). 
ABSORBER

optlmum denslty: 55-6E

optlmum gas pressure: 55-1 T

optimum thlckness: 51-1T; 57-33E; 60-32E

\section{ABSORPTION}

alloylng, effect of: $60-32 E, 33 E, 38 E, 53 E$ anomaly in lanthanides: 53-CIT

Bragg-Plerce Law: 57-6E

coefficient: 57-20E; 60-15E, 25T; $50 \mathrm{~A}$

crltlcal energy: 55-12E

dlscontlnulties: 59-1E

edge vs. bonding: 51-7E

edge, effect of excltations: 59-C6 T

edge, effect of magnetlc fleld: 59-c6T

edge vs. magnetic transformation: 56-24E

edge shift: 51-19T, 20E; 55-18E; 56-13E;

$57-13 \mathrm{E}, 23 \mathrm{E} ; 58-8 \mathrm{E}, 23 \mathrm{E} ; 60-53 \mathrm{E}$

edge, theory of: 41-1T; $51-6 \mathrm{~T} ; 60-24 \mathrm{~T}$

energies, Wigner-Seitz method: 53-CIT

excitation, source for: 57-37E; 58-2E, I7E, $26 \mathrm{E}$

fine structure: 56-25E; 57-9E; 59-16E, 32E; $60-25 \mathrm{~T}, 34 \mathrm{E}$

flne structure vs. bonding: 56-23E; 57-3T

fine structure vs. color centers: 57-30T

flne structure vs. crystal orientation: 58-9E

flne structure vs, electron interactlon: $60-46 \mathrm{~T}$

fine structure, theory of: 49-3T; 54-14T; $57-38 \mathrm{~T}$

1 ine width, theory of: 52-C7T

phase transformation, effect of: $54-4 E$

spectra: (See "Absorption Spectra Index")

states: $58-24 \mathrm{E}$

statistical error In measurement: 60-C1TT

synchrotron radiation: 55-33E

temperature, effect of: 60-9E, 20E

theory of: 50-12T; 52-5E; 57-10E; 58-26T,

CI7T; 59-8E; 60-15E, 24T, 47E

thermal vibration, effect of: $59-7 \mathrm{E}$

tlme, effect of: $54-4 E$

valence electrons: $57-\mathrm{C} 8 \mathrm{E}$

window: $52-4 \mathrm{E}$

ADSORPTION ON ALUMINUM: 6O-CTT

ALLOYS

compositlon vs. emission edge splltting: 57-27E

electrical conductlon: 60-C13T

theory of: $38-1 \mathrm{E}$

\section{ATOMIC RADII}

Orbital: 60-C20

Pauling: $47-$ C1T

ATOMIC VALENCE FROM X-RAY DATA: 60-3T

ATTENUATION MEASUREMENTS: 59-35E
AUGER EFFECT: 35-3E; 36-1E; 51-C2T; 57-C6E, C14E; $58-\mathrm{C} 13 \mathrm{~T}$

calculation of: $55-\mathrm{c} 6 \mathrm{~T}$

cascade mechanism: 55-c8T

electronic: 57-C12E; 58-C19T

Korringa's method: 59-C7T

transitions: 56-C10; 57-CI3E

BAND CALCULATIONS:

(See "Energy Band Calculations")

BANDW IDTH:

excess, equatlon for: 54-13T

Internal levels: 58-23T

vs. atomic distance: 60-C2T

\section{BINDING ENERGY}

In uranium: 59-C2IE

of 4 th and 5 th periods: 59-C20E

theory of: 52-CIT; 59-32E

BOND LENGTHS: $\quad 60-C 20$

\section{BOND ING}

AuSn, AuAl2, CuzSn8: 47-ClT

$\mathrm{CrSi}_{2}:$ 60-36E

Fe-AI: 60-Cl6E

NiAs structure: 60-33E

vs. absorption edge: 57-5E

Bloch theory: $55-\mathrm{C} 2 \mathrm{~T}$

borides: $58-\mathrm{C} 7 \mathrm{~T}, \mathrm{Cl} 8 \mathrm{~T}$

carbides: 48-CIT; 53-C2T, C6T; 58-C18T

vs. emisslon edge: $57-5 \mathrm{E}, 57-22 \mathrm{~T}$

vs. emission flne structure: $57-38 E$

vs. hardness: 53-C6T

hybrid: 47-C1T; 51-C3T, C4T; 52-C2R; 57-C2T; $60-\mathrm{Cl} 3 \mathrm{~T}$

intermetalllc compounds: $58-\mathrm{C} 16 \mathrm{~T}$

Ligand theory: 56-C8; 57-C2T

l lne broadenling: 55-19E

vs. IIne shape asymmetry: 50-13E, 14E; 56-14T

metalloids: 58-20E

nitrldes: 48-C1T; 53-C2T

oxides: $48-\mathrm{CIT}$

sillcldes: $58-\mathrm{Cl} 18 \mathrm{~T}$

vs. soft X-ray spectra: 54-6E

Sommerfeld-Grimm theory: 55-C2T

strength calculations: 54-C2T

transition metals: 58-C23T; 59-C23T

transition metal complexes: 56-C8

uranium compounds: $56-65$

BREMSTRAHLUNG, X-RAY

spectra: 55-2E

Sommerfeld theory of: 56-CIE 
BRILLOUIN ZONE

deduced from soft X-ray data: 58-C6T

electrical conductivity: $55-17 \mathrm{~T}$

graphite: 59-17T

temperature effect on: 60-C3E

theory of: $54-$ C9T

CHARACTERISTIC ELECTRON ENERGY LOSS: 57-37E; $60-8 \mathrm{E}$

CHEMICAL SHIFT IN INNER LEVELS: 58-29E, 3IE

COMPTON RADIATION: 53-1E

COHTINUDOS SPECTRA: 51-13E; 55-8E, C5T; 59-20E

filtering out: $60-28 E$

CORRECTION FOR (See also "Instrumental Corrections")

instrument broadening: 56-C3T; 57-33E; 58-18E;

59-30E, 3E; 60-C8T

instrument.distortion: $56-C 4 T$

COUNTING ABSOLUTE QUANTA: 60-29A, 31E

CRYSTAL SPECTROMETERS:

(See "Spectrographs, crystal")

CRITICAL POTENTIAL: 59-20E, 22E

CRYSTALS

calcite: $\quad 60-5 T$

gypsum: $52-4 E$

mica: $\quad 52-4 \mathrm{E}$

quartz: $52-21 \mathrm{~A}$

DAMPING PARAMETERS: 59-C26T

DEBYE TEMPERATURE: $60-\mathrm{Cl} 16 \mathrm{E}$

DENSITY-OF-STATE CURVES

from $X$-ray spectra: $57-31 T$

impurity effects: $52-\mathrm{C} 6 \mathrm{~T}$

theoretical: 5I-CIT; 52-C5T; 55-C3T

DOPPLER EFFECT: $56-C 2 T$

EDGE SHIFT DUE TO ALLOY ING: 60-27E, 34E

ELECTRICAL PROPERTIES: 58-CI4T; 60-C3E

ELECTRON DISTRIBUTION: 59-C2T, C29E, C3OE

by neutron scattering: 59-C30E

by $X$-ray reflection: 55-38E

ELECTRON ENERGY LOSS: 57-35E; 58-C9T; 60-8E

ELECTRON GUN, DESIGN OF: 51-12E, 15A; 58-5A, 7E

ELECTRON ORBITALS: 59-C25T

symmetry properties: 59-CI3T

ELECTRON STOPPING POWER, THEORY OF: 52-C7T

ELECTRON THEORY OF METALS: 53-3E
ELECTRON TRANSFER: 59-10E

ELECTRON VACANCY EFFECT: 55-24E; 57-16E; 59-9E, 12E

ELECTRONIC ENERGY LEVELS

absolute: 55-27E

vs. atomic number: 55-7E

derived: 56-9E

locallzed: 55-14E

ELECTRONIC SPECTROSCOPY: 52-24E; 54-19E, 2OE; $55-29 E ; 56-22 E$

\section{ELECTRONIC STRUCTURE}

CuzAu: 60-C3E

alkall oxides: $60-13 \mathrm{~T}$

borldes: $60-\mathrm{C} 14 \mathrm{~T}$

intermetallic compounds: $58-\mathrm{Cl} 6 \mathrm{~T}$

$\mathrm{NaCl}$ type hard substances: 58-C1T

orbital theory of transition metals: 58-C23T

tellurium: 59-C5T

thorium in compounds: 55-3E

transition metals: $60-\mathrm{C} 8 \mathrm{~T}$

transltion period, Ist, deduced: 57-C10T; 58- C8T

EMISSION, SOFT X-RAY

critical energy of: 55=12E

spectra: (See "Emission Spectra Index")

theory of: $52-\mathrm{ClT}$

ENERGY BAND CALCULATIONS

augmented plane wave: $53-\mathrm{C} 1 \mathrm{~T}$
Bloch theory: $60-\mathrm{C} 13 \mathrm{~T}$

conduction band limits: 57-32T

effect of field: $57-\mathrm{ClT}$

Fermi-Thomas field approximation: 54-C5T, C11T graphlte: $52-C 4 T$

Hartree field: 35-Cl

Hartree-Fock field for Iron: 59-c28

inner band widths: $57-8 \mathrm{~T}$

interpolation method: $60-C 4 T$

LCAO method, simplified: 54-C10T

Mulliken's molecular integral approximation: 56-c9

orthoganalized plane wave: $54-C 4 T$

overlap integrals: $59-\mathrm{C} 3 \mathrm{~T}$

Roothan's self-consistent molecular orbital: 56-C9

secular Reitz equation: 59-C5T

self-consistent field: $60-48 \mathrm{~T}$

self-conslstent potential for dlamond: 59-C15

Slater free electron momentum dependence: $59-$ C28T

Slater-Koster interpolation: 57-C9T

Slater two electron integrals: $59-\mathrm{C} 28$

tight binding approximation: 59-C2T

ENERGY BANDS FROM X-RAY DATA: 58-3E, C2T

EXCHANGE ENERGY: 59-33E

EXCHANGE INTERACTION: 55-30T; 59-37E, CI2T

EXCITATION POTENTIAL: 53-1IE; 59-20E, 22E

EXCITATIONS: 55-30T; 58-C21T, C22T; 59-C6T 


\section{EXCITED STATES}

wave functions of: 58-C10

FERMI SURFACE: 55-C7T; 57-32T; 60-C13T

FILTERS FOR SOFT X-RAYS: $55-34$ E

FORBIDDEN ENERGY BANDS: 55-13E

FORBIDDEN LINES: 52-9E, IOE

FLUORESCENT EXCITATION: 59-C21E; 60-29A

FLUORESCENT YIELD: 57-C6E, CIIE; 59-C8E

calculation of: $55-\mathrm{C} 6 \mathrm{~T}$

FREE ENERGY OF FORMATION: 53-C6T

FRESNEL ZONE PLATE: 60-CIA

GEIGER COUNTER RECORDING: 57-26A

GRAT ING: $\quad$ 56-20E

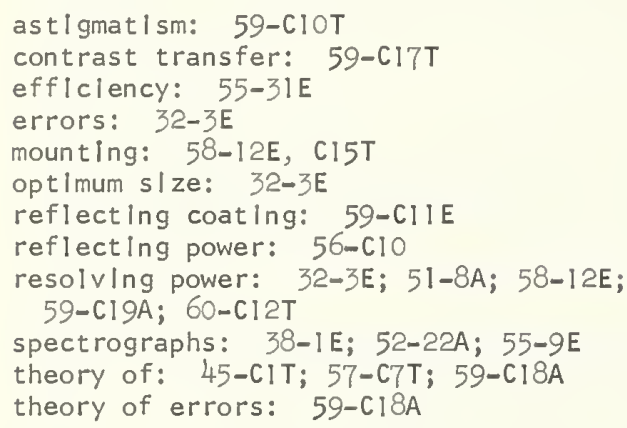

HEAT OF FORMATION, RELATION TO SPECTRA: 5O-4E

HYBRID BONDS: (See "Bonding, Hybrid")

IMPURITIES

effect of: $56-4 E ; 57-C 3 T ; 59-6 T$

Thomas-Ferml treatment: 56-l1E

INSTRUMENTAL CORRECTIONS: 54-23A; 55-5T

(See also, "Correctlon for -")

INTERACTION COEFFICIENTS OF SOFT X-RAYS: 59-CI2 IONIZATION ENERGIES, CALCULATED: 55-C7T ISOTOPE SHIFT, THEORY OF: 54-C5T, CIIT KIKUCHI BANDS: $\quad 58-4 \mathrm{E}$

KRONIG'S METHOD: 60-40E, 45T

KORR INGA'S METHOD: 59-C7T

LEVEL WIDTH (See "Band WIdth")

LIFETIME OF A STATE: 58-29T; 60-45T

LINE BROADENING DUE TO BONDING: 55-19E
LINE INTENSITY: $59-$ C24T; 60-23T, 49T

vs. atomlc number: 55-4E

LINE NOMENCLATURE: (See 'Nomenclature of $X$-ray Lines")

LINE SHAPE: $52-14 \mathrm{E} ; 56-26 \mathrm{E} ; 59-\mathrm{C} 22 \mathrm{E}$

calculated: $55-\mathrm{C} 4 \mathrm{~T} ; 57-32 \mathrm{~T}$

due to magnetic state: 56-17E

LINE SHIFT: $\quad 57-13 E ; 57-22 T, C 4 T ; 58-16 E ; 59-28 E ;$ $60-19 E$

LINE WIDTH: $51-16 E ; 52-8 T$

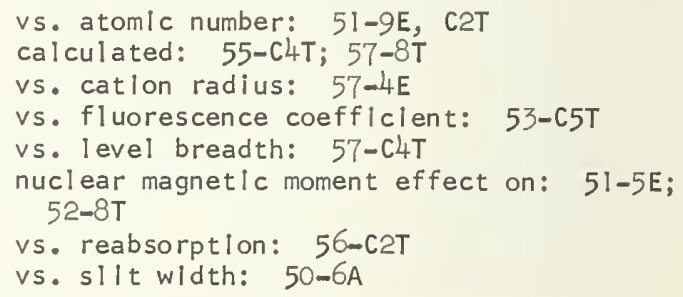

LOW TEMPERATURE SPECIMEN STAGE: 60-12E

MAGNETO-MECHANICAL RAT10: 58-CIIT

MAGNETIC PROPERTIES: $58-$ CI $14 T$

MECHANICAL PROPERTIES OF INTERMETALL IC COMPOUNDS

vs, atomic radius ratlo: $54-\mathrm{C} 6 \mathrm{~T}$

MOLECULAR ORBITAL CALCULATIONS: $56-C 8$

MULTIPLICITY: 53-2E; 55-26E; 58-25E

NOMENCLATURE OF X-RAY LINES: 52-1T; 53-5T

OXIDATION OF ALUMINUM: $60-C 7 T$

OPTICAL PROPERTIES

metals: 58-ci4T; 60-C19

PHOTOELECTR IC

methods: $59-\mathrm{CI} 9 \mathrm{E}, 20 \mathrm{E}, 60-4 \mathrm{E}$

propertles of thin films: $59-\mathrm{C} 27 \mathrm{E}$

transitions: 60-7T

yield: 60-30E, 43A, CI9, C6

\section{PHOTOELECTRON}

emlssion: 58-30E, $31 \mathrm{E}$

magnetic analysis of: 58-30E

production: $58-13 \mathrm{E} ; 60-31 \mathrm{E}, \mathrm{CI} 8 \mathrm{~T}$ 
PHOTOGRAPHIC

plates: $52-4 E$

recording: 56-26E; 57-14E, 25E, 29E, 35E, $36 \mathrm{E}, 37 \mathrm{E} ; 58-26 \mathrm{E}, 32 \mathrm{E}, 33 \mathrm{E}, 34 \mathrm{E}, 35 \mathrm{E}, 36 \mathrm{E}$;

59-1E, 11E, 12E, 13E, 14E, 23E, 31E, 3E,

$41 E, 42 E ; 60-13 E, 21 E, 22 E, 32 E$.

PHOTOMULTIPLIER: 59-8E, 9E, IOE

Be-Cu: 56-18E; 58-5A, 10E; 59-35E; 60-10E, $12 \mathrm{E}, 18 \mathrm{~A}, 30 \mathrm{E}, 31 \mathrm{E}, 50 \mathrm{~A}, \mathrm{C} 6$

electronics: $\quad 51-15 A, 12 E, 60-52 E$

PLASMA OSCILLATIONS: 58-C9T; 59-8E; 60-2E

POLARIZATION EFFECTS: 60-1E

PROPORTIONAL COUNTER RECORDING: 59-29E, 34E, C8E; 60-17A

QUADRUPOLE LINES: $57-29 E$

QUASI-STATIONARY STATES: 50-8E; 56-10T; 59-20E, 22E

theory of: $42-1 T ; 50-9 T$

RADIATION RECEIVERS:

(See also "Photomultipliers")

absolute efficiency of: $60-44 \mathrm{~A}$

REABSORPTION: $59-36 E$

REFRACTION OF X-RAYS: 56-C8E

RETARDATION EFFECTS: $60-49 T$

\section{SATELLITES}

Auger effect: 35-3E

excitation potential: 36-2E, 3E, $4 \mathrm{E}$

Identification: 55-C1T

intensity: 55-11E

positlon relationship: 60-14T

theory of: 35-1E; 40-4E; 52-3E, 17E; 60-CIIT

Wentzel-Druyvesteyn formula: $31-1 \mathrm{E}$

\section{SCATTERING}

X-ray: 53-6T; 58- C24E; 59-19E, 20E

anomalous: $54-8 \mathrm{~T}$

SCINTILLATION COUNTER RECORDING: 59-15E, C4T

Horl's procedure: $54-8 \mathrm{~T}$

SCREEN ING

constants: $60-48 T$

effect: $57-22 T$

energy: 59-33E

Sommerfeld theory of: 56-C7

\section{SECONDARY ELECTRON}

analyzer: $56-c 6$

spectra: 53-C4E; 57-CI4E
SIGMA FORMATION: 58-CI2T

vs. edge shift: $57-23 \mathrm{E}$

SINGLE CRYSTAL SPECIMENS: $57-18$ E; 58-4E, 9 E

SLIT WIDTH

vs. 1 ine width: $50-6 \mathrm{~A}$

SMEKAL LINES: $\quad 56-8$ E

SOFT X-RAY EMISSION

critical energy: 55-12E

theory of: $52-\mathrm{ClT}$

SOLID SOLUTION

Frledel theory of: $54-C 3 T$

SPARK DISCHARGE SOURCE: 53-18E; 55-4E, 39E, 56-1E, $3 E$

calculation of spectral intensity: 56-12E

SPECIFIC HEAT

theory of: $49-2 T$

SPECIMEN SURFACE PREPARATION: 58-1OE

ion bombardment: $60-c 10$

scraping: 58-7E; 60-iOE, $11 \mathrm{E}, 12 \mathrm{E}$

SPECTRAL WINDOW: $58-7$ E

SPECTROGRAPHS

alignment of: $56-2 \mathrm{~T}$

compound formation, effect of: $57-24 \mathrm{E}$

crystal: 52-23A; 55-37E; 57-12E, $24 \mathrm{E}$;

$60-32 E, 44 \mathrm{~A}$

double crystal: 59-16E, 29E, 34E; 60-26E, $47 \mathrm{E}$

double grating: $57-21 \mathrm{~A} ; 60-\mathrm{C} 12 \mathrm{~T}$

drive mechani m: 58-11A

grating type: 57-7E; 58-5A, 10E, 32E; 59-9E,

IOE, 3E; 60-2E, 1OE, IIE, 12E, 13E, 17A,

$18 \mathrm{~A}, 28 \mathrm{E}, 29 \mathrm{~A}, 39 \mathrm{E}$

moving grating: $57-C 7 T$

moving specimen: $57-28 \mathrm{E}$

permanent magnet: 53-C3E

resolution: $57-12 E$

SPLITTING FACTOR: 58-CIIT

SURFACE

electronic structure: $52-C 3 T$

SYMCHROTRON RADIATION: 53-8E; 55-32E, 33E;

$56-\mathrm{C} 11 ; 58-21 \mathrm{~T}, \mathrm{C} 20 ; 60-51 \mathrm{~T}$

TAPE RECORDING

for computer Input: 54-22A 
TEMPERATURE

effect of: 57-C3T; 59-24E, 26E; 60-9E, 20E effect on bandwldth and displacement: 60-C5T

THERMAL VIBRATION: 57-15E; 59-21T

THIN FILMS

structure of: $34-1 T ; 39-6 T, 54-16 E$

TRANS ITION PROBABILITY: 55-C5T; 58-28T; 59-CII

Auger: $42-2 \mathrm{E}$

dipole: $60-49 \mathrm{~T}$

quadrupole: 40-2E

Kronlg's method: $60-45 T$

TRANS ITIONS

magnet Ic: $55-16 \mathrm{E}$

radlative: $41-3 T$

TRANSPORT EQUATION: 6O-CI3T

VALENCE BANDS

width of: $52-3 E$

VAPOR DEPOSITION

of alloys: 59-c9

VOLUME OF POLYHEDRA: 54-C9T

WAVE FUNCTIONS OF EXCITED STATES

relation to $X$-ray spectra: $58-C 10$

X-RAY FOCUSING: 60-CIA 
ACTA CRYSTALlographica (Acta. Cryst.)

$\begin{array}{llll}1958 & \frac{1}{5} & 180-187 & (\mathrm{C}-1) \\ 1951 & \frac{5}{3} & 348-350 & 4) \\ 1951 & 5 & 351-356 & (5) \\ 1953 & \frac{6}{7} & 352-356 & (4) \\ 1954 & 1 & 249-259 & (c-9)\end{array}$

ADVANCES IN PHYSICS

$1954 \quad 3 \quad 446-507 \quad(C-3)$

AIR FORCE OFFICE OF SCIENTIFIC RESEARCH

1954 AFOSR-TR-54-13 (Tech. Rept. No. 1) 68 pp. (16)

1954 AFOSR-TR-347 (Tech. Rept. No. 8) 16 pp. $(\mathrm{C}-11)$

AMERICAN JOURNAL OF PHYSICS

$1960 \quad \underline{28} \quad 235-242 \quad R-11$

ANALES DE LA REAL SOCIEDAD ESPANOLA DE FISICA Y QUYMICA

1951 47a 197-220 (C-3)

ANNALEN DER PHYSIK (Ann. Physik)

1959 (7) $3 \quad 352-359 \quad$ (21)

ANNALES ACADEMIE SCIENTARUM FENN ICAE

(Ann. Acad. Sci. Fennicae)

1959 Ser. A. VI No. 1512 pp (C-24)

ANNALES DE PHYSIQUE (Ann. Phys.)

1952
1958
1960
1960 $\left\{\begin{array}{llcl}12) & 7 & 852-902 & (14) \\ 13) & \frac{1}{5} & 915-964 & 509-565 \\ \frac{5}{5} & 1559-1614 & (27) \\ c-9) & (32)\end{array}\right.$

ANNUAL REPORT OF SCIENTIFIC WORK, FACULTY OF SCIENCE, OSAKA UNIVERSITY

(Ann. Rept. Sci. Work, Fac. Scl. Osaka U.)

$$
\begin{array}{llll}
1959 & 7 & 1-88 & R-17
\end{array}
$$

ARKIV FOR FYSIK (Arkiv Fysik)

\begin{tabular}{|c|c|c|}
\hline $\begin{array}{l}1952 \\
1952 \\
1952 \\
1953 \\
1953 \\
1954 \\
1955 \\
1956 \\
1957 \\
1958 \\
1958 \\
1958 \\
1958 \\
1959 \\
1959 \\
1959\end{array}$ & $\begin{array}{l}\frac{3}{4} \\
\frac{4}{6} \\
\frac{6}{\frac{8}{9}} \\
\frac{10}{\frac{12}{13}} \\
\frac{13}{13} \\
\frac{14}{14} \\
\frac{15}{15}\end{array}$ & $\begin{array}{l}167-169 \\
389-390 \\
517-534 \\
213-222 \\
513-592 \\
391-400 \\
495-529 \\
279-289 \\
301-318 \\
297-302 \\
483-500 \\
513-550 \\
557-564 \\
1-30 \\
241-250 \\
397-429\end{array}$ \\
\hline
\end{tabular}

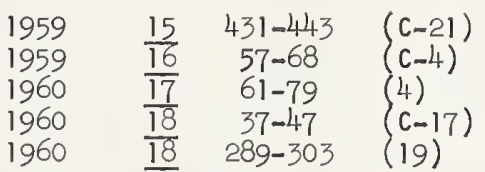

AUSTRALIAN JOURNAL OF PHYSICS (Australian J. Phys.)

$$
\begin{array}{llll}
1958 & \frac{11}{12} & 449-452 & 184 \\
1959 & \underline{12} & (7) \\
1960 & \underline{13} & 238-246 & (-22) \\
c-13)
\end{array}
$$

BELL SYSTEM TECHNICAL JOURNAL

$1958 \quad \underline{37} \quad 1047-1084 \quad(C-14)$

BRITISH JOURNAL OF RADIOLOGY (Brit. J. Radiol.)

$$
1955 \quad \underline{28} \quad 605-609 \quad \text { (8) }
$$

BULLETIN DE LA CLASSE DES SCIENCES DE L'ACADEMIE ROYALE DE BELGIQUE

(Bull. Classe Sci. Acad. Roy. Belg.)

$$
\begin{array}{llll}
1949 & 35 & 1059-1072 \\
1951 \\
1953
\end{array} \quad \underline{37} \begin{aligned}
& 4) \\
& 630-639 \\
& 205-216
\end{aligned}\left(\begin{array}{l}
10 \\
10
\end{array}\right)
$$

BULLETIN OF THE ACADEMY OF SCIENCES OF THE USSR PHYSICAL SERIES

(Bull. Acad. Scl. USSR Phys. Ser.)

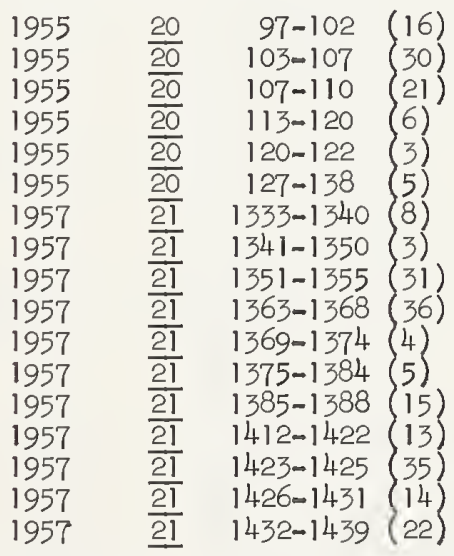

BULLETIN OF THE AMERICAN PHYSICAL SOCIETY (Bull. Am. Phys. Soc.)

$$
1957 \text { (2) } 1 \quad 258
$$

CAHIERS DE PHYSIQUE

$$
\begin{array}{lccc}
1955(54) & 2 & 1-36 & (17) \\
1959(106) & \frac{13}{23} & 237-256 & c-16) \\
1960(113) & 14 & 25-28 & 24) \\
1960(115) & \frac{14}{14} & 119-123 & (25)
\end{array}
$$


CANADIAN DEPARTMENT OF MINES AND TECHNICAL SURVEYS, MINES BRANCH RESEARCH REPORTS

(Canadlan Dept. Mines Tech. Surveys, MInes Branch Repts.)

$$
1958 \quad \underline{R} 42 \quad 77 \text { pp. } \quad(C-23)
$$

CANADIAN JOURNAL OF CHEMISTRY (Can. J. Chem.)

$$
1959 \quad 37 \quad 460-474 \quad(c-25)
$$

CANADIAN JOURNAL OF PHYSICS (Can. J. Phys.)

$$
1953 \quad 31 \quad 469-471 \quad(C-3)
$$

CHIMICA CHRONIKA (ChIm. Chronlka)

$$
1958 \quad 23 \quad(8-9) \quad 231-235 \quad \text { (27) }
$$

\begin{tabular}{|c|c|c|c|}
\hline 1950 & 230 & $636-638$ & $(7$ \\
\hline 1950 & $\overline{231}$ & $574-576$ & (1) \\
\hline 1951 & 232 & $1074-1076$ & $(c-2)$ \\
\hline 1951 & $\overline{232}$ & $1086-1088$ & (8) \\
\hline 1951 & 233 & $376-377$ & 2 \\
\hline 1951 & 233 & $937-939$ & \} 9 \\
\hline 1951 & 233 & $1183-1186$ & 5 \\
\hline 1952 & 235 & $613-615$ & \\
\hline 1953 & 236 & $1014-1016$ & 16) \\
\hline 1953 & 236 & $1244-1246$ & 15) \\
\hline 1953 & 236 & $1547-1549$ & 14) \\
\hline 1953 & 236 & $1767-1769$ & 13) \\
\hline 1953 & 236 & $2149-2150$ & $(c-5)$ \\
\hline 1954 & 238 & $2296-2298$ & $(18)^{\prime}$ \\
\hline 1954 & 239 & $1780-1782$ & (7) \\
\hline 1955 & 240 & $1205-1207$ & 18) \\
\hline 1955 & 240 & $2222-2224$ & 19 \\
\hline 1955 & 241 & $1929-1932$ & 311 \\
\hline 1956 & $\overline{242}$ & $100-102$ & (4) \\
\hline 1956 & 242 & $1433-1436$ & 18 \\
\hline 1957 & 244 & $747-749$ & 27) \\
\hline 1957 & $2 \overline{24}$ & $1230-1233$ & 16 \\
\hline 1957 & 245 & $1412-1415$ & 21 \\
\hline 1957 & $2 \sqrt{45}$ & $1794-1797$ & (25 \\
\hline 1957 & 245 & $2253-2256$ & 11 \\
\hline 1958 & 246 & $94-97$ & 17 \\
\hline 1958 & 247 & $876-879$ & \\
\hline 1958 & 247 & $921-923$ & 201 \\
\hline 1959 & 248 & $778-781$ & $c-5$ \\
\hline 1959 & $2 \longdiv { 2 8 }$ & $1156-1158$ & 25 \\
\hline 1959 & 248 & $1314-1316$ & (13) \\
\hline 1959 & 248 & $1985-1987$ & 11 \\
\hline 1959 & 248 & $2085-2087$ & 12) \\
\hline 1959 & 248 & $2324-2326$ & 4) \\
\hline 19 & $\overline{248}$ & $2327-2329$ & 1 \\
\hline & 249 & $1099-1101$ & 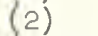 \\
\hline & 2 & $834-836$ & $(-5)$ \\
\hline & 25 & $3620-3621$ & $c-12)$ \\
\hline
\end{tabular}

COMPTES RENDUS DES SEANCES DE L'ACADEMIE DES SCIENCES (Compt. Rend. - French Academy)

CURRENT SCIENCE (INDIA) [Current ScI. (IndIa).]

1954
1954 $\quad \underline{23} \quad \begin{aligned} & 117-118 \\ & \underline{23}\end{aligned} \quad 357 \quad\left(\begin{array}{l}14) \\ 17\end{array}\right)$

CZECHOSLAVAKIAN JOURNAL OF PHYSICS

(Czech. J. Phys.)

$\begin{array}{lrrr}1952 & \frac{1}{8} & 97-120 & (c-1) \\ 1958 & 271-276 & (c-10) \\ 1960 & 10 & 405-406 & (c-11)\end{array}$

DOKLADY AKADEMIYA NAUK SSSR (Doklady Akad. Nauk. SSSR)

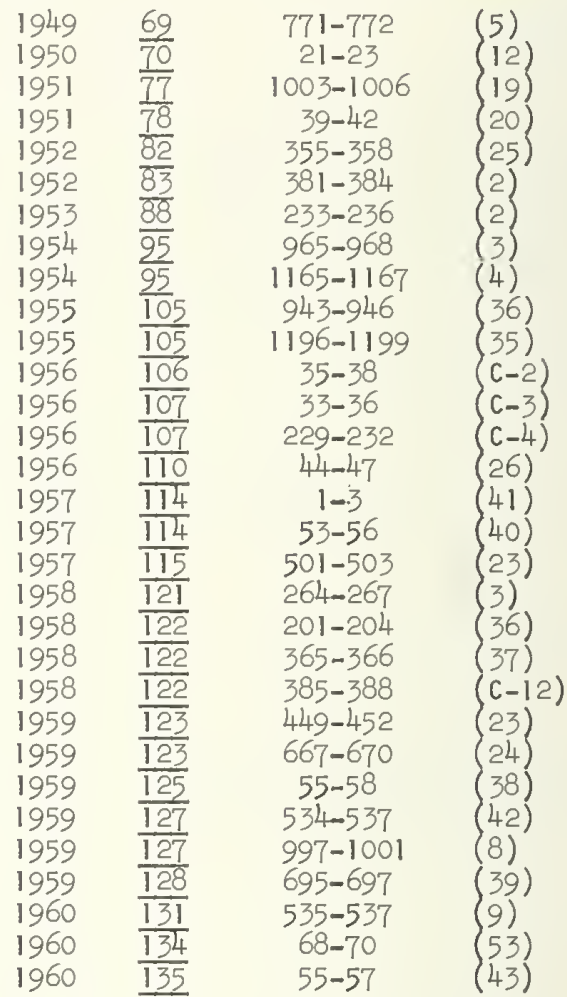

ENCYCLOPEDIA OF PHYSICS (Handbuch der PhysIk)

\begin{tabular}{|c|c|c|}
\hline $\begin{array}{l}1956 \\
1956 \\
1957 \\
1957 \\
1957 \\
1958 \\
1958 \\
1959 \\
1959 \\
1959 \\
1959 \\
1960 \\
1960 \\
1960 \\
1960 \\
1960\end{array}$ & $\begin{array}{l}\frac{3}{3} \\
\frac{4}{5} \\
\frac{5}{5} \\
\frac{6}{6} \\
\frac{7}{7} \\
\frac{7}{8} \\
\frac{8}{9} \\
\frac{2}{2} \\
\frac{10}{10}\end{array}$ & $\begin{array}{c}314-320 \\
561-562 \\
187 \\
8-14 \\
390-394 \\
147-153 \\
951-952 \\
225-234 \\
294-295 \\
211-215 \\
478-480 \\
243-247 \\
385-389 \\
530-534 \\
148-150 \\
390-396\end{array}$ \\
\hline
\end{tabular}

$\begin{array}{llrr}1957 & 30 & 78-245 & R-12 \\ 1957 & \underline{30} & 246-304 & R-16\end{array}$

FIZIKA MeTALLOV I Metalloveden I (Fiz. Metal. I Metall lovedne)

FORTSCHRIFT CHEMIE FORSCHUNG (Fortschrift Chem. Forschung)

$1954 \quad 3 \quad 41-69$ 
INDIAN JOURNAL OF PHYSICS (IndIan J. Phys.)

$$
\begin{array}{lll}
1956 & \underline{30} & 415-422 \\
1958 & 32 & 397-399
\end{array} \quad\left(\begin{array}{l}
20) \\
C-6
\end{array}\right)
$$

INSTRUMENTS AND EXPERIMENTAL TECHNIQUES(U.S.S.R.)

$$
1960 \quad 1960 \quad 755-761 \quad \text { (44) }
$$

ISSLEDOVAN IYA PO ZHARAPROCHNYM SPLAVAM AKADEMIYA NAUK SSSR INSTITUT METALLURGII IMENI A. A. BAIKOVA (Issledovaniya po Zharoproch. Splavam Akad. Nauk. S.S.S.R., Inst. Met. im A. A. Baikova)

$$
1958 \quad 3 \quad 249-251 \quad \text { (14) }
$$

IZVESTIA AKADEMIYA NAUK SSSR, OTDELENIE KHIMICHESKIKH NAUK (I zvest. Akad. Nauk. SSSR Otdel. Khim. Nauk)

$1959 \quad 1959 \quad 1495 \quad$ (40)

IZVESTIA AKADEMIYA NAUK SSSR, OTDELEN IE TEKNICHESKIKH NAUK METALLURGIYA I TOPL IVO

(Izvest. Akad. Nauk SSSR Otdel. Tekh. Nauk Met. I Toplivo)
1959
1959
(2) $82-85$
(19)

IZVESTIA AKADEMIYA NAUK SSSR SERUIIAFIZICHESKAIIA (Izvest. Akad. Nauk SSSR Ser. Flz.)

$\begin{array}{llll}1951 & \frac{15}{20} & 225-230 & (3) \\ 1955 & \frac{20}{20} & 107-111 & 113-117 \\ 1955 & \frac{20}{20} & 118-121 & (30) \\ 1955 & \frac{20}{20} & 128-133 & (6) \\ 1955 & \frac{20}{20} & 133-135 & (3) \\ 1955 & \frac{20}{20} & 142-151 & (5) \\ 1955 & \frac{20}{20} & 784-789 & (25) \\ 1956 & \frac{20}{20} & 790-793 & 17) \\ 1956 & \frac{20}{20} & 815-819 & (13) \\ 1956 & \frac{21}{21} & 1342-1350 & (8) \\ 1957 & \frac{21}{21} & 1351-1361 & (3) \\ 1957 & \frac{21}{21} & 1362-1366 & (31) \\ 1957 & \frac{21}{21} & 1375-1380 & (36) \\ 1957 & \frac{21}{21} & 1381-1386 & (4) \\ 1957 & \frac{21}{21} & 1387-1396 & (5) \\ 1957 & \frac{21}{21} & 1397-1400 & (15) \\ 1957 & \frac{21}{21} & 1424-1434 & (13) \\ 1957 & \frac{21}{21} & 1435-1437 & 35) \\ 1957 & \frac{21}{21} & 1438-1444 & (14) \\ 1957 & \frac{21}{21} & 1445-1457 & (22) \\ 1957 & \frac{21}{24}(4) & 393-396 & (5) \\ 1960 & \frac{24}{24}(4) & 397-406 & (6-2) \\ 1960 & \frac{24}{24}(4) & 407-414 & (3) \\ 1960 & \frac{24}{24}(4) & 422-423 & (16) \\ 1960 & \frac{24}{24}(4) & 424-427 & (48) \\ 1960 & \frac{24}{24}(4) & 428-432 & (8) \\ 1960 & \frac{24}{24}(4) & 435-440 & (42) \\ 1960 & \frac{24}{24}(4) & 441-4442 & (7) \\ 1960 & \frac{24}{24}(4) & 44.3-446 & (6) \\ 1960 & \frac{24}{24}(4) & 447-454 & (34) \\ 1960 & \frac{24}{24}(4) & 455-460 & (37) \\ 1960 & \frac{24}{24}(4) & 461-464 & (22) \\ 1960 & \frac{24}{24}(4) & 465-469 & (23) \\ 1960 & \frac{24}{24}(4) & 473-475 & (20) \\ 1960 & \frac{24}{4}(4) & & \end{array}$

IZVESTIA SEKTORA FIZIKO-KHIMICHESKOGO ANALIZA

$$
1953 \text { 22 104-110 (C-6) }
$$

JOURNAL DE CHIMIE PHYSIQUE (J. ChIm. Phys.)

$\begin{array}{llcl}1950 & 47 & 892-897 & (2 \\ 1954 & \underline{51} & 76-88 & (6)\end{array}$

JOURNAL DE PHYSIQUE ET LE RADIUM (J. Phys. Radlum)

$\begin{array}{llcl}1952 & \frac{13}{13} & \begin{array}{c}113-121 \\ 505-515\end{array} & (7) \\ 1952 & \frac{13}{15} & 8) \\ 1954 & \text { Suppl.to No. } 1 & 16 \mathrm{~A}-22 \mathrm{~A} & (23) \\ 1955 & \frac{16}{16} & 253-262 & (7) \\ 1955 & \frac{16}{16} & 271-273 & (25) \\ 1955 & \frac{16}{16} & 422-427 & (26) \\ 1955 & \underline{16} & 644-649 & (\mathrm{C}-4) \\ 1958 & \underline{19} & 573-581 & (\mathrm{C}-8)\end{array}$

\begin{tabular}{|c|c|c|}
\hline $\begin{array}{l}1951 \\
1952 \\
1956 \\
1956 \\
1956 \\
1957 \\
1958 \\
1960 \\
1960\end{array}$ & $\begin{array}{l}\frac{\frac{19}{20}}{\frac{25}{25}} \\
\frac{\frac{25}{26}}{\frac{28}{32}} \\
\frac{33}{33}\end{array}$ & $\begin{array}{c}528-533 \\
1298-1301 \\
142-146 \\
617-619 \\
619-623 \\
1758-1759 \\
83-87 \\
767-770 \\
275-280 \\
813-820\end{array}$ \\
\hline
\end{tabular}

JOURNAL OF APPLIED PHYSICS (J. Appl. Phys.)

$\begin{array}{llll}1949 & \frac{20}{28} & 1141-1147 & (6) \\ 1957 & 98-105 & (20) \\ 1958 & \underline{29} & 804-809 & (\mathrm{c}-20) \\ 1960 & \underline{31} & 715-723 & (\mathrm{c}-10)\end{array}$

JOURNAL OF CHEMICAL PHYSICS (J. Chem. Phys.)

JOURNAL OF THE CHEMICAL SOCIETY (LONDON) (J. Chem. Soc. - London)

$$
1954 \quad 1954 \quad 332-357 \quad(C-2)
$$

JOURNAL OF THE CHEMISTRY AND PHYSICS OF SOLIDS

(J. Chem. Phys. Sollds)

$\begin{array}{llcl}1957 & \frac{2}{3} & 67-71 & (34) \\ 1957 & 282-302 & (37) \\ 1958 & \frac{6}{6} & 99 & (c-11) \\ 1958 & \frac{6}{7} & 178-179 & (1) \\ 1958 & 65-77 & (c-16) \\ 1959 & \frac{7}{8} & 382 & (c-6) \\ 1959 & \underline{10} & 87-98 & (c-13) \\ 1959 & \underline{10} & 147-161 & (c-30)\end{array}$

JOURNAL OF THE LESS COMMON METALS (J. Less Common Metals)

$$
1959 \quad 1 \quad 396-411 \quad(C-23)
$$


JOURNAL OF THE OPTICAL SOCIETY OF AMERICA (J. Opt. Soc. Am.)

$\begin{array}{llll}1932 & \frac{22}{35} & 245-264 & (3) \\ 1945 & \frac{35}{45} & 311-352 & (c-1) \\ 1955 & \frac{45}{48} & 656-761 & (31) \\ 1958 & 690-703 & (c-17) \\ 1959 & \frac{49}{49} & 446-459 & (c-18) \\ 1959 & 460-465 & (c-18) \\ 1959 & \frac{49}{49} & 471-475 & (c-27) \\ 1959 & \frac{49}{49} & 609-618 & (c-11) \\ 1959 & \frac{11}{49} & 951-960 & (c-18) \\ 1959 & \frac{49}{49} & 961-965 & (c-19) \\ 1959 & 49 & & \end{array}$

JOURNAL OF THE PHYSICAL SOCIETY OF JAPAN

(J. Phys. Soc. Japan)

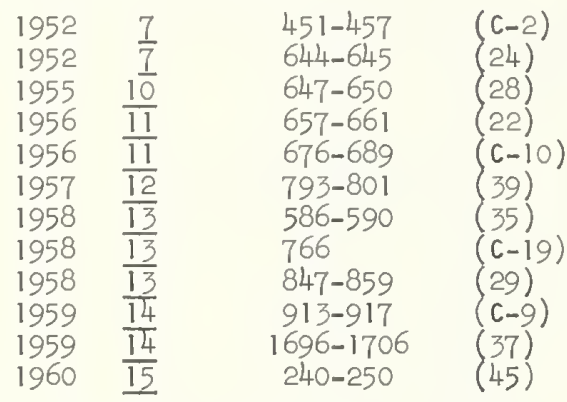

JOURNAL OF THE ROYAL INSTITUTE OF CHEMISTRY (J. Roy. Inst. Chem.)

$1960 \quad 84 \quad 311-320 \quad R-4$

JOURNAL OF SCIENTIFIC AND INDUSTRIAL RESEARCH (INDIA) (J. Scl. \& Indust. Research - India)

$\begin{array}{llll}1950 & \frac{9 B}{1 O B} & 263-265 & (5) \\ 1951 & \frac{1 O B}{11 B} & 1-4 & (4) \\ 1952 & \frac{11 B}{11 B} & 199-200 & (9) \\ 1952 & \frac{1}{12 B} & 639-641 & (5) \\ 1953 & \frac{12 B}{14 B} & 129-130 & (9) \\ 1955 & \frac{15 B}{15 B} & 615-618 & (9) \\ 1956 & \frac{15 B}{16 B} & 524-527 & (28) \\ 1957 & \frac{16 B}{19 B} & 111-112 & (40) \\ 1960 & 112 & & \end{array}$

JOURNAL OF SCIENTIFIC INSTRUMENTS (J.SCi. Instr.)

$$
\begin{array}{llll}
1958 & 35 & 393-395 & (5) \\
1960 & \underline{37} & 460-462 & (18)
\end{array}
$$

LANDOLT-BORNSTEIN TABLES

19551 (4) 6th edition 769-867 R-5

LIBRARY OF CONGRESS

$$
1953 \text { NSF-tr-7, } 3 \text { pp. }
$$

MASSACHUSETTS INSTITUTE OF TECHNOLOGY, RESEARCH LABORATORY OF ELECTRONICS (Research Lab, of Electronlcs MIT)

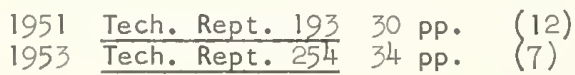

MASSACHUSETTS INSTITUTE OF TECHNOLOGY, SOLID STATE AND MOLECULAR THEORY GROUP

1959 Tech. Rept. 12258 pp. (C-28)

METHODS OF EXPERIMENTAL PHYSICS - SOL ID STATE PHYSICS

$1959 \underline{B-6} \quad 281-292 \quad R-10$

MIKROCHIMIKA ACTA (MikrochIm. Acta)

$1955 \quad \underline{1955} \quad 684-695$

NATURE

$\begin{array}{llll}1952 & 169 & 889 \\ 1956 & \frac{178}{186} & 814 \\ 1960 & \frac{379-380}{186} & 958\end{array} \quad\left\{\begin{array}{l}10 \\ 1960\end{array}\right.$

NATURWISSEN SCHAFTEN

$\begin{array}{llll}1952 & 38 & 169-177 & (12) \\ 1958 & 45 & 309 & (8) \\ 1960 & \underline{47} & 319 & (14)\end{array}$

NAUCHNY I BYULLETEN LEN INGRADSKOGO GOSUDARSTVENNOGO ODENA LENINA UNIVERSTETA IMENI A. A. ZHDANOVA (Nauch. Byul1. LenIngrad. - Gosudarst. Univ. IM A. A. Zhdanova)

$$
1951 \underline{1951}(28) 8-11
$$

NAUCH. ZAPISKI KAFIDR. MAT. FIZ. I ESTESTVOZVAN ODESS GOSUDARST PEDAGOG INST.

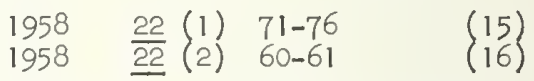

NAUK POVIDOMLENNYA KIEV UNIVERSITET

$$
1956 \quad 1956 \text { (1) } \quad 41-42
$$

NUCLEON ICS

$$
1955 \quad 13(3) \quad 36-37
$$

OFFICE OF NAVAL RESEAPC.T

1950 ONR Report "NAVEXDS" $\mathrm{P}-103381$ pP. (R-18) OFFICE OF ORDNANCE RESEARCH 1960 O0R Project No. 2486, Tech. Rept. No. 1
(51)

OFFICE OF TECHNICAL SERVICES

$\begin{array}{rrrll}1958 & \text { PB 135404, } 14 \text { PP. } & (21) \\ 1958 & \text { PB 151453, } 117 \text { PP. } & \text { R-8 } \\ 1959 & \text { PB 143952, } 30 \text { PP. } & (30) \\ 1959 & \text { PB 144965, } & 84 \text { PP. } & (\mathrm{C}-12) \\ 1960 & \text { PB 158025, } & 14 \text { PP. } & (52)\end{array}$

OPTICA ACTA

$$
\begin{array}{llcl}
1958 & 5 & 31-39 \\
1959 & \underline{6} & 175-185
\end{array} \quad\left\{\begin{array}{l}
10) \\
c-17)
\end{array}\right.
$$


OPTICS AND SPECTROSCOPY

$\begin{array}{llll}1959 & \frac{7}{8} & 498-500 & (31) \\ 1960 & \frac{1}{9} & 297-299 & (28) \\ 1960 & \frac{2}{9} & 262-265 & (29) \\ 1960 & \frac{9}{9} & 265-267 & (31) \\ 1960 & 2 & 343-346 & (30)\end{array}$

OPTIK

1957
1959 I 14 $\quad \begin{aligned} & 263-276 \\ & 288-303\end{aligned} \quad\left(\begin{array}{l}c-7) \\ C-10\end{array}\right)$

OPTIKA I SPEKTROSKOPIIA

$\begin{array}{llll}1959 & 7 & 850-852 & (31) \\ 1960 & \frac{9}{9} & 505-508 & 29) \\ 1960 & 2 & 511-513 & 31) \\ 1960 & 9 & 653-657 & (30)\end{array}$

PHILOSOPHICAL MAGAZINE (Phil. Mag.)

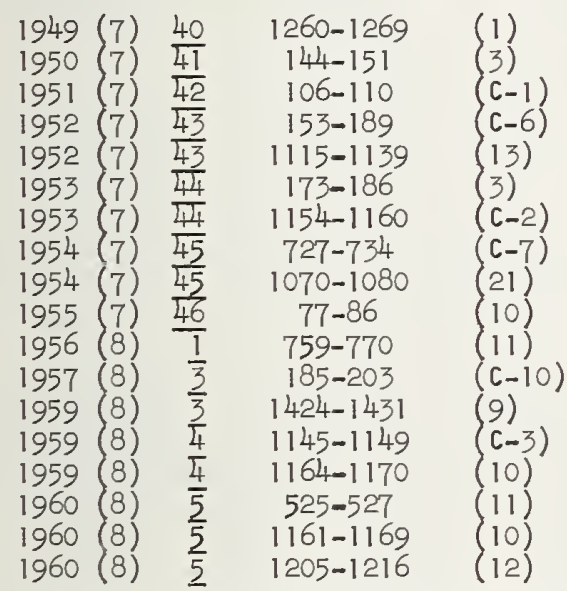

PHILOSOPHICAL TRANSACTIONS OF THE ROYAL SOCIETY (LONDON) (PhIl. Trans. Roy. Soc. - London)

$$
1940 \quad \text { A239 } 95-134 \quad \text { (6) }
$$

PHYSICA

$\begin{array}{llrl}1948 & 14 & 175-183 & (1) \\ 1950 & \frac{11}{16} & 377-378 & 11) \\ 1954 & \frac{20}{20} & 801-812 & (c-4) \\ 1954 & 1135-1137 & 15) \\ 1955 & \frac{20}{21} & 85-102 & 37) \\ 1956 & \frac{22}{26} & 706-706 & (2) \\ 1960 & \underline{26} & 143-144 & (c-3)\end{array}$

PHYSICAL REVIEW (Phys. Rev.)

$\begin{array}{llcl}1929 & 34 & 574-581 & (1) \\ 1931 & \frac{34}{38} & 1802-1807 & (1) \\ 1932 & \frac{40}{42} & 477-483 & (2) \\ 1932 & \frac{42}{44} & 605-608 & (1) \\ 1933 & \frac{44}{44} & 955-960 & (1) \\ 1933 & \frac{44}{45} & 379-384 & (1) \\ 1934 & \frac{45}{48} & 133-135 & (2) \\ 1935 & \frac{13}{48} & 664-670 & (c-1) \\ 1935 & \frac{1}{48} & 722-724 & (1) \\ 1935 & \frac{48}{49} & 1-8 & (6) \\ 1936 & \frac{49}{49} & 132-139 & (2) \\ 1936 & \frac{49}{49} & 502-507 & (3) \\ 1936 & 4 & & \end{array}$

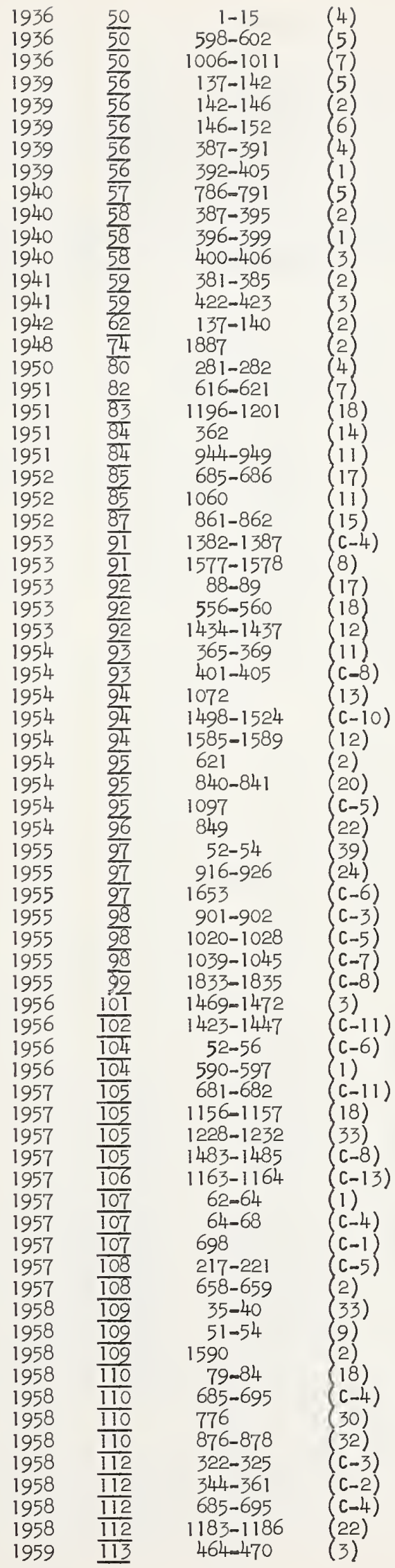


PHYSICAL REVIEW (Continued)

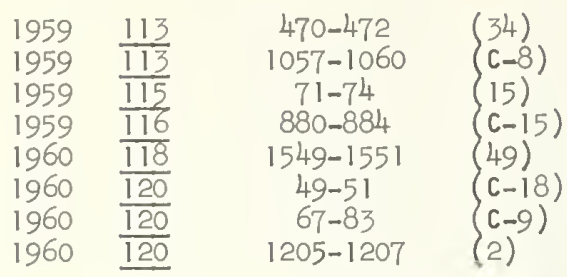

PHYSICAL REVIEW LETTERS (Phys. Rev. Letters)
1959
$\frac{2}{2}$
47
148
$\left(\begin{array}{l}c-2) \\ c-29)\end{array}\right.$

PHYSICS OF METALS AND METALLOGRAPHY

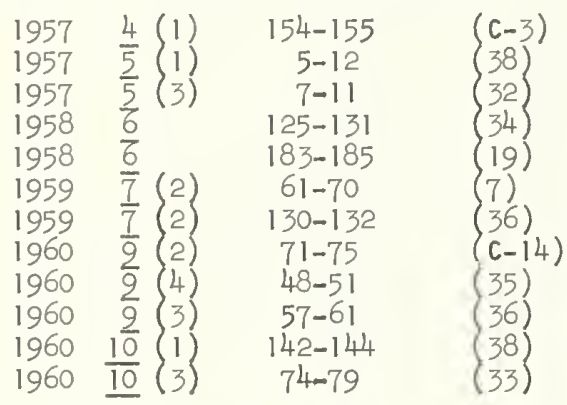

PORTUGALIE PHYSICA

$$
19513 \quad 117-126 \quad \text { (16) }
$$

POWDER METALLURGY

$$
1958 \quad 1958(1,2) \quad 172-188 \quad(C-18)
$$

PRIBORY I TEKHNIKA EKSPERIMENTA

$$
1960 \text { No. } 5 \quad 67-73 \quad \text { (44) }
$$

\begin{tabular}{|c|c|c|}
\hline $\begin{array}{l}1951 \\
1952 \\
1952 \\
1952 \\
1953 \\
1954 \\
1955 \\
1955 \\
1955 \\
1955 \\
1957 \\
1957 \\
1959 \\
1959 \\
1960 \\
1960\end{array}$ & $\begin{array}{l}\frac{\frac{64 A}{65 A}}{\frac{65 A}{65 A}} \\
\frac{66 A}{67 B} \\
\frac{68 A}{68 A} \\
\frac{68 A}{68 B} \\
\frac{70 A}{70 A} \\
\frac{73}{74} \\
\frac{75}{76}\end{array}$ & $\begin{array}{c}318-319 \\
192-202 \\
815-825 \\
1015-1022 \\
333-340 \\
348-356 \\
322-328 \\
654-656 \\
717-725 \\
472-473 \\
262-274 \\
466-473 \\
924-936 \\
604-608 \\
337-344 \\
791-793\end{array}$ \\
\hline
\end{tabular}

PROCEEDINGS OF THE PHYSICAL SOCIETY (LONDON)

(Proc. Phys. Soc. - London)

PROCEEDINGS OF THE CAMBRIDGE PHILOSOPHICAL SOCIETY (Proc. Cambridge Phil. Soc.)

$\begin{array}{llll}1938 & 34 & 109-114 \\ 1939 & \underline{35} & 108-113 \\ 1952 & \underline{48} & 457-469\end{array} \quad\left\{\begin{array}{l}1 \\ 3 \\ c-3\end{array}\right)$

PROCEEDINGS OF THE INTERNATIONAL CONGRESS OF PURE AND APPLIED CHEMISTRY (Proc. Intern. Congr. Pure and Appl. Chem.)

$$
1947 \quad 11 \quad 249-259 \quad \text { (C-1) }
$$

\begin{tabular}{|c|c|c|}
\hline $\begin{array}{l}1937 \\
1940 \\
1952 \\
1957 \\
1959 \\
1960\end{array}$ & $\frac{\frac{A-161}{A-176}}{\frac{A-212}{A-240}} \frac{A-249}{A-254}$ & $\begin{array}{l}420-440 \\
229-262 \\
363-376 \\
145-160 \\
555-573 \\
327-343\end{array}$ \\
\hline
\end{tabular}

PROCEEDINGS OF THE ROYAL SOCIETY (LONDON) (Proc. Roy. Soc. - London)

PROGRESS OF THEORETICAL PHYSICS (KYOTO)

(Progr. Theoret. Phys. - Kyoto)

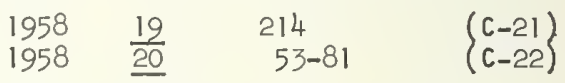

RADIO ENGINEERING AND ELECTRONICS (USSR)

$$
1957 \text { 음 (3) 99-106 }
$$

RADIOTEKHNIKA I ELEKTRONIKA (Radlotekh, I Elektron)

$$
1957 \quad 2 \quad 328-333 \quad \text { (26) }
$$

REPORTS ON PROGRESS IN PHYSICS

$$
19395 \text { 257-283 R-15 }
$$

REVIEW OF SCIENTIFIC INSTRUMENTS (Rev. Sci. Instr.)

$\begin{array}{llll}1951 & \frac{22}{23} & 543 & (15) \\ 1952 & \frac{23}{23} & 523-528 & (22) \\ 1952 & \frac{23}{26} & 747-750 & (6) \\ 1955 & \frac{26}{29} & 421-424 & 34) \\ 1958 & \frac{29}{31} & 210-211 & (1) \\ 1960 & \frac{31}{31} & 891-895 & (17) \\ 1960 & \underline{c}-6)\end{array}$

REVIEWS OF MODERN PHYSICS (Revs. Modern Phys.)

$$
\begin{array}{llc}
1941 & \frac{13}{30} & 1-57 \\
1958 & \frac{30}{31} & 59-62 \\
1959 & 616-645
\end{array} \quad\left(\begin{array}{l}
R-1) \\
C-24) \\
R-9)
\end{array}\right.
$$

REVISTA DA FACULDADE DE CIENCIAS (LISBOA)

(Rev. Fac. Cienc. UnIv. LIsboa)

$$
1954 \text { Ser 3B } 2 \quad 65-140 \quad \text { (10) }
$$

RUSSIAN JOURNAL OF INORGAMC CHEMISTRY

$$
1959 \text { 4 (1) 104-105 }
$$

SCIENCE AND CULTURE (INDIA)

$$
\begin{array}{llll}
1952 & 17 & 479-480 \\
1956 & \underline{21} & 624-626
\end{array} \quad \text { (1) }
$$

SCIENCE OF LIGHT (TOKYO)

$$
1958 \quad I(2) \quad 23-27 \quad(c-15)
$$


SCIENCE REPORTS OF THE TOHOKU UN IVERSITY (Scl. Repts. Tohoku UnIv.)

FIRST SERIES

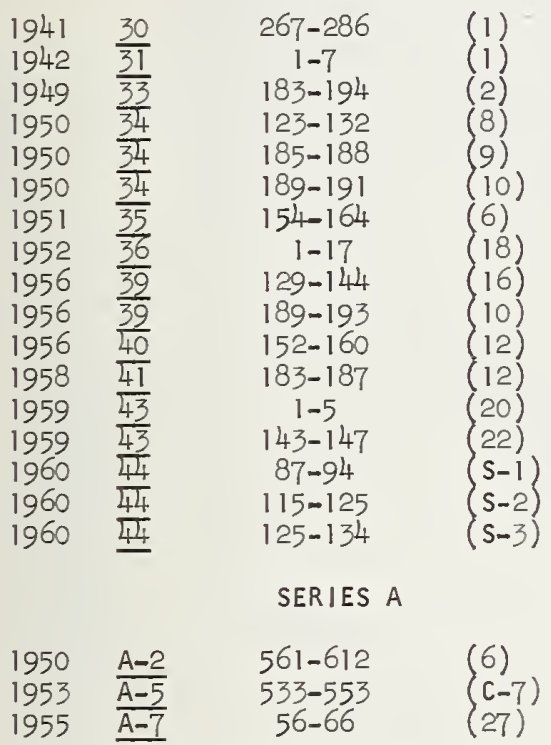

SCIENTIFIC PAPERS OF THE INSTITUTE OF PHYSICAL AND CHEMICAL RESEARCH (TOKYO)

(Sci. Papers Inst. Phys. Chem. Research - Tokyo)

$$
1936 \text { 28 243-25 }
$$

SITZUNGSBERICHTE DER OSTERRECCHISCHEN AKADEMIE DER WISSENSCHAFTEN (Osterr. Akad. Wiss. Math. Maturin KI Sitzber)

$$
1953 \text { Abteilung 11A } 162 \text { 235-252 (10) }
$$

SOVIET PHYSICS "DOKLADY" (Sov. Phys. "Doklady")

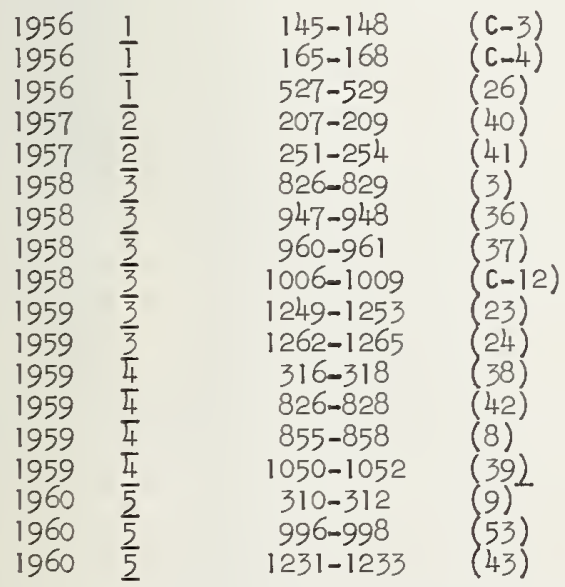

SOVIET PHYSICS "JETP" (SOV. Phys. "JETP")

$\begin{array}{llll}1958 & 3 & 133 & (c-13) \\ 1958 & \frac{3}{7} & 414-420 \\ 1959 & \frac{9}{12} & 856-858 \\ 1960 & & 886-890 & (28) \\ 6 & & \end{array}$

SOVIET PHYSICS "TECHNICAL PHYSICS" (SOV. PhYS. "Tech. Phys.")

$$
1960 \underline{5} \quad 1016-1017
$$

TECHNOLOGY REPORTS OF OSAKA UNIVERSITY (Tech. Repts. Osaka UnIv.)

$$
1954 \underline{4} \quad 1-5
$$

TRUDY SEMINARA PO ZHAROSTOIKIM MATERIALAM AKAD. NAUK. (UKR. Inst. Metallokeram I Spetsial, Splavov, Kiev)

$$
\begin{array}{llll}
1958 & \frac{5}{5} & 15-20 \\
1958 & 2 & 21-27
\end{array} \quad\left(\begin{array}{l}
26) \\
20)
\end{array}\right.
$$

TRUDY STALINIRSK GOSUDARST INST.

$$
1956 \quad \underline{3} \quad 589-598 \quad \text { (C-8) }
$$

UCHENYE ZAPISKI ROSTOV NA DONU

$$
1958 \quad 68(8) \quad 91-104
$$

UKRAINSKII FXZICHNII ZHURNAL (Ukrain. FIz. Zhur.)

$$
\begin{array}{llll}
1959 & \frac{4}{5} & 260-267 & (27) \\
1960 & 2 & 231-234 & (41)
\end{array}
$$

UNITED STATES ATOMIC ENERGY COMMISSION REPORTS (U. A. AT. ENERGY COMM.)

$\begin{array}{rlrll}1953 & \text { AEC-tr-3629 } & 6 \mathrm{pp} . & (\mathrm{C}-6) \\ 1955 & \text { NP } 5803 & 24 \mathrm{pp} . & (33) \\ 1955 & \text { NP } 5805 & 16 \mathrm{pp} . & (32) \\ 1956 & \text { AECU } 3190 & 75 \mathrm{pp} . & \mathrm{R}-14 \\ 1956 & \text { AECU } 3578 & 81 \mathrm{pp} . & (21) \\ 1956 & \text { ISC-830 } & 118 \mathrm{pp} . & (\mathrm{C}-9) \\ 1957 & \text { NAASR-1839 } & 50 \mathrm{pp} . & (\mathrm{C}-9) \\ 1959 & \text { NP } 7906 & 20 \mathrm{pp} . & (35) \\ 1959 & \text { UCRL-5612 } & 520 \mathrm{pp} . & (\mathrm{C}-14) \\ 1960 & \text { NP } 8475 & 29 \mathrm{pp} . & (50)\end{array}$

UNIVERSITY MICROFILMS AND DISSERTATION ABSTRACTS (UnIv. Microfilms Diss. Abs.)

1954 PUBL $9735 \quad 72$ PP. DIss.Abs. $142096(\mathrm{C}-1)$ 1955 PUBL $10,744 \quad 108$ pp. Diss.Abs. $\frac{15}{17} 280$ (14) 1957 PUBL 2l,074 93 pp. Diss.Abs. 17 1097$1098 \quad$ - 17 (7) 1957 PUBL 19,976 137 pp. Diss.Abs. 17657 (C-14) 1958 PUBL MIC-58= 105 Pp. Diss. Abs. 1954 (13) 3076

1959 MIC-59-154 99 pp. Diss.Abs. 192365 (16) $1959 \overline{M i C-59-135} 155$ pp. Diss.Abs. 192368 (29) 1959 MाC-59-5891 93 pp. (C-7) 1960 MTC-60-880 107 Pp. Diss.Abs. 204142 (39) $1960 \overline{M ा C-60-1197} 99$ pp. Diss.Abs. $\overline{20} 4147$ (26) 1960 MTC-60-4486 87 pp. Diss.Abs. $\frac{21}{21}$ 1609(C-19) 1960 MTC $-60-5350 \quad 92$ pp. Diss.Abs. 212343 (47)

VESTNIK LENINGRAD SKOGO UNIVERISITETA (Vestnik LenIngrad. Unlv.)

$$
1960 \text { 15 (No. 16) Ser FIz i Khim (3) 36-41 }
$$

VOPROSY FIZ. METAL I. METALLOVED AKAD NAUK UKR. S.S.R. SBORNIK NAUCH RABOT 
X-SEN (X-Rays)
$1955 \underline{8}$
$55-60$
(29)

ZEITSCHRIFT FUR METALLKUNDE (Z. Metallkunde)

$$
1955 \quad \underline{46} \quad 647-650 \quad(\mathrm{C}-2)
$$

¿EITSCHRIFT FUR NATURFORSCHUNG (Z. Naturforsch)

$\begin{array}{llll}1953 & \frac{8 a}{10 a} & 429-432 & (6) \\ 1955 & \frac{102-503}{12 a} & 670-671 & (13) \\ 1957 & 12 a & 571-572 & (4) \\ 1958 & 13 a & 572\end{array}$

ZEITSCHRIFT FUR PHYSIK (Z. PhysIk)

$\begin{array}{llcl}1951 & 131 & 1-9 & (13) \\ 1954 & \frac{136}{138} & 491-533 & (8) \\ 1954 & 71-79 & (9) \\ 1955 & \frac{140}{142} & 152-164 & (2) \\ 1955 & \frac{161-162}{144} & 529-537 & (1) \\ 1956 & \frac{145}{145} & 341-346 & (c-7) \\ 1956 & \frac{147}{147} & 264-270 & (30) \\ 1957 & \frac{149}{149} & 412-424 & (19) \\ 1957 & \frac{13}{153} & 338-358 & (-1) \\ 1958 & \frac{159}{159} & 178-193 & (21)\end{array}$

ZEITSCHRIFT FUR PHYSIKALISCHE CHEMIE (Z. PhYsIK Chem.)

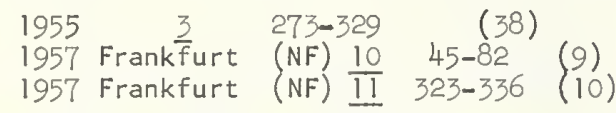

ZHURNAL EKSPERIMENTAL 'NOI । TEORETICHESKOI FIZIKI (Zhur Eksp. I Teoret. Flz.)

$\begin{array}{llll}1949 & \frac{19}{20} & 413-420 \\ 1950 & \frac{20}{20} & 442-445 \\ 1950 & \frac{20}{30} & 209-450 \\ 1958 & \frac{30}{34} & 599-608 \\ 1958 & \frac{340}{1959} & 1203-1206 \\ 1960 & \underline{39} & 1269-1275 & (3)\end{array} \quad\left\{\begin{array}{l}13) \\ 14) \\ c-13) \\ 28) \\ 6) \\ 46)\end{array}\right.$

ZHURNAL NEORGANICHESKOI KHIMII(Zhus Neorg. Khim.)

$$
1959 \quad 4 \quad 245-246 \quad \text { (41) }
$$

ZHURNAL TEKHNICHESKOI FIZIKI (Zhur. Tekh. Fiz.)

$$
1960 \quad 30 \quad 1085-1086 \quad \text { (15) }
$$

BIBL IOGRAPHIC AIDS

ABSTRACTS JOURNAL OF METALLUURG USSR

AST IA BULLETIN

BULLETIN SIGNALETIQUE (SECTION XIII, STRUCTURE DES SOLIDES ET DES FLUIDES)

\section{CHEMICAL ABSTRACTS \\ CHEMICAL TITLES}

ENG INEER ING INDEX

NUCLEAR SCIENCE ABSTRACTS

PHYSICS ABSTRACTS 


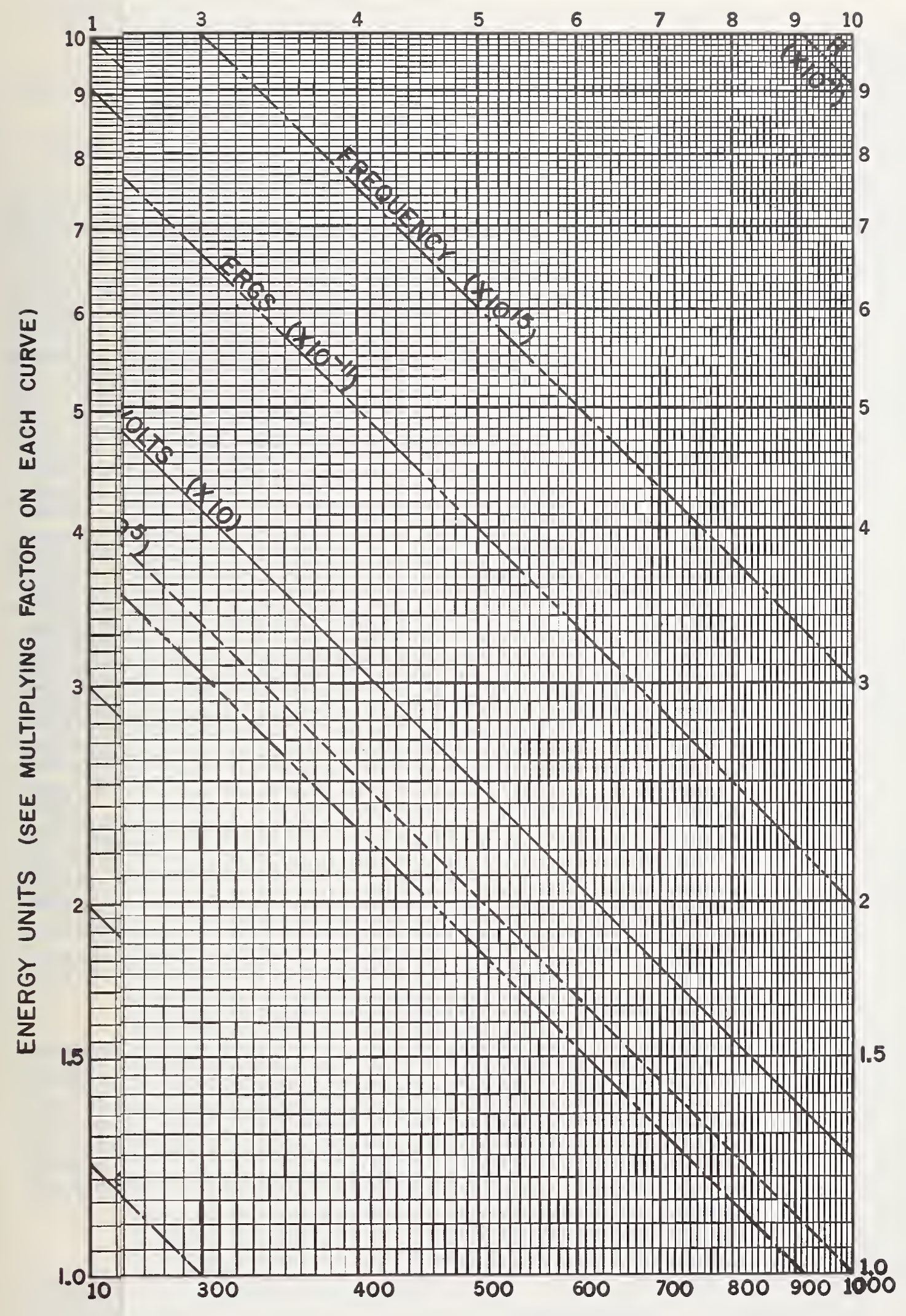





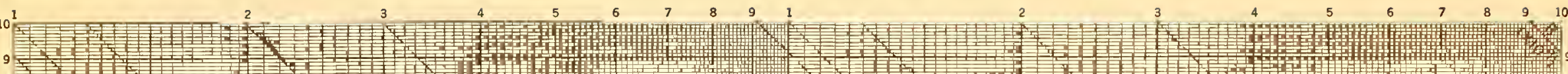

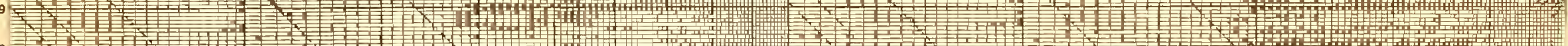

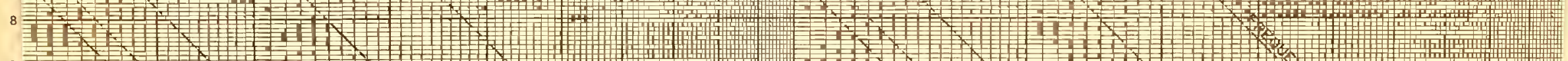

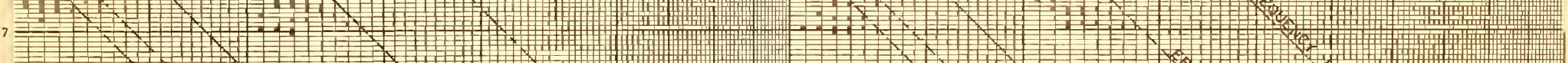

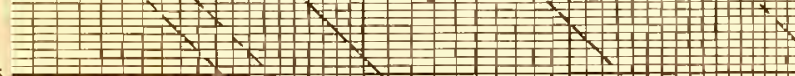

(2)

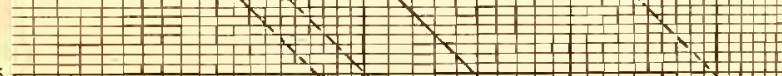

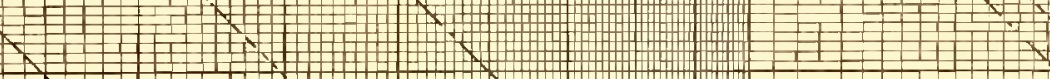

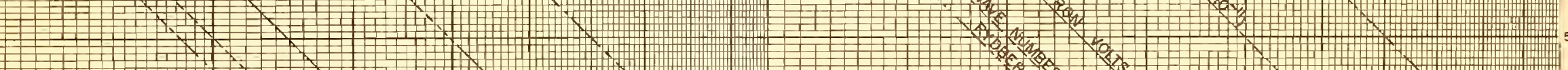

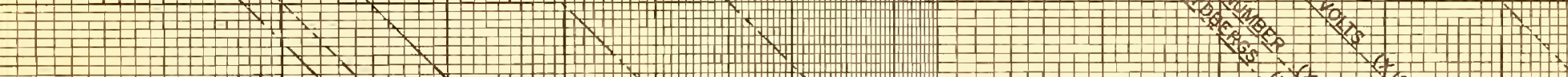

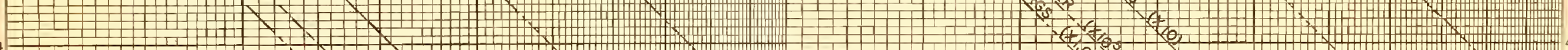

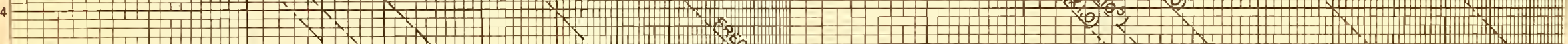

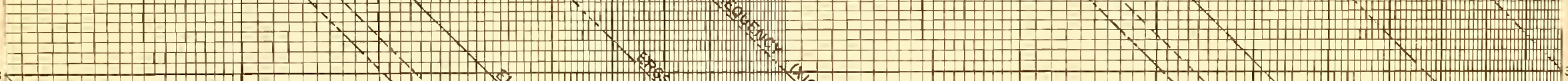

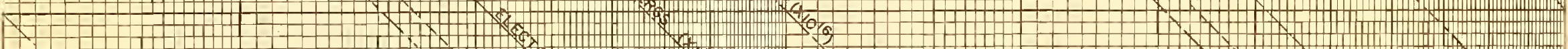

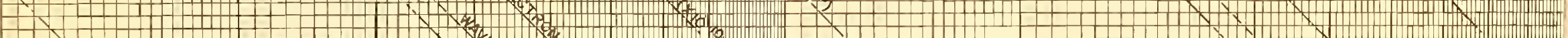

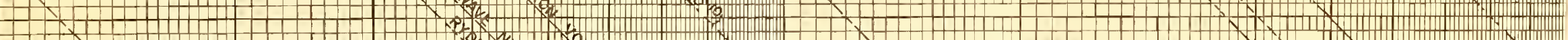

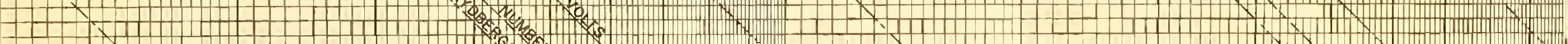

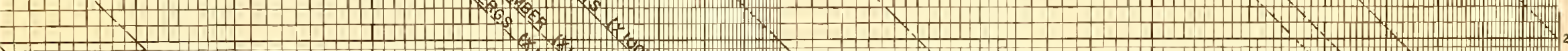

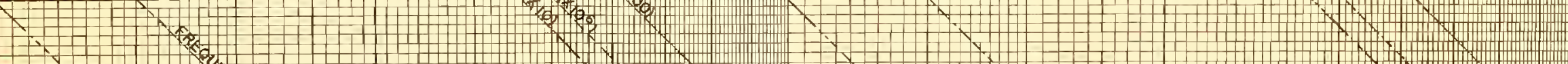

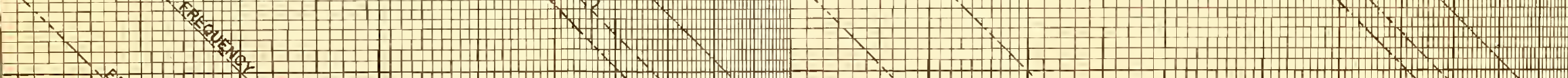

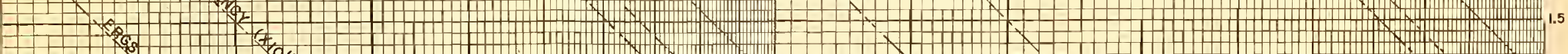

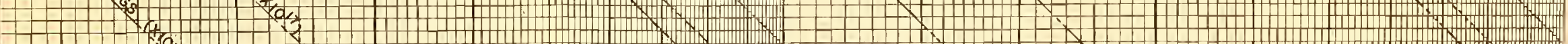

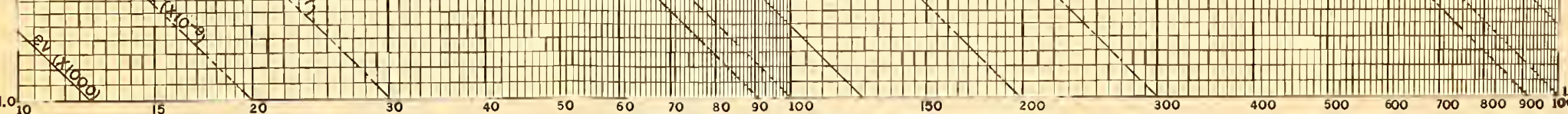

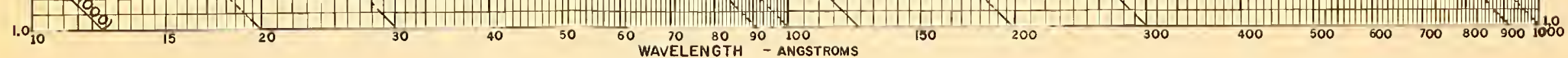





\title{
U.S. DEPARTMENT OF COMMERCE
}

\author{
Luther H. Hodges, Secretary
}

\section{NATIONAL BUREAU OF STANDARDS}

A. T. Astin, Director

\section{THE NATIONAL BUREAU OF STANDARDS}

The scope of actirities of the National Bureau of Standards at its major laboratories in Washington, D.C., and Boulder, Colo., is suggested in the following listing of the dirisions and sections engaged in technical work. In general, each section carries out specialized research, derelopment, and engineering in the field indicated by its title. A brief description of the activities, and of the resultant publications, appears on the inside of the front corer.

WASHINGTON, D.C.

Electricity. Resistance and Reactance. Electrochemistry. Electrical Instruments. Magnetic Measurements. Dielectrics. High Voltage.

Metrology. Photometry and Colorimetry. Refractometry. Photographic Research. Length. Engineering Metrology. Mass and Scale. Volumetry and Desimetry.

Heat. Temperature Physics. Heat Measurements. Cryogenic Physies. Equation of State. Statistical Physics. Radiation Physics. X-ray. Radioactivity. Radiation Theory. High Energy Radiation. Radiological Equip. ment. Nucleonic Instrumentation. Neutron Physics.

Analytical and Inorganic Chemistry. Pure Substances. Spectrochemistry. Solution Chemistry. Standard Reference Materials. Applied Analytical Research. Crrstal Chemistry.

Mechanics. Sound. Pressure and Tacuun. Fluid Mechanics. Engineering Mechanies. Rheology. Combustion Controls.

Polymers. Macromolecules: Synthesis and Structure. Polymer Chemistry. Polymer Physics. Polrmer Characterization. Polymer Eraluation and Testing. Applied Polymer Standards and Research. Dental Research.

Metallurgy. Engineering Metallurgy. Microsenpy and Diffraction. Metal Reactions. Metal Physics. Electrolysis and Metal Deposition.

Inorganic Solids. Engineering Ceramics. Glass. Solid State Chenistry. Crystal Growth. Physical Properties. Crystallography.

Building Research. Structural Engineering. Fire Research. Mechanical Ssstems. Organic Building Materials. Codes and Safety Standards. Heat Transfer. Inorganic Building Materials. Metallic Building Materials. Applied Mathematics. Numerical Analysis. Computation. Statistical Engineering. Mathematical Physics. Operations Research.

Data Processing Systems. Components and Techniques. Computer. Technology. Measurements Automation. Engineering Applications. Srstems Analrsis.

Atomic Physics. Spectroscopy. Infrared Spectroscopy. Solid State Phrsies. Electron Physics. Atomic Physies.

Instrumentation. Engineering Electronics, Electron Devices. Electronic Instrumentation. Mechanical Instruments. Basic Instrumentation.

Physical Chemistry. Thermochemistry. Surface Chemistry. Organic Chemistry. Molecular Spectroscopy. Molecular Kineties. Mass Spectrometry.

Office of Weights and Measures

BOULDER, COLO.

Cryogenic Engineering Laboratory. Cryogenic Fquipment. Cryogenic Processes. Properties of Materials. Cryogenic Technical Serrices.

\section{CENTRAL RADIO PROPAGATION LABORATORY}

Ionosphere Research and Propagation. Low Frequency and Very Low Frequency Research. Ionosphere Research. Prediction Services. Sun-Earth Relationships. Field Engineering. Radio Warning Services. Vertical Soundings Research.

Radio Propagation Engineering. Data Reduction Instrumentation. Radio Noise. Tropospheric Measurements. Tropospheric Analysis. Propagation-Terrain Fiffects. Radio-Meteorology. Lower Atmosphere Physics.

Radio Systems. Applied Electromagnetic Theors. High Frequency and Very High Frequency Research. Modulation Research. Antenna Research. Narigation Sxstems.

Upper Atmosphere and Space Physics. Lpper Atmosphere and Plasma Physies. Ionosphere and Exosphere Scatter. Airglow and Aurora. Ionospheric Radio Astronomi.

\section{RADIO STANDARDS LABORATORY}

Radio Physics. Radio Broadcast Service. Radio and Microwave Materials. Atomic Frequency and TimeInterral Standards. Millimeter-Ware Research.

Circuit Standards. High Frequency Electrical Standards. Microwave Circuit Standards. Electronic Calibration Center. 
